\title{
The Simulation of Dynamic Ductile Failure in Pipelines
}

\author{
by \\ Norman Pokutylowicz
}

Department of Mining and Metallurgical Engineering McGill University

Montreal, Canada

A Thesis Submitted to the Faculty of Graduate Studies and Research

in partial fulfillment of the requirements for the degree of

Doctor of Philosophy

CNorman Pokutylowicz

December, 2000 
National Library

of Canada

Acquisitions and Bibliographic Services

395 Wellington Street Ottawa ON K1A ON4 Canada
Bibliothèque nationale du Canada

Acquisitions et services bibliographiques

395, rue Wellington Ottawa ON K1A ON4

Canada
The author has granted a nonexclusive licence allowing the National Library of Canada to reproduce, loan, distribute or sell copies of this thesis in microform, paper or electronic formats.
The author retains ownership of the copyright in this thesis. Neither the thesis nor substantial extracts from it may be printed or otherwise reproduced without the author's permission.
L'auteur a accordé une licence non exclusive permettant à la Bibliothèque nationale du Canada de reproduire, prêter, distribuer ou vendre des copies de cette thèse sous la forme de microfiche/film, de reproduction sur papier ou sur format électronique.

L'auteur conserve la propriété du droit d'auteur qui protège cette thèse. $\mathrm{Ni}$ la thèse ni des extraits substantiels de celle-ci ne doivent être imprimés ou autrement reproduits sans son autorisation. 
There are some things that cannot be learned quickly, and time, which is all we have, must be paid heavily for their acquiring. They are the very simplest things, and because it takes a man's life to know them, the little new that each man gets from life is very costly and the only heritage he has to leave.

$$
\text { - Ernest Hemingway }
$$


I Dedicate this to:

\author{
My wife, \\ Nayla Chartouni
}

And to my mother and father, Lisette Lavoie and Victor Pokutylowicz 


\section{ABSTRACT}

A finite-element based model was constructed in order to assist in determining what material properties affect the resistance to dynamic ductile failure in pipelines. Such failure is caused by stable axial tearing that involves a substantial amount of plastic deformation, and is driven by the kinetic energy of the expanding gas. Various semiempirical relationships exist in the literature to predict the toughness required for resistance to the propagation of a dynamic ductile failure, but these tend to be ineffective when applied to higher strength grades of steel. The present finite-element model is composed of two main sub-models. The gas decompression algorithm is based on analytical expressions and calculates the gas pressure throughout the pipe as the ductile fracture propagates. The material-response algorithm determines the behaviour of the material under the changing loading conditions by simulating the material response.

This work produced the first simulation in which the crack tip was not advanced 'artificially', but propagated or arrested in response to the entire system, i.e. the linepipe and the decompressing gas.

For simulations in which the variables affecting the flow stress were altered, the rate of work hardening had the greatest influence on the crack tip propagation characteristics, while the states of stress and strain ahead of the propagating crack tip were shown to undergo a complex evolution during the failure process.

On the basis of literature data for full-scale crack-arrest tests performed using X70 grade linepipe steel, the model was shown to be in good agreement with crack arrest/propagate observations and the crack velocity measurements, as well as effectively reproducing the burst pipe geometry.

Finally, for higher strength grade linepipe steels, the model was able to match the results measured from the full-scale crack arrest test. The results from the simulations of 
this test demonstrated that, as in the actual test, the crack would arrest in the third segment, but this appeared to be heavily influenced by the material properties of the following segment. 


\section{RÉSUMÉ}

Une simulation sur ordinateur basée sur la méthode des éléments finis a été construite afin de déterminer quelles propriétés de l'acier affectent la résistance à la rupture ductile dynamique dans les gazoducs. Une telle rupture est provoquée par un déchirement axial stable impliquant une quantité substantielle de déformation plastique, et est entraîné par l'énergie cinétique du gaz. Plusieurs relations quasi-empiriques dans la littérature prédisent la tenacité requise pour la résistance à la propagation ductile dynamique de la rupture, mais celles-ci tendent à être inefficaces une fois appliquées à des catégories plus élevées de résistance d'acier. Le modèle actuel d'élément fini se compose de deux sous-modèles principaux. L'algorithme de décompression de gaz est basé sur des expressions analytiques et calcule la pression de gaz partout dans le gazoduc pendant que la rupture ductile se propage. L'algorithme de matériau détermine le comportement de l'acier dans les conditions de charge variable en simulant la réponse du matériau.

Ce travail a produit la première simulation dans laquelle l'extrémité de la fente n'a pas été avancée ' artificiellement ', mais a propagé ou arrêté en réponse au système entier, c'est-à-dire, l'état du tuyau et les caractéristiques de décompression du gaz.

Pour les simulations dans lesquelles les variables affectant l'effort d'écoulement ont été modifiées, la cadence du durcissement a eu la plus grande influence sur la propagation de la fente, alors que les états de déformation et de contrainte en avant de l'extrémité de la fente subissaient une évolution complexe pendant le procédé.

Sur la base de données de la littérature pour des essais d'arrêt-de-fente réalisés en utilisant de l'acier de qualité X70, le modèle est en bon accord avec les résultats d'arrêt/propage et de vitesse de fente. Le modèle a également reproduit la géométrie de l'éclatement. Pour des aciers de catégorie de résistance plus élevée, le modèle a reproduis les résultats d'un essai d'arrêt-de-fente. Les résultats des simulations de ces essais ont 
démontré que, comme dans l'essai réel, la fente arrêterait dans le troisième segment, mais ceci a semblé être fortement influencé par les propriétés matérielles du segment suivant. 


\section{ACKNOWLEDGEMENTS}

First, I would like to express my greatest appreciation to my supervisors: Professors Steve Yue and James A. Nemes of McGill University and Ruzica A. Petkovic and Michael J. Luton of ExxonMobil Corporate Strategic Research who provided support and guidance, and were a source of great inspiration. Their enthusiasm, broad experience and encouragement throughout the course of this work made this project possible. I am particularly indebted to Professor Yue for providing me the chance to pursue graduate studies, for all of the interesting discussions and lessons I have learned from him. I would particularly like to acknowledge Professor Nemes for assembling a one-week intensive course on finite element modeling, which was a critical stepping stone during the early stages of this project. I would also like to express further gratitude to Dr. Petkovic and Dr. Luton for giving me the opportunity to work on such a challenging project in a very ambitious and creative environment. Much appreciation is directed towards Dr. Petkovic for her enthusiasm and her guidance, which proved to be valuable in all facets of my life. Dr. Luton's passion for scientific enquiry proved to be very refreshing.

I am indebted to my wife, Nayla Chartouni, for her patience and understanding, to my parents and brother, Gary, for their invaluable moral support and inspiration, and to the Chartouni family for their encouragement. Words alone cannot express the gratitude I feel towards my family.

Much appreciation is directed to Tony Prete for being the best friend that anyone could expect, to Brown Chin for the assistance provided during the earlier stages of this project and for every other benefit that comes along with being a good friend, and to my friend Mario Winkler for the very interesting and varied discussions. I would also like to thank Joseph Hazboun for his support.

I would also like to acknowledge the help and support of Liza Monette, Ann B. Rinaldi, Barbara Carstensen, and all of the Advanced Structural Materials Section. 


\section{TABLE OF CONTENTS}

Page

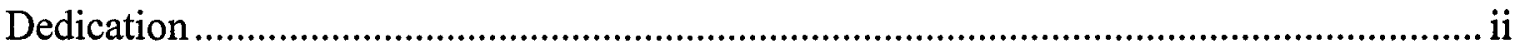

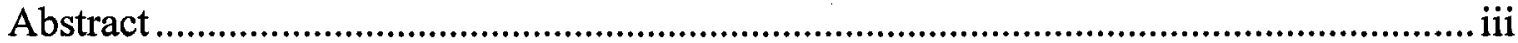

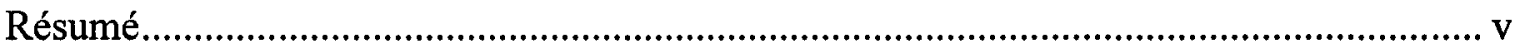

Acknowledgements........................................................................................................ vii

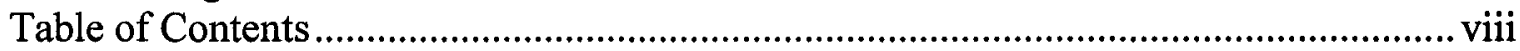

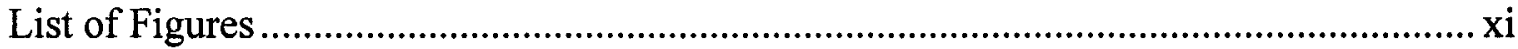

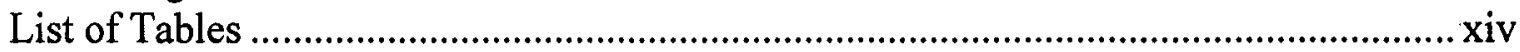

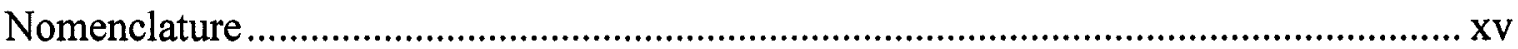

\section{CHAPTER 1: INTRODUCTION}

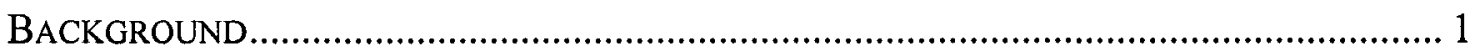

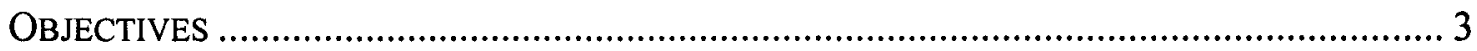

INCENTIVES FOR EFFICIENT GAS TRANSPORTATION ……....................................... 3

THE STRUCTURE OF THIS THESIS ………............................................................ 4

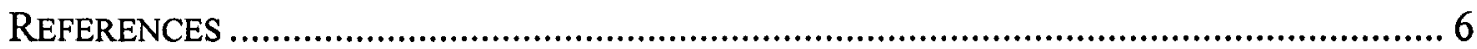

\section{CHAPTER 2: LITERATURE REVIEW}

DeVElopMent AND STATUS OF High StRENGTH LOW Alloy STEELS FOR LiNEPIPE..... 7

Microstructure/Strength Relationships.......................................................... 9

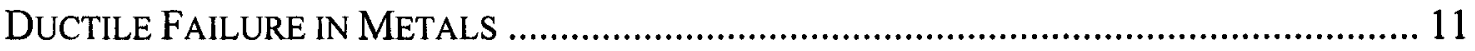

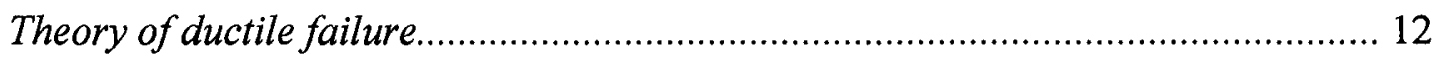

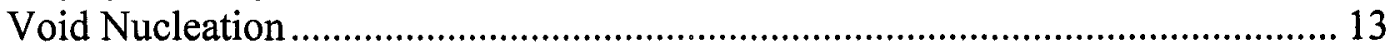

Void Growth and Coalescence........................................................................ 15

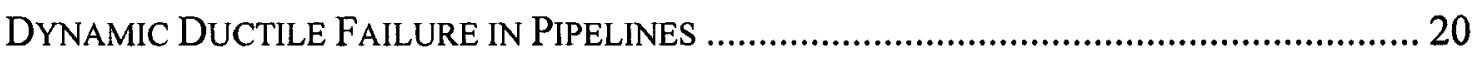

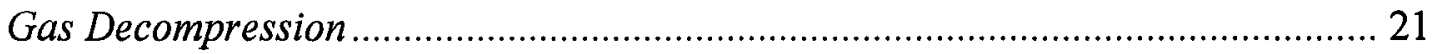

One-Dimensional Isentropic Decompression .................................................... 23

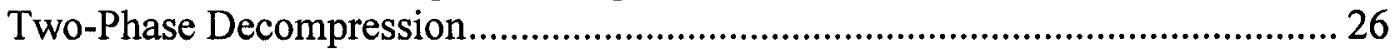

Current Ductile Fracture Resistance Testing Methodology .................................... 28

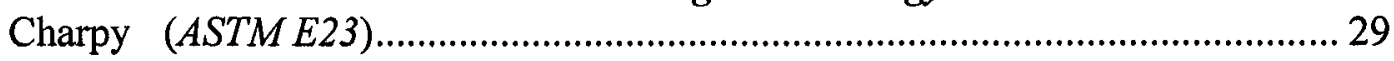

Drop-Weight Tear Test (ASTM E436) ............................................................... 32

Crack-Tip-Opening Angle .................................................................................. 33

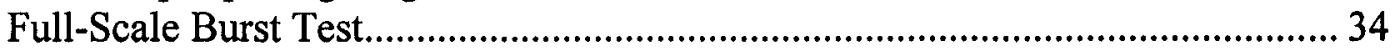

Formulas for Fracture Velocity ......................................................................... 35

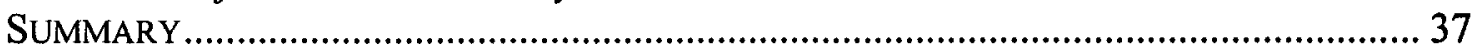

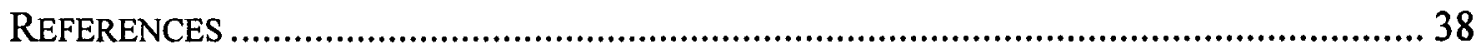

\section{CHAPTER 3: THE MATERIAL MODEL}

CONSTITUTIVE Model 


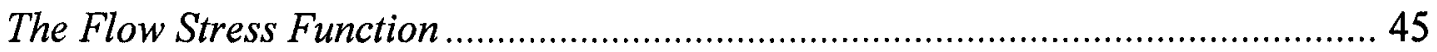

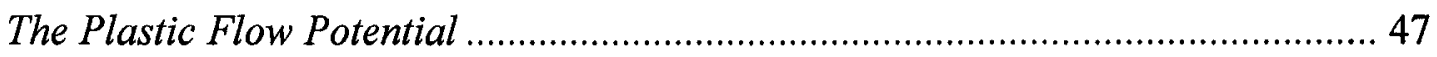

The Hardening Rule ......................................................................................... 49

Failure Criteria

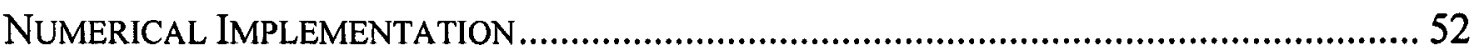

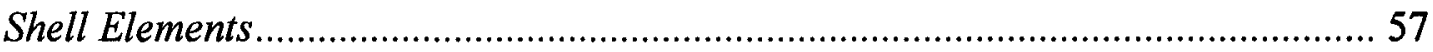

Flow Stress Evolution ...................................................................................... 59

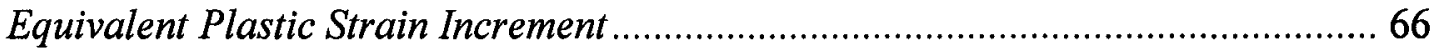

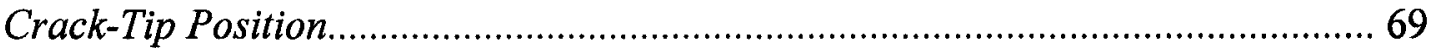

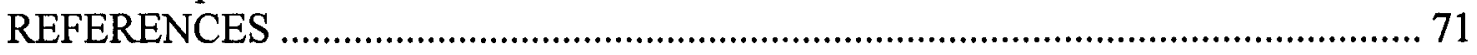

\section{CHAPTER 4: PARAMETER DETERMINATION}

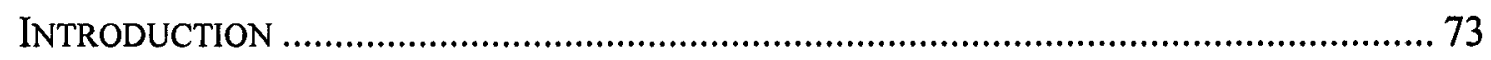

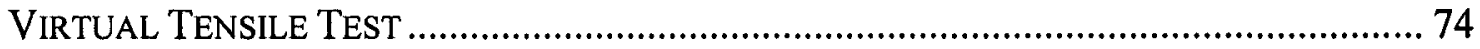

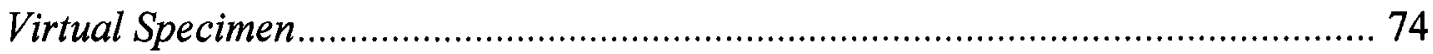

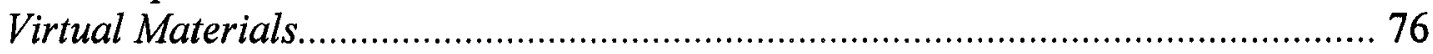

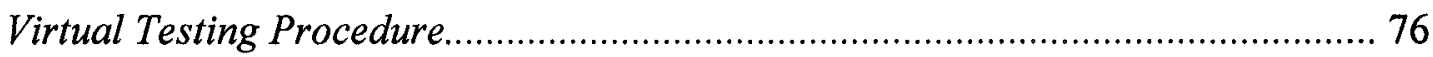

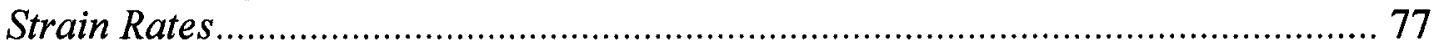

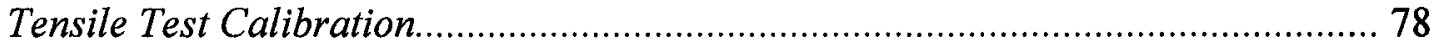

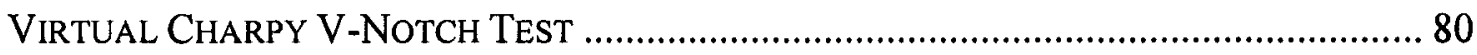

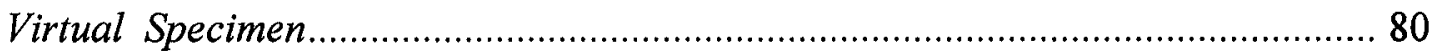

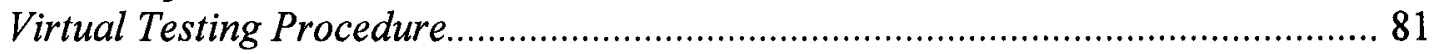

Charpy V-Notch Test Verification .................................................................. 82

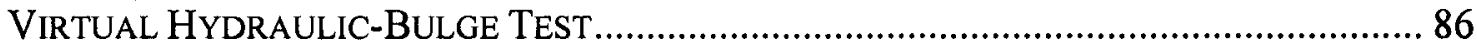

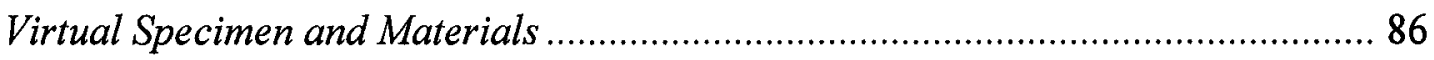

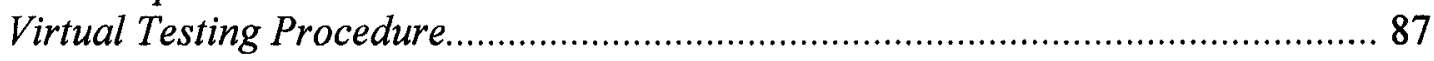

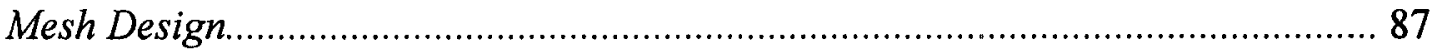

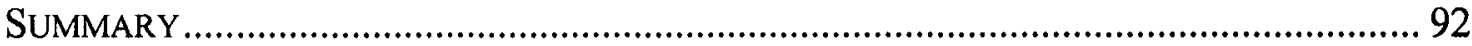

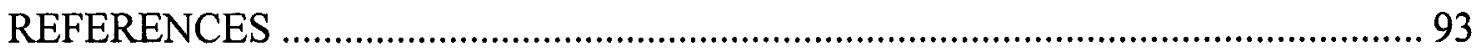

\section{CHAPTER 5: PIPELINE RUPTURE SIMULATION}

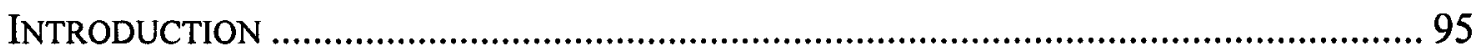

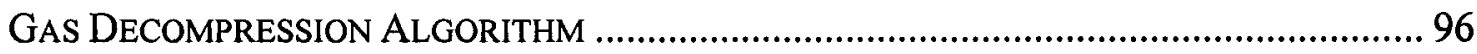

Internal Pipe Pressure Distribution: Measured .................................................... 97

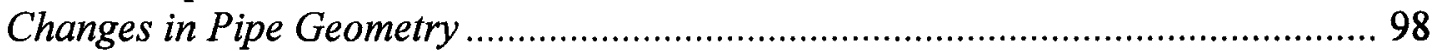

Gas Pressure Ahead of the Fracture-Tip............................................................ 99

Gas Pressure On the Flaps........................................................................... 100

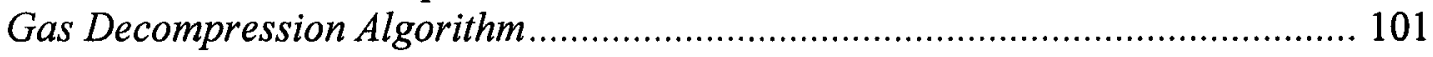

VIRTUAL FULL-SCALE LINEPIPE CRACK-ARREST TEST ................................................ 103

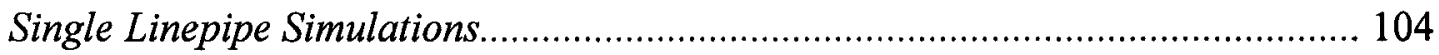




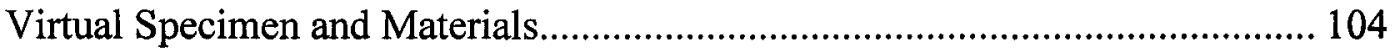

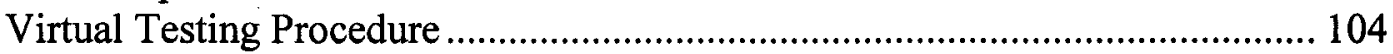

Multi-Linepipe Simulations............................................................................ 105

Virtual Specimen and Materials...................................................................... 106

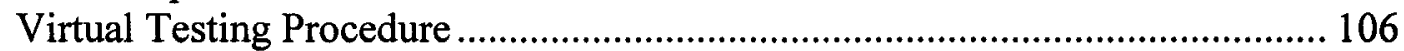

Design and Development Challenges DuRING CONSTRUCTION OF THE Full-

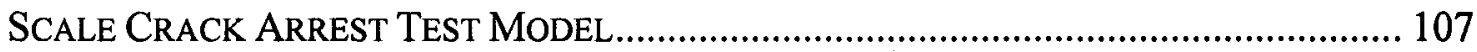

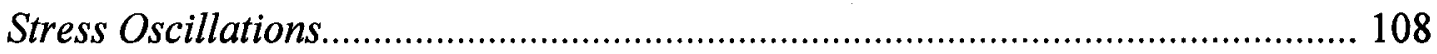

FuLL-SCALE CRACK ARREST SIMULATIONS....................................................... 112

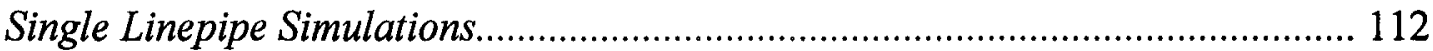

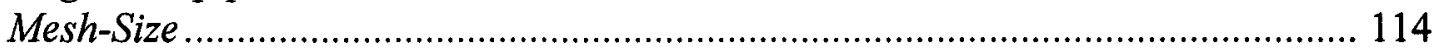

Post-Crack Gas Decompression Characteristics .................................................. 116

Multiple Linepipe Simulations.......................................................................... 117

Effect on Crack-Tip Propagation Characteristics ............................................... 120

Stress and Strain State...................................................................................... 123

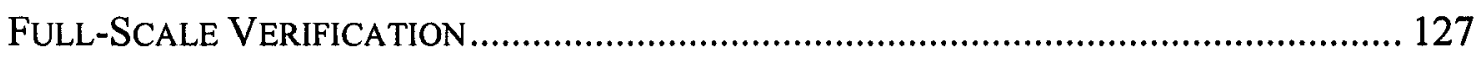

HIGHER GRADE LINEPIPE STEEL .................................................................... 130

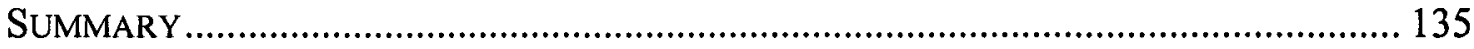

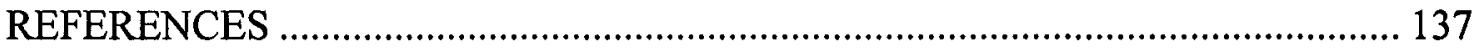

\section{CHAPTER 6: CONCLUSIONS AND RECOMMENDATIONS}

CONCLUSIONS

RECOMMENDATIONS FOR FUTURE WORK 


\section{LIST OF FIGURES}

Page

Figure 1.1: Global map illustrating the remoteness of major natural gas reserves from major markets.

Figure 2.1: Contributions to strengthening in typical ferritic microstructure linepipe steels ............................................................................................... 10

Figure 2.2: Void nucleation, growth, and coalescence in ductile metals....................... 16

Figure 2.3: Illustration for Thomason's load-limit model for void instability ............... 20

Figure 2.4: Schematic diagram of the idealized case of one-dimensional gas decompression...................................................................................... 22

Figure 2.5: Schematic diagram of the geometry of the opening of the ductile fracture .. 23

Figure 2.6: Decompression path enters the two-phase region for rich gases.................. 26

Figure 2.7: Effect of phase change on the decompression wave velocity ...................... 27

Figure 2.8: Decompression curve variation with initial pressure ................................ 28

Figure 2.9: Schematic diagram of a Charpy V-notch impact specimen ....................... 29

Figure 2.10: Extrapolation of CVN-based prediction methods leads to errors. .............. 31

Figure 2.11: Schematic diagram of a drop-weight tear test (DWTT) specimen ............. 32

Figure 2.12: Crack driving force, (CTOA) $)_{\max }$, for various linepipe steel grades ............ 34

Figure 2.13: Schematic diagram of the set-up for a full-scale linepipe burst test........... 35

Figure 2.14: Fracture arrest determination using fracture velocity curves for 3 different steels and a gas decompression curve for air.

Figure 3.1: a) Mises flow stress surface (a cylinder) in stress space

b) Mises flow stress surface ( $a$ circle) seen from the $\sigma_{1}=\sigma_{2}=\sigma_{3}$ axis ...... 46

Figure 3.2: Illustration of the normality rule for plastic flow .................................... 47

Figure 3.3: Commonly used work-hardening rules ................................................. 49

Figure 3.4: Expansion of the mises flow stress surface with isotropic hardening.......... 50

Figure 3.5: Flowchart of the material response algorithm for shell elements ................ 58

Figure 3.6: Flowchart of the algorithm for flow stress evolution ................................ 61

Figure 3.7: Schematic diagram of a return-mapping procedure on the effective stress effective plastic strain plane.

Figure 3.8: Flowchart of the algorithm for determining the equivalent plastic strain

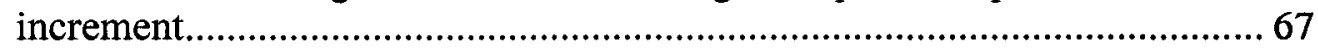

Figure 3.9: Flowchart of the algorithm for updating the crack-tip position .................... 70

Figure 4.1: Schematic diagram of a standard round tension test specimen .................... 75

Figure 4.2: Depiction of the portion of the specimen modelled and a sample mesh ....... 75

Figure 4.3: Schematic diagram of the virtual tensile test experimental set-up ............... 77 
Figure 4.4: Graph of the \%elongation as a function of the material algorithm failure parameter .79

Figure 4.5: Schematic diagram of a type A Charpy V-Notch test specimen .................... 81

Figure 4.6: Depiction of a sample undeformed mesh for the Charpy specimen............... 81

Figure 4.7: Equivalent plastic strain contours for the Charpy test simulation of Steel 2

Figure 4.8: Force versus displacement graph for the Charpy test finite element simulation of steel 2 from Table 4.2

Figure 4.9: Graph of absorbed energy (J) versus displacement for the Charpy test finite element simulation of steel 2 from Table 4.2.

Figure 4.10: Graph of the predicted versus measured CVN values for some of the steels from Table 4.2

Figure 4.11: Schematic diagram of the specimen used in the hydraulic bulge test .........87

Figure 4.12: The various mesh designs used for bulge test set 1 ..................................... 88

Figure 4.13: The various mesh designs used for bulge test set 2 .................................... 89

Figure 4.14: The various mesh designs used for bulge test set 3 ..................................... 89

Figure 4.15: Equivalent plastic strain contours for bulge test set 1 .................................. 90

Figure 4.16: Equivalent plastic strain contours for bulge test set 2 .................................. 90

Figure 4.17: Equivalent plastic strain contours for bulge test set 3 .................................. 91

Figure 5.1: Schematic diagram of the ductile fracture initiation in the linepipe 96

Figure 5.2: Output from circumferentially located pressure transducers in a CSM

full-scale burst test

Figure 5.3: The cross-sectional change with position relative to the ductile fracture tip.

Figure 5.4: Illustration of a point-of-interest behind the fracture tip.............................. 101

Figure 5.5: Flowchart of the gas decompression algorithm.......................................... 102

Figure 5.6: Schematic diagram of the set-up for a full-scale linepipe burst test............. 103

Figure 5.7: Graph of the pressure profile used during the "oscillations" simulations ... 109

Figure 5.8: Plot of stress history for simulation A1 .................................................... 109

Figure 5.9: Schematic diagram illustrating the location of the element used for the stress history graphs

Figure 5.10: Graph of the modified pressure-loading profile ........................................ 111

Figure 5.11: Plot of the stress history for simulation A1 with the modified profile...... 111

Figure 5.12: Graph illustrating the concept of deformation work to fracture (energy/vol)

Figure 5.13: Graph of the measured fracture velocity versus the calculated deformation fracture work for literature data.

Figure 5.14: Sensitivity analysis of fracture velocity to the plasticity variables ........... 114

Figure 5.15: Principal elements whose size was altered for the sensitivity analysis ..... 114

Figure 5.16: Graph of results for the finer meshes used for the tests in Table 5.5 ........ 116 
Figure 5.17: Graph of results for the comparison of gas decompression characteristics

Figure 5.18: Schematic diagram of the use of several linepipe segments for the set-up of a full-scale linepipe burst test

Figure 5.19: Qualitative comparison between the model's predictions and observations from full-scale crack arrest tests

Figure 5.20: Graph of the through-thickness strain profile from the fracture surface for various arbitrary locations along the pipe axis for Steel 3 from Table 4.1

Figure 5.21: Graph of crack-tip velocity versus crack-tip position for two different cases of a tougher pipe placed after the initiator.

Figure 5.22: Graph of crack-tip velocity versus crack-tip position for a less tough pipe placed after a tough pipe

Figure 5.23: Graph of crack-tip velocity versus the material failure parameter. 123

Figure 5.24: A graph of the stress versus the distance ahead of the fracture-tip. The horizontal solid line indicates the initial equivalent von Mises yield stress of the pipe material

Figure 5.25: Graph comparing the final strain state experienced during the crack-arrest test and Charpy test, and the calculated in-plane strain history for the linepipe material in the crack path

Figure 5.26: Diagram of the Kamaishi test set up along with the material properties for each linepipe segment.

Figure 5.27: A graph of the predicted versus measured fracture velocities 129

Figure 5.28: Schematic diagram of the set-up for the virtual crack-arrest test for the higher grade steel linepipe

Figure 5.29: A graph of the measured crack-tip position versus time for the simulations 


\section{LIST OF TABLES}

Page

Table 2.1: Optimal values for the micromechanical parameters of the Gurson-Tvergaard equation. 18

Table 2.2: Empirical equations for ductile fracture arrest............................................ 30

Table 2.3: Review of current laboratory fracture toughness assessment methods .......... 37

Table 4.1: Mechanical properties of some of the steels used to calibrate the model....... 76

Table 4.2: Material model failure parameters selected from the simulations..................80

Table 4.3: Table of the measured Charpy energy values versus the predicted values from the finite element simulations

Table 5.1: Mechanical properties, geometry and operating conditions of steels tested in single linepipe experiments that used tabular stress-strain data.

Table 5.2: Mechanical properties, geometry and operating conditions of steels tested in linepipe experiments that used a function to calculate the flow curve.

Table 5.3: Mechanical properties, geometry and operating conditions of additional steels tested in the multi-linepipe experiments. 106

Table 5.4: Principal variables modified during the oscillations study 108

Table 5.5: Material and mesh properties and results of mesh-sensitivity analysis .

Table 5.6: Material properties and results of multi-linepipe sensitivity analysis 121

Table 5.7: Comparison of predicted and measured crack velocities 129

Table 5.8: Material properties of higher-grade linepipe steels 130

Table 5.9: Material properties used for the virtual higher-grade linepipe steels

Table 5.10: Table outlining which steels used for which segment for each simulation 131

Table 5.11: Conditions for the full-scale crack arrest test simulations ........................ 131

Table 5.12: Empirical equations for ductile fracture arrest ...................................... 133

Table 5.13: Calculated and predicted CVN values for the higher-grade steel

Table 5.14: Results obtained from the actual and the virtual crack-arrest test for the higher-grade steel 


\section{NOMENCLATURE}

a1 void height

a2 void width

A constant, used in the flow stress equation

$\mathrm{A}_{1}$ constant, used in the gas decompression equation

$\mathrm{A}_{2}$ constant, used in the gas decompression equation

$\mathrm{b}$ magnitude of the Burger's vector

$\mathrm{B}$ constant, used in the flow stress equation

$b_{1}$ constant, used in the (CTOA $)_{\max }$ equation

$\mathrm{b}_{2}, \quad$ constant, used in the (CTOA) $)_{\max }$ equation

$b_{3}$ constant, used in the (CTOA) $\max$ equation

$\mathrm{b}_{4} \quad$ constant, used in the (CTOA) $\max$ equation

C a fourth-order, tangent material stiffness tensor

$\mathbf{C}_{\mathrm{ijkl}}$ elastic tangent modulus

c sound velocity in the gas

$\mathrm{c}_{0} \quad$ sound velocity in the gas at the start of the gas expansion

$(\mathrm{CTOA})_{\mathrm{c}}$ fracture resistance of the material based on the crack-tip-opening angle

$(\mathrm{CTOA})_{\max }$ driving force of the material based on the crack-tip-opening angle

$\mathrm{Cv}$ Charpy energy

d ferrite grain size

$\mathrm{d}_{\mathrm{v}} \quad$ distance between voids

$d_{1} \quad$ constant used in failure parameter equation that is sensitive to the triaxiality

$d_{2} \quad$ constant used in failure parameter equation that is sensitive to the triaxiality

D diameter of the test specimen

$D^{\text {el }}$ elastic strain rate tensor

$\mathrm{D}_{\text {mean }}$ mean pipe diameter

D $^{\text {pl }} \quad$ plastic strain rate tensor

$\mathbf{D}^{\text {tot }}$ total strain rate tensor

E Young's modulus

$\mathrm{E}_{\mathrm{CVN}}$ energy required to fracture the Charpy specimen

$\mathrm{e}_{\mathrm{uts}} \quad$ engineering strain at the maximum engineering stress during uniaxial tension

$\mathrm{F} \quad$ von Mises flow stress condition, flow stress function

$\mathrm{F}_{\mathrm{i}} \quad$ force component

$f_{v} \quad$ void volume fraction

$f_{v, c} \quad$ critical value of the void volume fraction

$f_{\mathrm{v}, \mathrm{F}} \quad$ value of void volume fraction at final fracture

$f_{\mathrm{V}}^{*} \quad$ effective void volume fraction

$f_{\mathrm{V}, \mathrm{U}}^{*}$ ultimate void volume fraction value at which the macroscopic stress carrying capacity vanishes

$\hat{g} \quad$ stress potential

$\mathrm{G}$ gauge length of the test specimen

$\mathrm{H}$ backfill depth 
$\mathrm{h} \quad$ pipe wall thickness

I identity tensor

$\mathrm{J}_{2}^{\prime} \quad$ second invariant of the reduced stress tensor

$\mathrm{k}_{\mathrm{x}} \quad$ strengthening factor

$\mathrm{k}_{\mathrm{y}}$ constant

$\mathrm{L}$ effective element length of the smallest element

n work-hardening exponent

$\mathrm{p} \quad$ hydrostatic pressure

$P \quad$ gas pressure

$\mathrm{P}_{0} \quad$ initial pressure; gas pressure at the start of the gas expansion

$\mathrm{P}_{\mathrm{c}} \quad$ gas pressure at the crack-tip

$P_{c f} \quad$ critical flow pressure

$\mathrm{q}_{1} \quad$ constant, used in the Gurson/Gurson-Tvergaard equation

$\mathrm{q}_{2}$ constant, used in the Gurson/Gurson-Tvergaard equation

$\mathrm{q}_{3}$ constant, used in the Gurson/Gurson-Tvergaard equation

$\mathrm{q}_{4} \quad$ constant

$\mathrm{R}$ gas constant

$\mathrm{r}$ particle radius

$\mathbf{R}$ rotation tensor

$R_{0} \quad$ radius of the initial, spherical void

$\mathrm{R}_{\mathrm{p}} \quad$ pipe radius

$R_{v} \quad$ average radial displacement of a void

S stress deviator tensor

$\mathrm{s}_{\mathrm{ij}}^{*} \quad$ predicted trial deviatoric stress component

$\bar{s}^{\text {tr }} \quad$ effective trial stress

T absolute temperature

$\mathrm{t}$ time

$t_{\text {cr }} \quad$ critical time at which the pipe rupture is large enough for the gas to escape

$\mathrm{T}_{0} \quad$ absolute temperature at the start of the gas expansion

$\mathrm{v}_{\mathrm{fl}} \quad$ flow velocity

$\mathrm{v}_{\mathrm{CT}} \quad$ crack tip velocity

$\mathrm{x}, \mathrm{x}_{\mathrm{i}}$ position along the pipe axis (where $i=$ an integer)

$\mathrm{x}_{\mathrm{a}} \quad$ position along the pipe axis ahead of the crack tip

$\mathrm{x}_{\mathrm{b}} \quad$ position along the pipe axis behind the crack tip

$\mathrm{x}_{\mathrm{CT}} \quad$ crack-tip position along the pipe axis

$\mathrm{x}_{\mathrm{DW}}$ position along the pipe axis of the leading decompression wavefront

$\mathrm{x}_{\mathrm{mat}}$ position along the pipe axis of the material point that has most recently failed

$\alpha \quad$ constant

$\varepsilon_{\text {eq }} \quad$ equivalent (von Mises) plastic strain

$\varepsilon_{1} \quad$ maximum remote normal strain

$\bar{\varepsilon}^{\mathrm{pl}} \quad$ equivalent plastic strain

$\Delta \boldsymbol{\varepsilon}_{\mathrm{kl}} \quad$ incremental strain tensor

$\Delta \varepsilon_{\mathrm{ij}} \quad$ component of the strain increment tensor 
$\Delta \varepsilon_{\mathrm{ij}}^{\mathrm{el}, \mathrm{c}}$ corrected elastic strain increment

$\Delta \varepsilon_{\mathrm{ij}}^{\mathrm{el}, \mathrm{p}}$ predicted elastic strain increment

$\Delta \bar{\varepsilon}^{\mathrm{pl}} \quad$ equivalent plastic strain increment

$\bar{\varepsilon}_{\mathrm{cr}}^{\mathrm{pl}} \quad$ critical effective plastic strain for failure

$\bar{\varepsilon}_{\mathrm{f}}^{\mathrm{pl}} \quad$ failure parameter

$\delta_{\mathrm{ij}} \quad$ Kronecker delta ( $\delta=1$ when $i=j, \delta=0$ when $i \neq j$ )

$\Phi$ flow stress function (calculated from Gurson)

$\Gamma \quad$ damage parameter

$\gamma \quad$ specific heat ratio, $c_{p} / c_{v}$

$\mu \quad$ shear modulus

$v \quad$ Poisson's ratio

$\theta \quad$ Temperature

$\rho$ density

$\rho_{0} \quad$ density at the start of the gas expansion

$\rho_{\text {vap }}$ vapour density

$\boldsymbol{\sigma}$ Cauchy stress tensor

$\dot{\sigma} \quad$ Cauchy stress rate tensor

$\boldsymbol{\sigma}_{\mathrm{ij}}^{*} \quad$ predicted stress tensor

$\bar{\sigma} \quad$ equivalent stress, effective flow stress

$\boldsymbol{\sigma}^{\nabla} \quad$ Green-Naghdi stress rate tensor

$\sigma_{\mathrm{kk}}^{*} \quad$ predicted equivalent pressure stress

$\sigma_{\mathrm{ij}}^{*} \quad$ predicted stresses component

$\sigma_{\mathrm{ij}}^{\mathrm{n}} \quad$ stress tensor from the previous time step

$\bar{\sigma}^{\text {tr }} \quad$ effective trial stress, elastic predictor stress

$\sigma_{0} \quad$ intrinsic matrix hardening

$\sigma_{1} \quad$ maximum principal stress

$\sigma_{\mathrm{c}} \quad$ critical stress value for decohesion, void nucleation

$\Delta \sigma_{d} \quad$ change in the interface stress

$\sigma_{\mathrm{DSL}} \quad$ dislocation strengthening

$\sigma_{\mathrm{Fl}} \quad$ flow stress

$\sigma_{\mathrm{h}} \quad$ hoop stress

$\sigma_{i, i=1,2,3}$ principal stresses

$\sigma_{i j} \quad$ stress tensor component

$\sigma_{\text {ISS }} \quad$ interstitial solid solution strengthening

$\sigma_{\mathrm{m}} \quad$ mean stress

$\sigma_{\mathrm{n}} \quad$ net section stress between voids

$\sigma_{\mathrm{n}(\mathrm{c})}$ critical value of the net section stress between voids 
$\sigma_{\mathrm{PPT}} \quad$ precipitation strengthening

$\sigma_{\mathrm{SPH}} \quad$ second phase strengthening.

$\sigma_{\text {SSS }} \quad$ substitutional solid solution strengthening

$\sigma_{\text {SUB }} \quad$ substructure strengthening

$\sigma_{y} \quad$ yield strength; yield stress of the fully dense matrix material, flow stress

$\boldsymbol{\Omega}$ spin rate

$\omega \quad$ height above the bottom of the pipe

$\Psi \quad$ work-hardening rate 


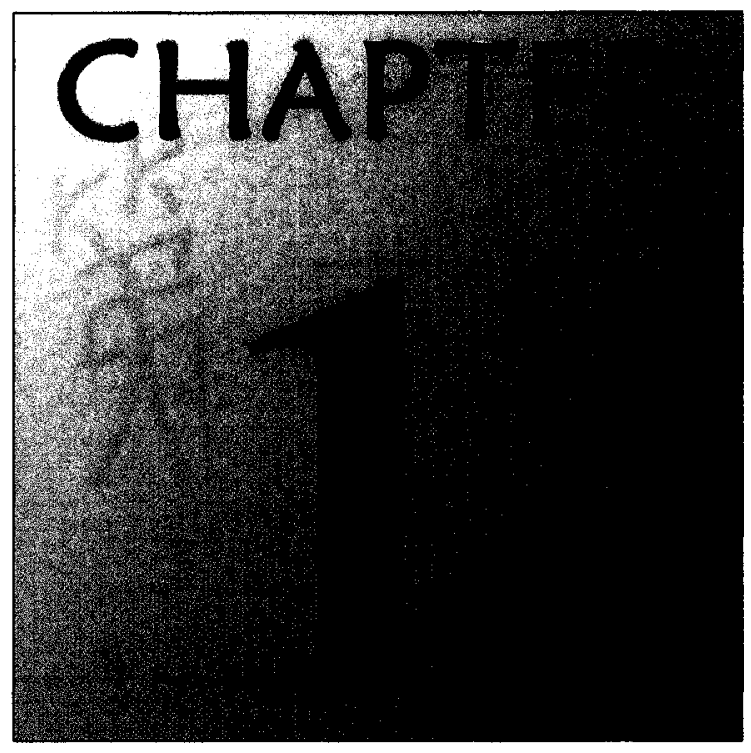

\section{Introduction}

\subsection{Background}

The current worldwide yearly consumption of fossil fuels is $2.5 \times 10^{9}$ tons of coal, $3.7 \times 10^{12}$ liters $\left(23 \times 10^{9}\right.$ barrels $)$ of oil and $80 \times 10^{12} \mathrm{~m}^{3}$ of natural gas [1 - 4]. The consumption of coal reached a maximum in the 1920's and has been declining ever since [5]. Although the United States consumption of oil, which is the current dominant fossil fuel today, reached its peak consumption in the 1970's and has been subsequently declining, the world consumption will not attain its peak until the second decade of this century. If the succession of primary resources continues, most forecasts see natural gas as the dominant source of energy, which will be likely to peak in the 2030's. It is further predicted that natural gas will be the dominant energy source through the $21^{\text {st }}$ century. Since it is estimated that the world population will grow to about 10 billion by 2100 , worldwide energy consumption will more than double even if per capita energy 
consumption remains relatively unchanged. Assuming peak natural gas usage in 2030, an average growth rate in gas consumption of $3 \%$ per year, and given a reasonable growth in the standard of living, gas demand by the end of the next century will be $200 \times 10^{12} \mathrm{~m}^{3}[6]$. Accordingly, more than $120 \times 10^{12} \mathrm{~m}^{3}$ of natural gas from new sources will have to be made available in major population areas at that time.

Inasmuch as current and likely newly discovered gas resources are located in remote ${ }^{*}$ locations (Figure 1.1), the demand for gas can only be achieved with economic, long distance pipelines. Accordingly, low cost, high strength linepipe will be essential to the energy delivery system throughout the $21^{\text {st }}$ century.

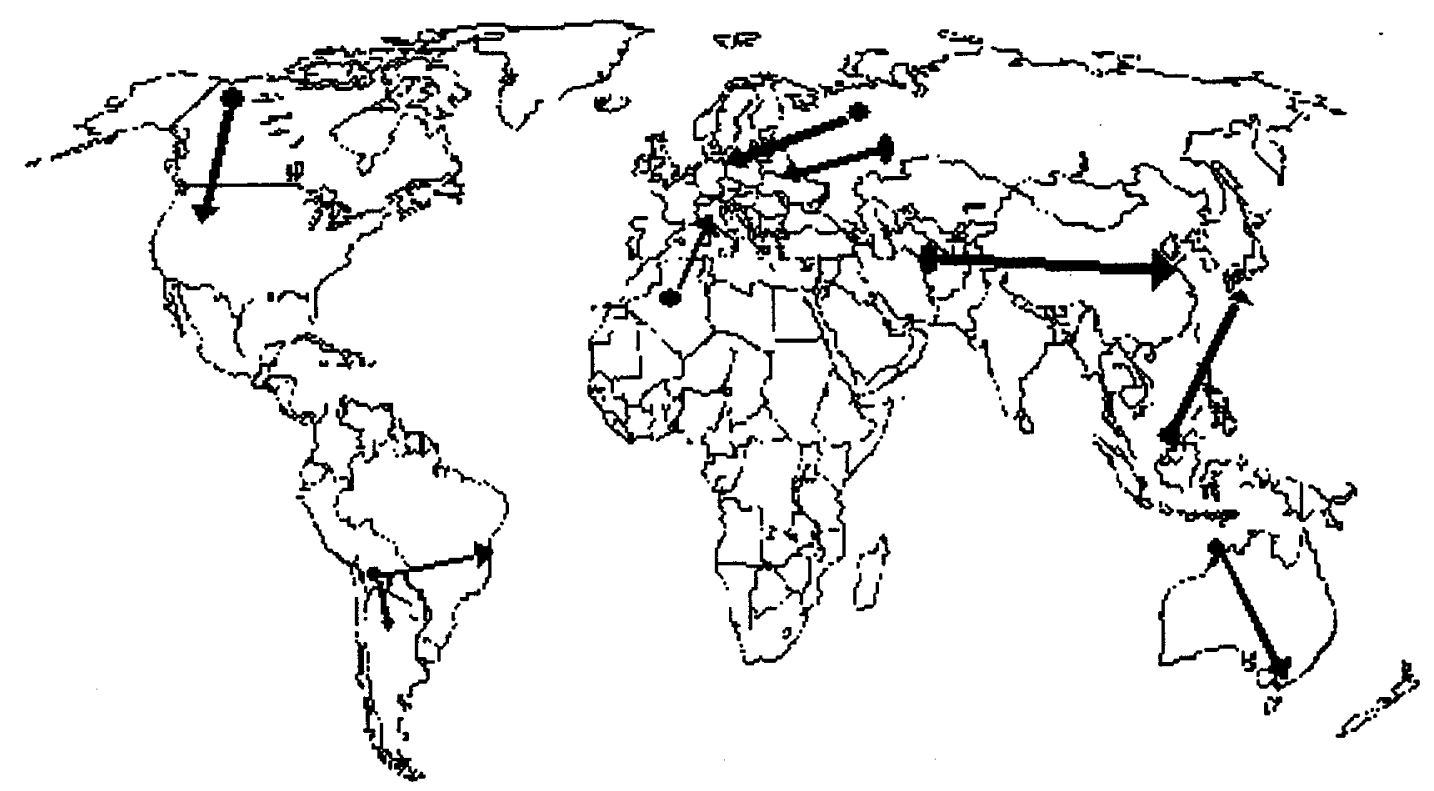

Figure 1.1: Global map illustrating the remoteness of major natural gas reserves from major markets.

Improved gas transmission economics can be achieved by the use of low cost, high strength easily weldable linepipe. The steels are required to have a low ductile-tobrittle transition temperature to combat fracture initiation under operating conditions. Furthermore, the steels are required to exhibit high toughness, in the ductile range, to

\footnotetext{
* The word remote is taken here to mean locations that are very distant from centers of consumption
} 
prevent catastrophic running fracture in the event of accidental fracture initiation. This latter property requirement is the subject of the present study.

\subsection{Objectives}

This study focuses on the identification of the characteristics of the steel that control running ductile fracture in pipelines, with the intent of guiding the microstructural design of a new generation of linepipe steels.

The strategy that has been followed to meet this objective is to construct a finite element model that has the following functions:

a) Properly simulates pipeline fracture given the mechanical properties of the material

b) Identifies the sensitivity of the failure process to all potential property variables

\subsection{Incentives for Efficient Gas Transportation}

Examining the current technology in use, the steel utilized is typically $\mathrm{X} 70^{1}$ grade, can have a diameter of up to 1.5 meters ( 60 inches), and a wall thickness of up to $2.5 \mathrm{~cm}$ ( 1 inch), which is dictated by the gas pressure requirements. The total cost of a landbased gas transmission project is made up of:

\section{$\underline{\text { Percent }}$}

i. $\quad$ linepipe (the material)

$30 \%-40 \%$

ii. compressors

$25 \%$

iii. labour (welding crews, etc.)

$30 \%$

iv. right of way

$1 \%$

- typically 'reserve' $7.6 \mathrm{~m}$ ( 25 feet $)$ of land on either side of the pipe. It's the right to use the land for ' $x$ ' years

\footnotetext{
${ }^{\mathrm{I}}$ This designation typically refers to the specified minimum yield strength, i.e. $70 \mathrm{ksi}$ in this case
} 
Although the costs for the last three components (ii-iv) are relatively fixed, there is the possibility of changing the cost of the first component by increasing the strength of the linepipe material. In general, however, if an increase in strength is possible, it leads to an increase in material cost due to additional alloying or thermo-mechanical processing. Although X65 grade linepipe has been in use since the 1960's, there have been no long distance pipelines constructed with grades stronger than X80 since the 1980's. Even the Alliance Pipeline, which is due to be operational in late 2000 and runs approximately $2700 \mathrm{~km}$ long from British Columbia, Canada, to Chicago, Illinois, USA, utilizes X70 grade material [7]. Evidently any increase in yield strength, $\sigma_{y}$, results in an equivalent reduction in the requirements for minimum pipe wall thickness.

The material utilized for a pipeline project is purchased according to weight. For example, a pipeline project from Turkmenistan to Beijing, China would be approximately 6500 kilometers in length and would cost almost \$US 10 billion, assuming the cost is \$US 1.5 million per kilometer of pipeline [8]. Therefore, the ability to utilize thinner pipes (less material) could result in capital cost savings of up to $10 \%$ [8], which could translate to savings of almost $\$ 1$ billion for this pipeline.

\subsection{The Structure of this Thesis}

This chapter serves as the background to the motivation for this research undertaking.

Chapter two is an overview of the state-of-the-art in all the components that are relevant to the study. A brief review of the metallurgy of high-strength low alloy steels is presented. Current theories of ductile failure in metals will be examined. Subsequently, dynamic ductile failure in pipelines, including the factors influencing rapid gas decompression are addressed. Finally, the methods utilized for failure-control are discussed. 


\section{Chapter 1: Introduction}

Chapter three describes the algorithm used to evaluate the material response as well as a description of the gas decompression algorithm utilized for the simulation of pipeline dynamic ductile fracture. A description of the numerical implementation of this algorithm is also presented in this chapter.

The applications used in this study for the determination of parameters, which includes the virtual testing laboratory, are presented in the fourth chapter. These applications consist of: the tensile test, charpy v-notch test, and the hydraulic-bulge test.

Finally, the focus of the study, which is the behaviour of full-scale linepipe dynamic ductile fracture, is examined in chapter five.

The conclusions of this study and recommendations for future work are presented in chapter six. 


\section{REFERENCES}

1. Oil Security", Climate Protection and the National Interest, World Resources Institute, Washington, Figure 12, 1997

2. World Resources 1998-1999, World Resources Institute, Washington, 1999, p. 332

3. Griffin, K., 1996 World Natural Gas Production, International Energy Annual, U.S. Department of Energy, 1997

4. Grillot, M., Gross Heat Content of Dry Natural Gas, International Energy Annual, U.S. Department of Energy, 1997

5. Ausubel, Jesse H., Resources and Environment in the $21^{\text {st }}$ Century: Seeing Past the Phantoms, World Energy Council Journal, July 1998, pp. 8-16

6. World Energy Consumption, International Energy Outlook, U.S. Department of Energy, 1997

7. Collins, Laurie E.; Kostic, Milos; Lawrence, Tom; Mackenzie, Robert and Townley, Nathan, "High Strength Linepipe: Current and Future Production", Proceedings of the International Pipeline Conference 2000, October 1-5, 2000, Calgary, Alberta, Canada, ASME International, pp. 185-191

8. Luton, Michael, ExxonMobil Research and Engineering, private communication, March 1999 


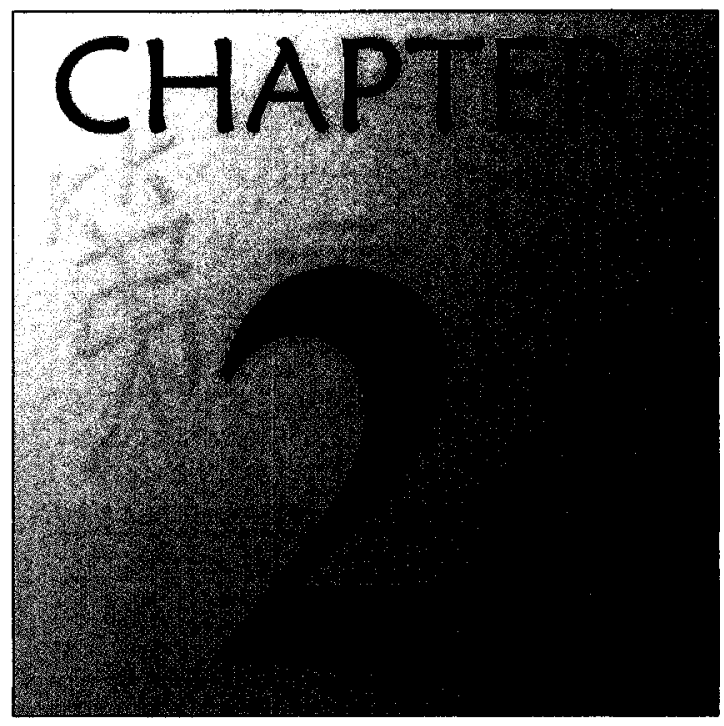

\section{Literature Review}

\subsection{Development and Status of High Strength Low Alloy Steels for Linepipe}

High strength steels have been available for over forty years for constructional applications, pressure vessels, naval ships and submarine hulls. However, the grades of steel that have been developed for these applications are somewhat different from those necessary for pipelines. In all the above application, achieving the required strength in the steel is not the primary controlling parameter in the development of high strength steel, but achieving the combination of parameters that are called for, particularly the weldability, toughness, and, in the case of linepipe, resistance to propagating ductile fracture of the steel, which becomes ever more critical as the strength increases.

Over the past years there has been a continuous demand for increasing strength for linepipe materials accompanied by a corresponding demand for improved toughness properties. 
From the steel producers' viewpoint, this drive towards higher strength has presented a challenge in meeting the combined demands of higher strength, good toughness and excellent weldability.

In reviewing pipemaking technology over the last 30 years, conventional hotrolling and normalising was replaced in the mid-70's by thermomechanical processing in order to achieve an $\mathrm{API}^{\ddagger} \mathrm{X} 70^{\dagger}$ grade steel with microalloying additions of niobium and vanadium, and with reduced carbon content to maintain weldability. Improvements in this approach, using accelerated cooling after rolling, emerged in the 1980's. This development allowed the carbon content to be further reduced while achieving the strength requirements for X80. Such steels also exhibited excellent weldability. Steel developments have continued within the various manufacturers of high quality, ferritic/bainitic pipeline steel grades to reduce the microalloying additions in order to reduce costs and enhance weldability.

Linepipe is manufactured either as seamless linepipe or by three different processes that start with either plate or strip: high-frequency resistance welding $(H F E R W)$, spiral manufacturing sequence $(S M S)$ and double submerged arc welding $(D S A W)$. The inherent characteristics of either the equipment or each manufacturing route may limit metallurgical options for increasing yield or tensile strength [1].

Grade X-80 linepipe has been manufactured from all three processes that start with a flat product (HFERW, SMS, DSAW), and the DSAW process has been successfully utilized to produce $\mathrm{X}-100$ grade linepipe on a trial production basis [2,3].

Except for the seamless pipe making process, the required mechanical properties in the final pipe can be developed in the starting plate or they can be developed during a final heat treatment. As the yield strength of the incoming plate increases, it becomes

\footnotetext{
\# American Pipeline Institute

${ }^{\dagger} \mathrm{X} 70$ typically refers to the specified minimum yield strength, i.e. $70 \mathrm{ksi}$ in this case
} 
more and more difficult to form it and the design capacity of the coiling, uncoiling, and pipe forming equipment is eventually exceeded.

\subsubsection{Microstructure/Strength Relationships}

Empirical relationships have been developed between composition and microstructural features and mechanical properties. The first quantitative relationships are attributable to Pickering and Gladman [4], with later refinements added by many contributors [5 - 12]. The microstructure-yield strength relationship has evolved from the simple Hall-Petch form to the following expanded form:

$$
\sigma_{\mathrm{y}}=\sigma_{\mathrm{O}}+\sigma_{\mathrm{SSS}}+\sigma_{\mathrm{ISS}}+\sigma_{\mathrm{PPT}}+\sigma_{\mathrm{DSL}}+\sigma_{\mathrm{SUB}}+\sigma_{\mathrm{SPH}}+\mathrm{k}_{\mathrm{y}} \mathrm{d}^{-1 / 2}
$$

where $k_{y}$ is a constant, ' $d$ ' is the ferrite grain size, $\sigma_{O}$ is the intrinsic matrix hardening, $\sigma_{\text {SSS }}$ is the substitutional solid solution strengthening, $\sigma_{\text {ISS }}$ is the interstitial solid solution strengthening, $\sigma_{\mathrm{PPT}}$ is the precipitation strengthening, $\sigma_{\mathrm{DSL}}$ is the dislocation strengthening, $\sigma_{\mathrm{SUB}}$ is the substructure strengthening, and $\sigma_{\mathrm{SPH}}$ is the second phase strengthening.

Of all the terms, only $\sigma_{\mathrm{O}}$ and $\sigma_{\mathrm{SSS}}$ are independent of the steel processing history. In the case of ferritic microstructures, the substitutional solid solution strengthening term is given by:

$$
\sigma_{\mathrm{SSS}}=\mathrm{k}^{\mathrm{Mn}}(\% \mathrm{Mn})+\mathrm{k}^{\mathrm{Si}}(\% \mathrm{Si})+\mathrm{k}^{\mathrm{P}}(\% \mathrm{P})+\mathrm{k}^{\mathrm{Cu}}(\% \mathrm{Cu})+\mathrm{k}^{\mathrm{Ni}}(\% \mathrm{Ni})+\ldots
$$

Here the contribution due to each element is taken as the product of the amount of the element present $(\% x)$ and a strengthening factor $\left(\mathrm{k}^{\mathrm{x}}\right)$. This solid-solution strengthening term can be applied effectively to hot-rolled steels, thermomechanically 
controlled processing $(T M C P)$ products, as well as normalized, or annealed products. All of the remaining terms are dependent both on composition and processing history. These have to be optimized for production of higher yield strength linepipe. The contributions to the yield strength of ferritic microstructure linepipe steels are shown in Figure 2.1.

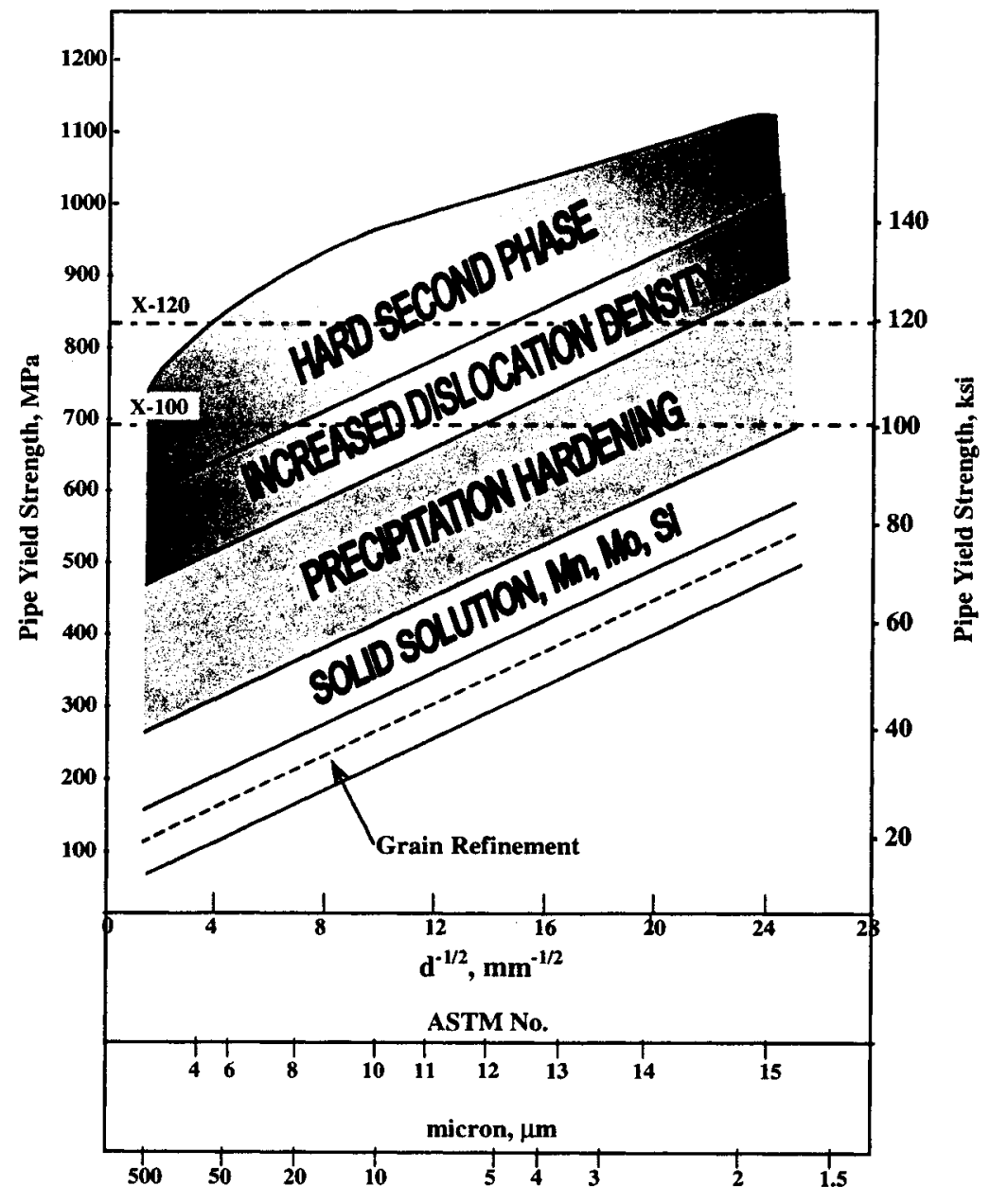

Figure 2.1: Contributions to strengthening in typical ferritic microstructure linepipe steels. [adapted from 1]

Here the strong influence of grain refinement is evident and this places a severe limitation on the type of processing that can be used to achieve higher strengths. For example, in conventional quench and tempered linepipe the grain refinement is limited by the relatively large austenite grain size present prior to the quench. By contrast, when the 
austenite is severely controlled-rolled just prior to accelerated cooling, significantly fine microstructures, and consequently high strengths, can be achieved. Additional strengthening can be achieved by increasing the dislocation density of the ferrite by controlled rolling the plate in the intercritical regime. To produce strengths that are in excess of $700 \mathrm{MPa}$ in material with a grain size greater than approximately $10 \mu \mathrm{m}$, it is necessary to introduce harder phases, such as bainite and martensite, by controlled cooling of well-conditioned austenite.

\subsection{Ductile Failure in Metals}

Many methods exist for defining toughness. Current assessment techniques are intimately tied to their engineering applications, which expose these components to certain stresses and constraints. The toughness of the steel is determined relative to the externally applied stresses and the existence of an assumed defect [13]. The two toughness assessments that can be made from the common tests are the ductile shelf energy and the impact ductile-to-brittle transition temperature. Both are controlled by the metallurgical features that control the extent of energy absorption when an impact test specimen fails in a ductile mode

Ductile fractures observed in service conditions, for example in linepipe steels, are associated mainly with the plastic deformation energy accompanying the propagation of the fracture [13]. Although the tests for evaluating the resistance of a specific grade of steel to brittle fracture are well established, those for dynamic ductile tearing are not. Thus far, the issue of ductile tearing resistance has been evaluated largely through empirical methods, which can be fairly accurate when used for interpolation, but often fail when the results are extrapolated to higher strength grades. The resistance of a grade of steel to dynamic ductile failure is not well understood, as will become apparent in the following sections. 


\subsubsection{Theory of ductile failure}

The micromechanism of fracture in various material systems is a subject that attempts to relate the microstructural events that lead to fracture. It is of importance to material scientists and it is essential to the development of materials with optimum strength and toughness. Often, microstructural issues are circumvented when fracture is approached from a solid mechanics viewpoint, where material is only considered as a continuum.

Several fracture-propagation-resistance assessment techniques utilize a single parameter (i.e., J-Integral) to express how a material performs and are usually based on traditional fracture mechanics, but when the single parameter assumption ceases to be valid (i.e. typically with excessive plastic deformation), the situation becomes considerably more complicated. The lab test is no longer a reliable indicator of how the large structure will behave, and the two configurations (lab test and large structure) may even fail by different mechanisms. Therefore, new proposals must be undertaken to develop alternatives to single parameter approaches based on traditional fracture mechanics. The microscopic fracture mechanisms must also be considered in conjunction with the continuum theory.

In ductile failure, microvoids nucleate at inclusions and second phase particles; the voids grow together to form a macroscopic flaw, which leads to fracture. The commonly observed stages are [14-18]:

1. formation of a free surface at an inclusion or second phase particle by either interface decohesion or particle cracking

2. void growth around the particle, due to plastic strain and hydrostatic stress

3. void coalescence 
Therefore, a 'new' model might incorporate the stages mentioned above, or simplifications of these. Depending on the material and situation, void growth or void coalescence may be the rate-controlling step during ductile failure.

\subsubsection{Void Nucleation}

Voids form around a second phase particle or inclusion when the interfacial bond is broken between the particle and matrix. Several void nucleation stress models have been developed, some based on continuum theory $[19,20]$, which are effective for particles greater than approximately $1 \mu \mathrm{m}$, while others, which are required for particles $<1 \mu \mathrm{m}$ in diameter, incorporate dislocation-particle interactions [21,22].

The most widely used model for void nucleation, which is based on continuum theory, is due to Argon et al. [19] in which the interfacial stress at a cylindrical particle is compared to the sum of the mean (hydrostatic) stress and the effective (von Mises) stress. Decohesion occurs when the interfacial stress, which is a linear combination of these two stresses, reaches a critical value, $\sigma_{c}$, i.e., fracture occurs when

$$
\bar{\sigma}+\sigma_{\mathrm{m}} \geq \sigma_{\mathrm{c}}
$$

where the effective stress, $\bar{\sigma}$, is given by

$$
\bar{\sigma}=\frac{1}{\sqrt{2}}\left[\left(\sigma_{1}-\sigma_{2}\right)^{2}+\left(\sigma_{1}-\sigma_{3}\right)^{2}+\left(\sigma_{3}-\sigma_{2}\right)^{2}\right]^{1 / 2}
$$

where the $\sigma_{\mathrm{i}}(i=1,2,3)$ are the principal normal stresses and the mean stress, $\sigma_{\mathrm{m}}$, is given by:

$$
\sigma_{\mathrm{m}}=\frac{\sigma_{1}+\sigma_{2}+\sigma_{3}}{3}
$$


It has been shown that void nucleation occurs more readily in a triaxial (hydrostatic) tensile stress field, i.e. the nucleation strain decreases as the hydrostatic stress increases [19].

A dislocation model for void nucleation at submicron particles was developed by Goods and Brown [22], who pointed out that dislocations elevate the stress at the interface by an amount $\Delta \sigma_{\mathrm{d}}$, which is given by:

$$
\Delta \sigma_{\mathrm{d}}=5.4 \alpha \mu \sqrt{\frac{\varepsilon_{1} b}{r}}
$$

where $\alpha$ is a constant that ranges from 0.14 to $0.33, \mu$ is the shear modulus, $\varepsilon_{1}$ is the maximum remote normal strain, ' $b$ ' is the magnitude of the Burger's vector, and ' $r$ ' is the particle radius.

Goods and Brown argue that void nucleation occurs when the total, maximum interface stress, which is given by the sum of $\Delta \sigma_{d}$ and the maximum principal stress, reaches a critical stress value, $\sigma_{c}$, i.e. fracture occurs when:

$$
\Delta \sigma_{\mathrm{d}}+\sigma_{1} \geq \sigma_{\mathrm{c}}
$$

This model has the virtue that void nucleation depends on particle size, as is observed in real materials. The local stress concentration increases with decreasing particle size, so that void nucleation becomes easier. The theory of Argon et al, which applies to particles with a radius greater than one micron, implies that $\sigma_{\mathrm{c}}$ is independent of particle size.

In contrast, it has been observed experimentally [23] that void nucleation occurs more readily at large particles, which is different than both the continuum and dislocation models. However, these models only consider nucleation by particle-matrix debonding, 
but alternative mechanisms of fracture, such as void nucleation due to the cracking of particles, are not considered.

\subsubsection{Void Growth and Coalescence}

Upon further plastic strain and hydrostatic stress, nucleated voids grow and eventually coalescence occurs, as is illustrated in Figure 2.2 [24].

There are numerous continuum models for void growth and coalescence, but Rice and Tracey [25] and Gurson [26] have published the two most widely referenced models. Both of these have been modified in more recent investigations [27,28]

Rice and Tracey considered a single void in an infinite solid and found that the void growth could be approximated by the following semi-empirical equation:

$$
\ln \left(\frac{\mathrm{R}_{\mathrm{v}}}{\mathrm{R}_{\mathrm{o}}}\right)=0.283 \int_{0}^{\varepsilon_{\mathrm{eq}}} \exp \left(\frac{1.5 \sigma_{\mathrm{m}}}{\sigma_{\mathrm{y}}}\right) \mathrm{d} \varepsilon_{\mathrm{eq}}
$$

where $R_{v}$ is the instantaneous void radius, $R_{o}$ is the initial void radius, and $\varepsilon_{e q}$ is the equivalent (von Mises) plastic strain.

Ensuing research demonstrated that equation 2.8 could allow for strain hardening if the yield strength, $\sigma_{y}$, is replaced by the effective stress, $\bar{\sigma}$ [29]. The Rice and Tracey model does not take into account interaction between voids, nor does it predict the ultimate rupture of the material since it is based on the growth of a single void. In order to characterize microvoid coalescence, a separate failure criterion must be applied. For example, it might be assumed that failure occurs when the nominal void radius reaches a critical value. 


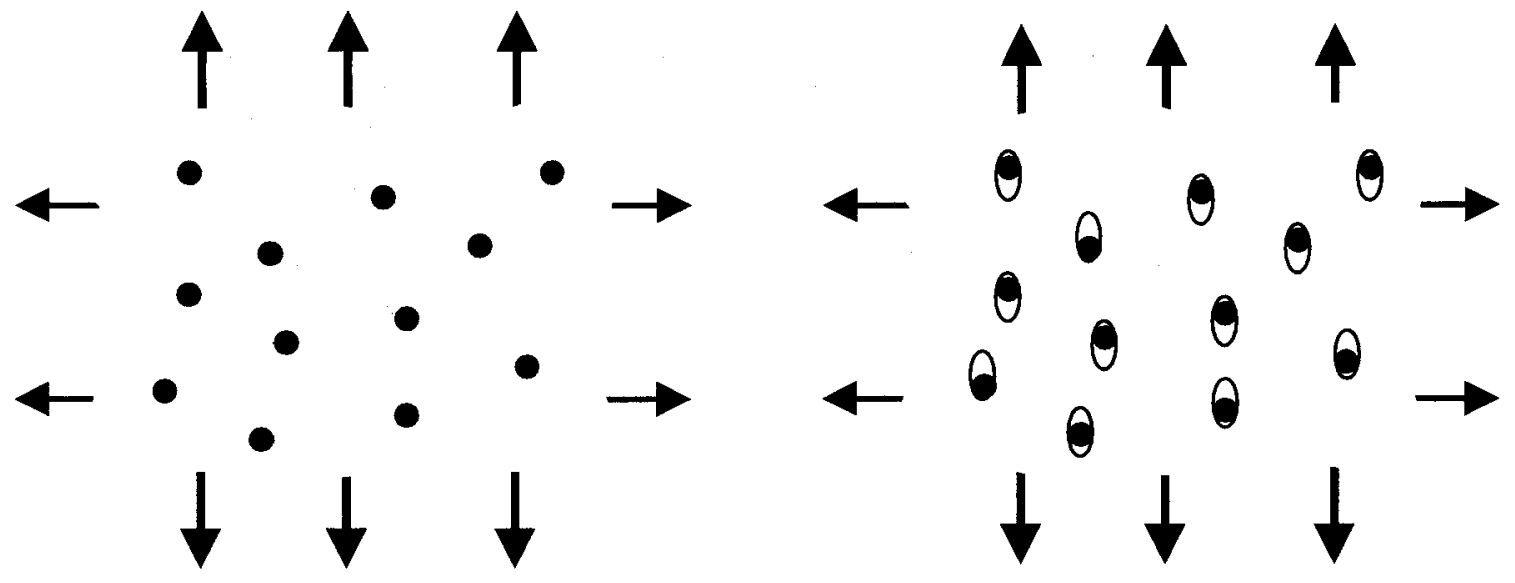

(a) Inclusions in a ductile matrix

(b) Void nucleation

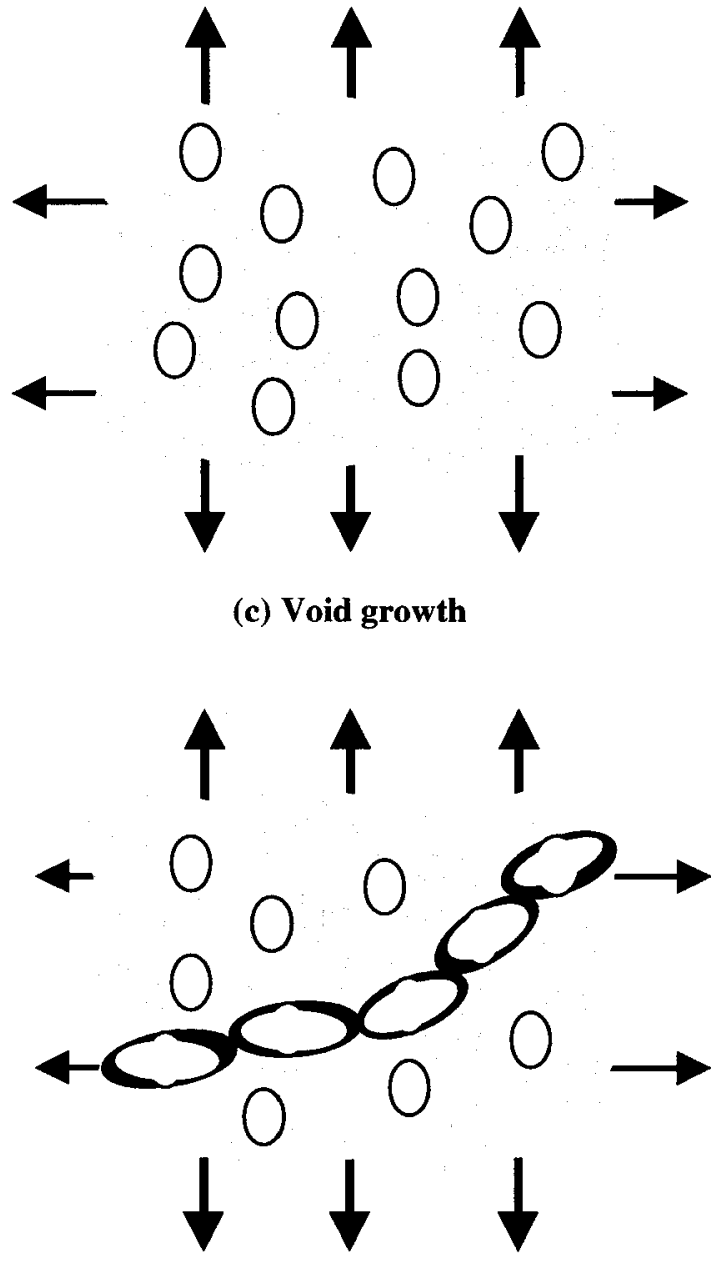

(e) Necking between voids

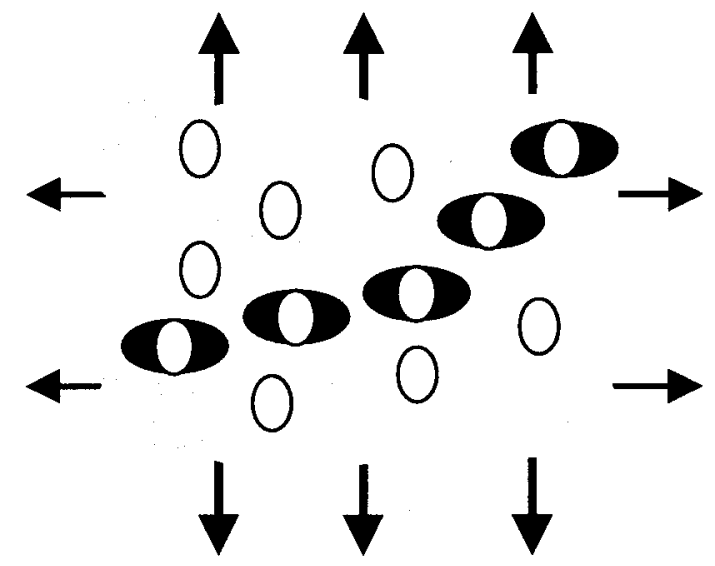

(d) Strain localization between

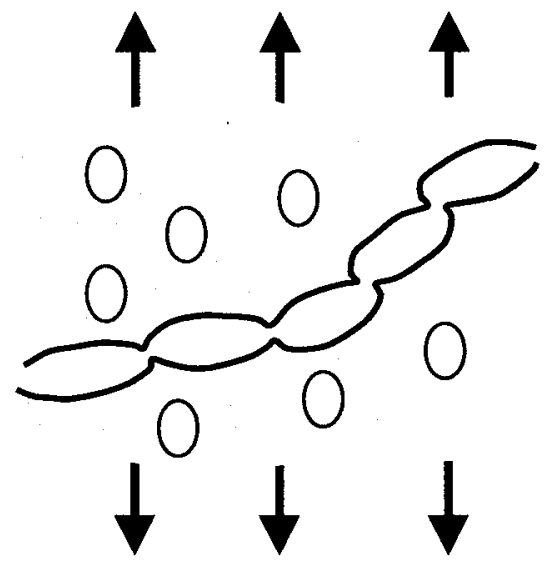

(f) Void coalescence and fracture

Figure 2.2: Void nucleation, growth, and coalescence in ductile metals [adapted from 24] 
This problem was addressed by Gurson [26] who considered plastic flow in a porous medium where the material behaves as a continuum. The presence of voids is taken into account indirectly by their influence on the global flow behaviour of the material. The Gurson model states that the yield stress is given by the function:

$$
\Phi=\left(\frac{\bar{\sigma}}{\sigma_{\mathrm{y}}}\right)^{2}+2 f_{\mathrm{v}} \cosh \left(\frac{3}{2} \frac{\sigma_{\mathrm{m}}}{\sigma_{\mathrm{y}}^{2}}\right)-\left(1+f_{\mathrm{v}}^{2}\right)=0
$$

where $f_{v}$ is the void volume fraction, $\bar{\sigma}$ is the effective von Mises stress, $\sigma_{\mathrm{m}}$ is the mean stress and $\sigma_{\mathrm{y}}$ is the yield stress of the fully dense matrix material. The principal difference between classical plasticity and the Gurson model is that the former assumes that yielding is independent of hydrostatic stress, while the yield surface in the latter exhibits a hydrostatic stress dependence. This has the effect of introducing a strainsoftening term.

Equation 2.9 reduces to the von Mises yield function with isotropic hardening, when $f=0$. In addition, this model indirectly contains a failure criterion because the size of the yield surface decreases with an increase in the void volume fraction. However, the model is unable to predict necking instability between voids because it does not consider discrete voids. The model is found to greatly overpredict the failure strains in real materials.

Tvergaard [27] proposed an alternative form for the function, containing three adjustable parameters, $q_{1}, q_{2}, q_{3}$, which define the shape of the yield surface:

$$
\Phi=\left(\frac{\bar{\sigma}}{\sigma_{\mathrm{y}}}\right)^{2}+2 \mathrm{q}_{1} f_{\mathrm{v}} \cosh \left(\mathrm{q}_{2} \frac{3}{2} \frac{\sigma_{\mathrm{m}}}{\sigma_{\mathrm{y}}^{2}}\right)-\left(1+\mathrm{q}_{3} f_{\mathrm{v}}^{2}\right)=0
$$

For typical metals, with relatively low work hardening rates, the parameters $q_{1}$ and $q_{2}$ 
take values in the range of 1.0 to 1.5 and 1.0 , respectively [29]. Typically, $\mathrm{q}_{3}$ is taken as $\mathrm{q}_{1}^{2}$.

This modification of the original Gurson equation has the effect of amplifying the influence of hydrostatic stress at all strain levels. The flow behaviour deviates slightly from classical plasticity through most of the deformation range in real materials, but at incipient failure, the deviation is rather abrupt [24].

For steels with moderate to high rates of strain hardening, the values for these parameters lead to unrealistic estimates. This arises because strain hardening tends to retard void growth and is not adequately represented in the Gurson-Tvergaard equation [30]. Extensive three-dimensional studies have resulted in the reporting of optimal values for the micromechanical parameters $\left(q_{1}, q_{2}\right)$ as a function of flow properties, such as work-hardening rate, $\mathrm{n}$, and $\sigma_{\mathrm{ys}} / \mathrm{E}$, as shown in Table 2.1 [31].

Table 2.1: Optimal values for the micromechanical parameters of the Gurson-Tvergaard equation [30].

\begin{tabular}{|ccccccc|}
\hline & \multicolumn{2}{c}{$\sigma_{\mathbf{y}} / \mathbf{E}=\mathbf{0 . 0 0 1}$} & \multicolumn{2}{c}{$\sigma_{\mathbf{y}} / \mathbf{E}=\mathbf{0 . 0 0 2}$} & \multicolumn{2}{c|}{$\sigma_{\mathbf{y}} / \mathbf{E}=\mathbf{0 . 0 0 4}$} \\
Hardening (n) & $\mathbf{q}_{1}$ & $\mathbf{q}_{2}$ & $\mathbf{q}_{1}$ & $\mathbf{q}_{2}$ & $\mathbf{q}_{1}$ & $\mathbf{q}_{2}$ \\
5 & 1.96 & 0.781 & 1.87 & 0.800 & 1.71 & 0.836 \\
6.7 & 1.78 & 0.933 & 1.68 & 0.856 & 1.49 & 0.901 \\
10 & 1.58 & 0.902 & 1.46 & 0.931 & 1.29 & 0.982 \\
\hline
\end{tabular}

The Gurson model was further modified by replacing $f_{\mathrm{v}}$ with an effective void volume fraction, $f_{\mathrm{V}}^{*}[28]$ :

$$
f_{\mathrm{v}}^{*}=\left\{\begin{array}{cc}
f_{\mathrm{v}} & \text { for } f_{\mathrm{v}} \leq f_{\mathrm{v}, \mathrm{c}} \\
f_{\mathrm{v}, \mathrm{c}}-\frac{f_{\mathrm{v}, \mathrm{U}}^{*}-f_{\mathrm{v}, \mathrm{c}}}{f_{\mathrm{v}, \mathrm{F}}-f_{\mathrm{v}, \mathrm{c}}}\left(f_{\mathrm{v}}-f_{\mathrm{v}, \mathrm{c}}\right) & \text { for } f_{\mathrm{v}}>f_{\mathrm{v}, \mathrm{c}}
\end{array}\right.
$$


where $f_{\mathrm{V}, \mathrm{U}}^{*}$ is the ultimate value at which the macroscopic stress carrying capacity vanishes and is proportional to $1 / \mathrm{q}_{1}, f_{\mathrm{v}, \mathrm{c}}$ is a critical value (described below) of the void volume fraction, and $f_{v, F}$ is the value of void volume fraction at final fracture. A significant disadvantage of the revised Gurson model is that it contains many parameters that are difficult to measure or determine.

The final ductile rupture of metals takes place by the development of local necking instabilities between voids. The early stages of the ductile failure process are adequately characterized by the revised Gurson model, but the events that lead to final rupture are not well described, because the model does not contain discrete voids. Therefore, it is incapable of predicting void interactions that lead to failure. The simple solution adopted is usually to assign a critical value for the cell porosity, $f_{\mathrm{v}, \mathrm{c}}$, which can vary between 0.15 to 0.25 [32-34].

For the problem of void interactions that lead to failure, Thomason developed a simple load-limit model for internal necking between microvoids [35], and it states that failure occurs when the net section stress between voids reaches a critical value, $\sigma_{\mathrm{n}(\mathrm{c})}$. Using Figure 2.3 as an example, the space between the voids is stable if

$$
\sigma_{1}<\sigma_{n(c)} \frac{d_{v}}{d_{v}+a_{2}}
$$

and fracture occurs when

$$
\sigma_{1}=\sigma_{n(c)} \frac{d_{v}}{d_{v}+a_{2}}
$$

where $\sigma_{1}$ is the maximum remote principal stress. Thomason used the Rice and Tracey model in conjunction with his model as a failure criterion and predicted failure strains that were relatively close to experimental observation. In addition, they were an order of magnitude lower than predicted by the original Gurson model. 


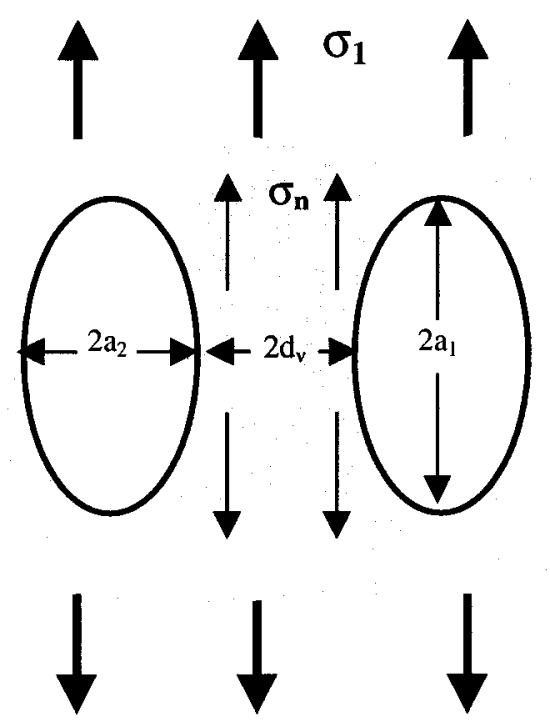

Figure 2.3: Illustration for Thomason's load-limit model for void instability [adapted from 35]

\subsection{Dynamic Ductile Failure in Pipelines}

Because of the decompression behaviour of the gas in pipelines, gas pipelines have the potential for long running fractures.

One of the principal issues that arises when designing high-pressure pipelines is failure control. Dynamic ductile failure is a phenomenon that is peculiar to high-pressure gas pipelines. It is a mode of failure that is driven by the energy of the expanding gas through a ruptured opening in the pipe. Whether or not an opening in the pipe will develop into a running fracture will depend critically on the intrinsic toughness of the linepipe. Two aspects of the toughness are important. First, the linepipe should have sufficient toughness to prevent the growth of a minimally detectable flaw from growing under normal operating pressures into a through-thickness crack. Since the pipe is only loaded elastically, the required toughness to prevent growth of manufacturing flaws can be calculated using fracture mechanics. Since pipelines are potentially subject to accidental damage, e.g. impact by earth moving equipment, earthquakes, etc., it is necessary to consider the possibility that highly localized damage can lead to localized embrittlement and loss of fracture toughness. In this way, a through-thickness rupture 
can occur in an otherwise tough pipe. Should such a through-thickness rupture occur, a running ductile fracture could only ${ }^{\ddagger}$ be prevented by the pipe having sufficient resistance to plastic tearing.

Because the possible utilization of higher strength steels will permit changes in pipe wall thickness and operating pressure, it is necessary to investigate how variations in these conditions might affect the fracture behaviour of the pipeline. For example, the maximum allowable operating pressure of a pipeline is usually that corresponding to $72 \%$ of the specified minimum yield strength. Therefore, an increase in the specified minimum yield strength permits an increase in the maximum allowable operating pressure for the same diameter and wall thickness, or a decrease in wall thickness for the same maximum allowable operating pressure.

In gas pipelines, arrest of unstable axial fractures has been studied in the gas industry [36-43]. Here, the ductile fracture travels at speeds that are slower than the gas decompression wavefront. Thus, in determining the driving force, the gas decompression behaviour for fracture is very important.

\subsubsection{Gas Decompression}

In order to predict whether a ductile fracture will propagate, there must exist the capability of predicting not only the fracture speed as a function of the metallurgical properties and the stress state in the pipe, but also the decompression behaviour of the gas.

The gas decompression behaviour depends greatly on whether the fluid behaves like an ideal gas, or exhibits two-phase decompression. Methane and air exhibit close to ideal behaviour, which allows analytical treatment of their decompression. When gas decompression occurs very rapidly, as in a pipeline rupture, heat-transfer in the gas is

\footnotetext{
${ }^{\ddagger}$ This presupposes that no mechanical crack arrestors are used.
} 
minimized. Furthermore, only a small fraction of the gas volume is subject to wall friction. This allows the decompression to be treated as an isentropic process and an analytical solution of the mass and momentum balances can be obtained.

Consider an infinitely long pipe shown in Figure 2.4. Initially the pipe is capped at $\mathrm{x}_{0}$ and pressurized with an ideal gas to pressure $\mathrm{P}_{0}$. The cap at $\mathrm{x}_{0}$ is instantaneously removed at time $t_{0}$, and the gas is free to escape through the entire cross-sectional area of the pipe.

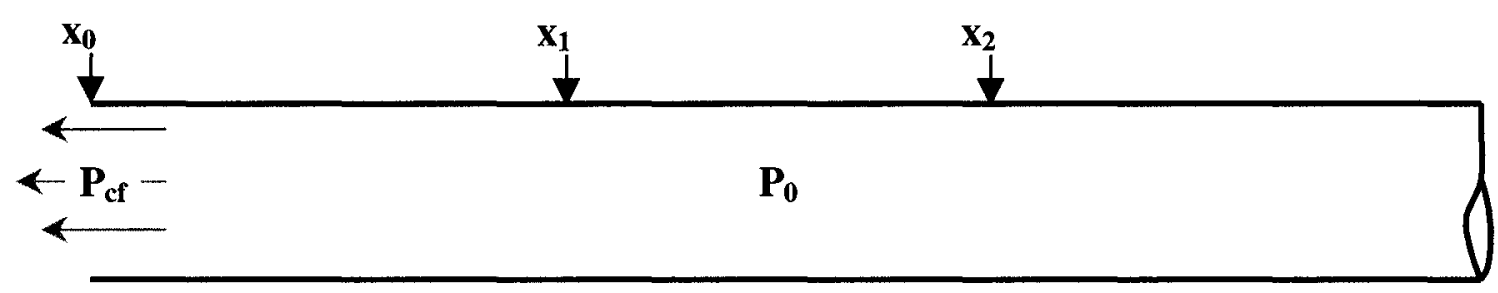

Figure 2.4: Schematic diagram of the idealized case of one-dimensional gas decompression

Immediately after the pipe is opened, the gas attains critical velocity, which is the maximum velocity that the gas can attain in a constant cross-section tube at any position $\mathrm{x}$, and is equal to the velocity of sound in the gas. The pressure decreases instantaneously to a value that is commensurate with the critical velocity, and then remains constant at that value. The gas pressure corresponding to the critical velocity is referred to as the critical flow pressure, $\mathrm{P}_{\mathrm{cf}}$. The pressure remains at the initial pressure, $\mathrm{P}_{0}$, at locations $\mathrm{x}_{1}$ and $x_{2}$ until the leading edge of the disturbance arrives.

At the leading edge of the disturbance, the wave velocity equals the velocity of sound in the gas at the initial conditions, i.e. $\mathrm{P}_{0}$, while at $\mathrm{x}_{0}$, the wave velocity equals zero. This occurs because the wave velocity is driven by the pressure differential between the internal pressure at position ' $x$ ' and the critical flow pressure. In the actual case, the geometry of a propagating fracture is much more complicated than this idealized case. As seen in Figure 2.5, the pipe is not severed across the cross-section at the origin of the fracture, and the fracture initiates from a narrow slit that must be longer than some 
critical length (Figure 2.5a). This narrow slit opens and lengthens (Figure 2.5b) until it reaches the characteristic geometry of a propagating ductile fracture (Figure $2.5 c$ ). The gas pressure remains close to the initial line pressure during the finite opening time associated with fracture initiation, because the narrow opening throttles the flow.

a)

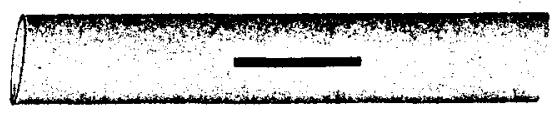

b)

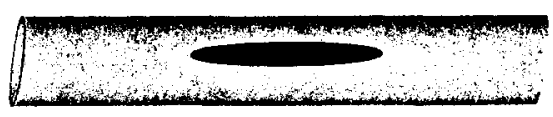

c)

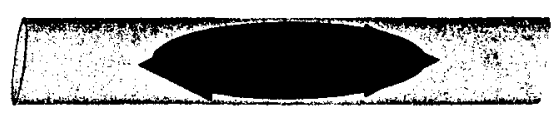

Figure 2.5: Schematic diagram of the geometry of the opening of the ductile fracture

Therefore, the assumption of one-dimensional flow, which is a reasonable description once the rupture has completely opened the pipe, is not valid near the origin of the fracture [50].

\subsubsection{One-Dimensional Isentropic Decompression}

The one-dimensional isentropic approach is the simplest for the decompression problem, and several assumptions are utilized in order to arrive at an analytical solution.

The decompression path, which is the combination of temperatures and pressures the gas experiences during decompression, is addressed in the first assumption. The gas expands and cools at the same time. If the assumption is made that the heat transfer and friction effects are negligible because the decompression is extremely rapid, this implies that the decompression path is isentropic (constant entropy) [44]. 
Other assumptions are: one-dimensional flow ahead of the fracture tip, no convective heat transfer, thus no mixing of gases at different temperatures, the gas is initially stationary (as compared to its velocity after sudden decompression), and gravity forces are negligible. The last assumption is that the gas, which is methane in this case, behaves like an ideal gas.

The equations for the conservation of mass and momentum under the above assumptions are given by:

$$
\frac{\partial \rho_{\mathrm{vap}}}{\partial \mathrm{t}}+\rho \frac{\partial \mathrm{v}_{\mathrm{fl}}}{\partial \mathrm{x}}+\mathrm{v} \frac{\partial \rho_{\mathrm{vap}}}{\partial \mathrm{x}}=0
$$

and

$$
\rho_{\text {vap }} \frac{\partial v_{f l}}{\partial t}+\rho_{\text {vap }} \cdot v_{f l} \frac{\partial v_{f l}}{\partial x}+\frac{\partial P}{\partial x}=0
$$

where $\rho_{\text {vap }}$ is the vapour density, $\mathrm{P}$ is the pressure, and $\mathrm{v}_{\mathrm{fl}}$ is the flow velocity. For a single-phase system, equation 2.15 becomes:

$$
\rho_{\text {vap }} \frac{\partial v_{f l}}{\partial t}+\rho_{\text {vap }} \cdot v_{f l} \frac{\partial v_{f l}}{\partial x}+c^{2} \frac{\partial \rho_{\text {vap }}}{\partial x}=0
$$

where $\mathrm{c}$ is the sound velocity in the gas

Simply stated, the boundary conditions for the sudden decompression problem are: the gas remains at the initial conditions ahead of the pressure disturbance; the exit velocity is sonic near the opening in the pipeline.

For an ideal gas, the equation of state is

$$
\mathrm{P}=\rho \mathrm{RT}
$$

where $\mathrm{T}$ is the absolute temperature, and $\mathrm{R}$ is the gas constant. From the following relationship, the velocity of sound can be calculated for an ideal gas in an isentropic 
process:

$$
c^{2}=\gamma \mathrm{RT}
$$

where $\gamma$ is the specific heat ratio, $c_{\mathrm{p}} / \mathrm{c}_{\mathrm{v}}$. For an isentropic expansion, the following relationships apply:

$$
\frac{\mathrm{P}}{\mathrm{P}_{0}}=\left(\frac{\rho}{\rho_{0}}\right)^{\gamma}=\left(\frac{\mathrm{T}}{\mathrm{T}_{0}}\right)^{\gamma / \gamma-1}=\left(\frac{\mathrm{c}}{\mathrm{c}_{0}}\right)^{2 \gamma / \gamma-1}
$$

where the variables with the subscript ' 0 ' represent the properties at the initial conditions. The pressure distribution as a function of $x / t$ is obtained from the following [45]:

$$
\frac{P}{P_{0}}=\left[\frac{2}{\gamma+1}-\frac{\gamma-1}{\gamma+1} \cdot\left(\frac{x}{c_{0} \cdot t}\right)\right]^{2 \gamma / \gamma-1}
$$

where ' $\mathrm{x}$ ' is the position along the pipe axis and $\mathrm{x}=0$ corresponds to the beginning of the pipe. Critical flow, which in the case of homogeneous fluids is the velocity at which pressure disturbances propagate through the fluid, i.e., the velocity of sound, exists at $\mathrm{x}=0$, and the critical pressure is given by:

$$
\frac{P_{c f}}{P_{0}}=\left(\frac{2}{\gamma+1}\right)^{2 \gamma / \gamma-1}
$$

For methane, $\gamma=1.4$, and the critical pressure is 0.279 times the initial pressure. Therefore, determination of the speed of sound makes it possible to develop curves of crack-tip pressure as a function of crack-speed.

In contrast, a non-ideal multicomponent dense mixture such as high-pressure natural gas does not behave like a perfect gas [45]. 


\subsubsection{Two-Phase Decompression}

Another important aspect of gas decompression behaviour is the influence of gas composition. While calculating the critical pressure during the isentropic decompression of methane can be straightforward, there are a number of variables that are introduced by the consideration of gases rich in hydrocarbons. Some so-called rich gases, which contain heavier hydrocarbons in addition to methane, cross the two-phase boundary between the gaseous and liquid phases when decompressing (Figure 2.6). The formation of liquids can change the decompression velocity, causing a plateau in the pressure versus decompression velocity curve (Figure 2.7). Depending on its location, the plateau can result in a significant increase in the required toughness to prevent long ductile fractures.

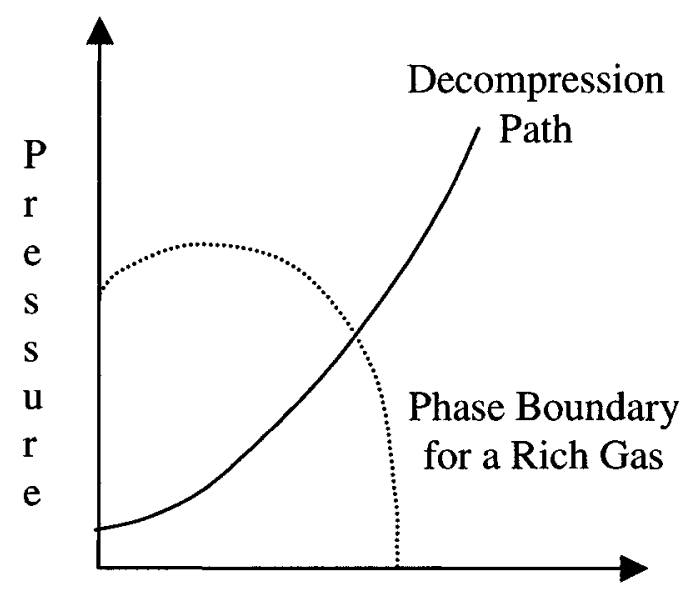

Temperature

Figure 2.6: Decompression path enters the two-phase region for rich gases [adapted from $43]$

Equation (2.21) can be taken as a lower bound on the decompression behaviour of all gases carried in transmission lines [42]. Analyses have been performed that illustrated that the rich gases were more damaging than methane, and that a "wet gas" is the most harmful. A "wet gas" is one in which the initial temperature and pressure are within the two-phase envelope, and its decompression behaviour can be taken as an upper bound for all rich-gas compositions and initial conditions [42]. 


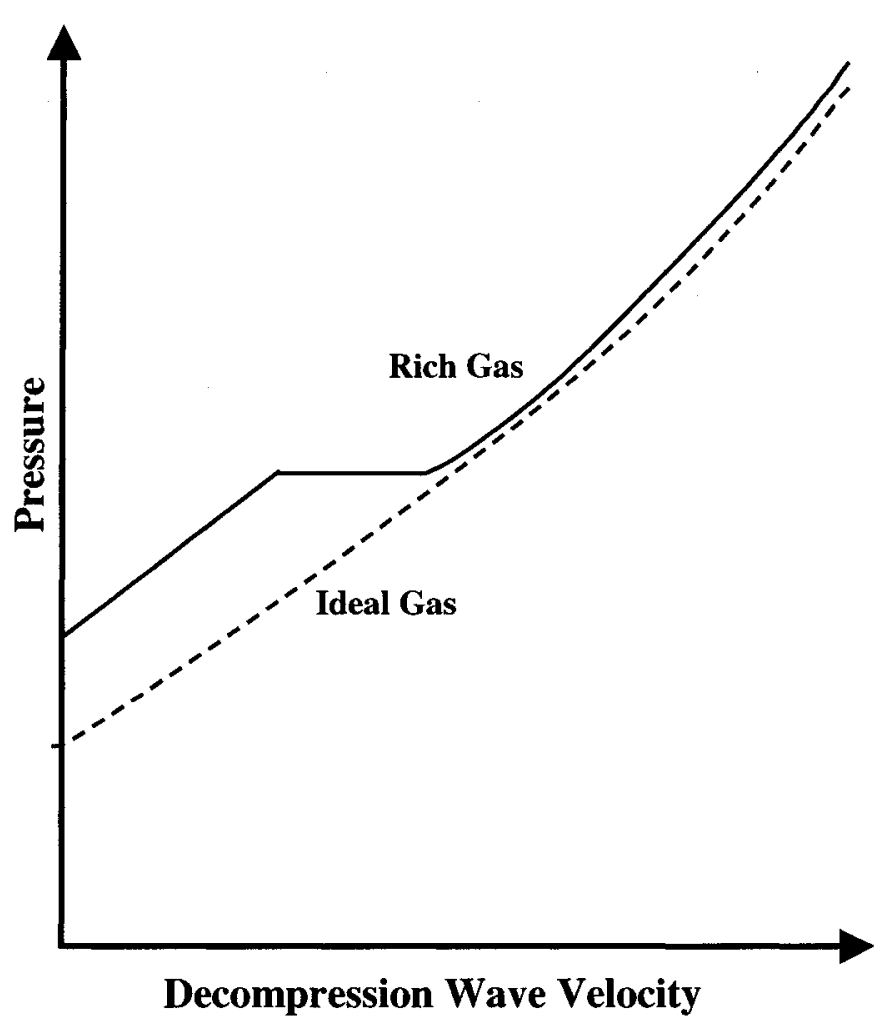

Figure 2.7: Effect of phase change on the decompression wave velocity [adapted from 1]

Studies performed in which the initial pressure of a rich gas was increased by a factor of three, showed the decompression curve decreased with increasing pressure (Figure 2.8). The pressure plateau, which features the decompression of the rich gas, i.e., the dual-phase gas, also decreased drastically. Thus, this behaviour suggests that, in ultra-high pressure pipelines, the gas can escape rapidly from the failed portion and the propagating fracture may be more easily arrested, but the author implied that a more detailed investigation of this potential behaviour was necessary.

For linepipe with a diameter greater than $500 \mathrm{~mm}$, nonisentropic effects of heat transfer and viscous dissipation will generally not be of concern $[44,45]$. 


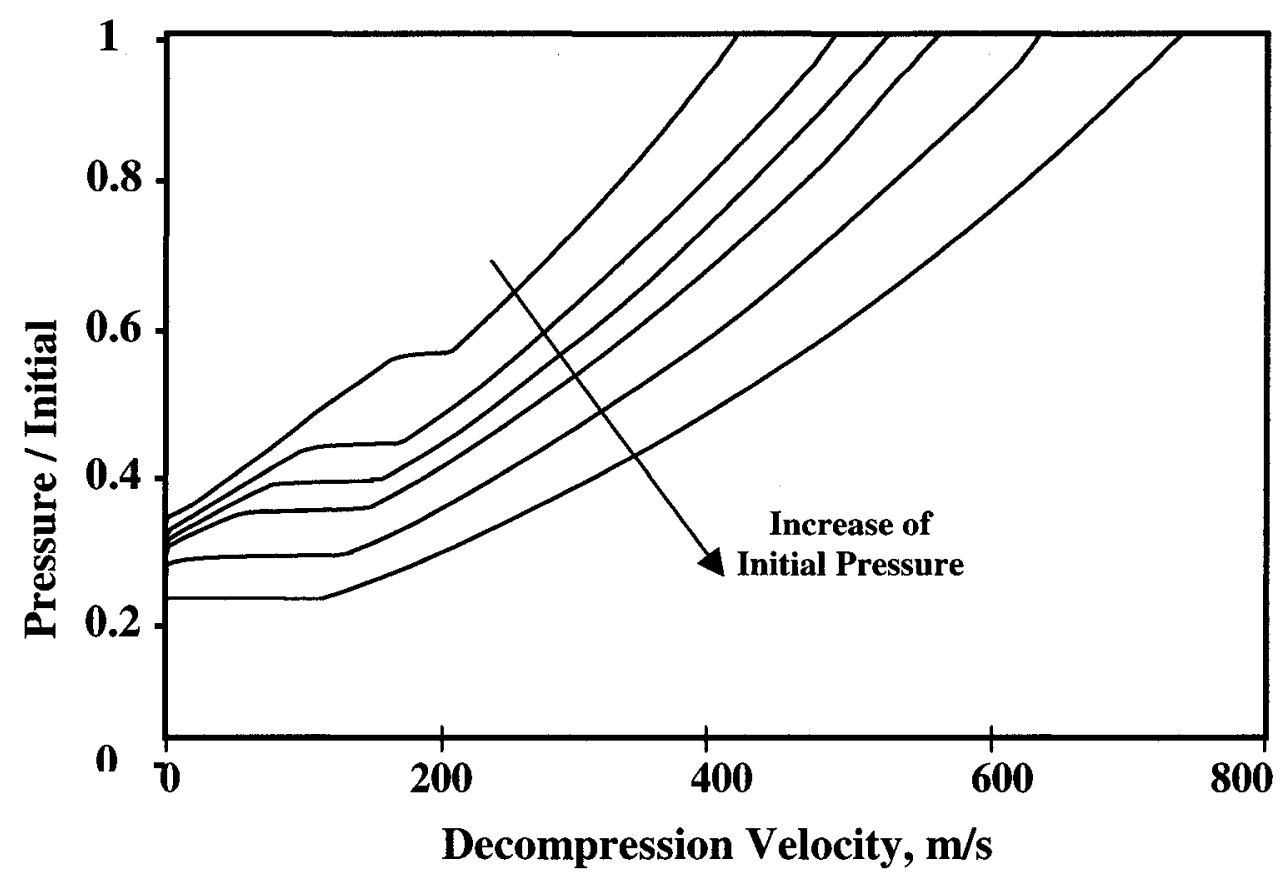

Figure 2.8: Decompression curve variation with initial pressure [adapted from 46]

\subsubsection{Current Ductile Fracture Resistance Testing Methodology}

Although there are many tests to evaluate the resistance of a material to crack extension; many of these apply only to 'brittle' fractures, i.e. where little or no macroplasticity is involved. In each of the $\mathrm{ASTM}^{I}$ fracture toughness testing standards and in other fracture toughness testing methods, the specimen design is similar, and the cracks are introduced by fatigue in the ASTM tests. The three important characteristics for each specimen are: the crack length, the thickness, and the width.

The currently accepted testing methods for assessing the dynamic ductile fracture toughness of steels are:

i. Charpy V-Notch

ii. Drop-Weight Tear Test

iii. Crack-Tip-Opening Angle

iv. Full-Scale Burst Test

\footnotetext{
${ }^{\mathrm{I}}$ American Society for Testing and Materials
} 


\subsubsection{Charpy (ASTME23)}

This test involves the impact of a small notched bar with a pendulum. The Charpy specimen is a simple notched beam that is impacted in three-point bending. The specimen is relatively small, does not consume much material, and the notch is usually machined to align with the linepipe's longitudinal axis. The energy absorbed by the specimen during fracture is a function of the difference in height of the pendulum before and after the impact. A number of investigators [47-52] have attempted to correlate Charpy energy to fracture toughness parameters, such as $\mathrm{K}_{\mathrm{IC}}$. Although these empirical correlations seem to work reasonably well in some cases, they are unreliable in general. There are several important differences between the Charpy test and fracture mechanics tests that preclude simple relationships between qualitative and quantitative measures of toughness. Fracture mechanics specimens tend to always have sharp fatigue cracks, while the Charpy test only has a machined notch, as seen in Figure 2.9. The Charpy specimen has less plastic constraint because it is subsize, and it experiences impact loading, while most fracture toughness tests are conducted under quasi-static conditions.
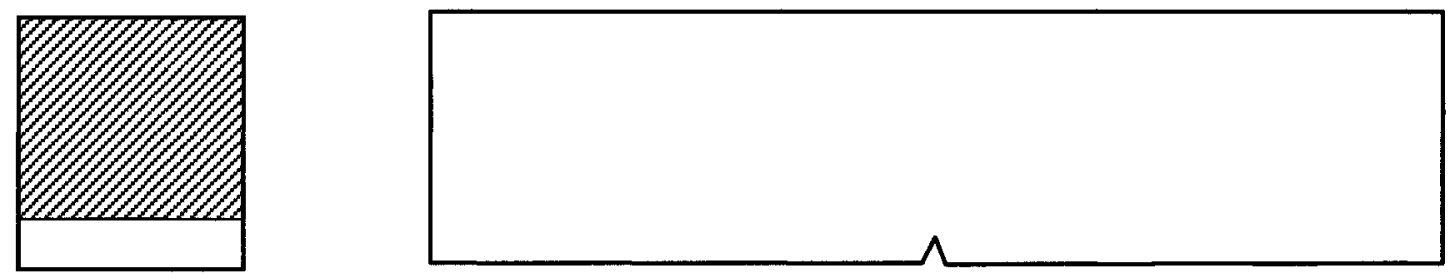

Figure 2.9: Schematic diagram of a Charpy V-notch impact specimen

If the striker is instrumented, it is possible to obtain dynamic quantitative information from fatigue precracked Charpy specimens. Such an experiment is essentially a miniature, dynamic fracture toughness test.

Within the pipeline industry, most of the fracture propagation evaluations are based on semi-empirical correlations that were partially derived or verified by full-scale tests. The belief is that the upper-shelf energy of the Charpy or Drop-Weight Tear tests could be used as an estimate of the resistance to ductile fracture propagation [39]. Laboratory tests are performed on either subsize specimens from the linepipe without 
flattening it, or from full-size specimen from flattened linepipe. As illustrated in Table 2.2, at least six research groups have developed equations predicting for subsize specimens the upper shelf Charpy V-Notch $(C V N)$ energy necessary to arrest a ductile fracture. Although the ductile fracture problem in pipelines has been addressed in the past using Charpy or Drop-Weight Tear tests, which are methodologies or testing methods adapted from the field of brittle fracture and are typically economical to perform, this approach has been questioned for applicability to higher strength grades of linepipe steel [1].

Table 2.2: Empirical equations for Ductile Fracture Arrest [39]

\section{Authors CVN Necessary to Arrest a Ductile Fracture}

Battelle/AGA

$$
C_{v}=2.382 \cdot 10^{-5} \sigma_{h}^{2}\left(R_{p} h\right)^{1 / 3}
$$

American Iron

\& Steel

$$
\mathrm{C}_{\mathrm{v}}=2.377 \cdot 10^{-4} \sigma_{\mathrm{h}}^{1.5}\left(2 \mathrm{R}_{\mathrm{p}}\right)^{0.5}
$$

Institute (AISI)

British Gas

Corp.

$$
\mathrm{C}_{\mathrm{v}}=\sigma_{\mathrm{h}}\left(2.08 \times 10^{-3} \cdot \frac{\mathrm{R}_{\mathrm{p}}}{\mathrm{h}^{0.5}}-10^{-6} \cdot \frac{\mathrm{V}_{\mathrm{a}} \cdot \mathrm{R}_{\mathrm{p}}{ }^{1.25}}{\mathrm{~h}^{0.75}}\right)
$$

Iron and Steel

Institute of

$$
C_{v}=2.498 \cdot 10^{-4} \sigma_{h}^{2.33}\left(2 R_{p}\right)^{0.3} h^{0.47}
$$

Japan (ISIJ)

Centro

Sviluppo

Materiali

(CSM, Italy)

$$
C_{v}=-0.627 h-6.8 \times 10^{-8}\left(\frac{H R_{p}{ }^{2}}{h}\right)+2.52 \times 10^{-4} R_{p} \sigma_{h}+1.245 \times 10^{-5}\left(\frac{R_{p} \cdot h \sigma_{h}^{2}}{H}\right)
$$

Mannesmann

$$
C_{v}=19.99 \cdot \exp \left[\left(0.287 \times 10^{-8}\right) \cdot \sigma_{h}^{1.76}\left(2 R_{p}\right)^{1.09} h^{0.585}\right\rfloor
$$

where $\sigma_{\mathrm{h}}$ is the hoop stress $(M P a), \mathrm{R}_{\mathrm{p}}$ is the pipe radius, $\mathrm{h}$ is the pipe wall thickness, $\mathrm{V}_{\mathrm{a}}$ is the acoustic velocity of the gas, and $\mathrm{H}$ is the backfill depth.

These empirical methods may present adequate or 'good' predictions when used to interpolate within grades of linepipe steel similar to those used to develop the database, but they are not as reliable when used as a predictive tool in different grades of steels. This is demonstrated in Figure 2.10. Here, the Battelle equation is used to predict the 
minimum full-size Charpy energy required to arrest a propagating ductile fracture, in $\mathrm{X} 65, \mathrm{X} 70$ and X80 grades of linepipe [39]. The calculated Charpy energy values are plotted against the actual values. If the correlation holds for all grades, the unity line should divide "propagate" from "arrest" behaviour.

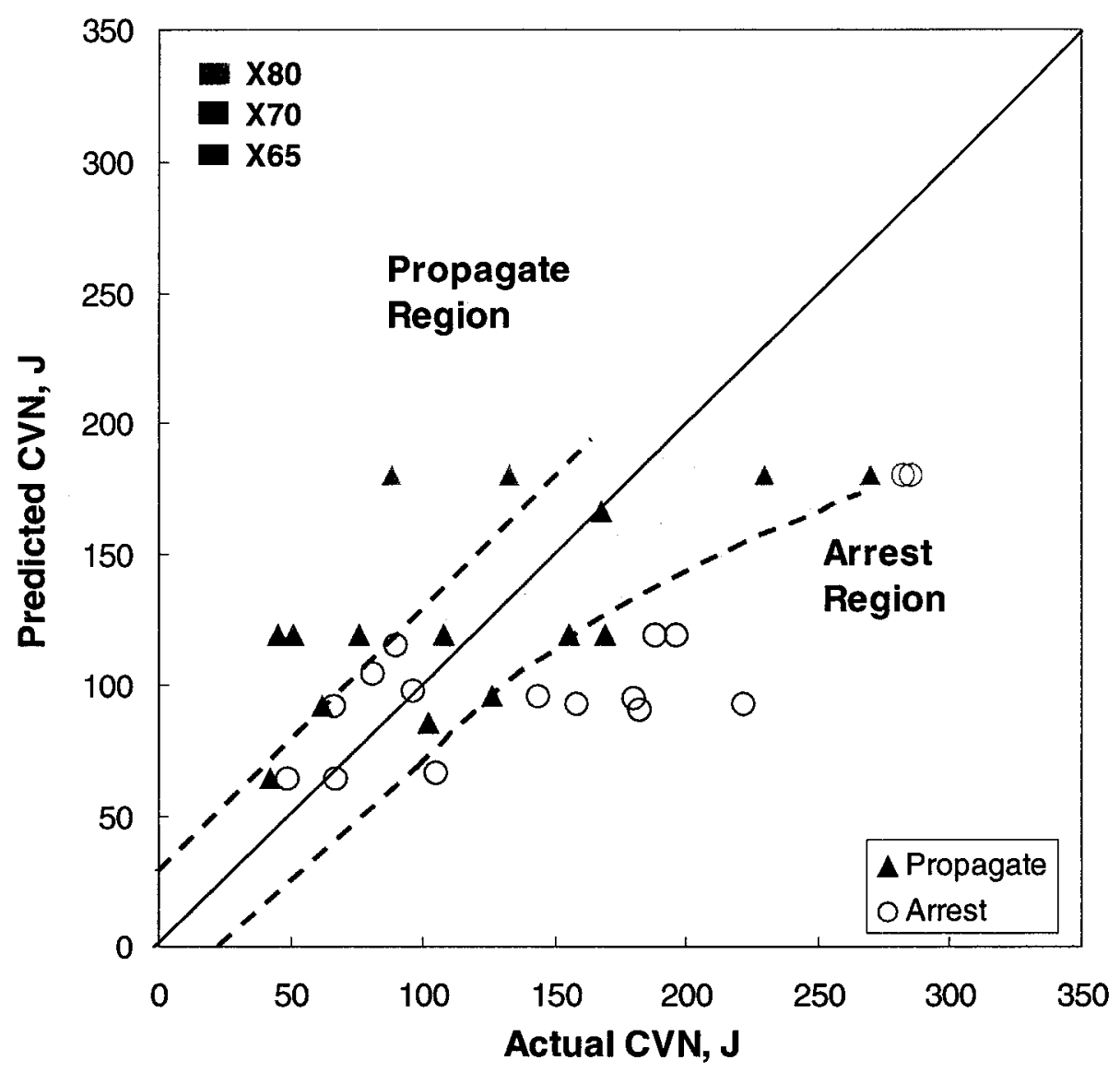

Figure 2.10: Extrapolation of CVN-based prediction methods leads to errors.

As is observed from Figure 2.10, the grey envelope and the dotted lines encompass the deviations in the predictions, which are seen by the triangular data points in the lower arrest region. The deviation increases as the grade increases because there is the possibility that the Charpy test is not a measure of dynamic ductile fracture resistance, and also because this methodology ignores the role of flow behaviour, dynamic pipe geometry and gas decompression behaviour. The energy levels of Charpy or DropWeight Tear tests become less meaningful for higher toughness steels [1] for several reasons including the size and geometry-dependence of Charpy test results. These lab 
test methods suffer from severe limitations in that the mode and extent of deformation, stress state, and strain rate are significantly different from those of the ductile fracture process in linepipe. The process of ductile fracture in a pipeline is similar to the ductile instability and failure processes encountered during sheetmetal forming. In the latter case, "formability" is related to material parameters that are measured in laboratory tension tests, such as work hardening rates and plastic anisotropy, via empirical or constitutive relationships [53]. Thus, in these circumstances it is not reasonable to expect the Charpy or Drop-Weight Tear tests to characterize the ductile fracture resistance of the linepipe material.

\subsubsection{Drop-Weight Tear Test (ASTM E436)}

This test can be used to determine the appearance of propagating fractures in a specimen. It can use the full-plate thickness ranging between $3.18-19.1 \mathrm{~mm}$, and, like the Charpy test, it was initially developed to determine the temperature range where the fracture mode changes from brittle cleavage to ductile shear. The specimen has an appearance similar to Figure 2.11, where it can be readily seen that the notch is shallow and its angle is approximately $45^{\circ}$. A weight, which is sufficient to cause fracture, is dropped onto the specimen. The percent shear area is then determined from the fracture surface.

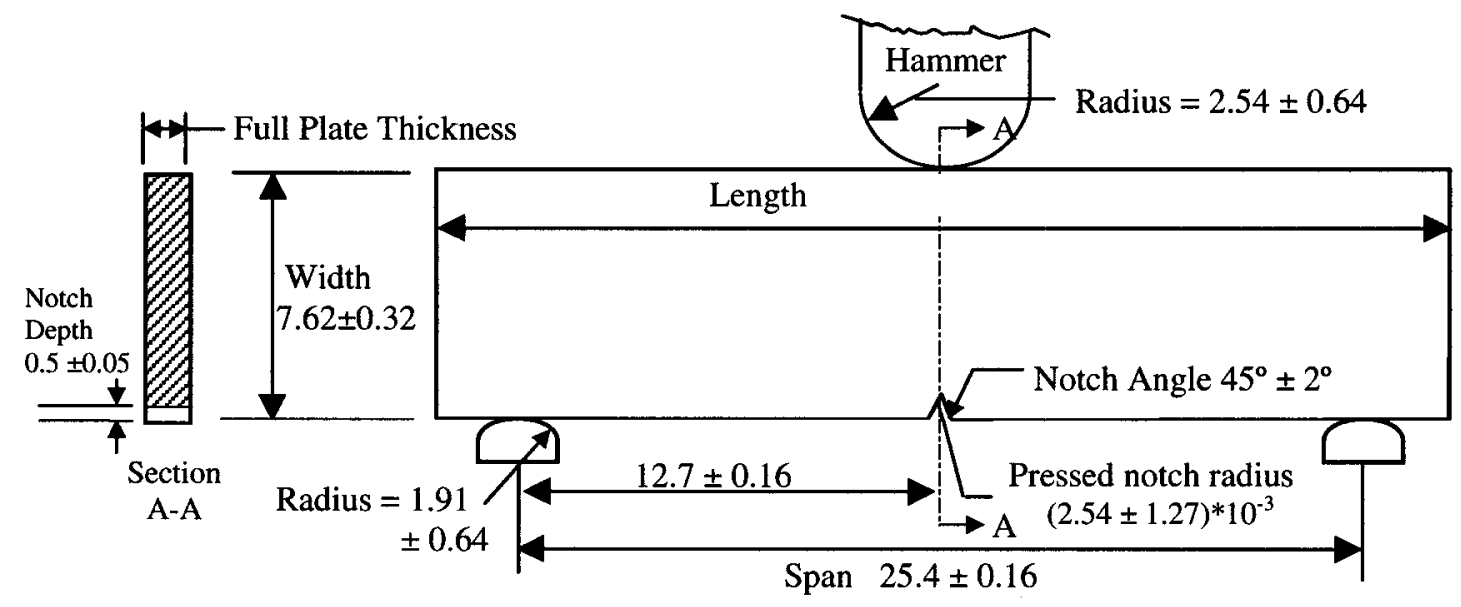

Figure 2.11: Schematic diagram of a drop-weight tear test (DWTT) specimen with units in $\mathrm{cm}$ 
The tests are used in a similar manner as the Charpy test. Thus, it also suffers from the same inadequacies.

\subsubsection{Crack-Tip-Opening Angle}

Currently, the tests most widely used to evaluate the resistance of pipelines to the propagation of ductile fractures are the Charpy V-Notch $(C V N)$ and the Drop-Weight Tear Test (DWTT). A new approach using the crack-tip-opening angle (CTOA) has been proposed [41-43]. For a given pipeline design, the fracture resistance of the material, which is referred to as $(\mathrm{CTOA})_{c}$, is compared to the driving force of the pressurized gas, termed (CTOA) $\max$. The condition for ductile failure arrest to occur is:

$$
(\mathrm{CTOA})_{\mathrm{c}}>(\mathrm{CTOA})_{\max }
$$

Dynamic fracture tests using three-point bending specimens with two different ligament lengths are used to determine the value of $(\mathrm{CTOA})_{c}$. PFRAC, which is a software developed at the Southwest Research Institute, is utilized in order to determine $(\text { CTOA })_{\max }$. Based on several PFRAC calculations using a variety of pipeline designs, gas pressures, and gases, a parametric equation was developed to determine (CTOA $)_{\max }$, as follows:

$$
(\text { CTOA })_{\max }=b_{1}\left(\frac{\sigma_{h}}{E}\right)^{b_{2}}\left(\frac{\sigma_{h}}{\sigma_{F l}}\right)^{b_{3}}\left(\frac{D_{\text {mean }}}{h}\right)^{b_{4}}
$$

where $\sigma_{\mathrm{h}}$ is the hoop stress, $\sigma_{\mathrm{F}}$ is the flow stress, $\mathrm{E}$ is Young's modulus, $\mathrm{D}_{\text {mean }}$ is the mean pipe diameter, $h$ is the pipe wall thickness, and $b_{1}, b_{2}, b_{3}$ and $b_{4}$ are constants that vary, depending on the type of gas.

The parametric equation was used to evaluate the variation of (CTOA) $\max$ with pipe grade for a 1 meter outer-diameter pipeline operating at $21 \mathrm{MPa}$ with either methane 
or rich gas at $72 \%$ of the specified minimum yield stress. The fracture propagation driving force due to the pressurized gas, (CTOA $)_{\max }$, was shown to increase with the yield strength of the pipeline material, as is illustrated in Figure 2.12.

The shortcomings of the CTOA method are that although the CTOA from a dropweight tear test is compared with the $\mathrm{CTOA}_{\max }$ from a simulation of a full-scale pipe burst, the laboratory values are never compared with actual values from a full-scale burst test. Also, there are no scaling assumptions between CTOA measurements from lab results and CTOA values determined for simulations of full-scale burst tests, even though they undergo different loading paths.

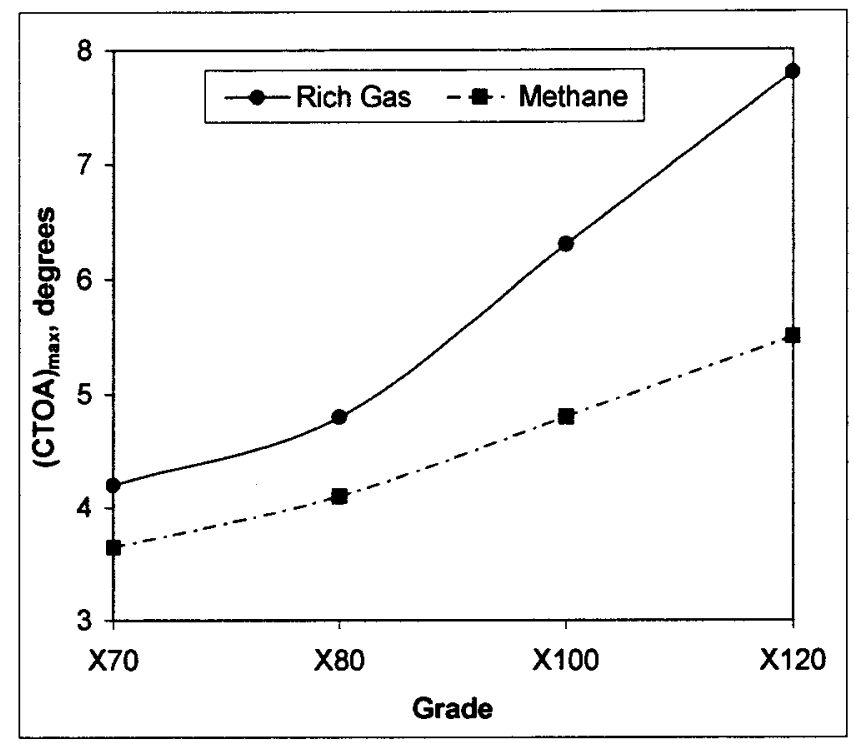

Figure 2.12: Crack Driving Force, $(\mathrm{CTOA})_{\max }$, for various linepipe steel grades [14]

\subsubsection{Full-Scale Burst Test}

At present, the only test used to evaluate the 'actual' resistance of pipelines to ductile fracture propagation is the full-scale burst test. Since there is no standard method of performing this evaluation, the test conditions tend to vary. Generally the test consists of several sections of linepipe, which are often made of different steels, welded together, as shown in Figure 2.13. The linepipes total approximately 70 meters in length, and the 
central linepipe is used to initiate the fracture process, by explosively forcing a wedge into it. The ductile fracture then propagates in both directions, and this is a good indication of whether a dynamic ductile fracture will either arrest or propagate in a linepipe made of a certain steel.

At each end of the set-up, there is a thick crack arrestor, concrete fixturing, and a gas reservoir. Also, the pipe diameter used is not fixed for each test and it has varied between 0.76 to $1.42 \mathrm{~m}$. In order to get a good indication as to whether a specific steel can arrest a ductile fracture for different geometries (diameter and wall thickness), multiple tests would have to be performed, but each test is extremely expensive and can cost upwards of US $\$ 750 \mathrm{~K}$. Therefore, tests are performed only for the intended geometry.

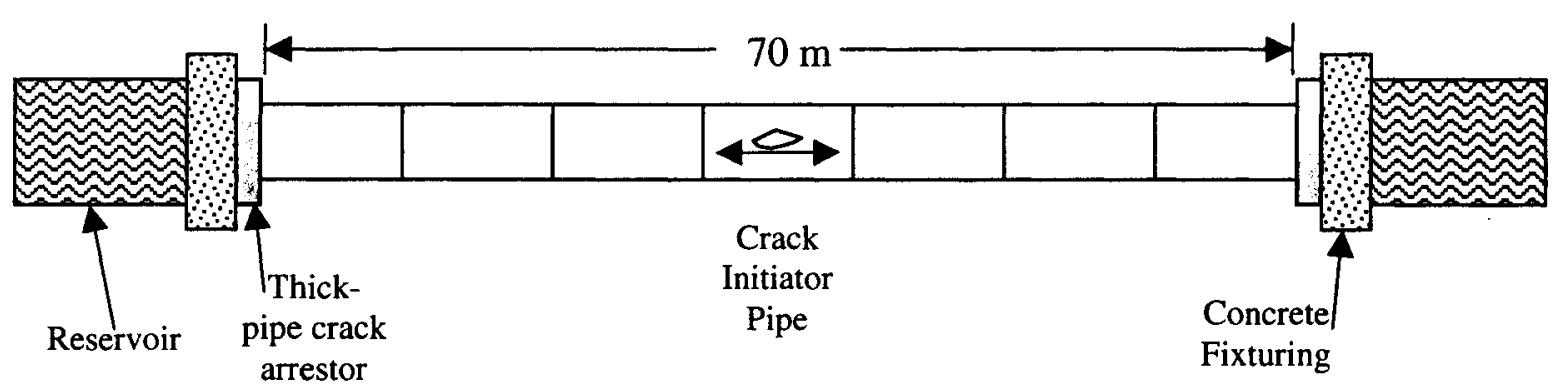

Figure 2.13: Schematic diagram of the set-up for a full-scale linepipe burst test

\subsubsection{Formulas for Fracture Velocity}

Evaluating the fracture velocity for a given pipeline as compared to the decompression velocity of the gas is an alternative approach to studying fracture propagation. After a pipe has ruptured, gas decompression waves at different pressure levels propagate away from the opening. The fracture tip will remain ahead of the gas pressure required for the fracture to arrest if the fracture speed is high enough, and the fracture may propagate long distances in this case. Alternatively, if the fracture is slower than the pressure front, the fracture will slow down and eventually arrest. Therefore, the fracture velocity decreases when the steel's fracture resistance increases.

Fracture velocity equations have been developed $[39,40,54]$ based on many 
variables, and the accuracy of these has not been verified, but it is useful to observe the predicted trends. According to the equations, the fracture velocity increases with increasing gas velocity and yield strength. For higher yield strength pipe, higher initial pressures can be used, which also results in an increase in sonic velocity

Of equal importance in evaluating the potential for propagating ductile failure is the gas decompression velocity. The decompression gas velocity is a function of the initial temperature and pressure, and can be determined using the equation of state of the gas. A plot of both the decompression and fracture velocities can be used to graphically determine the fracture toughness necessary to prevent propagating ductile fracture, as is seen in Figure 2.14.

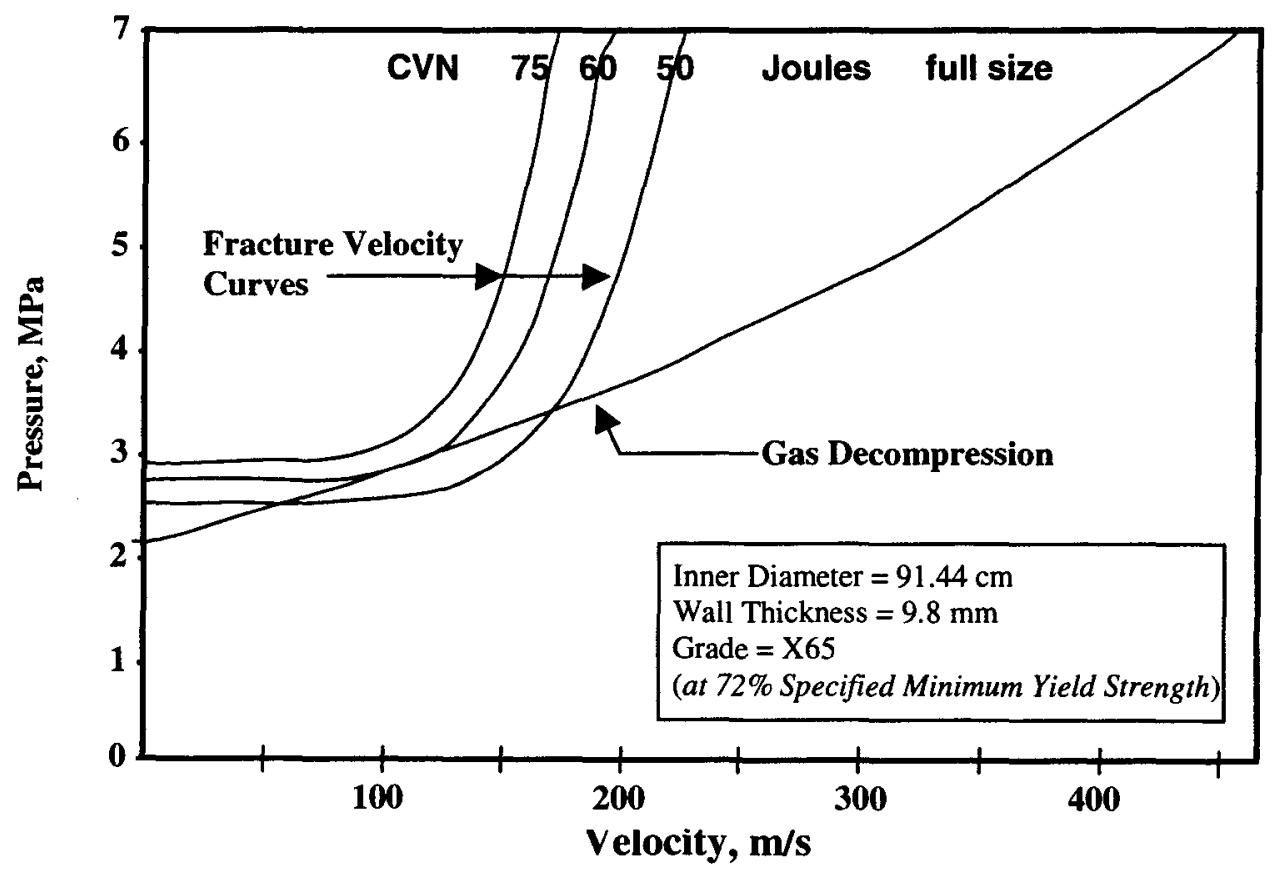

Figure 2.14: Fracture arrest determination using fracture velocity curves for 3 different steels and a gas decompression curve for air [adapted from 39]

Long ductile failure propagation is possible if the fracture velocity lies on the right of the decompression curve at any pressure. Alternatively, the fracture velocity must lie to the left of the decompression curve at all pressures in order to ensure arrest of the ductile failure. 
The curve-based method illustrated in Figure 2.14 is also susceptible to extrapolation errors because the material response curve is based on Charpy V-Notch measurements.

\subsection{Summary}

In this chapter, concepts and theories related to linepipe were reviewed. The methods of determining failure control as well as current testing methods were reviewed, and a summary of the laboratory assessment methods is presented in Table 2.3. The laboratory assessment methods have many significant inadequacies. Therefore, there exists a need for a more theoretically based method of assessing the ductile-fracture propagation resistance of steel. An appropriate link between these concepts and the mechanical response of the pipe material can constitute a powerful tool in the understanding and computer simulation of this tearing process. The next chapter will therefore be devoted to an overview of the material response algorithm used within a finite element analysis method, which has been selected as the technique to be developed in this thesis.

Table 2.3: Review of current laboratory fracture toughness assessment methods

\begin{tabular}{|c|c|c|}
\hline Method & Advantages & Disadvantages \\
\hline $\begin{array}{l}\text { Instrumented Charpy Impact } \\
\text { (with a sharp notch) }\end{array}$ & $\begin{array}{ll}\text { 1. } & \text { requires small specimen } \\
\text { 2. error is small for predominantly brittle } \\
\text { fractures }\end{array}$ & $\begin{array}{l}\text { 1. can provide extremely pessimistic } \\
\text { values, especially at higher } \\
\text { temperatures } \\
\text { 2. lonsiderable scatter of } \\
\text { measurements above brittle } \\
\text { transition temperature } \\
\text { 3. difficulty in separating the crack } \\
\text { initiation \& propagation } \\
\text { components of the process } \\
\text { 4. not good simulation of } \sigma \& \varepsilon \text { state }\end{array}$ \\
\hline Drop Weight Tear Test & 1. applicable to large specimen & $\begin{array}{l}\text { 1. results variable } \\
\text { 2. not good simulation of } \sigma \& \varepsilon \text { state }\end{array}$ \\
\hline Crack Tip Opening Angle & 1. constant during crack growth & $\begin{array}{l}\text { 1. direct local measurement is } \\
\text { difficult } \\
\text { 2. direct global measurement is not } \\
\text { possible } \\
\text { 3. linear representation of flow stress }\end{array}$ \\
\hline
\end{tabular}




\section{REFERENCES}

1. Gray, J Malcolm, Final Report for AGA Project No. NG-18(4), American Gas Association, February 1984

2. Hashimoto, T., et al, "Recent Development of Large Diameter Linepipe of Grade X80 and $X-100$ ", Proceedings OMAE Conference, Houston, Texas, Feb. 7-12, 1988, pp. $179-185$

3. Kawabata, F., et al, "Metallurgical and Mechanical Features of X-100 Linepipe Steel", Pipeline Technology, Vol II, Proceedings of Pipeline Technology Conference, Oostende, Sept. 11-14, 1995

4. Pickering, F.B. and Gladman, T. "Metallurgical Development in Carbon Steel”, ISS Special Report No. 81, 1963, p.10

5. Gladman, T., Dulieu, D. and McIvor, I.D., Microalloying 75, Union Carbide Corp., 1977, p. 32

6. Gladman, T., McIvor, I.D. and Pickering, F.B., J. Iron and Steel Institute, Vol 210, 1972, p. 916

7. Pickering, F.B., Proceedings of the Symposium on Hardenability Concepts With Applications to Steel, Chicago, USA, October 24-26, 1977, p. 163

8. Woodhead, J.H., Review of Principles of Microalloyed Bar and Forging Steels, Fundamentals of Microalloyed Forging Steels, TMS-AIME, 1987, pp. 3-18

9. Maynier, P., Jungmann, B. and Dollet, J., Creusot-Loire System for the Prediction of the Mechanical Properties of Low Alloy Steel Products, Hardenability Concepts With Applications to Steel, Chicago, USA, October 24-26, 1977, pp. 518-545

10. Hodgson, P.D. and Gibbs, R.K., Int. Symp. on Mathematical Modelling of Hot Rolling of Steel, S. Yue (ed.), CIM, Quebec, 1990, p. 76

11. Choquet, P., Fabregue, P., Giusti, J. and Chamont, B., Int. Symp. on Mathematical Modelling of Hot Rolling of Steel, S. Yue (ed.), CIM, Quebec, 1990, p. 34

12. Majita, J., Kuziak, R., Pietrzyk, M. and Krzton, H., Use of the Computer Simulation to Predict Mechanical Properties of C-Mn Steel After Thermomechanical Processing, Journal of Materials Processing Technology, Vol 60, 1996, pp. 581-588

13. Gladman, T., The Physical Metallurgy of Microalloyed Steels, The Institute of Materials, 1997, pp. 57-78 
14. Knott, J.F., "Micromechanisms of Fracture and the Fracture Toughness of Engineering Alloys", Fracture 1977, Vol 1, ICF4, Waterloo, Canada, June 1977, pp. $61-91$

15. Knott, J.F., "Effects of Microstructure and Stress-State on Ductile Fracture in Metallic Alloys", Advances in Fracture Research, Proceedings of the $7^{\text {th }}$ International Conference on Fracture (ICF7), Pergamon Press, Oxford, UK, 1989, pp.125-138

16. Wilsdorf, H.G.F., "The Ductile Fracture of Metals: a Microstructural Viewpoint.", Materials Science and Engineering, Vol. 59, 1983, pp. 1-19

17. Garrison, W.M. Jr. and Moody, N.R., "Ductile Fracture.", Journal of the Physics and Chemistry of Solids, Vol. 48, 1987, pp. 1035-1074

18. Knott, J.F., "Micromechanisms of Fibrous Crack Extension in Engineering Alloys", Metal Science, Vol. 14, 1980, pp. 327-336

19. Argon, A.S., Im, J., Safoglu, R., "Cavity Formation from Inclusions in Ductile Fracture"" Metallurgical Transactions, Vol. 6A, 1975, pp. 825-837

20. Beremin, F.M., "Cavity Formation From Inclusions in Ductile Fracture of a 508 Steel”, Metallurgical Transactions, Vol. 12A, 1981, pp. 823-731

21. Brown, L.M. and Stobbs, W.M., "The Work-Hardening of Copper Silica v. Equilibrium Plastic Relaxation by Secondary Dislocations", Philosophical Magazine, 1976, Vol. 34, pp. 351-372

22. Goods, S.H. and Brown, L.M., "The Nucleation of Cavities by Plastic Deformation", Acta Metallurgica, Vol. 27, 1979, pp. 1-15

23. Van Stone, R.H., Cox, T.B., Low, J.R. Jr., and Psioda, P.A., “Microstructural Aspects of Fracture by Dimpled Rupture," International Metallurgical Reviews, Vol. 30, 1985, pp. 157-179

24. Anderson, T.L., Fracture Mechanics: Fundamentals and Applications, $2^{\text {nd }}$ Edition, CRC Press, 1995, pp.251-302

25. Rice, J.R. and Tracey, D.M., “On the Ductile Enlargement of Voids in Triaxial Stress Fields", Journal of the Mechanics \& Physics of Solids, Vol. 17, 1969, pp. 201-217

26. Gurson, A.L., "Continuum Theory of Ductile Rupture by Void Nucleation \& Growth: Part 1 - Yield Criteria and Flow Rules for Porous Ductile Media", Journal of Engineering Materials and Technology, Vol. 99, 1977, pp. 2-15

27. Tvergaard, V., “On Localization in Ductile Materials Containing Spherical Voids", International Journal of Fracture, Vol. 18, 1982, pp. 237-252 
28. Tvergaard, V. and Needleman, A., "Analysis of the Cup-Cone Fracture in a Round Tensile Bar", Acta Metallurgica, Vol. 32, 1984, pp. 157-169

29. ABAQUS Explicit User's Manual Version 5.7, HKS Inc., 1998, p 10.2.5-3

30. Gao, X., Faleskog, J., Shih, C.F., and Dodds, R.H. Jr., "Ductile Tearing in PartThrough Cracks: Experiments and Cell-Model Predictions", Engineering Fracture Mechanics, Vol. 59, No.6, Pergamon Press, 1998, pp. 761-777

31. Faleskog, J. Gao, X., and Shih, C.F., "Cell model for nonlinear fracture analysis - I. Micromechanics calibration", International Journal of Fracture Vol. 89 Issue 4, 1998, pp. 355-373

32. Tvergaard, V., "Material Failure by Void Growth to Coalescence", Advances in Applied Mechanics, 1990, 27, pp. 83-151

33. Anderson, H., "Analysis of a Model for Void Growth and Coalescence Ahead of a Moving Crack Tip", Journal of the Mechanics and Physics of Solids, 1977, 25, pp. 217-233

34. Brown, L.M., and Embury, J.D., "The Initiation and Growth of Voids at Second Phase Particles", Proceedings of the $3^{\text {rd }}$ International Conference on Strength of Metals and alloys, Institute of Metals, London, 1973

35. Thomason, P.F., Ductile Fracture of Metals, Pergamon Press, Oxford, UK, 1990

36. Wilkowski, G.M. and Mihell, J.N., Ductile Fracture Arrest Methodology for Current and Future Grades of Linepipe Steels, Proc. of the Int. Symp. on Materials for Resource Recovery and Transportation, CIM, 1998, 267-295

37. Maxey, W., Keifer, J.F., and Eiber, R.J., "Ductile Fracture Arrest in Gas Pipelines", A.G.A. Catalogue Number L32176, May 1976

38. AISI Technical Report, "Running Shear Fracture in Line Pipe", Subcommittee of Large Diameter Pipe Producers, September 1, 1974

39. Eiber, R.J., Bubenik, T.A., and Maxey, W.A., "Fracture Control Technology for Natural Gas Pipelines", Project PR-3-9113, NG-18 Report No. 208, American Gas Association, December 1993

40. Demofonti, G., Maresca, A., and Buzzichelli, G., "Ductile Fracture Propagation and Arrest in Offshore Pipelines", Applied Mechanical Review, Vol. 41, No. 2, ASME, Feb. 1988, pp. 85-95

41. Kanninen, M.F., Leung, C.P., O’Donaghue, P.E., Morrow, T.B., Popelar, C.F., Buzzichelli, G., Demofonti, G., Hadley, I., Rizzi, L., and Venzi, S., "The Development of a Ductile Fracture Model", Joint Final Report, AGA Contract No. PR-15-527, and PR-182-526, AGA-Pipeline Research Committee, July 1992 
42. Kanninen, M.F., Grant, T.S., and Demofonti, G., "The Development and Validation of a Theoretical Ductile Fracture Model", Eighth Symposium on Line Pipe Research, AGA-Pipeline Research Committee, September 26-29, 1993, pp. 12-1 to 12-20

43. Kanninen, M.F., Morrow, T.B., Grant, T.S., and Demofonti, G., "The Development and Validation of a Ductile Fracture Analysis Model", Final Report, AGA Contract No. PR-15-9121, PR-15-9209, and PR-182-9210, AGA-Pipeline Research Committee, May 1994

44. Groves, T.K., Bishnoi, P.R. and Wallbridge, J.M.E., "Decompression Wave Velocities in Natural Gases in Pipe Lines", Canadian Journal of Chemical Engineering, 56, 1978, pp. 664-668

45. Picard, D.J. and Bishnoi, P.R., "The Importance of Real-Fluid Behaviour and Nonisentropic Effects in Modeling Decompression Characteristics of Pipeline Fluids for Applications in Ductile Fracture Propagation Analysis", Canadian Journal of Chemical Engineering, Vol 66, 1988, 3-12

46. Luton, M.J., Private Communication, March 1999

47. Marandet, B. and Sanz, G., "Evaluation of the Toughness of Thick Medium Strength Steels by LEFM and Correlations Between $K_{I C}$ and CVN" ASTM STP 631, American Society of Testing and Materials, Philadelphia, 1977, pp. 72-95

48. Rolfe, S.T. and Novak, S.T., "Slow Bend $K_{I C}$ Testing of Medium Strength High Toughness Steels" ASTM STP 463, American Society of Testing and Materials, Philadelphia, 1970, pp. 124-159

49. Barsom, J.M. and Rolfe, S.T., "Correlation Between $K_{I C}$ and Charpy V-Notch Test Results in the Transition Temperature Range" ASTM STP 514, American Society of Testing and Materials, Philadelphia, 1970, pp. 281-301

50. Sailors, R.H. and Corten, H.T., Relationship between Material Fracture Toughness Using Fracture Mechanics and Transition Temperature Tests ASTM STP 514, American Society of Testing and Materials, Philadelphia, 1973, pp. 164-191

51. Begley, J.A. and Logsdon, W.A., "Correlation of Fracture Toughness and Charpy Properties for Rotor Steels", Westinghouse Report, Scientific Paper 71-1E7, MSLRFP1-1971

52. Ito, T., Tanaka, K., and Sato, M., "Study of Brittle Fracture Initiation from Surface Notch in Welded Fusion Line, IIW Document X-704-730, September 1973Anderson, T.L., Fracture Mechanics: Fundamentals and Applications,2nd Edition, CRC Press, 1995 , p. 375

53. Hecker, Siegfried S., Experimental Studies of Sheet Stretchability, Formability: Analysis, Modeling, and Experimentation, TMS-AIME, 1979, pp.150-182 
Chapter 2: Literature Review

54. Kanninen, Melvin F. and Popelar, Carl H., Advanced Fracture Mechanics, Oxford University Press, 1985, pp. 251-255 


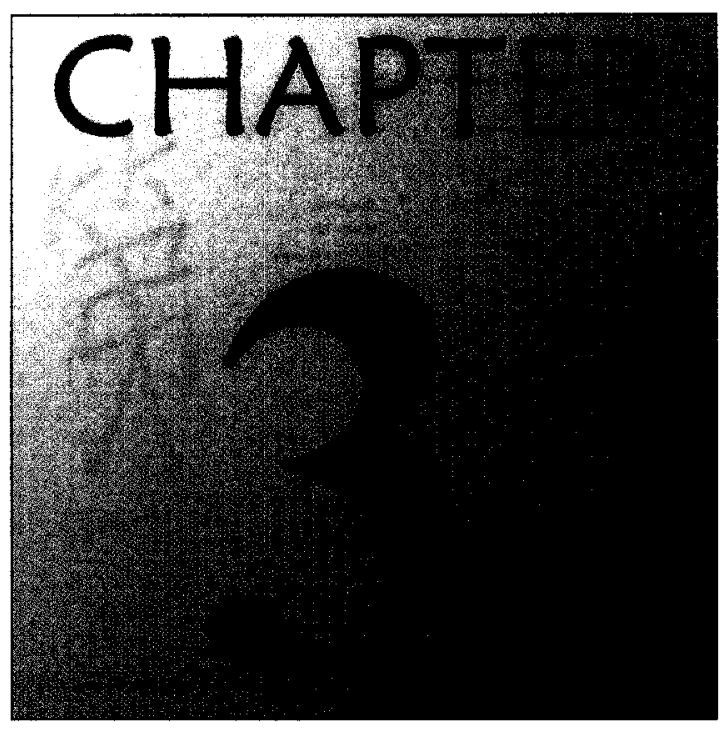

\section{The Material Model}

\subsection{Constitutive Model}

For small elastic strains, the additive decomposition of the rate of deformation is assumed to be given as:

$$
\mathbf{D}^{\mathrm{tot}}=\mathbf{D}^{\mathrm{el}}+\mathbf{D}^{\mathrm{pl}}
$$

where $\mathbf{D}^{\text {tot }}$ is the total strain rate, $\mathbf{D}^{\mathrm{el}}$ is the elastic strain rate, $\mathbf{D}^{\mathrm{pl}}$ is plastic strain rate.

Constitutive theory relates the stress to the strain, or, as in this case, the stress rate to strain rate. The Cauchy stress tensor, $\sigma$, is conventionally reduced by the hydrostatic pressure, which has negligible effect on the plastic deformation of the material. The reduced stress tensor or stress deviator tensor, $\mathbf{S}$, is defined in the following manner: 


$$
\mathbf{S}=\left[\sigma-\frac{1}{3} \operatorname{tr}(\sigma) \mathbf{I}\right]
$$

where $\mathbf{I}$ is the identity tensor of the same order as $\sigma$, and $\operatorname{tr}(\sigma)$ is the summation of solely the diagonal terms of that particular tensor.

The Green-Naghdi stress rate, $\sigma$, can be written in terms of the Cauchy stress rate tensor, $\dot{\sigma}$, and the spin rate, $\Omega$, as:

$$
\begin{aligned}
& \nabla \\
& \sigma=\dot{\sigma}-\Omega \sigma-\sigma \Omega^{\mathrm{T}}
\end{aligned}
$$

where

$$
\Omega=\dot{\mathbf{R}} \mathbf{R}^{T}
$$

where $\mathbf{R}$ is the rotation tensor and the last two terms of Equation 3.3 are the rate of the Cauchy stress caused by the rigid body rotation.

The elastic strain rate is related to the Green-Nagdhi stress rate by:

$$
\underset{\sigma}{\sigma}=\mathbf{C D}^{\mathrm{el}}
$$

where $\mathbf{C}$ is a fourth-order, tangent material stiffness tensor. For an isotropic material, Equation 3.5 can be related by Hooke's Law as:

$$
\mathbf{D}^{\mathrm{el}}=\left[\frac{1+\nu}{\mathrm{E}} \boldsymbol{\sigma}-\frac{v}{\mathrm{E}} \operatorname{tr}\left(\begin{array}{l}
\nabla \\
\boldsymbol{\sigma}
\end{array}\right) \mathbf{I}\right]
$$

where E is Young's modulus, and $v$ is Poisson's ratio. 


\subsubsection{The Flow Stress Function}

Conventional structural metals exhibit a region where their response to stress is purely elastic. Initially, the metal deforms elastically, which is described by its Young's modulus and Poisson's ratio, but as soon as the stress attains the flow stress value, plastic deformation occurs with a much lower effective modulus. The flow stress function defines the bounds of this domain, and is usually written as a function of stress, $\sigma$, temperature, if applicable, and any other number of hardness parameters, such as strainhardening or strain-rate hardening.

In stress space, the shape of the flow stress function (the flow stress surface) must be defined for each particular material. It has been observed that the flow stress in metals is independent of hydrostatic pressure [1]. For design calculations, this is usually a satisfactory assumption but it is only an approximation in the case of higher strength metals [2] and does not apply if yielding occurs when nucleation and growth of voids occurs, as might occur in regions of high triaxial tension [3-7].

Considerable mathematical simplicity is provided by smooth flow stress surfaces when associated flow is used. For design calculations involving metals, the Mises or distortion-energy criterion flow stress surface

$$
\mathrm{F}=\bar{\sigma}-\sigma_{\mathrm{y}}
$$

where $\bar{\sigma}$ is the von Mises stress and $\sigma_{\mathrm{y}}$ is the flow stress in uniaxial tension, is now used most commonly. The distortion energy is the part of the total strain energy per unit volume that is involved in shape-change as opposed to volume-change. The Mises flow stress surface is a cylinder centered around the hydrostatic pressure axis, $p$, in stress space (Figure 3.1). The flow stress is assumed isotropic; the metal flows at the same magnitude of stress regardless of the direction of the applied load. In addition, the material behaviour is elastic when the state of stress lies within the surface, and it flows 
and deforms plastically when it lies on the surface. As a result of the plastic deformation, the flow stress surface may change according to the defined hardening law.

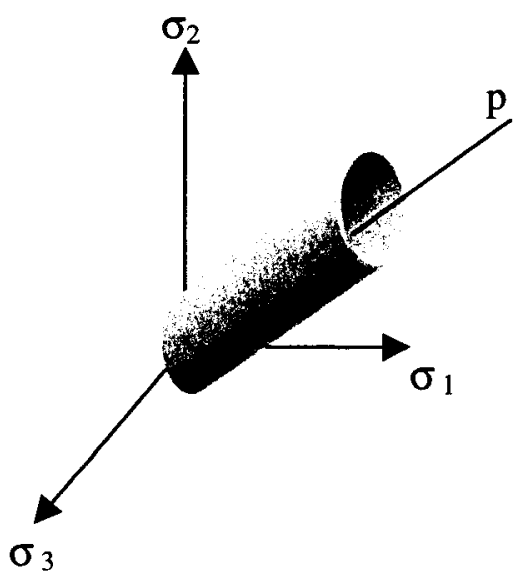

a)

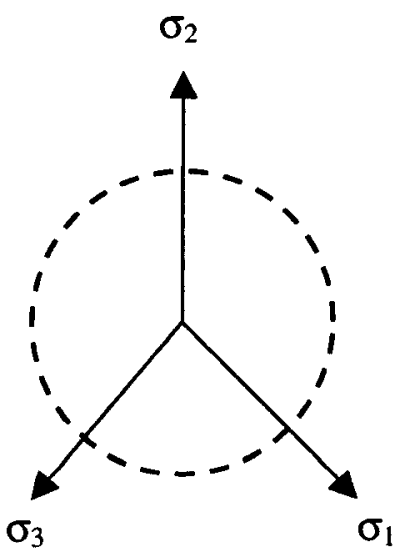

b)

Figure 3.1: a) Mises flow stress surface ( $a$ cylinder) in stress space

b) Mises flow stress surface (a circle) seen from the $\sigma_{1}=\sigma_{2}=\sigma_{3}$ axis

For an isotropic material, a von Mises flow stress condition is used such that:

$$
f\left(\sigma, \sigma_{\mathrm{y}}\right)=\bar{\sigma}-\sigma_{\mathrm{y}}\left(\bar{\varepsilon}^{\mathrm{p}}, \theta\right)=0
$$

where the equivalent stress, $\bar{\sigma}$,can be defined in terms of the second invariant of the reduced stress tensor as:

$$
\bar{\sigma}=\sqrt{3 \mathbf{J}_{2}^{\prime}}
$$

where the second invariant, $\mathbf{J}_{2}^{\prime}$,is defined as:

$$
\mathbf{J}_{2}^{\prime}=\frac{1}{2} \mathbf{S S}=\frac{1}{2}\left(S_{x}^{2}+S_{y}^{2}+S_{z}^{2}\right)+S_{x y}^{2}+S_{y z}^{2}+S_{z x}^{2}
$$




\subsubsection{The Plastic Flow Potential}

The boundary of the domain of purely elastic response is defined by the flow stress function, and plastic flow occurs once the stress point reaches the flow stress surface. The plastic flow potential determines the direction of plastic flow when the material flows, as illustrated in Figure 3.2. It has been shown that the incremental plastic strain vector must be normal to the flow stress surface [8]. As a consequence, any acceptable flow stress surface must be convex about its origin, and no component of the total strain acts in the direction of the hydrostatic stress [9]. In addition, the ratios of strain increments associated with flow are independent of any incremental stress changes, but are fixed instead by the ratios of prevailing stress components [10].

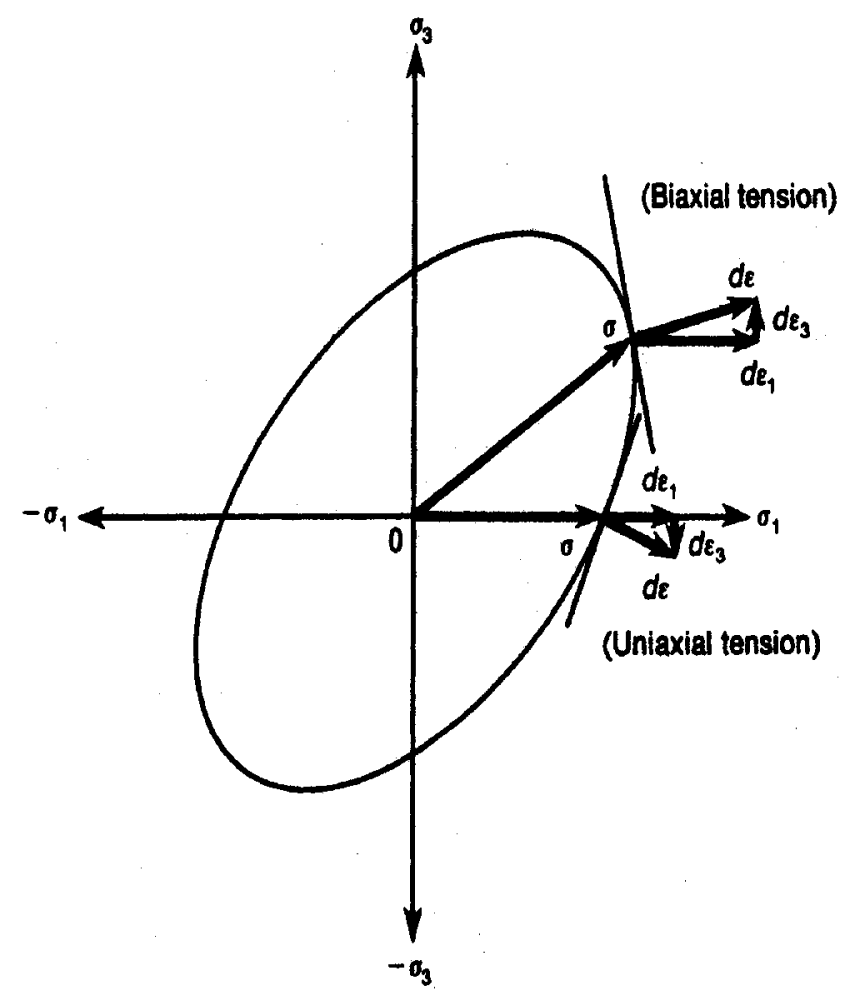

Figure 3.2: Illustration of the normality rule for plastic flow

Dislocation motion in metals is associated with crystalline plasticity. The Schmid law assumes that the rate at which dislocations travel in a given slip system depends only on the resolved shear stress on that slip system [11]. Therefore, the microscopic flow potential, which causes dislocation motion, is the same as the flow stress surface, which 
is the resolved shear stress reaching a critical value. Thus, the microscopic flow is associated, i.e. the plastic strain rate is in the direction of the normal to the flow stress surface.

In plasticity theories, the associated flow rule carries over from the microscale to the macroscale, where averaged continuum measures of stress and strain represent the loading and deformation of the material. Therefore, the macroscale continuum model will be associated when it can be demonstrated that the Schmid law governs the micromechanics. When the flow stress surface is smooth, the associated plastic flow provides simplification in the plasticity theory.

The flow direction is restricted with assumptions of the Mises surface and associated flow, but this should not be a concern when the plastic straining is predominantly monotonic. However, there may be a concern when the flow localizes, since real materials can flow in a range of directions. Thus, classical, associated flow, metalplasticity models have difficulty predicting necking accurately in plane stress sheets, but they are still useful for such studies [11].

The plastic strain rate of Equation (3.1) is assumed to be given by a stress potential, $\hat{g}$, as:

$$
\mathbf{D}^{\mathrm{pl}}=\partial \hat{g}(\sigma) / \partial \boldsymbol{\sigma}
$$

Assuming an associated flow rule, $\hat{g}$ can be written in terms of $f$, from Equation 3.7, as:

$$
\hat{g}(\boldsymbol{\sigma})=\bar{g}(f)=f\left(\bar{\sigma}, \sigma_{\mathrm{y}}\right)
$$

From the above definition, Equation 3.11 can be rewritten as:

$$
\mathbf{D}^{\mathrm{pl}}=\frac{\partial \mathrm{g}}{\partial \bar{\sigma}} \frac{\partial \bar{\sigma}}{\partial \boldsymbol{\sigma}}
$$


where $\frac{\partial \bar{\sigma}}{\partial \sigma}$ determines the direction normal to the von Mises flow stress surface in principal stress space.

\subsubsection{The Hardening Rule}

One of the most basic metallurgical properties of metal is the stress required to achieve plastic flow. Usually, the flow stress of a metal deformed at less than half of its melting temperature increases as straining increases. One of the most complex aspects of modeling inelastic deformation of metals is the evolution of this increase in flow stress.

In deformation involving plasticity, the strains involved may be very large. Even when only a small amount of plastic strain is involved in the deformation, the flow stress will change in a non-linear manner [1]. Due to work hardening, the flow stress itself increases with strain, and stress is no longer proportional to strain, but depends on the strain increment and strain rate.

In the uniaxial tension test, it is observed that the flow stress is not affected by elastic deformation. Thus, the material work hardens as a function of plastic flow variables only. Most simulations commonly use either perfect plasticity, linear, or power-law hardening (Figure 3.3).

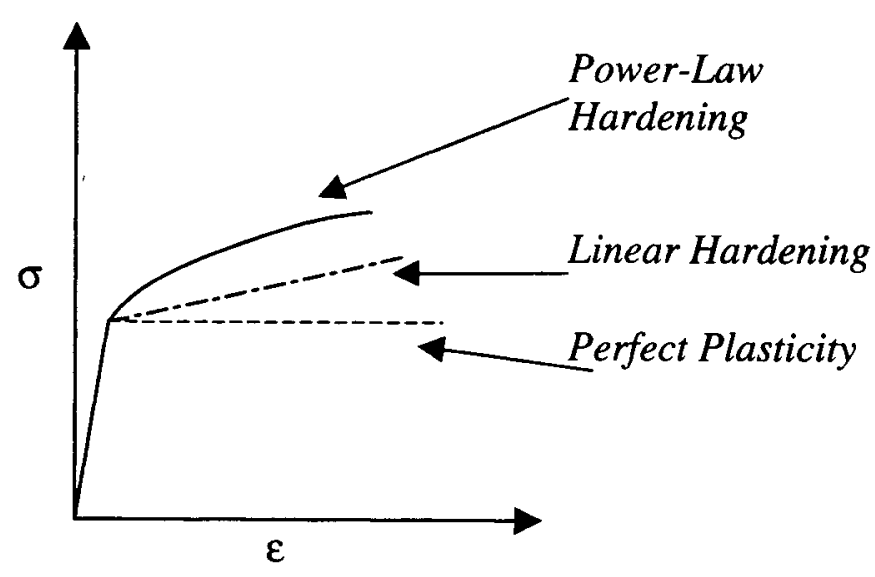

Figure 3.3: Commonly used work-hardening rules 
For gross plastic flow applications like metal forming, the very simple rule of perfect plasticity is usually sufficient [11]. This is the simplest case because there is no hardening and the flow stress does not evolve with deformation. As well, strainhardening effects are often less important than rate effects in problems involving high strain rates. Linear hardening is typically used as a gross approximation of strain hardening.

Isotropic hardening is a reasonable assumption for cases where the most important concern is to model the gross plastic flow, such as in the analysis of metal forming operations. As can be observed in Figure 3.4, this hardening rule produces a uniform increase in the flow stress surface in all directions such that the flow stress increases in all stress directions as plastic straining occurs. Upon reverse loading, isotropic hardening does not model the actual behaviour typified by the Bauschinger effect.

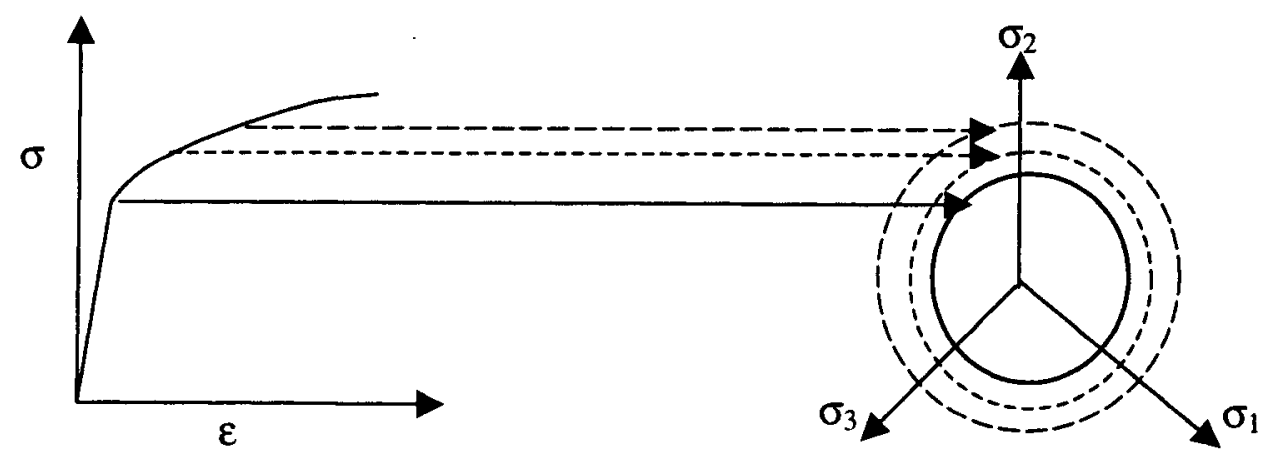

Figure 3.4: Expansion of the Mises flow stress surface with isotropic hardening

In this study, the flow stress, $\sigma_{\mathrm{y}}$, is defined as a function of the effective plastic strain:

$$
\sigma_{\mathrm{y}}\left(\bar{\varepsilon}^{\mathrm{pl}}\right)=\mathrm{A}+\mathrm{B}\left(\bar{\varepsilon}^{\mathrm{pl}}\right)^{\mathrm{n}}
$$

The equivalent plastic strain, $\bar{\varepsilon}^{\mathrm{pl}}$, is defined by the integral of the equivalent rate of plastic strain as: 


$$
\bar{\varepsilon}^{\mathrm{pl}}=\int_{0}^{\mathrm{t}} \dot{\bar{\varepsilon}}^{\mathrm{pl}} \mathrm{dt}=\int_{0}^{\mathrm{t}} \sqrt{\frac{2}{3} \mathbf{D}^{\mathrm{pl}} \mathbf{D}^{\mathrm{pl}}} \mathrm{dt}
$$

where $\mathbf{D}^{\mathrm{pl}} \mathbf{D}^{\mathrm{pl}}$ is the second invariant of the plastic strain rate tensor and is defined as:

$$
\mathbf{D}^{\mathrm{pl}} \mathbf{D}^{\mathrm{pl}}=\left(\mathrm{D}_{\mathrm{x}}^{\mathrm{pl}}\right)^{2}+\left(\mathrm{D}_{\mathrm{y}}^{\mathrm{pl}}\right)^{2}+\left(\mathrm{D}_{\mathrm{z}}^{\mathrm{pl}}\right)^{2}+2\left(\mathrm{D}_{\mathrm{xy}}^{\mathrm{pl}}\right)^{2}+2\left(\mathrm{D}_{\mathrm{yz}}^{\mathrm{pl}}\right)^{2}+2\left(\mathrm{D}_{\mathrm{zx}}^{\mathrm{pl}}\right)^{2}
$$

\subsubsection{Failure Criteria}

Plasticity theory was developed to predict the response of ductile metals to stresses beyond the elastic limit [12]. Classical plasticity theories do not, however, predict material fracture: the theory must be extended or some other theory used to describe the actual fracture event.

Component failure, however, does not necessarily mean fracture. For example, a component may be deemed to have failed after reaching unacceptably large deformations. In such cases, failure may be defined using only plasticity theory. If the failure is associated with localization, i.e., tearing of a sheet of material, or plastic buckling, a more sophisticated material model might be required because such localization depends on details of the constitutive behaviour that are usually ignored because of their complexity.

In these initial studies, failure was characterized by a critical value of the equivalent plastic strain, $\bar{\varepsilon}^{\mathrm{pl}}$ [13]. This value was set based on the strain-to-failure measured in uniaxial tension. Although the data presented in this study were obtained using isotropic yielding and hardening, the algorithm has the facility to incorporate anisotropic yield and hardening as well as a failure criterion dependent on the stress state. Failure is assumed to occur when the damage parameter reaches one. The damage parameter, $\Gamma$, is defined as: 


$$
\Gamma=\sum\left(\frac{\Delta \bar{\varepsilon}^{\mathrm{pl}}}{\bar{\varepsilon}_{\mathrm{f}}^{\mathrm{pl}}}\right)
$$

\subsection{Numerical Implementation}

The Finite Element Method is a numerical procedure for obtaining solutions to many problems encountered in engineering analysis. Although the basic concepts of the method have evolved over approximately 150 years, the method as presently known stems from the 1950's [1]. In this chapter, the focus will be on a system that uses continuum elements to obtain approximate solutions to solid mechanics problems.

The problem of the response of a system to an applied load can be described by a set of three coupled partial differential equations, but except for the simplest of geometries, the complexity is such as to preclude an analytic solution. Therefore, the finite element method is utilized to obtain a numerical solution to this boundary-value problem.

$$
\begin{aligned}
& F_{x}=\frac{\partial \sigma_{x x}}{\partial x}+\frac{\partial \sigma_{x y}}{\partial y}+\frac{\partial \sigma_{x z}}{\partial z} \\
& F_{y}=\frac{\partial \sigma_{z y}}{\partial x}+\frac{\partial \sigma_{y y}}{\partial y}+\frac{\partial \sigma_{y z}}{\partial z} \\
& F_{z}=\frac{\partial \sigma_{x z}}{\partial x}+\frac{\partial \sigma_{y z}}{\partial y}+\frac{\partial \sigma_{z z}}{\partial z}
\end{aligned}
$$

where $F_{i}$ is the body force component and $\sigma_{i j}$ is the stress tensor component. 
While closed-form solutions are obtainable for a very few simple geometries, and usually allow for a limited number of variables, discretization procedures allow the solution of a much broader class of problems and configuration variations.

Although the finite element analysis method is a solution to the equations of equilibrium, it is performed indirectly through the use of an energy minimization approach. In the case of elastic materials, finite element analysis is based on the theorem of minimum potential energy, which can alternatively be cast as a virtual work expression [14]. For minimum potential energy in a simple static case, the variation of the potential energy is determined, which includes strain energy and external loads. This variation is set to zero, from which a solution for the displacements is obtained. For dynamic problems, the equation of motion is obtained using the same approach, except that inertia terms are included as body forces using d'Alembert's Principle, which states that Newton's third law of motion is true for bodies that are free to move as well as for bodies rigidly fixed [15].

Until recently, most FE analysis required the use of powerful workstations or supercomputers, but the rapid development of desktop computers over the last few years has enabled FE simulations to be performed on a desktop PC without the drawback of much longer computing times.

There are two methods that are used for a finite element analysis: the implicit and explicit method. The implicit method uses a small number of steps and iterations that are required to achieve equilibrium after each step, the solution of a set of simultaneous equations that requires the inversion of a matrix, and it also requires the use of a tangent stiffness matrix. The explicit method uses a large number of small steps with no iterations, and decoupled equations. The explicit method has the advantage of requiring less computer memory because matrix inversion is not necessary, has no convergence problems, is capable of considering material softening, and is better able to track contact between surfaces. In contrast, the explicit method has the disadvantage of being only conditionally stable, thus the required time step may have to be extremely small. It also 
requires a diagonal mass matrix, therefore affecting the available types of elements, and it cannot really be used to solve static problems.

The stability limit of the central difference operator is a function of the time it takes an acoustic wave to travel a characteristic length, and is given in terms of:

$$
\Delta \mathrm{t} \leq \frac{\mathrm{L}}{\sqrt{\mathrm{E} / \rho}}
$$

where $\Delta t$ is the time step, $\mathrm{L}$ is the effective element length of the smallest element, $\sqrt{E / \rho}$ is the acoustic wave speed, $E$ is Young's modulus, and $\rho$ is the density. This time step limit is usually called the Courant condition. It follows that the time step becomes smaller as the finite element mesh size is reduced or when the acoustic wave speed is higher. The resulting solutions to the equations of motion are stable if the time step taken in the simulation is smaller than the Courant condition. No iterations are necessary for equilibrium within each time step. Therefore, the explicit code requires little computer time per time step.

The Explicit Finite Element Analysis starts with semi-discretised equations of motion (assuming no damping) for a given time $t^{n}$, where $n$ is the time step number:

The position, velocity, and accelerations can be determined for a time step, $t^{n+1}$, if all the pertinent information is available for the previous time step, $t^{n}$. Since the information is known for the first time step, $t^{1}$, all subsequent time steps can be calculated.

The material response algorithm simulates the behaviour of the material under various states of stress and strain. The algorithm also has the ability to interact with the fluid-flow algorithm in order to produce a self-evolving structure when used in the case 
of the full-size crack-arrest test simulation. The primary decision regarding the algorithm is whether the element-type used is a thin shell.

In the finite element method used in the current study, the material response history calculations are performed using an incremental, iterative computational procedure. Finite element codes are used along with user-developed subroutines for studying the characteristics of non-linear material models. These combined codes are utilized to determine the stress or strain history under uniform conditions typically found in test specimens.

In the numerical integration of the incremental equations of plasticity, the strains are computed directly from the displacements. In this study, the method used to solve for the stress for a given total strain increment is a backward Euler algorithm for the von Mises flow stress function with isotropic hardening, assuming the associated flow rule. The stress recovery calculated during plastic flow is also referred to as an elastic predictor - radial return numerical integration scheme [16-20].

Variables used as input from the finite element solver at iteration ' $\mathrm{n}$ ' include the stresses, $\sigma_{\mathrm{ij}}^{\mathrm{n}}$, and the total strain increment, $\Delta \varepsilon_{\mathrm{ij}}$. Variables initially defined by the user include the elastic modulus, E, Poissons ratio, $v$, the initial yield stress, $\sigma_{0}$, other variables used to define the post-yielding hardening behaviour, a variable to define the failure, and the pipe diameter.

The predicted stresses are determined by assuming that the strain increments are entirely elastic and adding the stress increment to the stress from the previous increment. Thus, the predicted stresses are calculated as follows:

$$
\sigma_{\mathrm{ij}}^{*}=\sigma_{\mathrm{ij}}^{\mathrm{n}}+\mathrm{C}_{\mathrm{ijk} \mathrm{l}} \Delta \varepsilon_{\mathrm{kl}}
$$


where $\sigma_{\mathrm{ij}}^{*}$ is the predicted stress tensor, $\sigma_{\mathrm{ij}}^{\mathrm{n}}$ is the stress tensor from the previous time step, $\mathrm{C}_{\mathrm{ijkl}}$ is the elastic tangent modulus, $\Delta \varepsilon_{\mathrm{kl}}$ is the incremental strain tensor and repeated indices imply summation with respect to that index. For an isotropic material, Equation 3.22 can be written as:

$$
\sigma_{i j}^{*}=\sigma_{i j}^{n}+\lambda \cdot \operatorname{tr}\left(\Delta \varepsilon_{i j}\right) \delta_{i j}+2 \mu \Delta \varepsilon_{i j}
$$

where $\operatorname{tr}\left(\Delta \varepsilon_{\mathrm{ij}}\right)$ is the trace of the strain increment and $\delta_{\mathrm{ij}}$ is the Kronecker delta. Also, $\mu$ is the shear modulus, which can be calculated from:

$$
\mu=\frac{E}{2(1+v)}
$$

whereas $\lambda$ is determined from the following:

$$
\lambda=\frac{\mu(E-2 \mu)}{3 \mu-E}
$$

The effective trial stress, $s^{\text {tr }}$, was defined by:

$$
\overline{\mathrm{s}}^{\mathrm{tr}}=\left(\frac{3}{2} \mathrm{~s}_{\mathrm{ij}}^{*} \mathrm{~s}_{\mathrm{ij}}^{*}\right)^{1 / 2}
$$

where $\bar{s}_{\mathrm{ij}}^{*}$ is the predicted effective trial deviatoric stress as determined from the predicted stresses:

$$
s_{\mathrm{ij}}^{*}=\sigma_{\mathrm{ij}}^{*}-\frac{1}{3} \sigma_{\mathrm{kk}}^{*}
$$


where $\sigma_{\mathrm{kk}}^{*}$ is the equivalent pressure stress. If the yield stress is exceeded, the trial stresses are scaled back to the yield surface, i.e., a radial return. Otherwise if the yield stress is not exceeded, the computed stress values are returned to the solver and nothing else is done.

\subsubsection{Shell Elements}

The large elastic-plastic deformation of thin shells, which is used mainly for the pipe simulation, was reproduced by the material model. In the case of shell elements, as can be seen from the flowchart illustrated in Figure 3.5, the material response algorithm is similar to the algorithm described above, except the plane stress constraint $\left(\sigma_{33}=0\right)$ must also be satisfied. Determining the correct elastic and plastic strain in the thickness direction satisfies this constraint. An initial estimate for the third strain component, $\Delta \varepsilon_{33}$, is made from the assumption that it is completely elastic, which is calculated from:

$$
\Delta \varepsilon_{33}=-\frac{v}{1-v}\left(\Delta \varepsilon_{11}+\Delta \varepsilon_{22}\right)
$$

The stress update is completed when the trial stress is within the flow stress surface. Alternatively, when the trial stress falls outside the flow stress surface, a second estimate is determined from the assumption that the strain increment is entirely plastic:

$$
\Delta \varepsilon_{33}=-\left(\Delta \varepsilon_{11}+\Delta \varepsilon_{22}\right)
$$




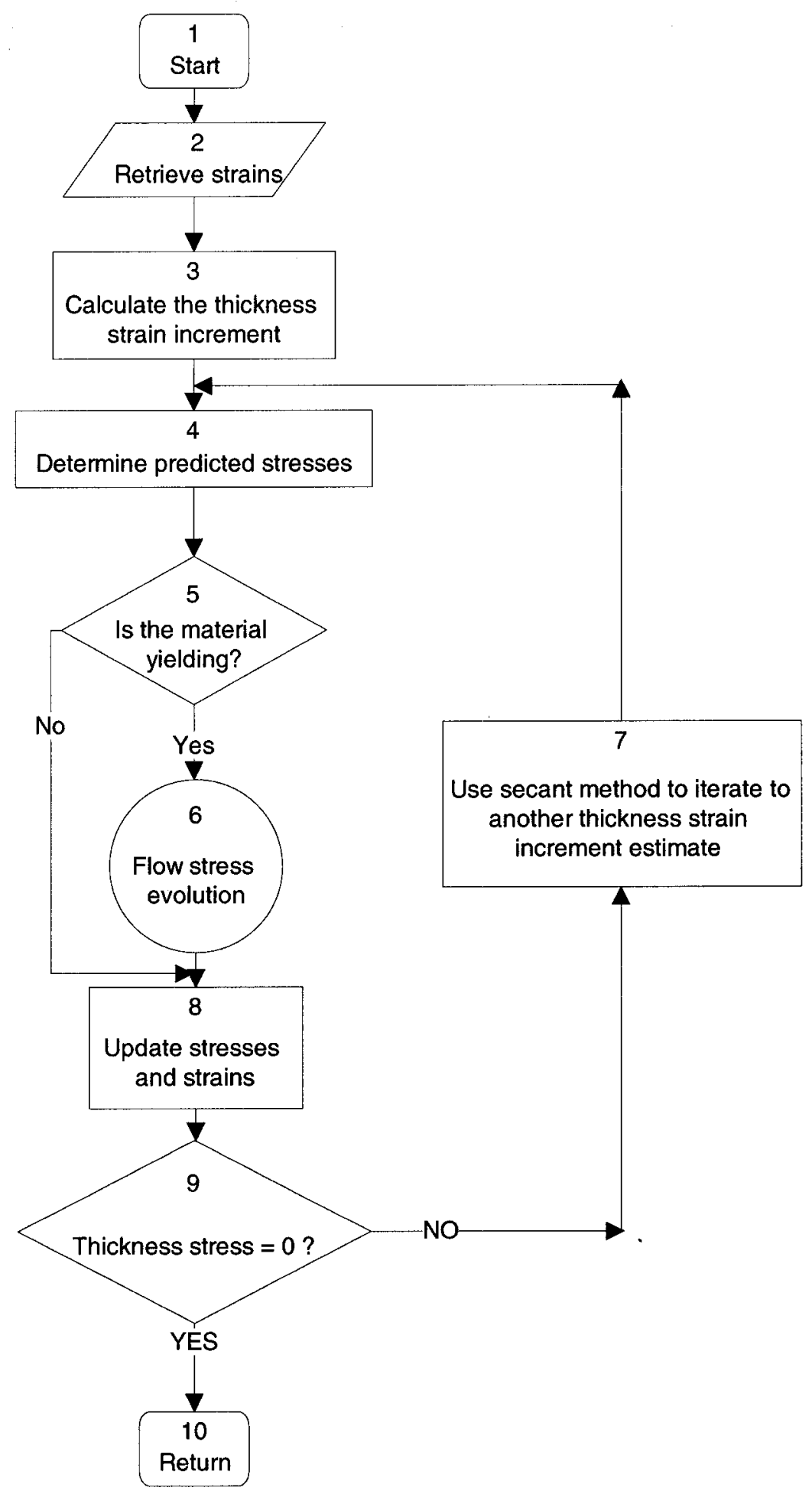

Figure 3.5: Flowchart of the material response algorithm for shell elements 
If the estimate from Equation 3.29 fails to satisfy the plane stress constraint as shown below,

$$
\sigma_{33}^{\mathrm{i}}=\sigma_{33}^{*}-\frac{3 \mathrm{G} \Delta \bar{\varepsilon}^{\mathrm{pl,i}} \mathrm{s}_{33}}{\bar{\sigma}}
$$

Subsequent estimates of the through-thickness strain, $\Delta \varepsilon_{33}$, are determined by using the Secant Method [21], which utilizes the two previous estimates as starting points, and is summarized below. These starting values for the through-thickness strain increment serve as bounds for the actual value of the strain increment.

$$
\Delta \varepsilon_{33}^{i+1}=\Delta \varepsilon_{33}^{i-1}-\frac{\Delta \varepsilon_{33}^{i}-\Delta \varepsilon_{33}^{i-1}}{\Delta \sigma_{33}^{i}-\Delta \sigma_{33}^{i-1}} \Delta \sigma_{33}^{i-1}
$$

Thereafter, the deviatoric stress and the next estimate of the normal stress are adjusted using the updated through-thickness strain increment. The iterations continue until the normal stress is sufficiently small. Once the convergence criterion is met, as illustrated by Equation 3.32 shown below, then all of the stress components are updated.

$$
\frac{\left|\Delta \varepsilon_{33}^{\mathrm{i}}-\Delta \varepsilon_{33}^{\mathrm{i}-1}\right|}{\left|\Delta \varepsilon_{33}^{\mathrm{i}+1}\right|}<10^{-4}
$$

\subsubsection{Flow Stress Evolution}

The material is assumed to be strained at a constant rate during the time step, and a predictor trial stress is computed at state ' $n+1$ '. At the end of the increment the flow stress function may be written as: 


$$
\mathrm{F}_{\mathrm{n}+1}=\mathrm{F}\left(\{\sigma\}_{\mathrm{n}+1},\left[\bar{\varepsilon}^{\mathrm{pl}}\right\}_{\mathrm{n}+1}\right)=0
$$

The trial state, $F_{(n+1) t}$, at the end of the increment is computed by assuming that the entire strain increment is elastic, that is:

$$
\left.\mathrm{F}_{\mathrm{n}+1}=\mathrm{F}\left(\{\sigma\}_{\mathrm{n}+1}, \bar{\varepsilon}^{\mathrm{pl}}\right\}_{\mathrm{n}}\right)=0
$$

From Figure 3.5 item 6, it is evident that in order to reach this stage the trial flow stress function must be greater than zero, as defined in the following equation:

$$
\mathrm{F}(\mathrm{n}+1) \mathrm{t}=\frac{1}{2} \mathrm{~s}_{\mathrm{ij}}^{*} \mathrm{j}_{\mathrm{ij}}^{*}-\frac{\sigma_{\mathrm{y}}^{2}}{3}>0
$$

where $s_{\mathrm{ij}}^{*}$ is the predicted deviatoric stress, which is defined in Equation 3.27. At this stage, the algorithm depicted in Figure 3.6 is used to scale the stresses back to the flow stress surface, which is pressure-independent in this work and evolves based on Equation 3.14 .

The algorithm for determining the equivalent plastic strain increment required to scale the equivalent stress back to the flow stress surface is executed next. 


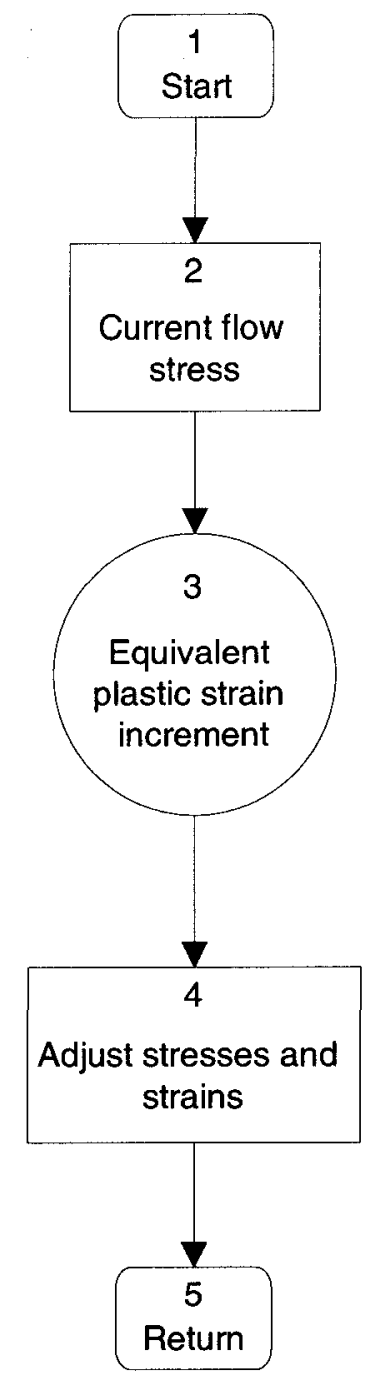

Figure 3.6: Flowchart of the algorithm for flow stress evolution

Illustrated in Figure 3.7 is a schematic of a return-mapping procedure on the effective stress - effective plastic strain plane [22], where $\bar{\sigma}^{\mathrm{tr}}$ is the trial stress value, and $\bar{\sigma}^{(n)}$ and $\bar{\sigma}^{(n+1)}$ are the effective flow stress after step $n$ and $n+1$, respectively. As shown in Figure 3.7, if the trial stress is greater than the flow stress value, then the material point is 'return-mapped' by plastic deformation until the stress attains the appropriate value on the flow stress surface. 


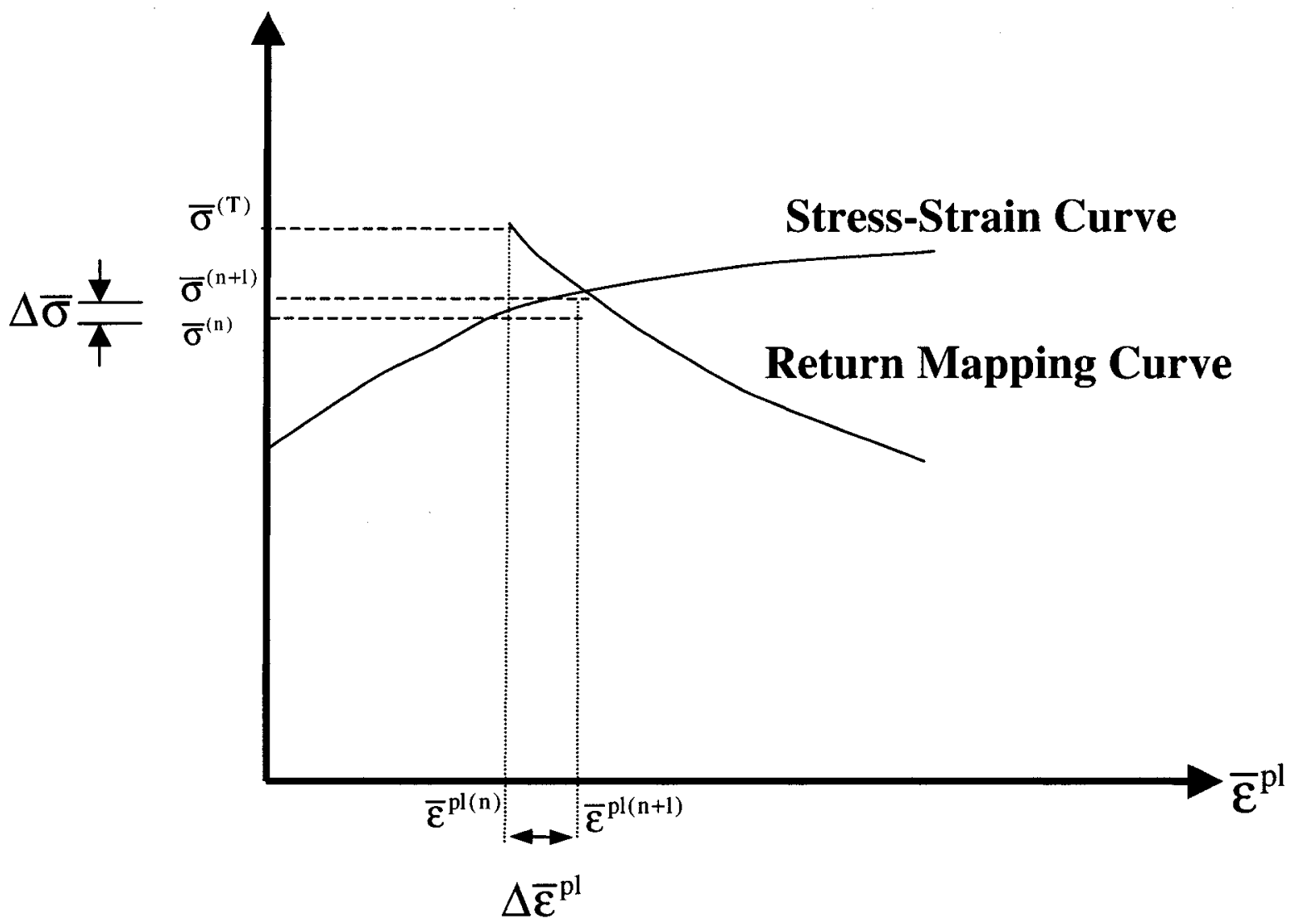

Figure 3.7: Schematic diagram of a return-mapping procedure on the effective stress effective plastic strain plane [22]

The Newton-Raphson method is used to iterate towards the plastic strain increment required to satisfy Equation 3.36. Providing that the initial solution is within the 'zone of attraction' and divergence does not occur, the Newton-Raphson numerical method is probably the most rapidly convergent process for the solution to non-linear problems [23]. It is the only process in which convergence to a solution is quadratic.

After some manipulation, the problem can be reduced to a single equation in terms of the incremental plastic strain [24]:

$$
\mathrm{F}=\bar{\sigma}^{\mathrm{tr}}-\sigma_{\mathrm{y}}\left(\bar{\varepsilon}^{\mathrm{pl}}\right)-3 \mu \Delta \bar{\varepsilon}^{\mathrm{pl}}=0
$$


where $\bar{\sigma}^{\mathrm{tr}}$ is the elastic predictor stress, $\bar{\varepsilon}^{\mathrm{pl}}$ is the total plastic strain at the beginning of the step, $\Delta \bar{\varepsilon}^{\mathrm{pl}}$ is the plastic strain increment during the current increment, ' $\mu$ ' is the shear modulus and can be calculated as follows:

$$
\mu=\frac{E}{2(1+v)}
$$

where ' $E$ ' is the elastic modulus, and ' $v$ ' is the Poisson's ratio. During each iteration, the plastic strain increment, $\Delta \bar{\varepsilon}^{\mathrm{pl}}$, is adjusted using the following:

$$
\Delta \bar{\varepsilon}_{i+1}^{\mathrm{pl}}=\Delta \bar{\varepsilon}_{\mathrm{i}}^{\mathrm{pl}}+\frac{\mathrm{F}}{3 \mu+\Psi}
$$

where ' $\Psi$ ' is the work-hardening rate, which is given by the slope of the flow stress versus equivalent plastic strain curve, that is

$$
\Psi=\frac{\mathrm{d} \bar{\sigma}}{\mathrm{d} \bar{\varepsilon}^{\mathrm{pl}}}
$$

Once the equivalent plastic strain is computed, the additional plastic strain and stress increments may be calculated.

After updating the plastic strain increment, the adjusted elastic strain increments are utilized to calculate a new value for the trial flow stress function, F, based on Equation 3.35. If the trial flow stress function is sufficiently close to zero, the iteration process for determining the correct strain and stress increment is terminated. Otherwise, the process is repeated.

The plastic strain increments are calculated by the following:

$$
\Delta \mathrm{e}_{\mathrm{ij}}^{\mathrm{pl}}=\Delta \overline{\mathrm{e}}^{\mathrm{pl}} \mathrm{n}_{\mathrm{ij}}
$$


where $\Delta \overline{\mathrm{e}}^{\mathrm{pl}}$ is the (scalar) equivalent plastic strain increment, and $\mathrm{n}_{\mathrm{ij}}$ is the unit normal tensor, which defines the normal to the flow stress surface in stress space, which is given by:

$$
\mathrm{n}_{\mathrm{ij}}=\frac{3}{2} \frac{\mathrm{s}_{\mathrm{ij}}}{\bar{\sigma}}
$$

where the $\mathrm{s}_{\mathrm{ij}}$ 's are the components of the deviatoric stress tensor, and $\bar{\sigma}$ is the von Mises effective stress, which is given by

$$
\bar{\sigma}=\sqrt{\frac{3}{2} s_{i j} s_{i j}}
$$

As a consequence of the assumption that the change in plastic volume is zero, the deviatoric plastic strain rate is therefore equal to the plastic strain rate [12].

It should be noted that for plane-stress elements, the thickness plastic strain increment is updated using:

$$
\Delta \mathrm{e}_{33}^{\mathrm{pl}}=-\left(\Delta \mathrm{e}_{11}^{\mathrm{pl}}+\Delta \mathrm{e}_{22}^{\mathrm{pl}}\right)
$$

The elastic strain increment predictions are then updated to reflect the plastic deformation increment:

$$
\Delta \varepsilon_{\mathrm{ij}}^{\mathrm{el}, \mathrm{c}}=\Delta \varepsilon_{\mathrm{ij}}^{\mathrm{el}, \mathrm{p}}-\Delta \mathrm{e}_{\mathrm{ij}}^{\mathrm{pl}}
$$


where $\Delta \varepsilon_{\mathrm{ij}}^{\mathrm{el}, \mathrm{c}}$ is the component of the corrected elastic strain increment tensor, $\Delta \varepsilon_{\mathrm{ij}}^{\mathrm{el}, \mathrm{p}}$ is the predicted total strain increment, and $\Delta \mathrm{e}_{\mathrm{ij}}^{\mathrm{pl}}$ is the component of the plastic strain increment tensor. Next the deviatoric stresses are adjusted back to the yield surface, as follows:

$$
s_{i j}=s_{i j}^{*}(1-2 \mu \cdot \varphi)
$$

where $s_{i j}$ are the components of the deviatoric stress tensor, $s_{i j}^{*}$ are the components of the predicted deviatoric stress tensor, $\mu$ is the shear modulus, and $\varphi$ is used to calculate the adjustment of the predicted deviatoric stress due to plastic strain and is determined as follows:

$$
\varphi=\sqrt{\frac{3}{2}} \cdot \frac{\Delta \overline{\mathrm{e}}^{\mathrm{pl}}}{\overline{\mathrm{s}}^{\mathrm{tr}}}
$$

It should be noted that a portion of the second component of Equation 3.45, i.e.,

$$
s_{\mathrm{ij}}^{*} \cdot \varphi
$$

results partly in the explicit conversion of the deviatoric stresses to tensors of unit magnitude. Next, the adjusted stresses, $\sigma_{\mathrm{ij}}$, are determined by combining the adjusted deviatoric stresses, $\mathrm{s}_{\mathrm{ij}}$, with the mean stress, $\frac{1}{3} \sigma_{\mathrm{kk}}$, as follows:

$$
\sigma_{\mathrm{ij}}=\mathrm{s}_{\mathrm{ij}}+\frac{1}{3} \sigma_{\mathrm{kk}}
$$




\subsubsection{Equivalent Plastic Strain Increment}

An expanded schematic diagram of Figure 3.6 item 3, which is the algorithm that determines the equivalent plastic strain increment, is displayed in Figure 3.8. It can be seen that there are four main calculations performed and two conditional statements evaluated for each iteration during the execution of this algorithm.

As was illustrated earlier with Equation 3.36, the flow stress function can be reduced to a single equation with respect to the incremental plastic strain, $\Delta \overline{\mathrm{e}}^{\mathrm{pl}}$, after some manipulation:

$$
\mathrm{F}=\bar{\sigma}^{\mathrm{tr}}-\sigma_{\mathrm{y}}\left(\bar{\varepsilon}_{\mathrm{i}+1}^{\mathrm{pl}}\right)-3 \mu \Delta \bar{\varepsilon}^{\mathrm{pl}}=0
$$

where $\bar{\varepsilon}_{\mathrm{i}+1}^{\mathrm{pl}}$ is the sum of the incremental and the prior total equivalent plastic strain, $\bar{\varepsilon}_{\mathrm{i}}^{\mathrm{pl}}$, from the previous iteration of the finite element algorithm:

$$
\bar{\varepsilon}_{i+1}^{\mathrm{pl}}=\bar{\varepsilon}_{\mathrm{i}}^{\mathrm{pl}}+\Delta \bar{\varepsilon}^{\mathrm{pl}}
$$

In order to determine a solution to Equation 3.36, the Newton-Raphson method [25] is used to iterate towards the equivalent plastic strain increment, $\Delta \bar{\varepsilon}^{\mathrm{pl}}$, required to satisfy the above criterion. Providing that the initial solution is within the 'zone of attraction' of this numerical method and divergence does not occur, convergence to a solution is quadratic. The Newton-Raphson method is distinguished from other methods by the fact that it requires the evaluation of both the function $f(x)$, and the derivative $\mathrm{f}^{\prime}(\mathrm{x})$, at arbitrary points $\mathrm{x}$. For an efficient realization of Newton-Raphson, the user provides a routine that evaluates both $f(x)$ and its first derivative $f^{\prime}(x)$ at the point $x$. 


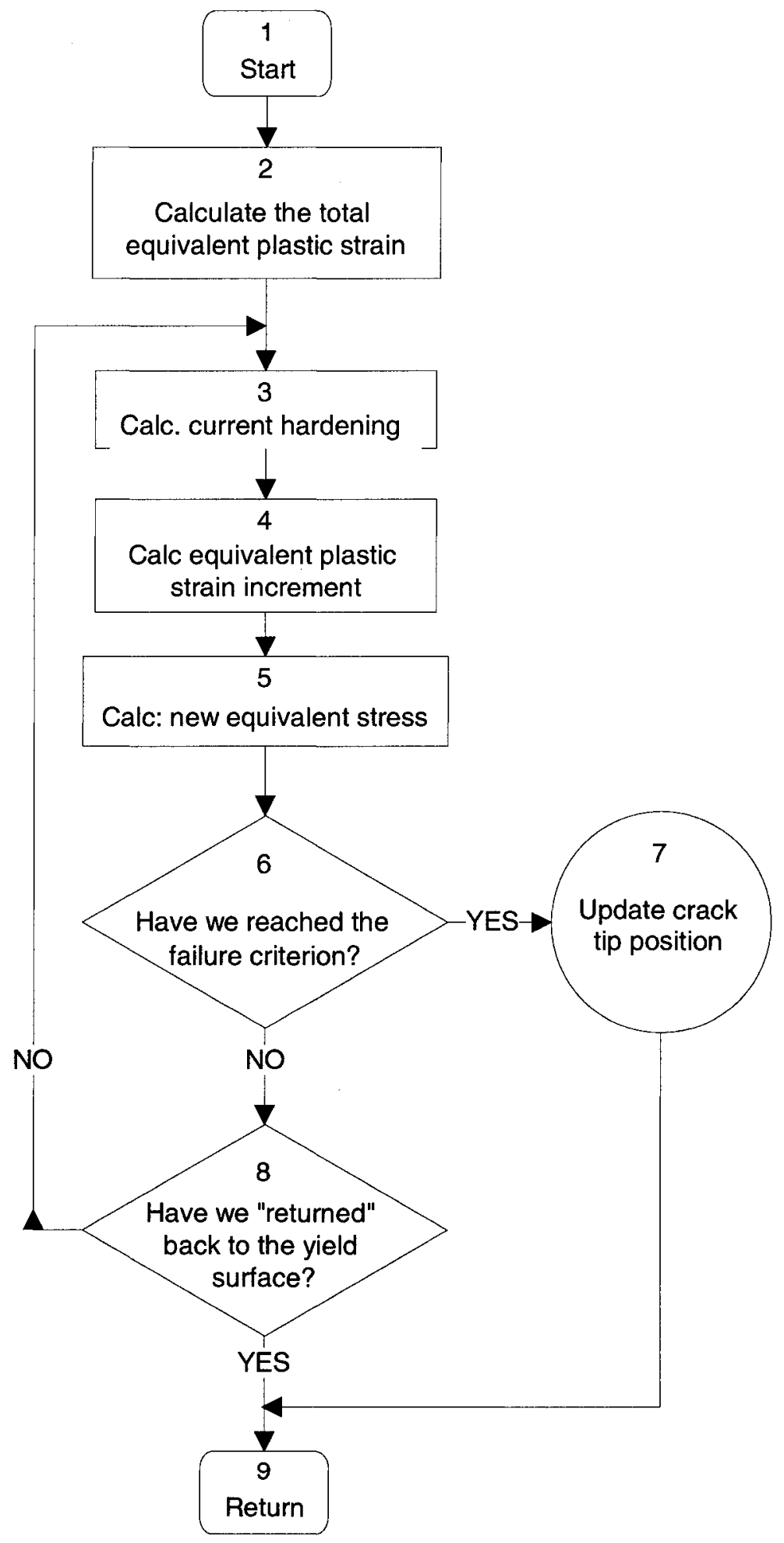

Figure 3.8: Flowchart of the algorithm for determining the equivalent plastic strain increment 
Thus, during each iteration the plastic strain increment, $\Delta \bar{\varepsilon}^{\mathrm{pl}}$, is adjusted using the following:

$$
\Delta \bar{\varepsilon}_{i+1}^{\mathrm{pl}}=\Delta \bar{\varepsilon}_{\mathrm{i}}^{\mathrm{pl}}+\frac{\mathrm{F}}{3 \mu+\Psi}
$$

where ' $\Psi$ ' is the work-hardening rate, which is given by the slope of the yield stress versus the equivalent plastic strain curve, that is

$$
\Psi=\frac{\mathrm{d} \sigma_{\mathrm{y}}}{\mathrm{d} \bar{\varepsilon}^{\mathrm{pl}}}
$$

The additional plastic strain increments and stress increments may be computed once the equivalent plastic strain is computed.

As is seen in the following equation, the sum of the incremental equivalent plastic strain, $\Delta \bar{\varepsilon}^{\mathrm{pl}}$, and the prior total equivalent plastic strain, $\bar{\varepsilon}_{\mathrm{i}}^{\mathrm{pl}}$, is compared with the failure criterion, which is based on a critical value of the equivalent plastic strain, $\bar{\varepsilon}_{\mathrm{cr}}^{\mathrm{pl}}$.

$$
\bar{\varepsilon}_{\mathrm{i}+1}^{\mathrm{pl}}=\left(\bar{\varepsilon}_{\mathrm{i}}^{\mathrm{pl}}+\Delta \bar{\varepsilon}^{\mathrm{pl}}\right) \geq \bar{\varepsilon}_{\mathrm{cr}}^{\mathrm{pl}}
$$

If the critical equivalent plastic strain has been attained or surpassed, then the algorithm for updating the crack-tip position is executed. It should be noted that the failure criterion can be modified and repositioned accordingly within the overall material response algorithm. 
After updating the plastic strain, a new value for the equivalent stress is calculated and this is subsequently used to calculate a new trial flow stress function, F, which is computed using Equation 3.35. If the trial flow stress function is sufficiently close to zero, the iteration process for determining the correct strain and stress increment is terminated. Otherwise, the process is repeated.

\subsubsection{Crack-Tip Position}

The crack-tip position, $\mathrm{x}_{\mathrm{CT}}$, is kept as a common variable between the model's algorithms. The algorithm utilized to update the crack-tip position is illustrated in the schematic diagram in Figure 3.9. The principal variables passed to this algorithm are axial locations of the current crack-tip position, $\mathrm{x}_{\mathrm{CT}}$, and the material point that has most recently failed, $\mathrm{x}_{\mathrm{mat}}$, as determined by Equation 3.17. At the start of the simulation, as is seen in items 2 and 3 in Figure 3.9, the crack-tip position is set to the beginning of the pipe.

$$
\mathrm{x}_{\mathrm{CT}}=0
$$

Because the principal coordinate of interest is the axial component, item 4 of Figure 3.9 implies that the axial location of the failed material point is compared with the current crack-tip axial location in order to determine if the crack-tip has advanced:

$$
\mathrm{X}_{\mathrm{mat}}>\mathrm{X}_{\mathrm{CT}}
$$

If the crack-tip has advanced, then the appropriate variables are updated. Otherwise, the subroutine is terminated. 


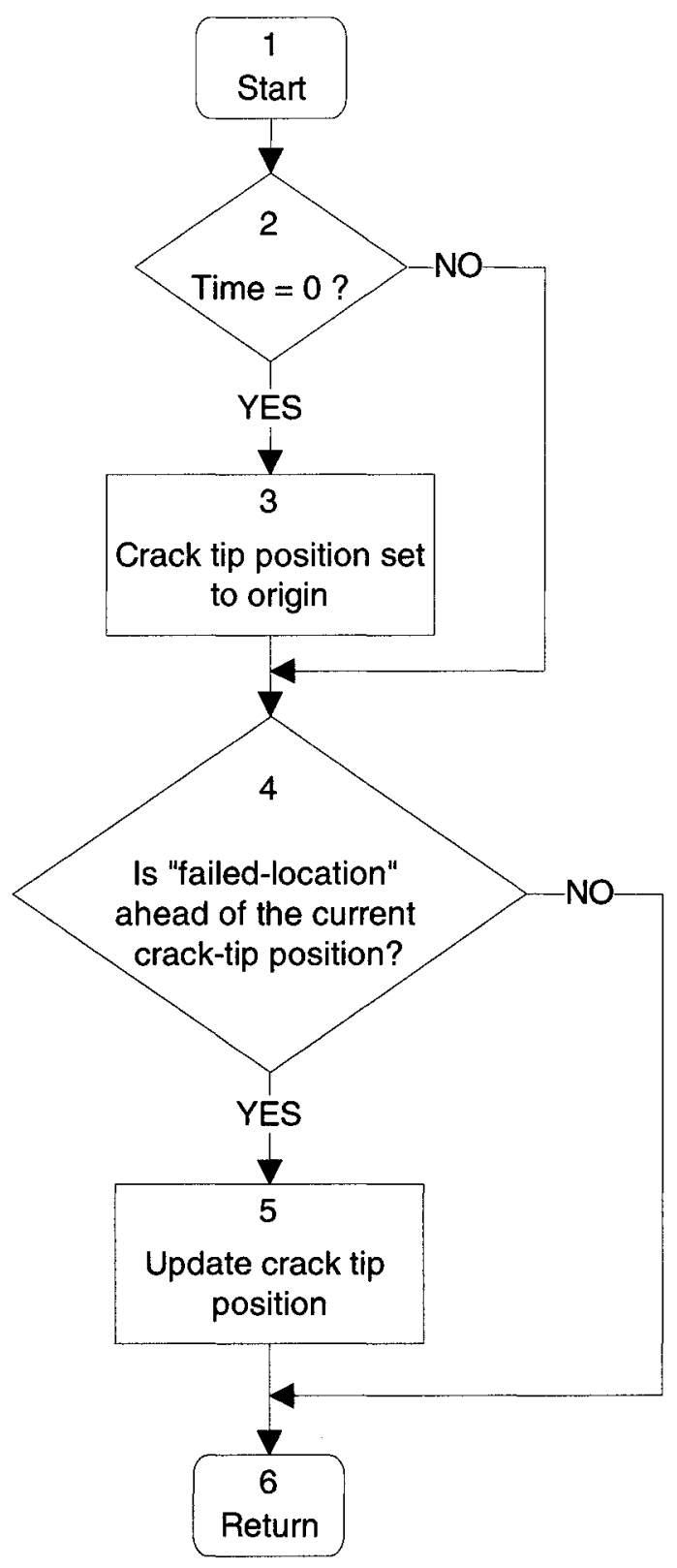

Figure 3.9: Flowchart of the algorithm for updating the crack-tip position 


\section{REFERENCES}

1. Rowe, G.W., Sturgess, C.E.N., Hartley, P., and Pillinger, I, Finite-Element Plasticity and Metalforming Analysis, Cambridge University Press, New York, 1991

2. Richmond, O. "Plastic Dilatancy in Metals", in Plasticity of Metals at Finite Strains : Theory, Experiment, and Computation : Proceedings of Research Workshop Held at Stanford University, July 29, 30, July 1, 1981, Eds. E.H. Lee and R.L. Mallett, Stanford, 1982

3. Van Stone, R.H., Cox, T.B., Low, J.R. Jr., and Psioda, P.A., "Microstructural Aspects of Fracture by Dimpled Rupture," International Metallurgical Reviews, Vol. 30, 1985, pp. 157-179

4. Rice, J.R. and Tracey, D.M., "On the Ductile Enlargement of Voids in Triaxial Stress Fields", Journal of the Mechanics \& Physics of Solids, Vol. 17, 1969, pp. 201-217

5. Gurson, A.L., "Continuum Theory of Ductile Rupture by Void Nucleation \& Growth: Part I - Yield Criteria and Flow Rules for Porous Ductile Media", Journal of Engineering Materials and Technology, Vol. 99, 1977, pp. 2-15

6. Tvergaard, V., "On Localization in Ductile Materials Containing Spherical Voids", International Journal of Fracture, Vol. 18, 1982, pp. 237-252

7. Hill, R., The Mathematical Theory of Plasticity, Oxford University Press, 1950

8. Drucker, D.C., Proceedings of the $1^{\text {st }}$ U.S. National Congress of Applied Mechanics, 1951, p. 487

9. Dieter, G.E., Mechanical Metallurgy $3^{\text {rd }}$ Edition, McGraw-Hill, 1986, p. 86

10. Backofen, W.A., Deformation Processing, Addison-Wesley, 1972, p. 39

11. Metal Inelasticity, Hibbitt, Karlsson, and Sorenson, USA, 1998

12. Lubliner, J., Plasticity Theory, Prentice Hall, 1998

13. Cockcroft, M.G. and Latham, D.J., Ductility and the Workability of Metals, Journal of the Institute of Metals, Vol. 96, Institute of Materials, 1968, pp. 33-39

14. Zienkiewicz, O.C. and Taylor, R.L., The Finite Element Method: Basic Formulation and Linear Problems, Vol. 1, McGraw-Hill, 1994

15. “Alembert, Jean Le Rond d', Encyclopedia Britannica, 1999

16. Simo, J.C., Taylor, R.L., "A Return Mapping Algorithm for Plane Stress Elastoplasticity", International Journal for Numerical Methods in Engineering, Vol. 22, no. 3, John Wiley \& Sons, March 1986, pp. 649-670

17. Dodds, R., "Numerical Techniques for Plasticity Computations in Finite Element Analysis, Computers and Structures", Vol. 26, no. 5, Pergammon Press, 1987, pp. 767-779 
18. Keppel, S.W. and Dodds, R.H., "Improved Numerical Techniques for Plasticity Computations in Finite-Element Analysis, Computers and Structures", Vol. 36, No. 1, Pergammon Press, 1990, pp.183-185

19. Key, S.W. and Krieg, R.D., "On the Numerical Implementation of Inelastic TimeDependent and Time-Indepenedent, Finite Strain Constitutive Equations in Structural Mechanics", Computer Methods in Applied Mechanics and Engineering, Vol. 33, North-Holland, 1982, pp.439-452

20. Krieg, R.D. and Key, S.W., "Implementation of a Time-Independent Plasticity Theory into Structural Computer Programs", Constitutive Equations in ViscoPlasticity: Computational and Engineering Aspects, AMD-20, ASME, 1976, pp.125-138

21. Press, W.H., Teukolsky, S.A., Vetterling, W.T. and Flannery, B.P., Numerical Recipes in C: The Art of Scientific Computing, Second Edition, Cambridge University Press, 1992, pp. 354-357

22. Lee, S.W., Yoon, J.W., Yang, D.Y.; A Stress Integration Algorithm for Plane Stress Elastoplasticity and its Applications to Explicit Finite Element Analysis of Sheet Metal Forming Processes, Computers and Structures, Vol. 66, no. 2-3, Elsevier Science, 1998, pp.301-311

23. Zienkiewicz, O.C. and Taylor, R.L., The Finite Element Method: Solid and Fluid Mechanics, Dynamics and Nonlinearity, Vol. 2, $4^{\text {th }}$ Edition, McGraw-Hill, 1991, pp. 214-216

24. Writing UMATs, VUMATs, and UELs, Hibbitt, Karlsson, and Sorenson, USA, March 1997, p. L1.69

25. Press, W.H., Teukolsky, S.A., Vetterling, W.T. and Flannery, B.P., Numerical Recipes in C: The Art of Scientific Computing, Second Edition, Cambridge University Press, 1996, pp. 362-367 


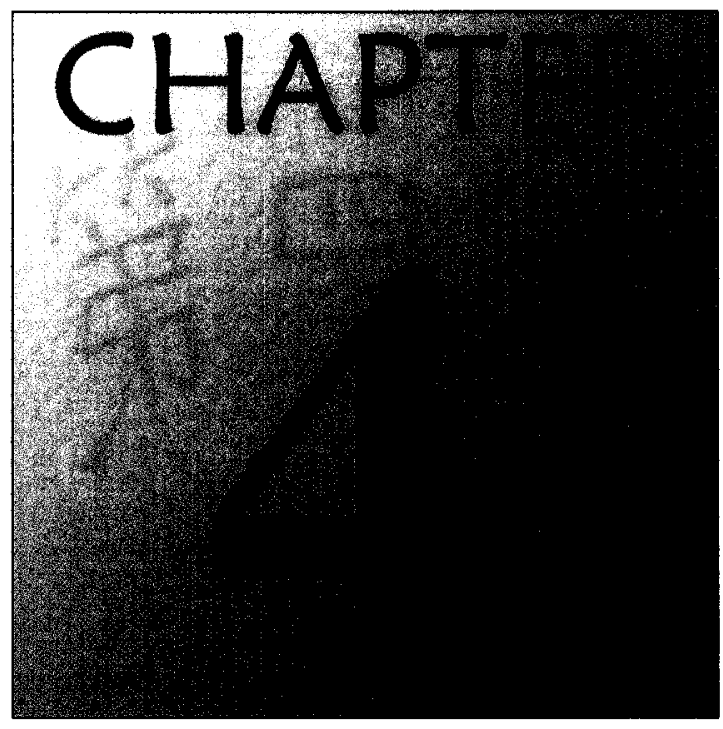

\section{Parameter Determination}

\subsection{Introduction}

The literature review presented in chapter two described the theoretical concepts utilized to study the dynamic ductile fracture propagation resistance behaviour of modern linepipe. However, in order to undertake an examination of such a complicated phenomenon, it is necessary to calibrate some of the parameters used in the material response algorithm, and to investigate some of the components of the study separately. A series of virtual laboratory tests, including ambient temperature axisymmetric tensile and Charpy V-notch tests were performed to determine the model parameters and a test based on the hydraulic-bulge test was also performed to assist in the model development.

The procedures and materials used for these various experiments are described in this chapter. This chapter will examine the calibration and verification of the materialresponse algorithm using the tensile and Charpy tests, respectively. The tensile test 
simulations are utilized to determine the failure parameter necessary to duplicate the percent elongation values from the laboratory tests, while the goal of the Charpy impact test simulations was to replicate the laboratory test results using the failure parameter determined from the tensile test simulations. Both sets of laboratory test data were obtained either from the literature, or were from virtual materials. An investigation of the effect of the material model failure parameter on the ductility of a tensile test is examined first. The subsequent section explores the Charpy simulation and its sensitivity to the various plastic flow variables.

\subsection{Virtual Tensile Test}

The ductile tearing process accompanying ductile crack extension is similar to the failure process occurring in thinner materials during sheet-metal stretch-forming operations [1]. For these applications the strain distribution and the events leading to instability and fracture are often correlated with tension test parameters such as uniform elongation and reduction of area, which are affected by the metallurgical properties of the material. It is believed that such data should allow one to better characterize the plastic deformation behaviour of different linepipe steels. The objective of the virtual tensile test was to determine the correct failure parameter to use in the material response algorithm in order to match the percent elongation from the actual laboratory tests.

\subsubsection{Virtual Specimen}

In this work only one type of tensile specimen was used for the simulations, which was constructed according to specifications that are designated in the ASTM standard [2]. The standard axisymmetric test specimen is illustrated in Figure 4.1. The shape of the ends of the specimen outside of the gauge length was unimportant for the virtual tests because only the behaviour of the gauge length was simulated. For any specimen built using this standard, it is important that the gauge length, $G$, used for elongation be four times the diameter, $\mathrm{D}$, of the specimen. The virtual specimen had a diameter of $12.5 \mathrm{~mm}$ 
and a gauge length of $50.0 \mathrm{~mm}$. Axisymmetric elements were utilized to construct the specimen, and due to symmetry conditions, only one quarter of the gage length was simulated, as depicted in Figure 4.2.

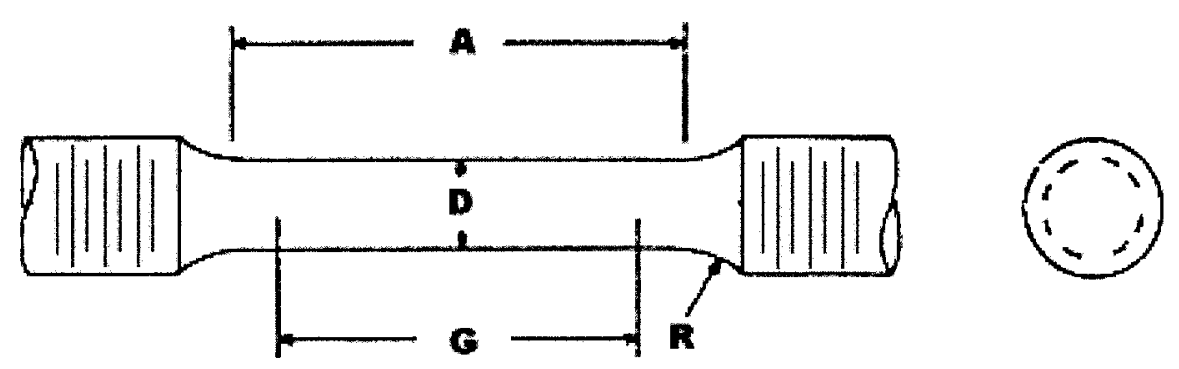

Figure 4.1: Schematic diagram of a standard round tension test specimen [2]

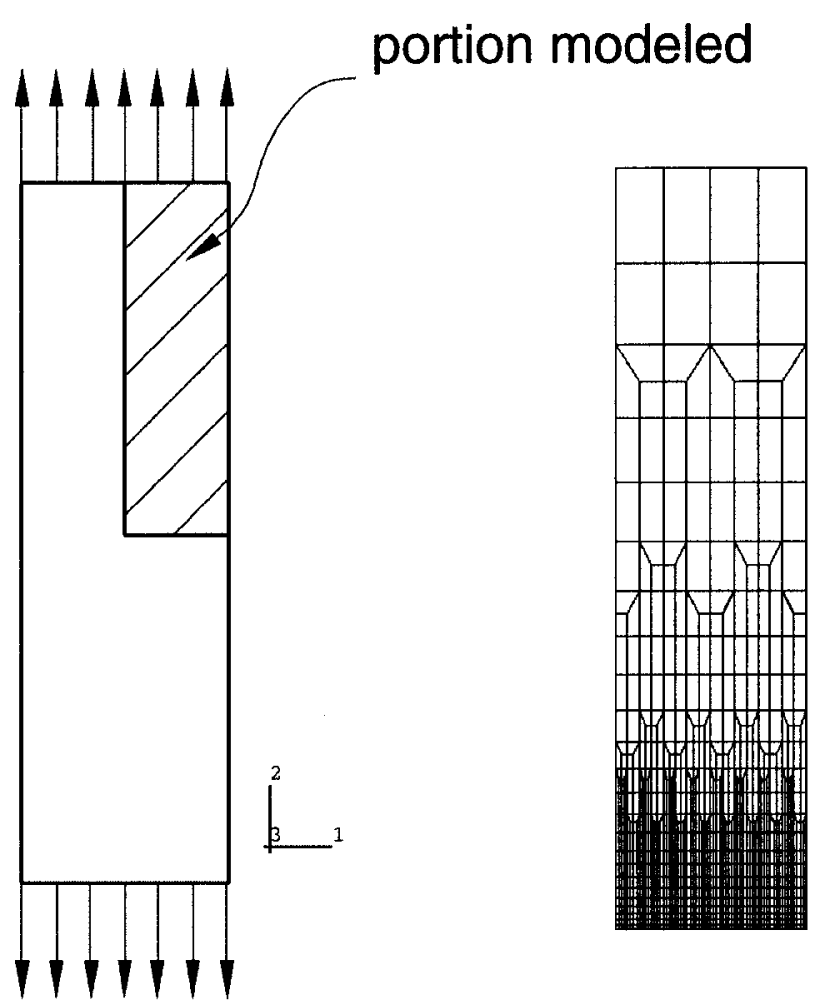

Figure 4.2: Depiction of the portion of the specimen modelled and a sample mesh [3] 


\subsubsection{Virtual Materials}

The materials examined consisted of API X70 grade linepipe steel with mechanical properties illustrated in Table 4.1. In addition to the properties presented in Table 4.1, which were modeled after some of the steels used for the tests in Kamaishi, Japan by the Iron and Steel Institute of Japan [4], the steels were assumed to have a density of 7800 $\mathrm{kg} / \mathrm{m}^{3}$, Poisson's ratio of 0.3 , and elastic modulus of $209 \mathrm{GPa}$.

The first four steels in Table 4.1 were quench and tempered, thus they had a microstructure of tempered martensite, whereas the remaining three steels were controlled-rolled and had a ferrite-pearlite microstructure. An inferred value of the strain-hardening exponent, $\mathrm{n}$, was derived from the reported yield strength and ultimate tensile strength of the steels using the method proposed by Holmes et al. [5].

Table 4.1: Mechanical properties of some of the steels used to calibrate the model [4]

\begin{tabular}{|c|c|c|c|c|c|}
\hline $\begin{array}{c}\text { Steel } \\
\#\end{array}$ & $\begin{array}{c}\text { Yield } \\
M P a\end{array}$ & $\begin{array}{c}\text { UTS } \\
M P a\end{array}$ & $\begin{array}{c}\text { Elongation } \\
\text { strain at UTS }\end{array}$ & $\begin{array}{c}\text { \%Strain at } \\
\text { Failure }\end{array}$ & $\begin{array}{c}\text { CVN } \\
\text { Full Size } \\
(\mathcal{J})\end{array}$ \\
\hline 1 & 545 & 649 & 0.073 & $19.8 \%$ & 45 \\
2 & 500 & 618 & 0.082 & $21.8 \%$ & 108 \\
3 & 490 & 612 & 0.085 & $23.2 \%$ & 169 \\
4 & 486 & 601 & 0.082 & $25.9 \%$ & 275 \\
5 & 505 & 656 & 0.094 & $21.7 \%$ & 119 \\
6 & 510 & 663 & 0.094 & $22.1 \%$ & 139 \\
7 & 497 & 602 & 0.077 & $25.7 \%$ & 196 \\
\hline
\end{tabular}

\subsubsection{Virtual Testing Procedure}

At the start of the experiment, the crosshead velocity was instantaneously set to the desired value, which maintained a constant rate of displacement. Maintaining a constant strain rate was not considered since the material models used were insensitive to strain- 
rate at the rates considered. Otherwise, the crosshead velocity would have required adjustment during testing in order to maintain a constant strain-rate. Additionally, the variables of interest were tabulated after each iteration. The specimens were deformed until failure.

As shown in Figure 4.3, the bottom and one side of the gauge length were fixed during each test simulation because only one quarter of the gauge-length was modelled due to symmetry conditions. The rigid crosshead was then displaced vertically instantaneously at a constant velocity for the duration of the simulation time.

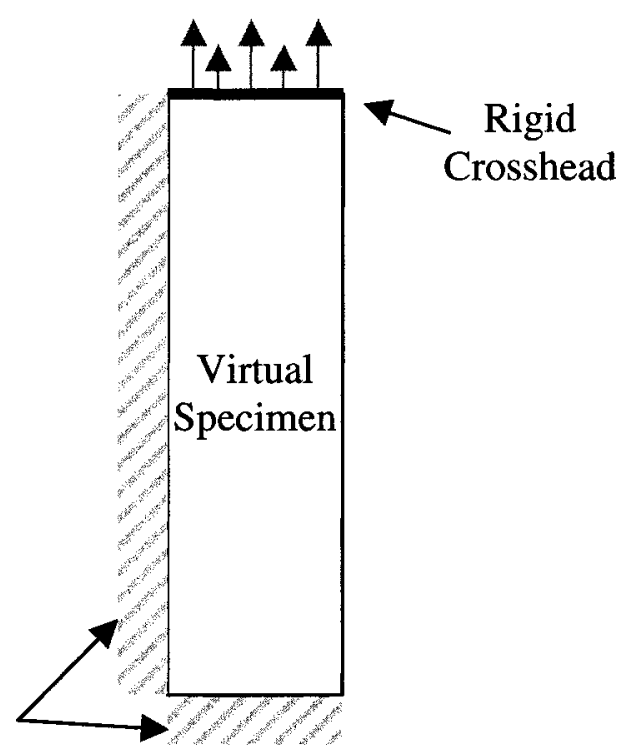

Figure 4.3: Schematic diagram of the virtual tensile test experimental set-up

\subsubsection{Strain Rates}

Unless stated otherwise, strain rates are given in the following in von Mises equivalent terms. The strain rate in shear strain terms can be obtained by multiplying by $\sqrt{3}$. For most virtual tests, an initial single von Mises equivalent strain rate of $16 \mathrm{~s}^{-1}$ was used. This choice was largely one of convenience since virtual testing at higher strain 
rates resulted in slight oscillations in some of the stresses, while testing at slower strain rates took an unreasonably long time to attain large strains, i.e., from several days to a week. Note that for the types of material tested, no strain-rate sensitivity was expected at rates below $1000 \mathrm{~s}^{-1}[4]$.

\subsubsection{Tensile Test Calibration}

For some of the steels used in the full-scale crack arrest test data examined in the literature, the data available were the initial yield stress, the ultimate tensile stress (UTS), the percent elongation at the UTS, the percent elongation at failure from tensile testing, and the Charpy V-notch energy. The calibration of the material algorithm involved determining the correct value of the failure parameter by attempting to match the percent elongation at failure values. It should be noted that the failure parameter, which is a value of equivalent plastic strain, represents the value of true strain that an element of material reaches at failure.

For the finite element tensile test simulations used for these data, the flow stress curve from the onset of yielding was simulated using the following equation:

$$
\sigma_{\mathrm{y}}\left(\bar{\varepsilon}^{\mathrm{pl}}\right)=\mathrm{A}+\mathrm{B}\left(\bar{\varepsilon}^{\mathrm{pl}}\right)^{\mathrm{n}}
$$

where $\bar{\varepsilon}^{\mathrm{pl}}$ is the equivalent plastic strain, 'n' is the strain hardening coefficient, and $\mathrm{A}$ and $B$ are material constants. The strain-hardening coefficient was set equal to the true strain at the ultimate tensile strength [6], as obtained from the elongation at the UTS.

For each steel the failure parameter in the material-response algorithm was varied from 0.80 to 1.55 . The corresponding percent elongations versus the failure parameters used for the simulations are shown in Figure 4.4. The failure parameter represents the 
equivalent plastic strain a material undergoes before fracture. This strain is evidently influenced by many factors, such as variations in the particles present to nucleate voids or of the cohesive strength between particles and the matrix. From this graph, the failure parameters chosen in order to match the percent elongation for the steels in Table 4-1 are shown in Table 4-2. The values were either chosen directly from the graph in Figure 4.4 or from a trend line based on the data points.

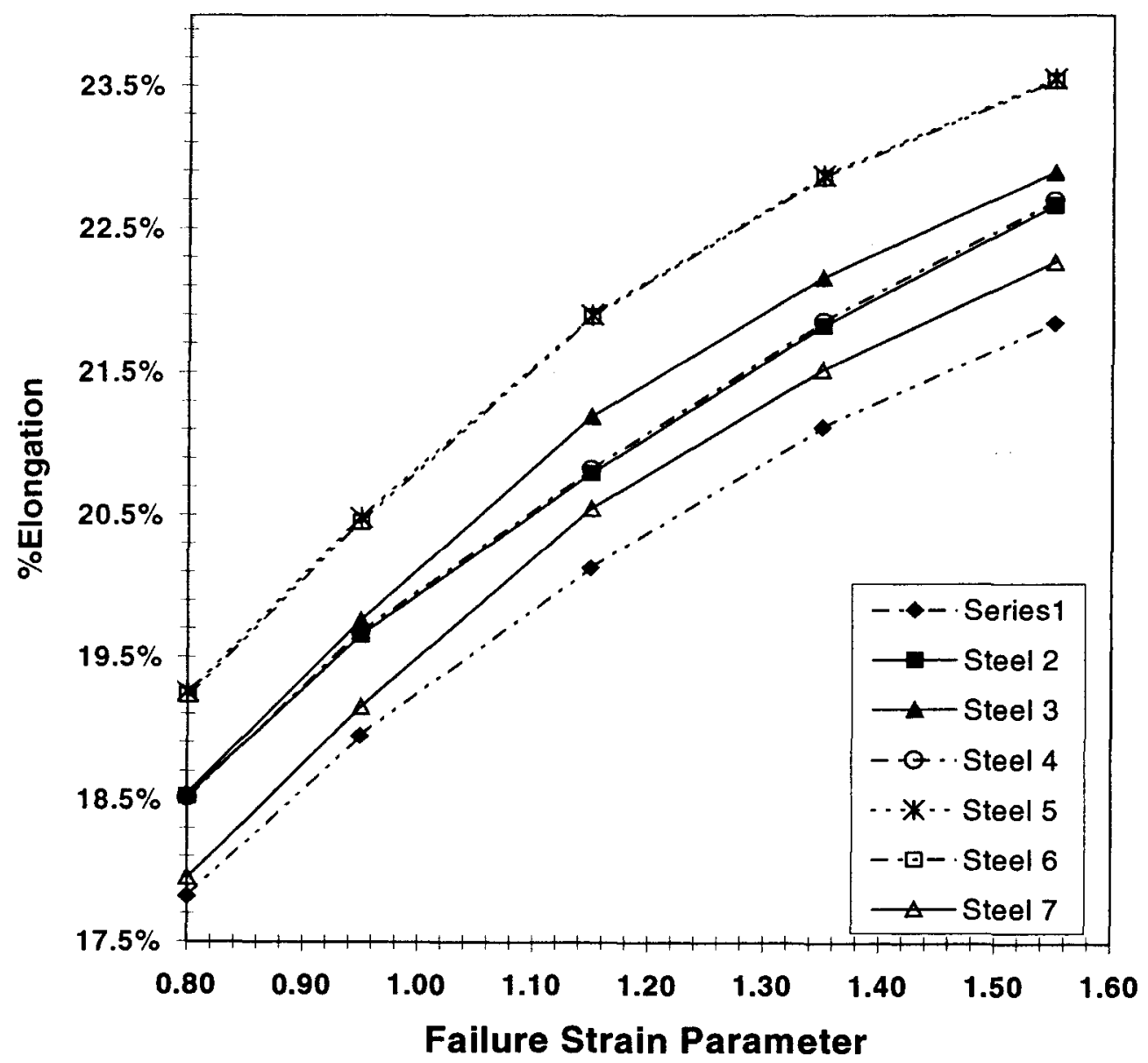

Figure 4.4: Graph of the \%elongation as a function of the material algorithm failure parameter 
Table 4.2: Material model failure parameters selected from the simulations

\begin{tabular}{|ccc|}
\hline Test & $\begin{array}{c}\text { \%Elongation } \\
\text { at Failure }\end{array}$ & $\bar{\varepsilon}_{\mathrm{f}}^{\mathrm{pl}}$ \\
\hline $\mathbf{1}$ & $17.3 \%$ & 0.78 \\
$\mathbf{2}$ & $21.8 \%$ & 1.35 \\
$\mathbf{3}$ & $23.2 \%$ & 1.64 \\
$\mathbf{4}$ & $25.9 \%$ & 2.56 \\
$\mathbf{5}$ & $21.7 \%$ & 1.12 \\
$\mathbf{6}$ & $22.1 \%$ & 1.19 \\
$\mathbf{7}$ & $25.7 \%$ & 2.50 \\
\hline
\end{tabular}

\subsection{Virtual Charpy V-Notch Test}

Although the Charpy V-Notch $(C V N)$ test has been widely accepted as a laboratory test that can be used as a tool to measure the ductile fracture resistance of linepipe material, it suffers from severe limitations in that the mode and extent of deformation, stress state and strain rate in the CVN test are significantly different from those of the ductile fracture process in the linepipe [4]. The CVN tests were performed in this case in order to attempt to further validate the material model parameters, especially the failure parameter, obtained from the virtual tensile tests.

\subsubsection{Virtual Specimen}

In this work, a Charpy specimen used for the simulations was constructed according to specifications that are designated in the ASTM standard [7]. Illustrated in Figure 4.5 is the standard, full-sized Type A test specimen. Due to symmetry conditions, only one quarter of the gauge length was simulated, as depicted by the schematic diagram of the meshed workpiece in Figure 4.6: 

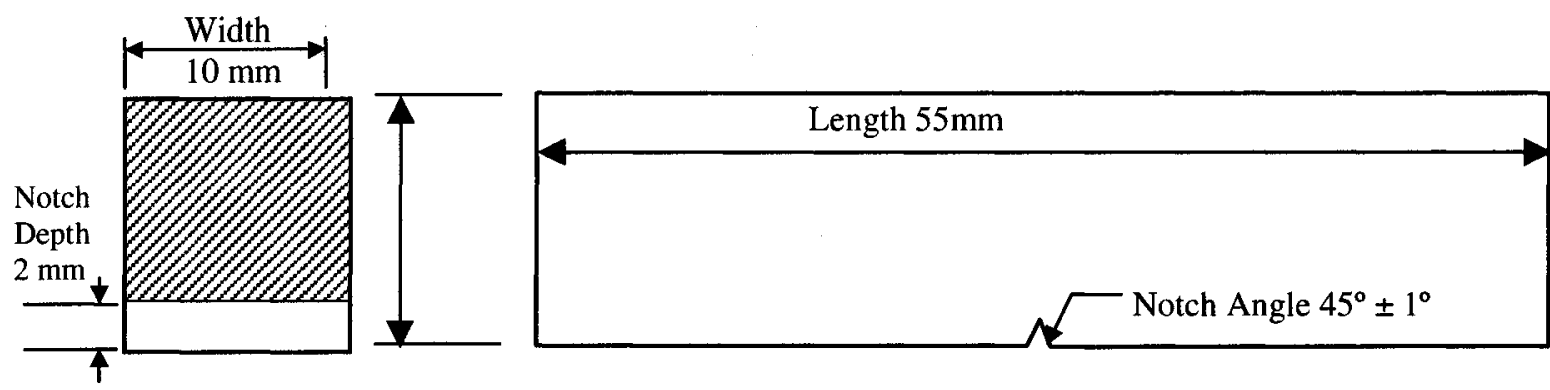

Figure 4.5: Schematic diagram of a type A Charpy V-Notch test specimen [7]

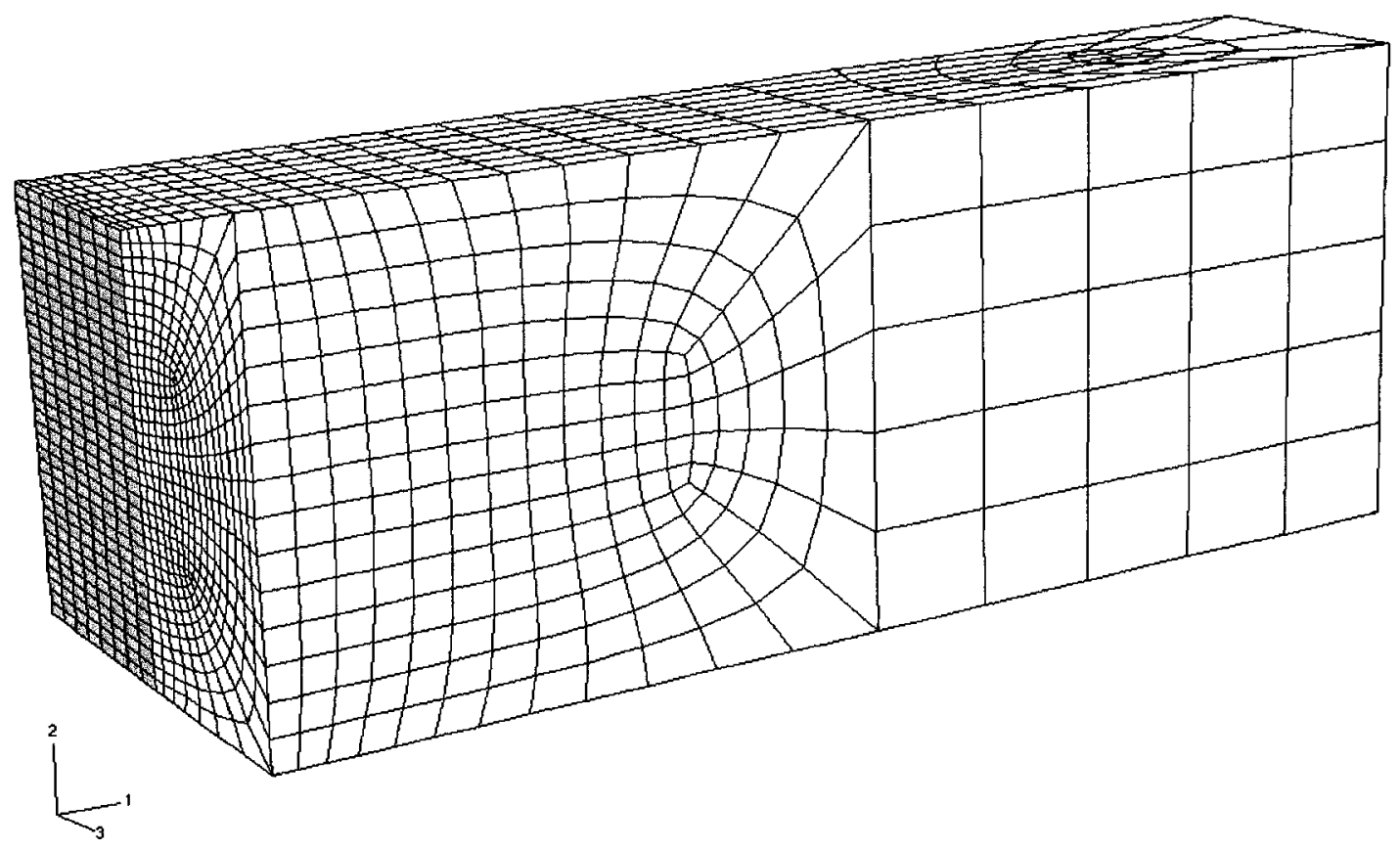

Figure 4.6: Depiction of a sample undeformed mesh for the Charpy specimen

\subsubsection{Virtual Testing Procedure}

The anvil, which is utilized to support the specimen, and the striking edge were also included as part of the simulation. As stated in the standard test procedure, the tangential velocity (the impact velocity) of the pendulum at the center of the strike was chosen to be between $3 \mathrm{~m} / \mathrm{s}$ and $6 \mathrm{~m} / \mathrm{s}$. Therefore, the velocity was always set to the higher-limiting velocity in order to hasten the simulation time. 
After the completion of a test, the integral of the force-displacement graph was obtained, which was also multiplied by a factor of four in order to account for the fourfold symmetry. It was used to obtain the energy absorbed by the specimen in order to fracture it, as given by the following:

$$
\mathrm{E}_{\mathrm{CVN}}=4 \times \int \text { Force } \cdot \mathrm{du}
$$

where $E_{C V N}$ is the energy required to fracture the CVN specimen and ' $u$ ' is the displacement.

\subsubsection{Charpy V-Notch Test Verification}

At the outset, the goal of simulating the Charpy V-notch impact test, of which an example of an undeformed mesh is shown in Figure 4.6, was to verify the materialresponse algorithm. The parameters used for the algorithm were the same as those utilized for the tensile test simulations. Figure 4.7 shows equivalent plastic strain contours resulting from the simulation for steel 2. Initially, the model is seen to reproduce the essential features as seen in Charpy tests performed on ductile material.

Quantitatively, the force versus displacement graph for steel 2 is displayed in Figure 4.8. Unfortunately, there were no equivalent plots of force versus displacement available from the actual laboratory tests performed because these were not instrumented Charpy testing machines. The integral of this plot produces the graph shown in Figure 4.9 , and it can be seen that the Charpy energy is predicted to be 144 Joules, which is an overprediction of $33 \%$. A comparison of the predicted Charpy energy values from the finite element simulations and the laboratory measurements is shown in Table 4.3, as well as graphically in Figure 4.10. It can be seen from Figure 4.10 that the predictions are always greater than the measurements, and these overpredictions range between $29 \%$ and $49 \%$, as is seen in Table 4.3 . 


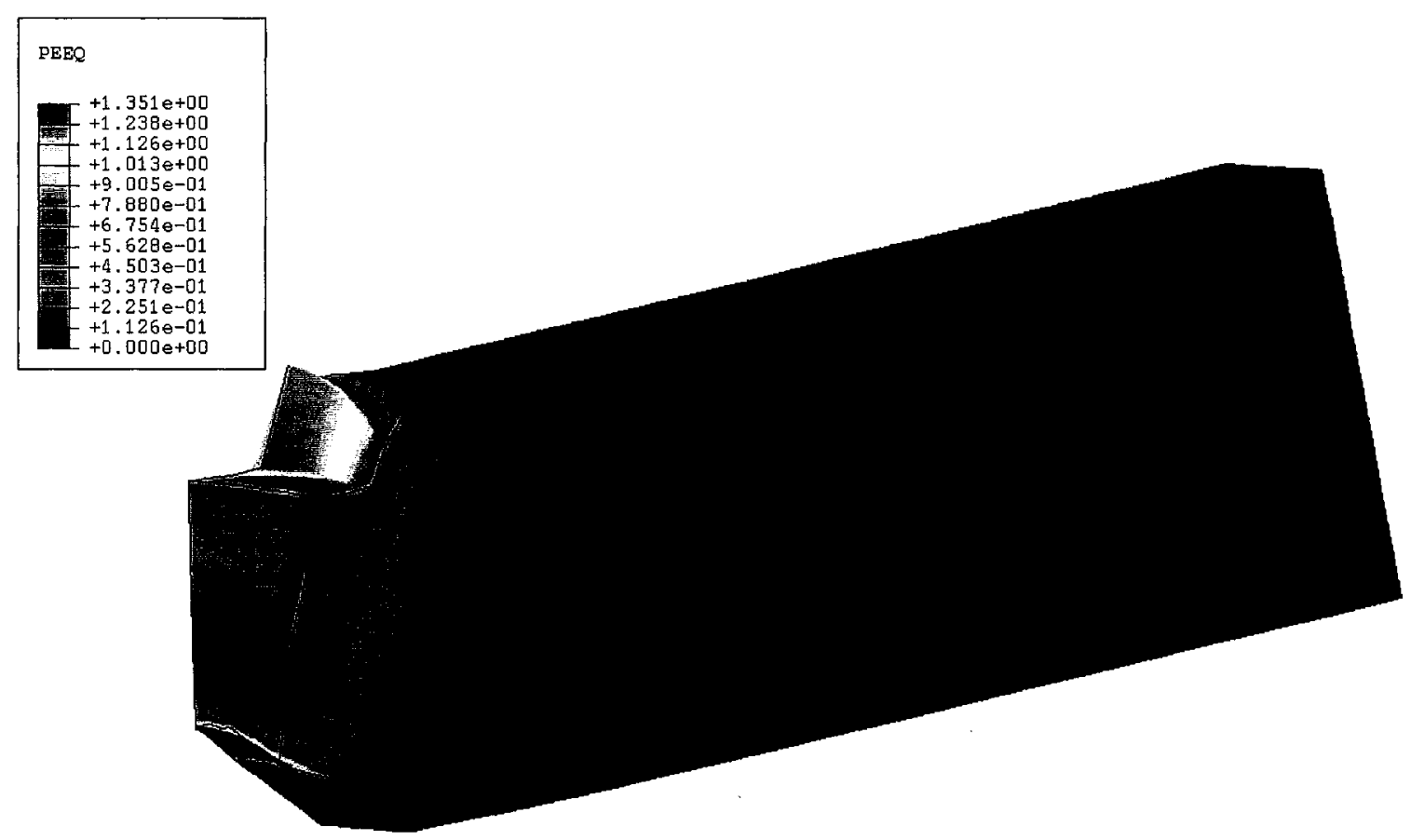

Figure 4.7: Equivalent plastic strain contours for the Charpy test simulation of Steel 2

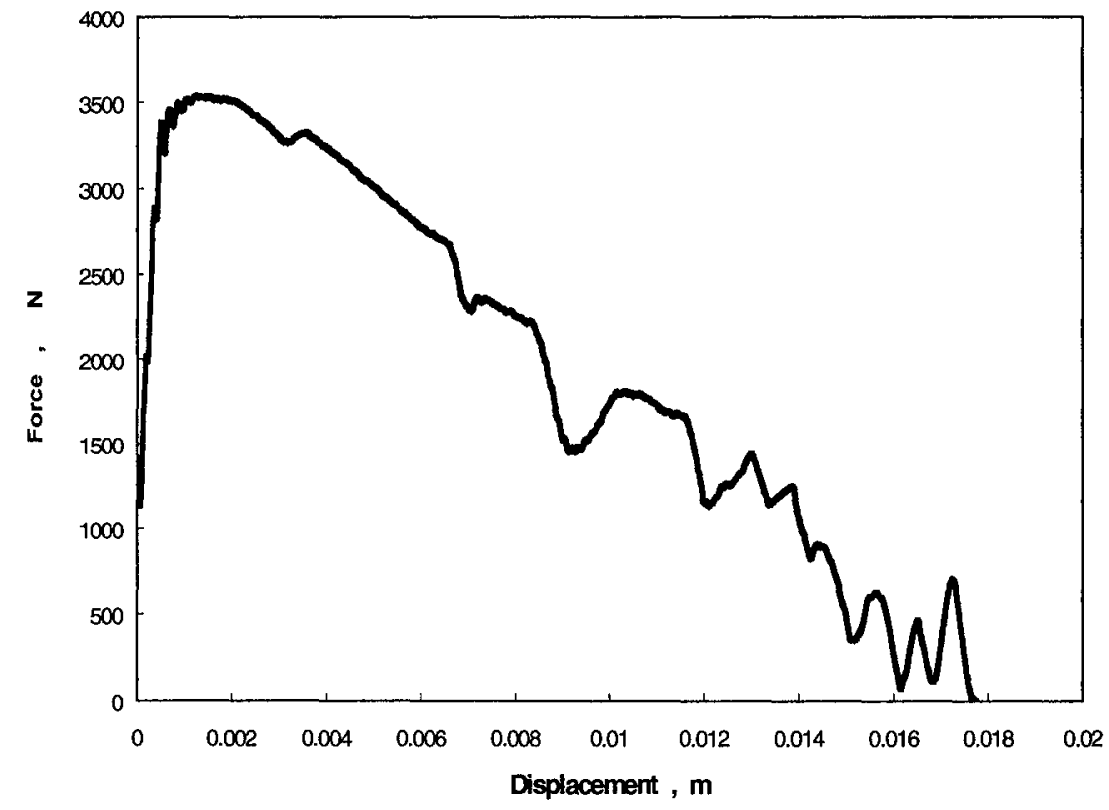

Figure 4.8: Force versus displacement graph for the Charpy test finite element simulation of steel 2 from Table 4.1 


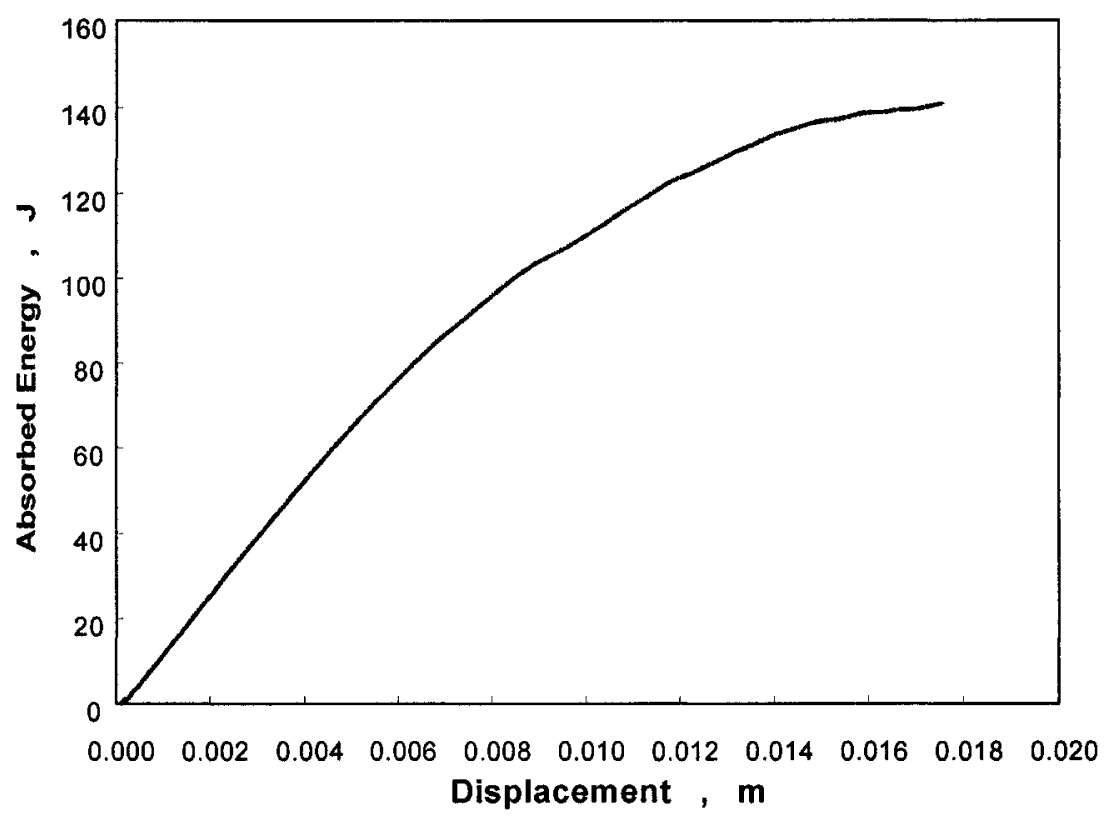

Figure 4.9: Graph of absorbed energy $(\mathrm{J})$ versus displacement for the Charpy test finite element simulation of steel 2 from Table 4.1

Table 4.3: Table of the measured Charpy energy values versus the predicted values from the finite element simulations

\begin{tabular}{|cccc|}
\hline Steel & $\begin{array}{c}\text { CVN measured } \\
(\mathrm{J})\end{array}$ & $\begin{array}{c}\text { CVN Predicted } \\
(\mathrm{J})\end{array}$ & \% Difference \\
\hline 1 & 45 & 58 & 29.1 \\
2 & 108 & 144 & 33.3 \\
3 & 169 & 251 & 48.5 \\
4 & 275 & 355 & 29.1 \\
5 & 119 & 165 & 38.7 \\
6 & 139 & 192 & 38.1 \\
7 & 196 & 280 & 42.9 \\
\hline
\end{tabular}




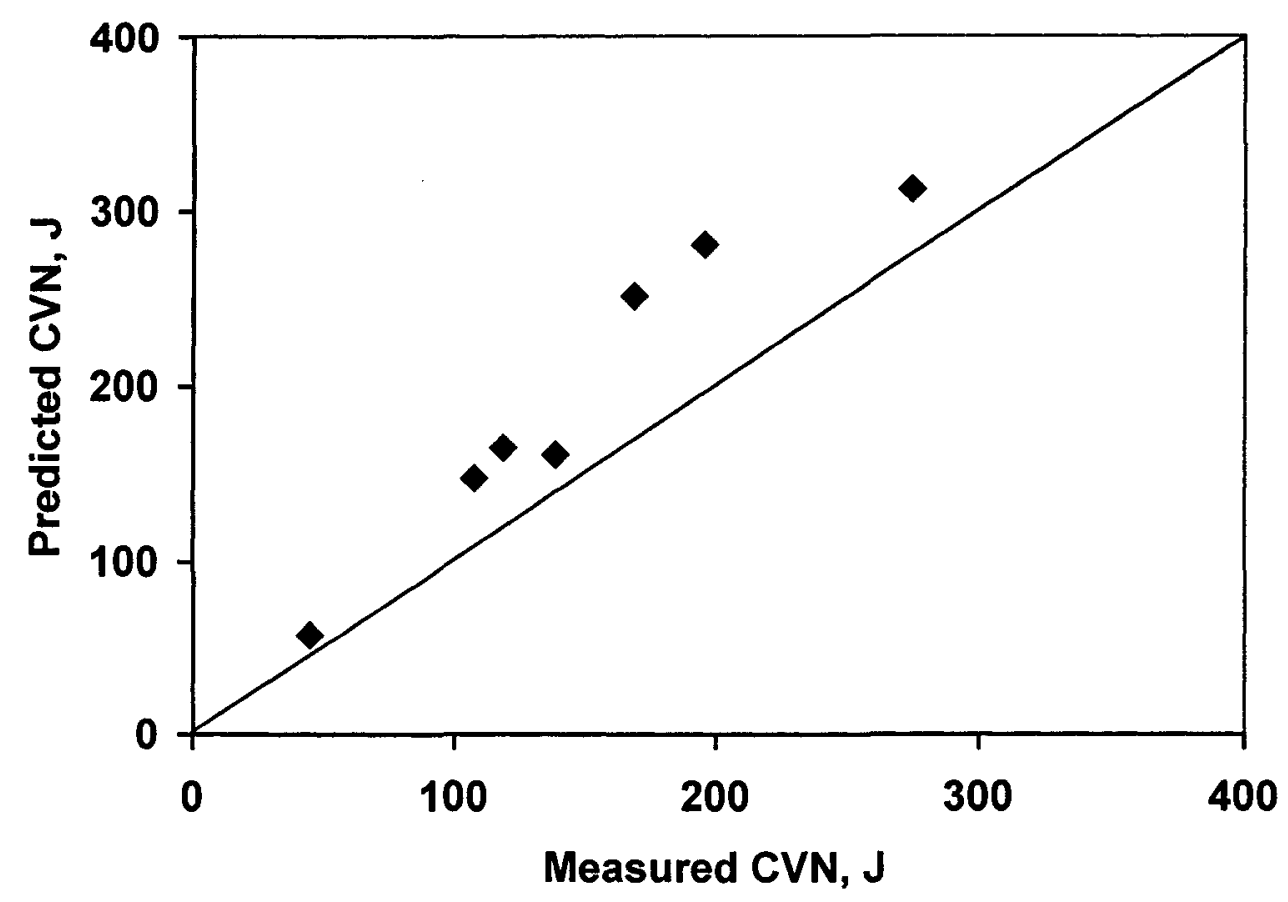

Figure 4.10: Graph of the predicted versus measured CVN values for some of the steels from Table 4.1

A possible explanation for the divergence between the predictions and the measurements is due to the use of a single strain parameter, which was based on the tensile test simulations, for each Charpy test simulation. For each steel examined, closer results may have been predicted for the Charpy test simulations if the failure strain parameter was not fixed, but set as a function of the state of stress, or that was sensitive to the triaxiality [8 - 12], similar to:

$$
\bar{\varepsilon}_{\mathrm{f}}^{\mathrm{pl}}=\mathrm{d}_{1}+\mathrm{d}_{2}\left(\frac{\mathrm{p}}{\bar{\sigma}}\right)
$$

where ' $p$ ' is the hydrostatic pressure, $\bar{\sigma}$ is the equivalent stress, and $d_{1}$ and $d_{2}$ are constants. Examination of this hypothesis could also be the subject of future work. 


\subsection{Virtual Hydraulic-Bulge Test}

A test that simulates biaxial-stretch-type deformation was constructed based on similar existing methods [13 - 16] whereby a sheet-specimen is deformed. The hydraulic-bulge test was chosen as the foundation because it determines the properties of sheet metals in biaxial stretching without involving surface friction effects. Additionally, the specimen is deformed into a dome, which involves out-of-plane stresses and strains [15]. This test was utilized to investigate the effect of various mesh architectures on the distribution of variables; such as stress and strain. Stretching is a very common mode of deformation in metal stamping, and stretchability is influenced by numerous factors that control the uniformity of deformation. The simulation was performed using constant hydraulic pressure on one side of the specimen and the periphery was fixed.

In addition to the current purpose for the use of this test, the hydraulic bulge test also has the following applications, which may be useful for characterizing the state of the material during dynamic ductile fracture:

1. Intrinsic material characterization in biaxial stretching

2. Testing to much higher strain levels than those achievable in tensile testing, particularly for heavily cold-worked material, and

3. Checking the validity of plasticity theories that attempt to predict the yielding behaviour of metals in all stress states from properties measured in uniaxial and plane-strain testing.

\subsubsection{Virtual Specimen and Materials}

As is illustrated in Figure 4.11, the specimen utilized for this test had dimensions of $1.30 \times 2.00$ meters and a thickness of 0.015 meters. Since the primary focus of this study was the effect of the mesh distribution on the deformation, the material properties were constant for all specimens. The material properties were set to match a typical API X65 
grade linepipe steel, with an elastic modulus of $209 \mathrm{GPa}$, a Poissons ratio of 0.3 , a yield strength of $450 \mathrm{MPa}$, and the flow stress evolution following a power-law-type behaviour. Additionally, there were no failure criteria present, thus avoiding any effect of fracturing and stress-concentrations on the variables of interest.

Although the periphery of a sheet metal sample is clamped between circular or elliptical die rings in a hydraulic bulge test, this test was performed by clamping the edges of the sheet.

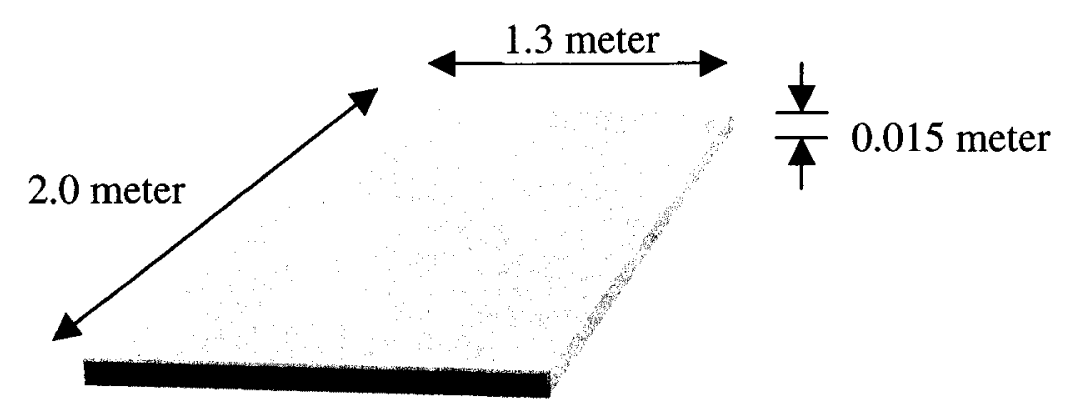

Figure 4.11: Schematic diagram of the specimen used in the hydraulic bulge test

\subsubsection{Virtual Testing Procedure}

The variables of interest were primarily the strain distribution, the maximum height of the sheet after each test, and the shape of the bulge. The initial pressure was instantaneously set to $6.0 \mathrm{MPa}$ for a total time of 0.05 seconds for test set 1 and test set 2, while the pressure was set to $7.5 \mathrm{MPa}$ for 0.01 seconds for the test set 3 . Each set of tests was performed at constant pressure during the length of the virtual experiment.

\subsubsection{Mesh Design}

Shell elements were utilized to study the effect of different meshes, particularly the use of transitions, i.e. linking a finer-mesh region with a coarser-mesh region with the use 
of non-rectangular polygons, in order to determine whether this would affect the state of stress and strain during loading as experienced from hydraulic-bulge testing.

Three sets of tests were performed and the different meshes used are illustrated in Figures 4.12 to 4.14 . Although all the sets looked at the effect of a generally coarser mesh, they also examined other effects. The first set, which is shown in Figure 4.12, was also used to examine the effect of transitioning unidirectionally from a fine mesh to a relatively coarser mesh, as is illustrated in mesh ' $b$ ' and ' $c$ '. The $2^{\text {nd }}$ and $3^{\text {rd }}$ sets were also used to look at the effect of using transition elements, as is shown in Figure 4.13b and Figure 4.14a, 4.14c and 4.14d.

Theoretically, the finer the mesh, the closer the stress and strain state should approximate an analytical solution or at least asymptotically approach a solution. Thus, an approximate solution of the stress and strain state should be observed in the mesh designs illustrated in Figures 4.12d, 4.13c and 4.14e. Equivalent plastic strain contour plots for the 3 different test sets are shown in Figures 4.15 to 4.17.

a)

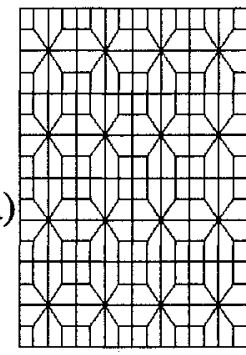

b)

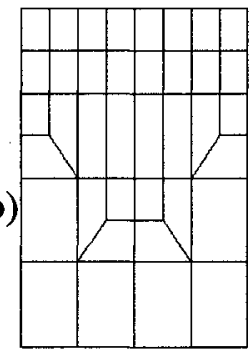

c)

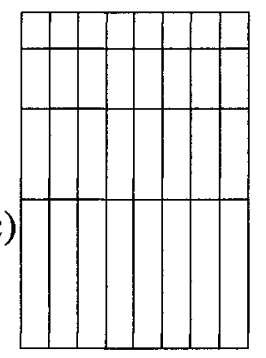

d)

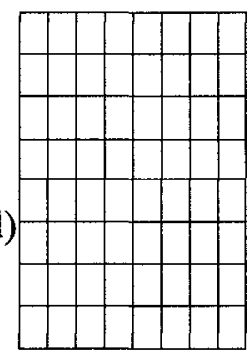

Figure 4.12: The various mesh designs used for bulge test set 1 
a)

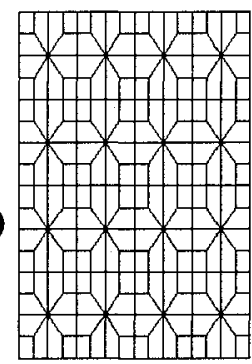

b)

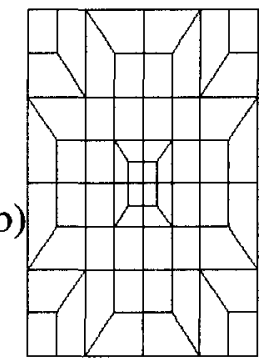

c)

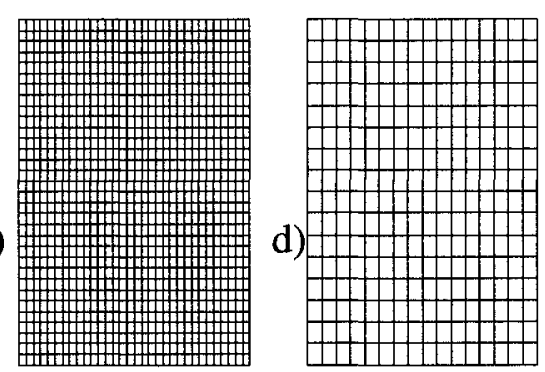

Figure 4.13: The various mesh designs used for bulge test set 2

a)

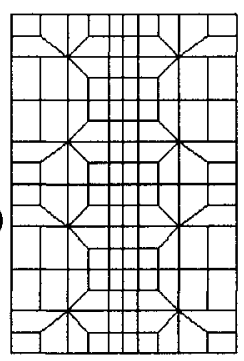

d)

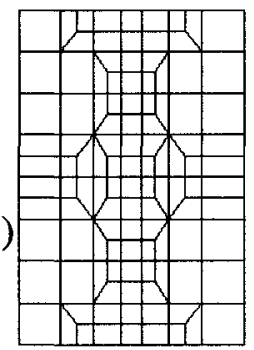

b)

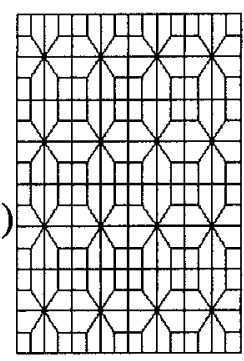

e)

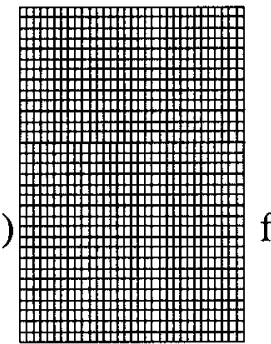

c)

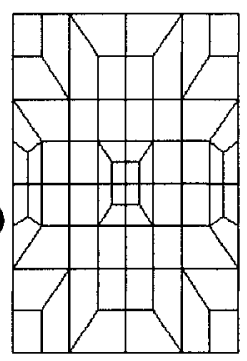

f)

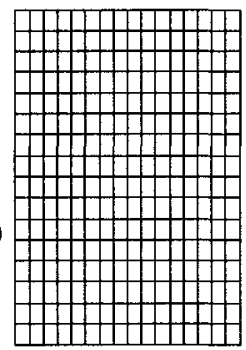

Figure 4.14: The various mesh designs used for bulge test set 3 


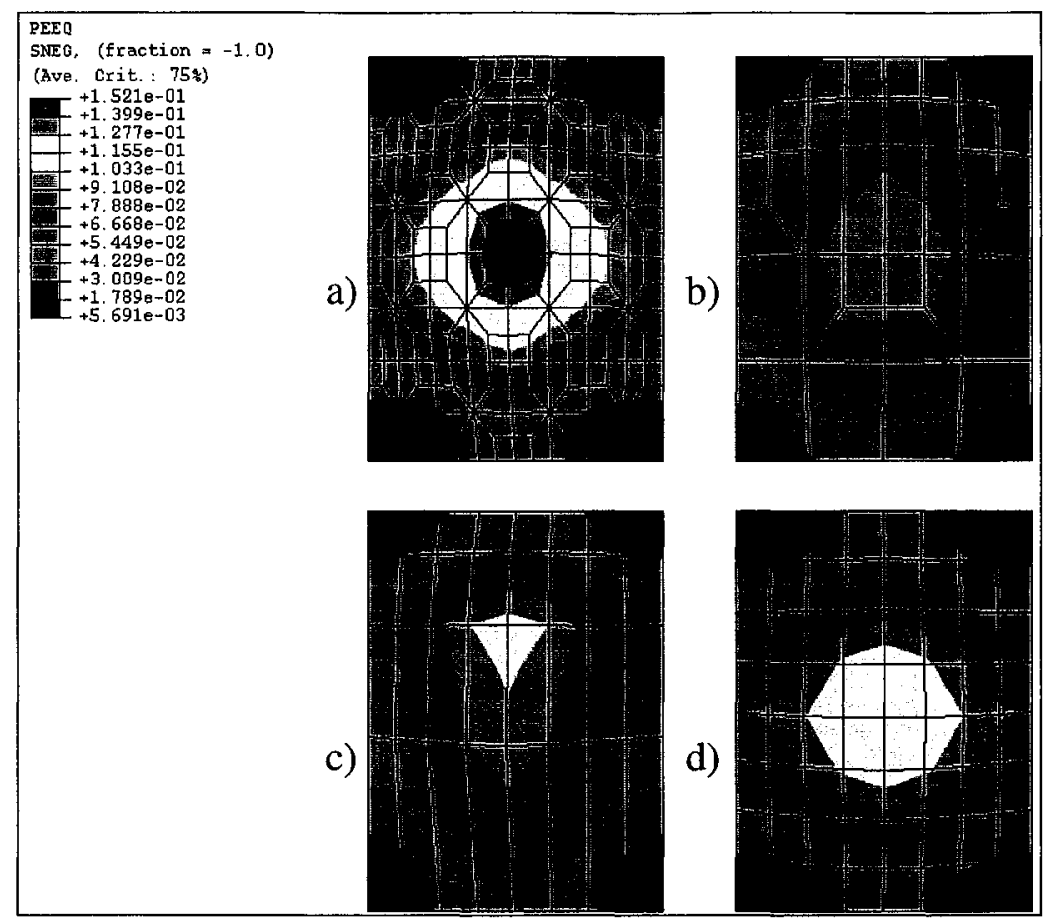

Figure 4.15: Equivalent plastic strain contours for bulge test set 1

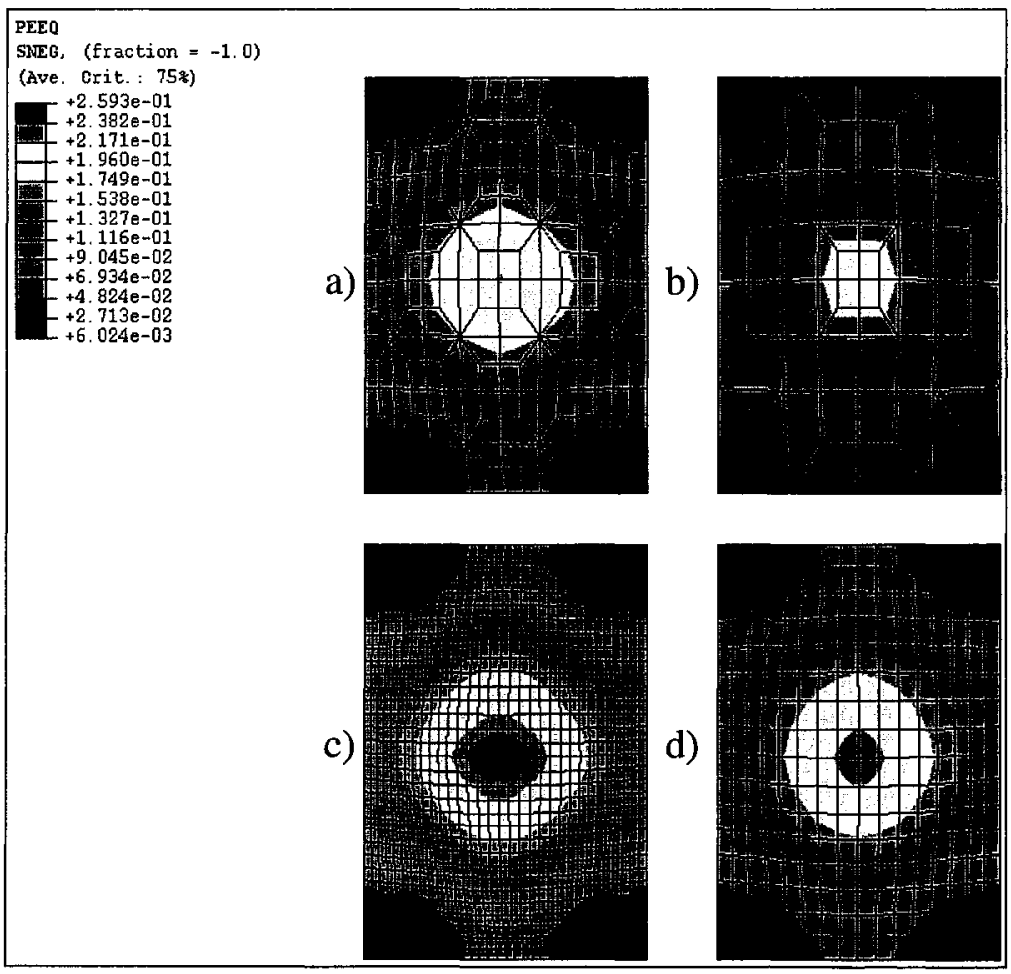

Figure 4.16: Equivalent plastic strain contours for bulge test set 2 


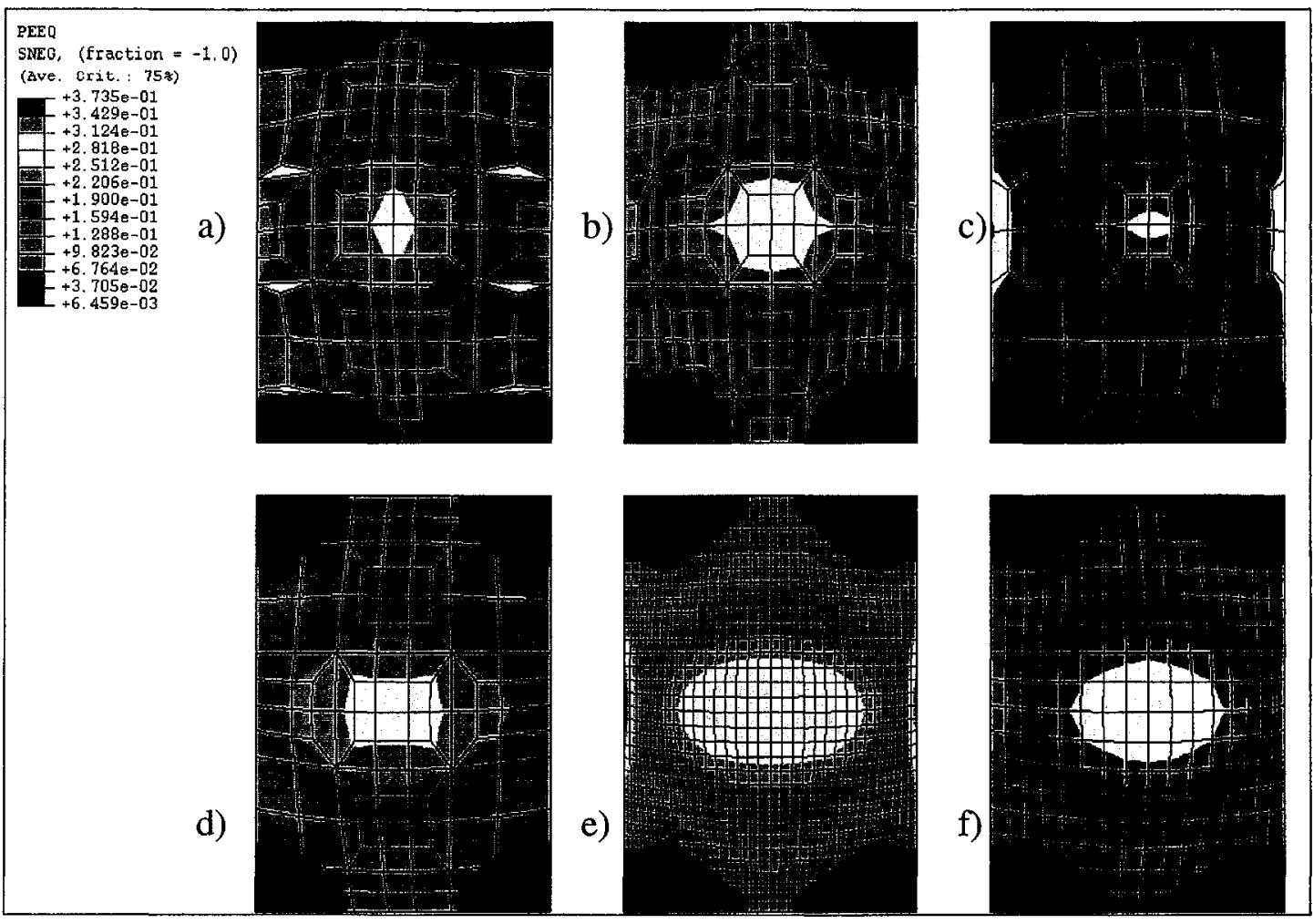

Figure 4.17: Equivalent plastic strain contours for bulge test set 3

It can be observed that using "transition elements" from a finer mesh to a relatively coarser mesh appears to modify the equivalent plastic strain contour maps (Figures 4.15b, 4.16a, 4.17c and 4.17d), while simply using a coarser mesh just coarsens the contours, as is seen Figures 4.16d and 4.17f.

Because of the possibility of the stress being concentrated at "transition elements" when they are used to connect relatively fine and coarse meshes [17], it was decided to avoid using this technique in order to decrease the total amount of elements used to mesh a structure. 


\subsection{Summary}

In this chapter, the materials and methods utilized in the various experiments from the laboratory-scale tensile tests, which were used to determine the necessary parameters for the material model, were described and discussed.

The tensile test simulations were used in order to obtain the failure parameter for the material response algorithm that would produce the same percent elongation as in the actual laboratory tests.

The Charpy v-notch simulations, which utilized a single strain parameter for each steel, were unable to successfully reproduce the laboratory values. The use of a failure parameter for each steel that was dependent on the stress state might have an increased chance of success. Additionally, the lack of strain-rate sensitivity in the material model could have contributed to the deviation of the predicted Charpy energy values from those measured experimentally.

The hydraulic bulge-test simulations, which were utilized to investigate the effect of various mesh architectures on the distribution of variables, showed that a finer mesh is desirable, and the use of transition-style elements, as in Figure 4.12b, should be avoided. Alternative mesh designs using transition elements, in which the symmetry of the structure is maintained, should be examined in order to assess the effect of increased element concentration in the zone of interest. 


\section{REFERENCES}

1. Gray, J Malcolm, An Interpretive Report for AGA Project No. NG-18(4), American Gas Association, February 1984, p. 7

2. "Standard Test Methods of Tension Testing of Metallic Materials", ASTM Designation E8-89b, American Society of Testing and Materials, Philadelphia, 1989, pp. 130-145

3. Necking of a Round Tensile Bar, Abaqus Explicit Example Problems Manual, Version 5.8, Hibbitt, Karlsson, and Sorenson, USA, 1998, p. 2.6-3

4. Gray, J Malcolm, Final Report for AGA Project No. NG-18(4), American Gas Association, February 1984, p. 8-11

5. Holmes, B., Priest, A.H. and Walker, E.F., "The Prediction of LinePipe Fracture Behaviour from Laboratory Tests", International Journal of Pressure Vessels and Piping, Vol 12, n 1, 1983, pp. 1-27

6. Hertzberg, Richard W., Deformation and Fracture Mechanics of Engineering Materials, Fourth Edition, John Wiley \& Sons, 1996, pp. 19-24

7. "Standard Test Methods for Notched Bar Impact Testing of Metallic Materials", ASTM Designation E23-88, American Society of Testing and Materials, Philadelphia, 1988, pp. 197-212

8. Rice, J.R. and Tracey, D.M., "On the Ductile Enlargement of Voids in Triaxial Stress Fields", Journal of the Mechanics \& Physics of Solids, Vol. 17, 1969, pp. 201-217

9. Gurson, A.L., "Continuum Theory of Ductile Rupture by Void Nucleation \& Growth: Part 1 - Yield Criteria and Flow Rules for Porous Ductile Media", Journal of Engineering Materials and Technology, Vol. 99, 1977, pp. 2-15

10. Tvergaard, V., "On Localization in Ductile Materials Containing Spherical Voids", International Journal of Fracture, Vol. 18, 1982, pp. 237-252

11. Abaqus Explicit User's Manual, Version 5.8-14, Hibbitt, Karlsson, and Sorenson, USA, 1999

12.Tvergaard, V. and Needleman, A., "Analysis of the Cup-Cone Fracture in a Round Tensile Bar", Acta Metallurgica, Vol. 32, 1984, pp. 157-169

13. Hecker, S.S., "Experimental Studies of Sheet Stretchability", Formability: Analysis, Modeling, and Experimentation, TMS-AIME, 1978, pp. 150-182

14. "Standard Test Method for Ball Punch Deformation of Metallic Sheet Material", ASTM Designation E643-84, American Society of Testing and Materials, Philadelphia, 1984, pp. 637-640

15. Taylor, Brian, "Formability Testing of Sheet Metals", Forming and Forging. ASM Handbook Vol 14, ASM International, 1988, pp. 877-899 
16. Duncan, J.L., Kolodziejski, J. and Glover, G., "Bulge Testing as an Aid to Formability Assessment", in Sheet Metal Forming and Energy Conservation, Proceedings of the $9^{\text {th }}$ Biennial Congress of the International Deep Drawing Research Group, Ann Arbour, Michigan, American Society for Metals, 1976, p. $131-150$

17. Nemes, J.A., McGill University, Private conversation, March 1999 


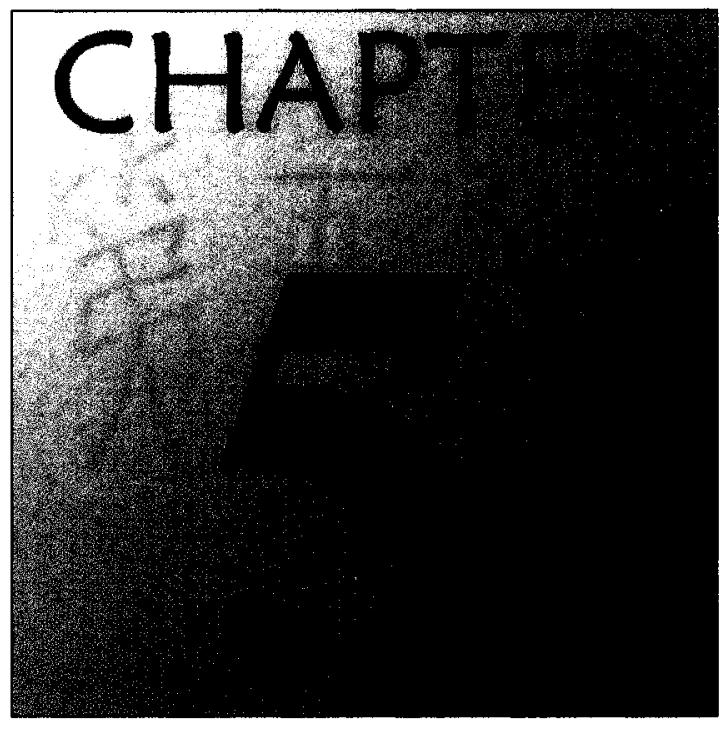

\section{Pipeline Rupture Simulation}

The full-scale linepipe burst tests were simulated to compare the predictive capabilities of the overall model. This investigation examines the influence of plastic flow parameters, such as the yield stress and the rate of work-hardening, on the resistance of steels to ductile tearing during full-scale crack-arrest tests. As was illustrated in the literature review, the majority of the existing work uses empirical relationships to evaluate this behaviour, and no work in this area has been performed that examines the influence of the plastic flow parameters. In addition, no self-evolving simulation of the full-scale crack-arrest test has been developed prior to this work.

This chapter focuses on the finite element analysis model of the full-scale crack-arrest test. Challenges in the design and development of such a model will be examined first. Next, comparisons between predicted and measured crack propagation behaviour will be made, as well as examining the influence of various material and gas decompression parameters and characteristics on the crack propagation behaviour. A sensitivity analysis will be presented next followed by a comparison of the various models for higher strength steel. 


\subsection{Gas Decompression Algorithm}

Several methods can be used to solve the differential equations for unsteady compressible fluid flow (Equations 2.14 and 2.15). Although the finite element and the finite difference methods are useful techniques for this purpose, they require powerful computers and are very time consuming. The most attractive technique is an analytical or even a semi-empirical solution of the equations, but several simplifying assumptions must be made in order to derive a solution. In the idealized case, the critical velocity in a constant cross-section tube is equivalent to the maximum velocity of sound in the gas, and the critical flow pressure can be calculated. The actual case is much more complex than the idealized case for various reasons. During fracture initiation, the internal pressure remains high near the fracture origin because a finite amount of time is required for the fracture to open sufficiently (Figure 5.1) for the gas to escape, and turbulence also occurs, thus one-dimensional flow is not valid. As illustrated in Figure 5.1, immediately after rupture, a slit in the pipe exists, and as the fracture travels from the origin, the fracture area becomes wedge-shaped. This delay in decompression close to the origin from the moment the fracture initiates to the instant it opens sufficiently for the gas to escape has been referred to as an opening effect. The actual linepipe decompression behaviour must be examined to determine the strategy.

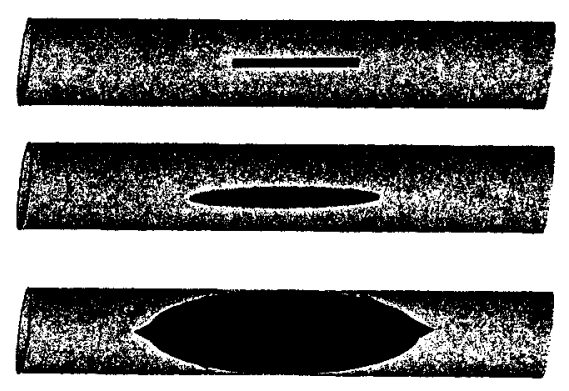

Figure 5.1: Schematic diagram of the ductile fracture initiation in the linepipe 


\subsubsection{Internal Pipe Pressure Distribution: Measured}

As can be observed from Figure 5.2 a series of circumferential pressure transducers were used around the circumference of the pipe surface in a full-scale crack arrest test in order to measure the pressure field during decompression [1]. These data were obtained in the stationary propagation regime in a pipe section distant from the initiation zone. The pipe had an external diameter of $142 \mathrm{~cm}$ (56 in.), wall-thickness of $19 \mathrm{~mm}$ (0.75 in.),

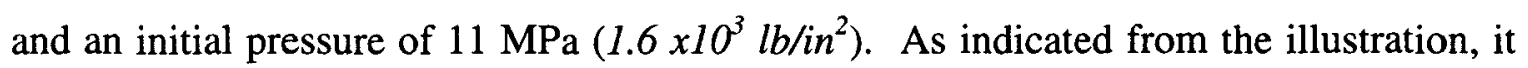
can be observed that ahead of the fracture tip the line pressure decreases by approximately $50 \%$ as the fracture tip is approached. In addition, the cross-sectional pressure distribution ahead of the fracture tip is uniform. In contrast, there is a crosssectional pressure variation with circumferential position behind the fracture tip, i.e., transducer $\mathrm{A}$, which is positioned at the bottom of the pipe, indicates a higher pressure than transducer $E$, which is near the top of the pipe.

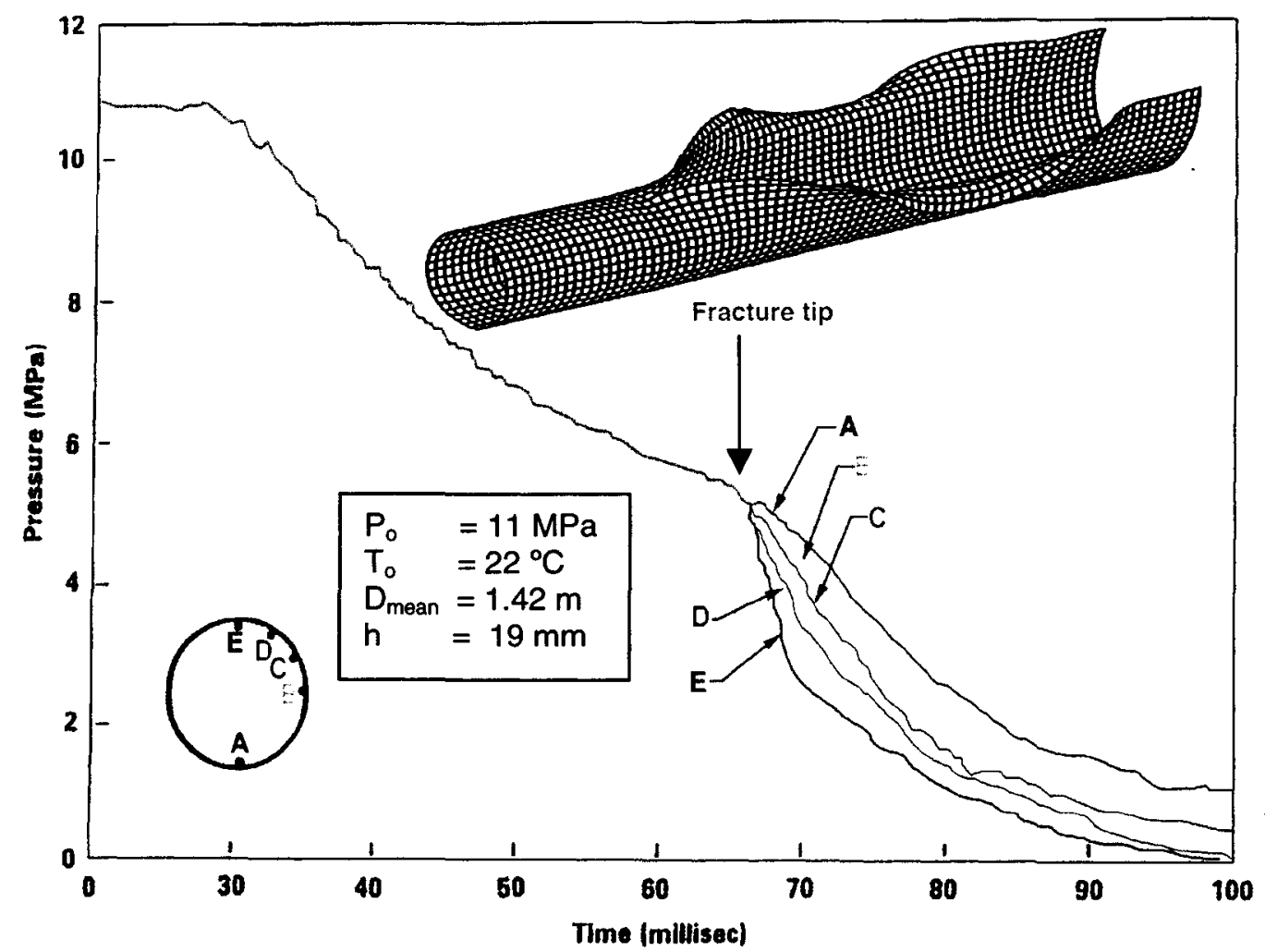

Figure 5.2: Output from circumferentially located pressure transducers in CSM full-scale burst test [adapted from 1$]$ 


\subsubsection{Changes in Pipe Geometry}

As the ductile fracture propagates, there is a change in the cross-sectional shape (Figure 5.3) that is important because it is necessary to determine the cross-sectional area, which has an influence on the internal pressure distribution and has a critical influence on the driving force. In front of the fracture tip, the cross-section remains a closed circle, while behind the fracture tip, the cross-section varies from a closed circle to a U-type shape at a normalized distance of approximately 2.5 diameters.

To determine the overall internal pressure distribution, the solution is divided in two parts: ahead of the ductile fracture tip and behind it.

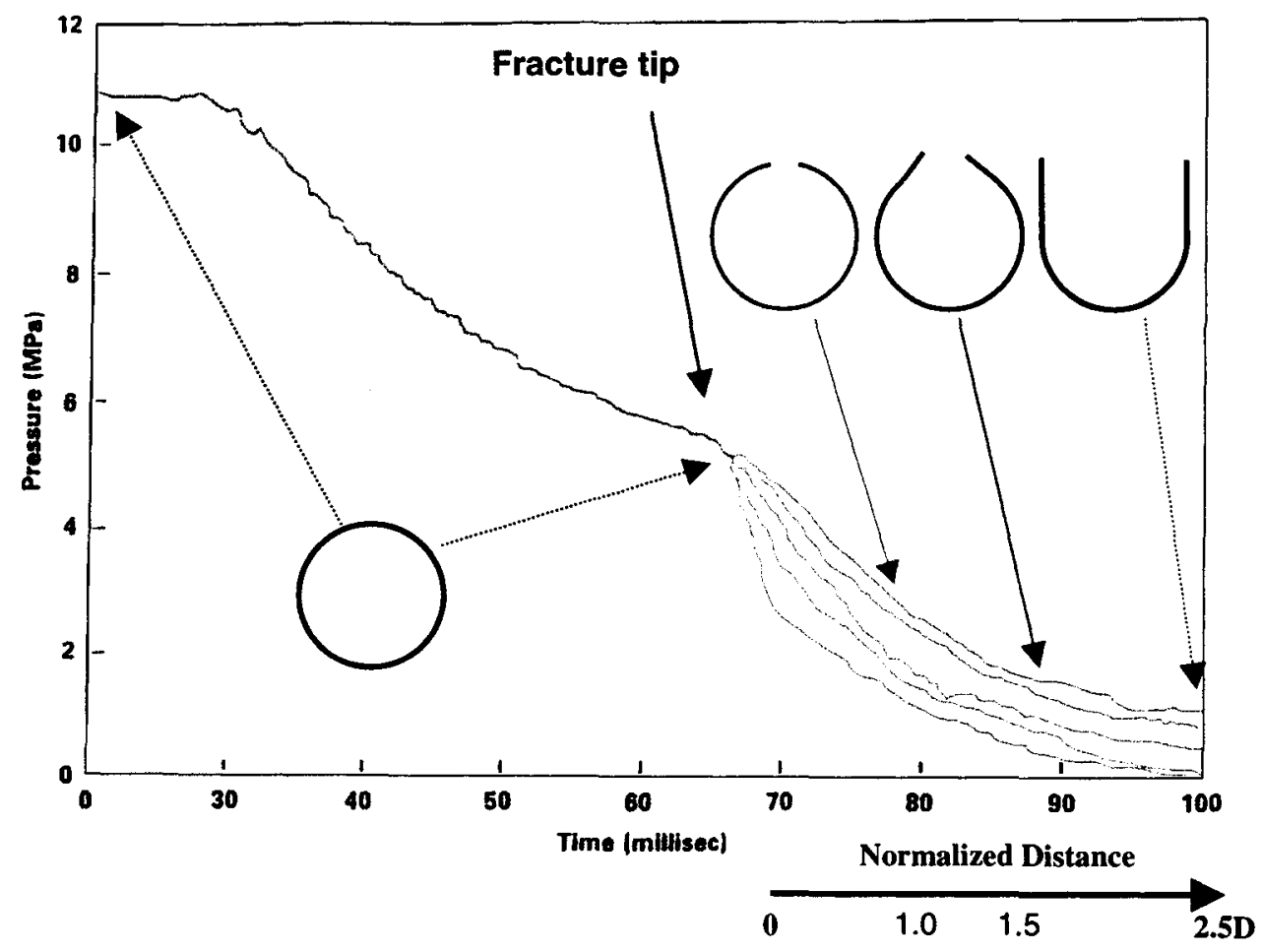

Figure 5.3: The cross-sectional change with position relative to the ductile fracture tip. 


\subsubsection{Gas Pressure Ahead of the Fracture-Tip}

In order to derive an analytical expression for the gas pressure ahead of the crack tip, it was assumed that the gas is either air or methane and behaves like an ideal gas during decompression [2,3]. In addition, as noted earlier, the process is adiabatic because the decompression is so rapid that there is insufficient time for heat transfer, and the decompression path is isentropic (constant entropy) because of negligible heat transfer and friction effects. Therefore, the internal pressure distribution ahead of the crack-tip can be determined with the following equations [4]:

$$
P= \begin{cases}P_{0} & \text { for } \frac{x_{a}}{t} \geq c_{0} \\ P_{0}\left[\frac{2}{\gamma+1}+\frac{\gamma-1}{\gamma+1} \cdot\left(\frac{x_{a}}{c_{0} t}\right)\right]^{2 \gamma / \gamma-1} & \text { for } \frac{x_{a}}{t}<c_{0}\end{cases}
$$

where $\mathrm{P}_{\mathrm{o}}$ is the initial pressure $(M P a), \mathrm{c}_{0}$ is the speed of sound in the gas at pressure $\mathrm{P}_{0}, \gamma$ is the specific heat ratio $\left(c_{p} / c_{v}\right), x_{a}$ is the position along the pipe axis ahead of the crack tip $(m)$, and $t$ is the time $(\mathrm{sec})$. Because the crack opening at the early stages of the rupture is narrow and throttles the gas flow, the gas pressure remains close to the initial line pressure, and Equation 5.1 is only utilized after $t$ has surpassed the critical time required for the rupture to open more than the equivalent of one pipe diameter, $t_{c r}$, which is shown as:

$$
t \geq t_{\text {cr }}
$$

Considering symmetry, the critical time is determined using:

$$
\mathrm{t}_{\mathrm{cr}}=\frac{0.5 \mathrm{D}}{\mathrm{v}_{\mathrm{CT}}}
$$


where $\mathrm{v}_{\mathrm{CT}}$ is the crack tip velocity. Only half $(0.5)$ of the diameter is used in the above equation due to symmetry.

Thus at each time interval, the pressure at any distance from the fracture origin could be determined from the previous equation if that location is ahead of the crack-tip.

For linepipe located behind the crack-tip, a different scheme is used to determine the internal pressure.

\subsubsection{Gas Pressure On the Flaps}

Behind the crack tip, pressure is seen to vary with distance from the crack-tip, as well as with circumferential position, as previously seen in Figure 5.2. The post crack-tip decompression model was based upon Bell's double-exponential release rate model [5], which was initially presented as a semi-empirical expression and later shown to be the correct solution for isothermal, quasi-steady pipe flow [6]. The model used to determine the gas pressure for a particular location (Figure 5.4) behind the crack-tip at a specific time is:

$$
P=P_{c} \exp \left[-\left(A_{1} \frac{x_{C T}-x_{b}}{D_{o}}\right)\left(\frac{\omega}{D_{o}}\right)^{A_{2}}\right]
$$

where $\mathrm{P}_{\mathrm{c}}$ is the crack-tip pressure $(M P a), \mathrm{A}_{1}$ and $\mathrm{A}_{2}$ are constants, $\mathrm{D}_{\mathrm{o}}$ is the pipe diameter $(m), \mathrm{x}_{\mathrm{Cr}}$ is the crack-tip position $(m), \omega$ is the height above the bottom of the pipe $(m)$ and $\mathrm{x}_{\mathrm{b}}$ is the position along the pipe axis behind the crack tip. 


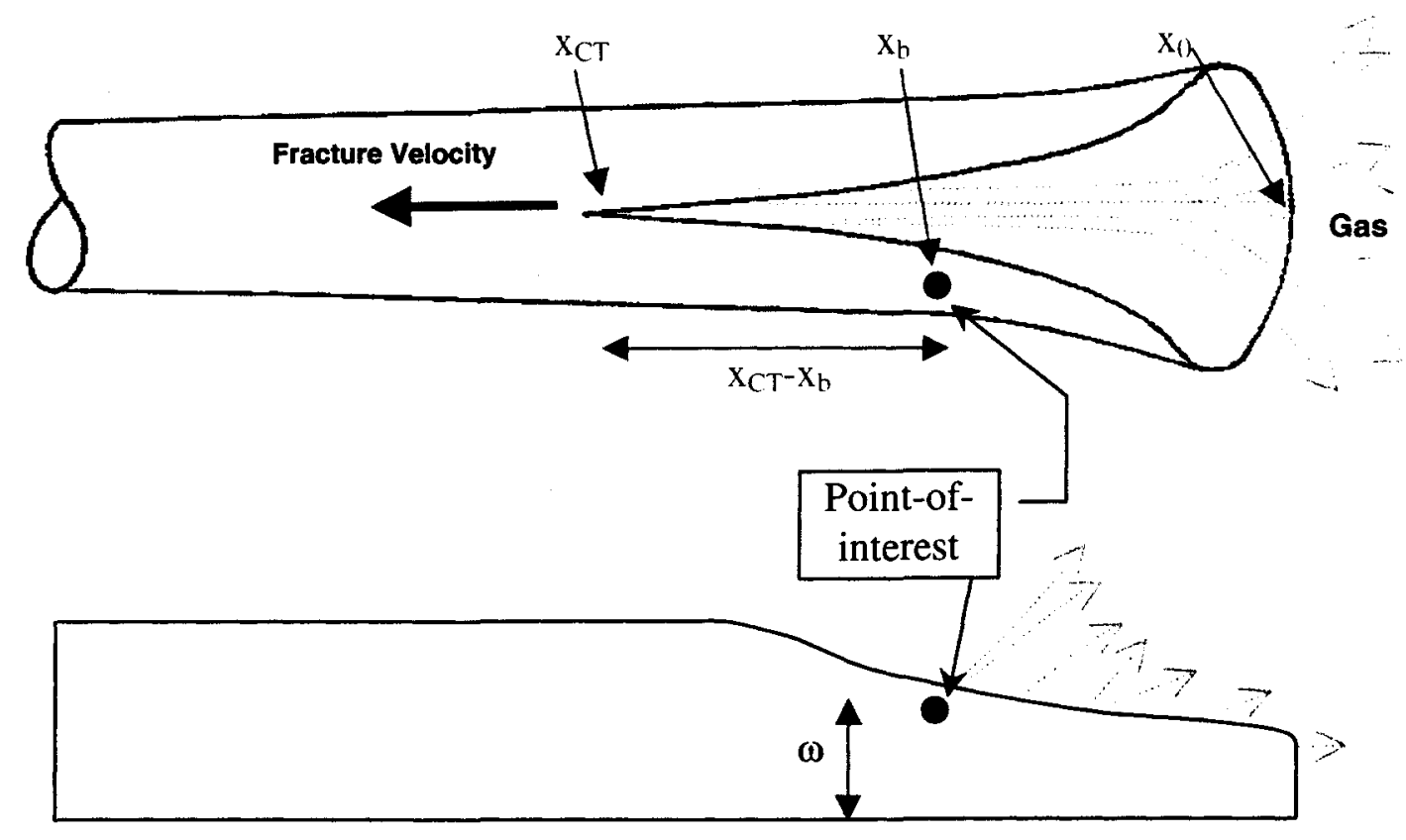

Figure 5.4: Illustration of a point-of-interest behind the fracture tip.

\subsubsection{Gas Decompression Algorithm}

The overall decompression algorithm is composed of the different constituents that have been described thus far. Figure 5.5 displays the flowchart that is utilized to establish which gas decompression model component is to be employed during a simulation:

Essentially, there is an initial incubation period whereby the pressure is maintained at the initial line pressure in order to account for the delay in decompression near the fracture origin. This variable can be either a specific time or a value for the ductile fracture crack propagation distance, $\mathrm{x}_{\text {crit }}$. Once the simulation has surpassed the incubation period, the algorithm compares the position of the current point-of-interest relative to the fracture-tip location, and then calculates the appropriate pressure value. 


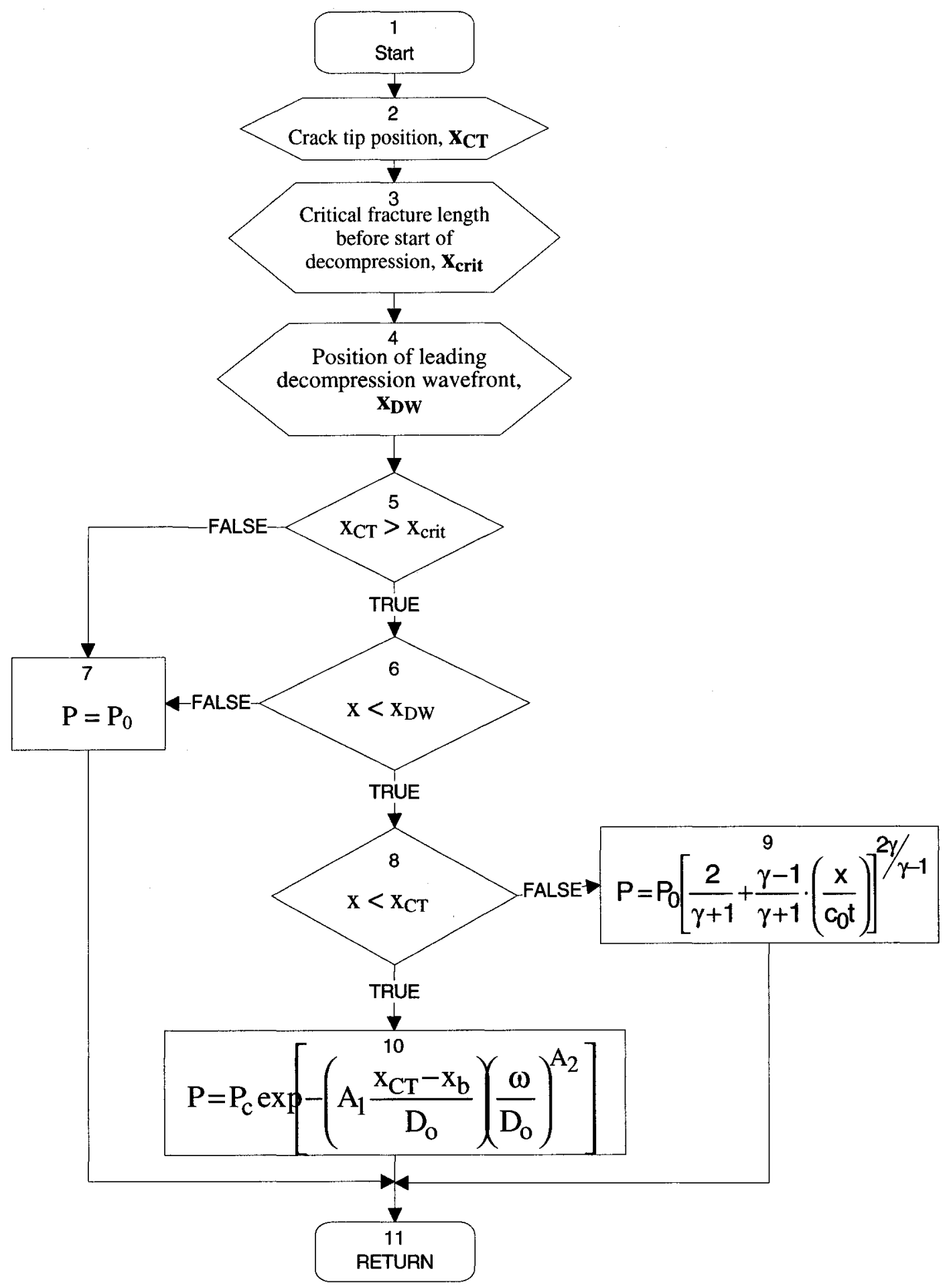

Figure 5.5: Flowchart of the gas decompression algorithm. 


\subsection{Virtual Full-Scale Linepipe Crack-Arrest Test}

Without a reliable, prediction model for ductile fracture propagation, only fullscale fracture tests can determine the "actual" resistance of pipelines to ductile fracture propagation. The test conditions tend to vary since there is no standard method of performing this evaluation. As is illustrated in Figure 5.6, the test consists of several sections of linepipe, which tend to be made of different steels, welded together. At each end of the set-up, there is a thick crack arrestor, concrete fixturing, and a gas reservoir. In order to initiate the fracture, a central segment of pipe is used and it is less tough than the remaining segments. The ductile fracture then propagates in both directions until arrest occurs in a segment that has sufficient toughness. To prevent damage to the gas reservoirs, the fracture is stopped by the arrestors set adjacent to the concrete fixturing if it is not arrested in the pipe. Tests are conducted on pipe segments having the same wall thickness and diameter, but with the toughness increasing toward the arrestors. Obviously, multiple tests have to be performed to establish the arrest capabilities of pipe with different geometries and operating conditions. For similar grades of steel, operating conditions and geometries, only limited data are available since full-scale linepipe crackarrest tests are expensive.

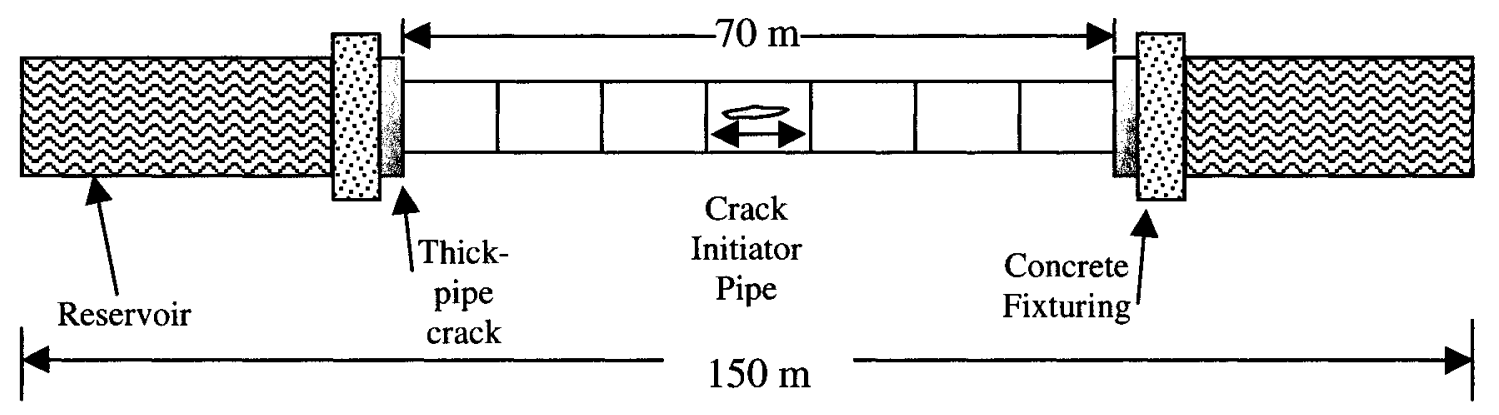

Figure 5.6: Schematic diagram of the set-up for a full-scale linepipe burst test 


\subsubsection{Single Linepipe Simulations}

These experiments were arranged in order to perform the linepipe crack-arrest test on single sections of linepipe. The purpose of these experiments was to evaluate the behaviour of one steel at a time without the influence of another linepipe made from steel with different properties.

\subsubsection{Virtual Specimen and Materials}

In addition to the materials and specimen geometry mentioned previously, other steels, geometries and operating conditions used in the single linepipe crack-arrest experiments are shown in Table 4.2, where the flow stress information was included in a tabular format, and in Table 4.3 where the flow behaviour of the steels was determined using functions. It should be noted that the materials utilised were either API X65 or X70 grade steel.

Table 5.1: Mechanical properties, geometry and operating conditions of steels tested in single linepipe experiments that used tabular stress-strain data.

\begin{tabular}{|cccccc|}
\hline $\begin{array}{c}\text { Yield } \\
M P a\end{array}$ & $\bar{\varepsilon}_{\mathrm{f}}^{\mathrm{pl}}$ & $\begin{array}{c}\text { Pipe Length } \\
m\end{array}$ & $\begin{array}{c}\text { Diameter } \\
m\end{array}$ & $\begin{array}{c}\text { Wall thickness } \\
m m\end{array}$ & $\begin{array}{c}\text { Initial Pressure } \\
M P a\end{array}$ \\
\hline 448 & 1.00 & 6.0 & 1.0 & 16.5 & 9.68 \\
448 & 0.65 & 6.0 & 1.0 & 16.5 & 9.68 \\
448 & \multirow{2}{*}{1.00} & 18.0 & 1.0 & 16.5 & 9.68 \\
\hline
\end{tabular}

\subsubsection{Virtual Testing Procedure}

The procedure for each test involved setting 3 to 4 elements near the edge of the pipe to a very low failure strain, i.e. approximately 0.025 . Then the pipes were loaded to full pressure within $5 \times 10^{-3}$ seconds, and then the system was allowed to evolve. The stress, strain, and other variables of interest were noted after each iteration. 
Table 5.2: Mechanical properties, geometry and operating conditions of steels tested in linepipe experiments that used a function to calculate the flow curve.

\begin{tabular}{|c|c|c|c|c|c|c|c|}
\hline $\begin{array}{l}\text { Yield } \\
M P a\end{array}$ & YS/UTS & $\mathbf{e}_{\mathbf{u t s}}$ & $\bar{\varepsilon}_{\mathrm{f}}^{\mathrm{pl}}$ & $\begin{array}{c}\text { Pipe Length } \\
m\end{array}$ & $\begin{array}{c}\text { Diam. } \\
m\end{array}$ & $\begin{array}{c}\text { Wall thickness } \\
\mathrm{mm}\end{array}$ & $\begin{array}{c}\text { Initial Pressure } \\
\qquad M P a\end{array}$ \\
\hline 450 & 0.94 & 0.06 & 0.7 & 6.0 & 1.0 & 15.0 & 9.68 \\
\hline$"$ & $"$ & $"$ & 1.5 & $"$ & $"$ & $"$ & $"$ \\
\hline$"$ & " & $"$ & 2.5 & $"$ & $"$ & $"$ & $"$ \\
\hline " & " & $"$ & 0.7 & 18.0 & $"$ & $"$ & $"$ \\
\hline$"$ & $"$ & $"$ & 1.5 & $"$ & $"$ & $"$ & $"$ \\
\hline$"$ & $"$ & 0.15 & $"$ & $"$ & $"$ & $"$ & $"$ \\
\hline$"$ & 0.84 & 0.06 & $"$ & $"$ & $"$ & $"$ & $"$ \\
\hline$"$ & 0.84 & $"$ & 0.7 & $"$ & $"$ & $"$ & $"$ \\
\hline " & 0.78 & $"$ & 0.8 & $"$ & 1.2 & 18.3 & 11.59 \\
\hline$"$ & 0.74 & $"$ & 1.5 & $"$ & 1.0 & 15.0 & 9.68 \\
\hline$"$ & $"$ & 0.15 & 1.5 & $"$ & $"$ & $"$ & $"$ \\
\hline 526 & 0.84 & 0.148 & 1.24 & 15.0 & 1.2 & 18.3 & 11.59 \\
\hline$"$ & $"$ & 0.055 & 1.47 & $"$ & $"$ & $"$ & $"$ \\
\hline$"$ & 0.94 & 0.06 & 1.5 & $"$ & $"$ & $"$ & $"$ \\
\hline$"$ & $"$ & 0.05 & 1.552 & $"$ & $"$ & $"$ & $"$ \\
\hline$"$ & 0.74 & 0.014 & 1.5 & $"$ & $"$ & $"$ & $"$ \\
\hline
\end{tabular}

where $e_{u t s}$ is the engineering strain at the maximum engineering stress during a uniaxial tensile test, $\bar{\varepsilon}_{\mathbf{f}}^{\mathrm{pl}}$ is the failure strain used in the material algorithm, and YS/UTS is the ratio of engineering yield stress to ultimate tensile stress

\subsubsection{Multi-Linepipe Simulations}

These experiments were set-up to perform the linepipe crack-arrest test on multiple sections of linepipe. In all cases, two linepipes made from different materials were utilized to perform the experiments. 


\subsubsection{Virtual Specimen and Materials}

In addition to the materials and specimen geometry mentioned previously, other steels, geometries and operating conditions used in the multi-linepipe crack-arrest experiments are shown in Table 5.3, where the flow behaviour of the steels was determined using the Johnson-Cook function [7]. It should be noted that the virtual materials utilised were all API X65 grade steel. The less-tough linepipe segment was 3 meters long while the tougher segment made up the remainder of the set up, which had a total length of 18 meters.

Table 5.3: Mechanical properties, geometry and operating conditions of additional steels tested in the multi-linepipe experiments.

\begin{tabular}{|c|c|c|c|c|c|c|}
\hline $\begin{array}{l}\text { Yield } \\
M P a\end{array}$ & YS/UTS & $\mathbf{e}_{\text {uts }}$ & $\bar{\varepsilon}_{\mathrm{f}}^{\mathrm{pl}}$ & $\begin{array}{c}\text { Diam. } \\
m\end{array}$ & $\begin{array}{c}\text { Wall Thickness } \\
m m\end{array}$ & $\begin{array}{c}\text { Initial Pressure } \\
\mathrm{MPa}\end{array}$ \\
\hline 450 & 0.778 & 0.092 & 0.80 & 1.0 & 15.0 & 9.86 \\
\hline$"$ & 0.700 & 0.060 & 1.00 & " & $"$ & $"$ \\
\hline$"$ & " & " & 1.15 & $"$ & $"$ & $"$ \\
\hline$"$ & $"$ & $"$ & 1.30 & $"$ & $"$ & $"$ \\
\hline " & " & " & 1.45 & " & $"$ & $"$ \\
\hline$"$ & " & $"$ & 1.60 & $"$ & $"$ & $"$ \\
\hline$"$ & 0.778 & 0.07 & 1.10 & $"$ & $"$ & $"$ \\
\hline
\end{tabular}

\subsubsection{Virtual Testing Procedure}

The testing procedure for the multi-linepipe crack-arrest experiment was similar to the procedure delineated for the single linepipe tests, in which a low failure strain was imposed on a few elements at the beginning of the set-up in order to initiate the ductile 
tearing process. The pipes were loaded to full pressure within $5 \times 10^{-3}$ seconds and the structure self-evolved. Subsequent to each iteration, the stress, strain, and other variables of interest were noted.

Additionally, for the steels in which the failure strain parameter was required for the material algorithm, uniaxial tensile tests were performed on the material in order to correlate the \% elongation to fracture with the failure strain of the material algorithm.

\subsection{Design and Development Challenges during Construction of the Full-Scale Crack Arrest Test Model}

During the design and development of the full-scale crack arrest test simulation, several challenges were encountered, such as: stress oscillations during the loading or unloading of the structure, mesh-design, the transition from the fully pressurized structure to the start of gas decompression, the transition from one-dimensional to two-dimensional gas decompression, achieving the plane-stress criterion during the use of shell elements, and obtaining the data necessary for the calculation of crack-tip velocity, which contributed to lengthening the time necessary to implement a functional model.

The current crack-tip position was obtained by incorporating a subroutine for determining it within the user-material algorithm that was developed for the finite element solver. The ability to observe and store the crack-tip position also aided in determining the transition from one-dimensional to two-dimensional gas decompression for the gas decompression algorithm, since this occurs at the crack-tip. The crack-tip velocity was obtained by differentiating the crack-tip position versus time data. Because a finite amount of time is required in order for the rupture to open sufficiently for the gas to escape, the transition from the fully pressurized structure to the start of gas decompression is adjusted as a function of crack-tip position, and is usually set for when the rupture has opened the equivalent of an entire pipe diameter. 


\subsubsection{Stress Oscillations}

Several simulations were performed in order to minimize any stress oscillations that occurred as a result of the initial loading. The main variables that were modified for these simulations are shown in Table 5.4 and the pressure-loading history of the structures is illustrated in the plot in Figure 5.7. In order to minimize the simulation time required for the initial pressure-loading period, the time at which full-pressure was attained was kept constant at $10^{-4}$ seconds, as is seen in Figure 5.7. During the routine examinations of loading history graphs (stress-time) for elements in the pipe model during the various simulations outlined in Table 5.4, it was observed that there were oscillations, as can be seen in Figure 5.8, which is a loading history graph for a top element 2 metres in front of the beginning of the pipe, as seen in Figure 5.9.

Table 5.4: Principal variables modified during the oscillations study

\begin{tabular}{|c|c|c|c|c|c|}
\hline & \multicolumn{2}{|c|}{$\begin{array}{l}\text { Bulk Viscosity } \\
\text { Coefficients }\end{array}$} & $\begin{array}{c}\text { Boundary } \\
\text { Conditions } \\
\text { at pipe ends }\end{array}$ & $\begin{array}{l}\text { stiffness- } \\
\text { proportional } \\
\text { damping }\end{array}$ & Note \\
\hline A1 & 0.06 & 1.2 & $\mathrm{n}$ & --- & \\
\hline A2 & 0.06 & 1.2 & $\mathrm{n}$ & -- & $\begin{array}{l}\text { Nodes at the bottom of the pipe were allowed } \\
\text { to rotate but were not allowed to be displaced } \\
\text { during } 10^{-4} \text { sec }\end{array}$ \\
\hline A3 & 0.12 & 1.2 & $\mathrm{n}$ & -- & \\
\hline A4 & 0.12 & 1.2 & $n$ & -- & smooth, num =23 \\
\hline A5 & 0.60 & 1.2 & $n$ & --- & 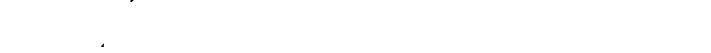 \\
\hline A6 & 1.20 & 1.2 & $n$ & --- & \\
\hline A7 & 0.30 & 1.2 & $y$ & --- & \\
\hline A8 & 0.06 & 1.2 & $y$ & --- & more elements, approx. 5300 \\
\hline A9 & 0.06 & 1.2 & $y$ & --- & $\begin{array}{l}\text { - no 'weak' elements } \\
\text { - only pressurize the pipe }\end{array}$ \\
\hline A10 & 0.12 & 1.2 & $y$ & $1.00 \mathrm{E}-05$ & \\
\hline A11 & 0.24 & 1.2 & $y$ & --- & \\
\hline
\end{tabular}




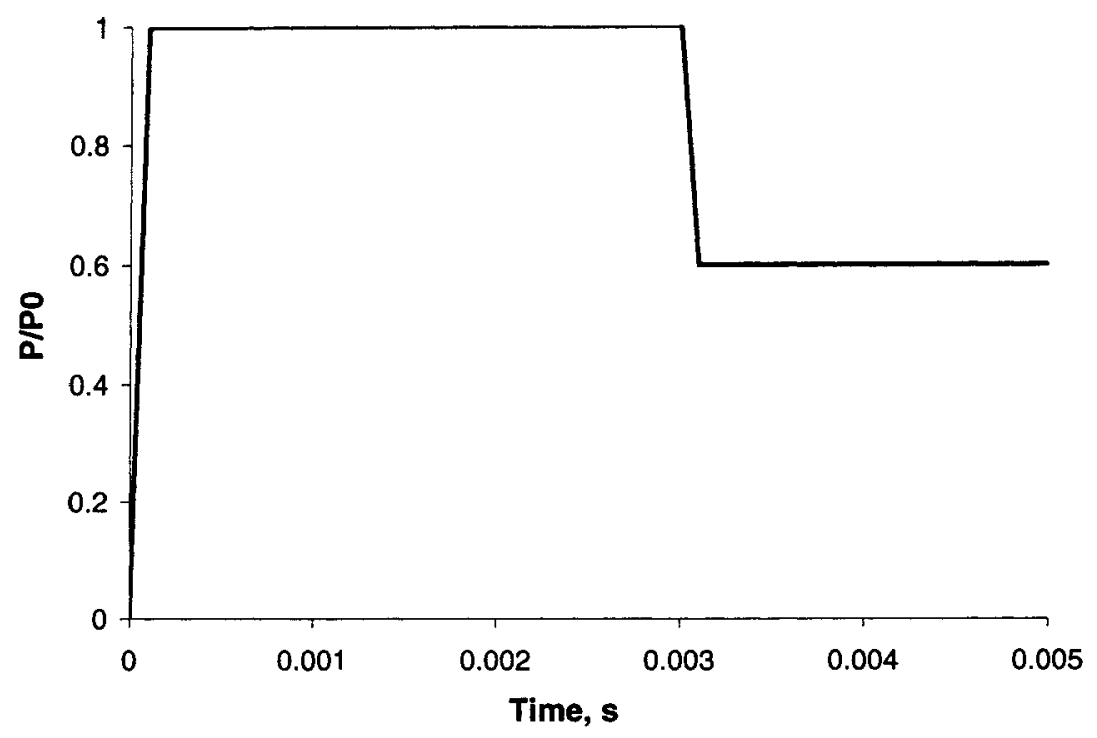

Figure 5.7: Graph of the pressure profile used during the "oscillations" simulations

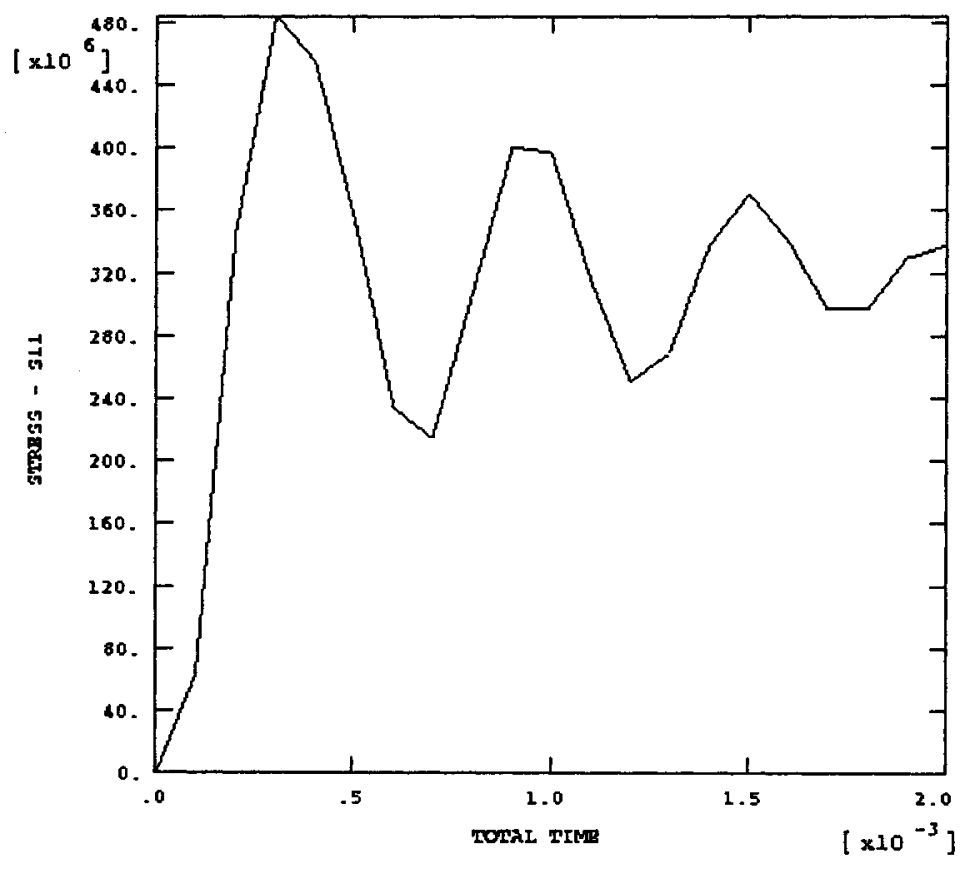

Figure 5.8: Plot of stress history for simulation A1 
Location of elements used
for loading history graphs

Figure 5.9: Schematic diagram illustrating the location of the element used for the stress history graphs

From Table 5.4, it can be seen that the variables modified in order to attempt to minimize or completely eliminate the amplitude of the oscillations are: stiffnessproportional damping, the boundary conditions at the ends of the pipe, and the bulk viscosity parameters: $\mathrm{b} 1$ and $\mathrm{b} 2$.

The purpose of bulk viscosity, which is used within the finite element solver, is to improve the modeling of high-speed dynamic events by introducing damping associated with volumetric straining (elastic straining). For bulk viscosity, the $1^{\text {st }}$ term is the linear bulk viscosity parameter, b1, which has a default value of 0.06 , and the $2^{\text {nd }}$ term is the quadratic bulk viscosity parameter, b2, which has a default value of 1.20 .

As is seen in Table 5.4, linear bulk viscosity, b1, which is found in all elements and is introduced to damp "ringing" in the highest element frequency, is the only variable that was modified during the analysis. The damping due to the linear bulk viscosity term is sometimes referred to as truncation frequency damping. It generates a bulk viscosity pressure that is linearly proportional to the volumetric strain rate. It should be noted that the bulk viscosity pressure is not included in the material point stresses because it is intended only as a numerical effect, and it is not considered part of the material's constitutive response. Changing the bulk viscosity parameters within the range shown in Table 5.4 had little effect on minimizing the oscillations observed from the stress history chart. 
The last variable modified, was the time required to load the pipe to full pressure, which was previously kept constant at $10^{-4}$ seconds, as is seen in Figure 5.7, but then modified to $10^{-3}$ seconds, as is observed in Figure 5.10. This was the last variable modified because any increase in this value would significantly increase the simulation time. As can be observed in Figure 5.11, this resulted in minimizing the oscillations.

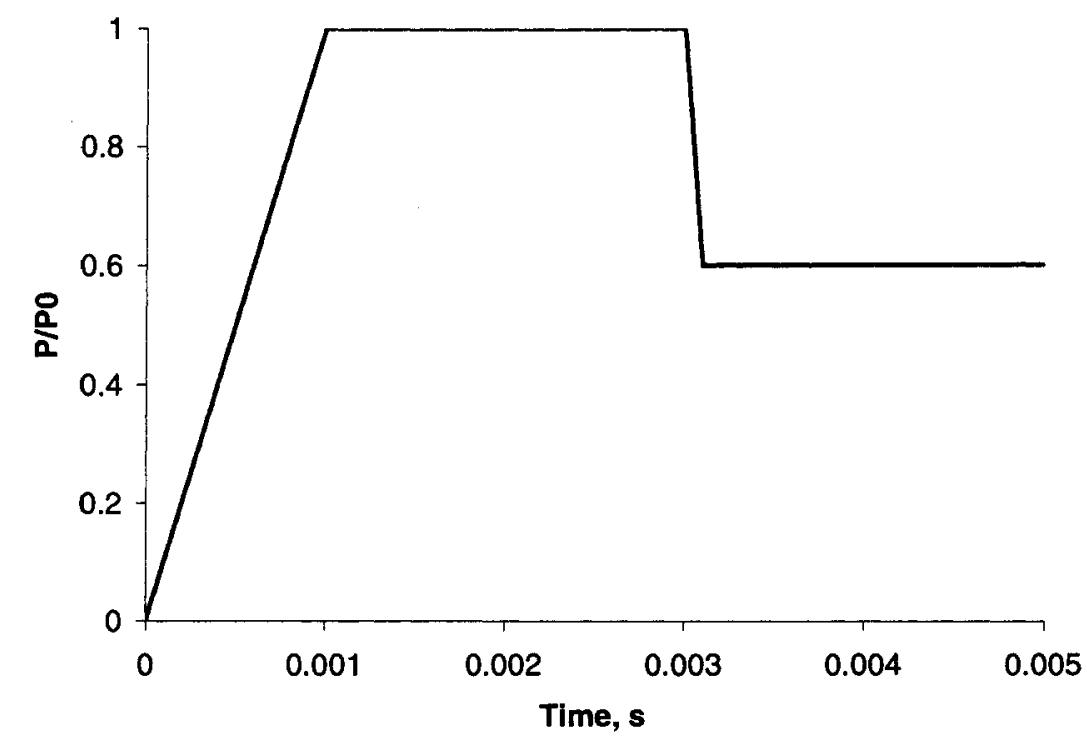

Figure 5.10: Graph of the modified pressure-loading profile

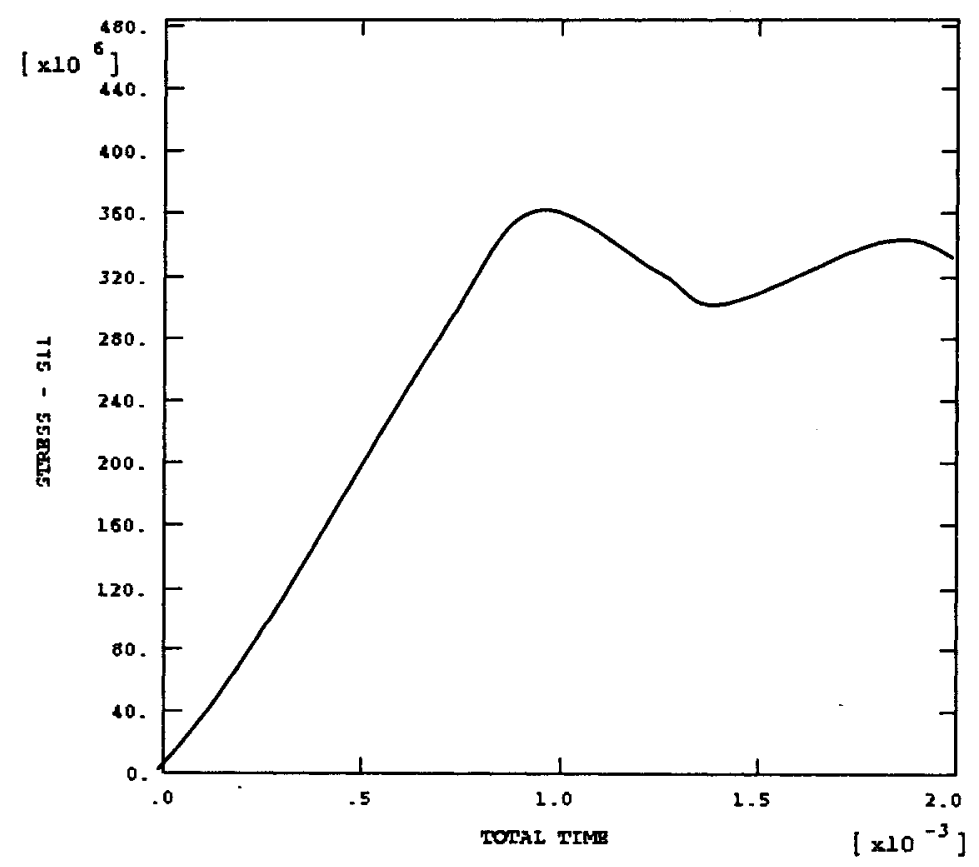

Figure 5.11: Plot of stress history for simulation $A 1$ with the modified profile 


\subsection{Full-Scale Crack Arrest Simulations}

Finite element simulations of full-scale crack arrest tests were performed using several different initial configurations, but these can be initially subdivided into main groups: those simulations using one segment of linepipe or those made up of more than one linepipe segment.

\subsubsection{Single Linepipe Simulations}

The reason for performing these simulations was to isolate the effects of the plasticity and flow stress behaviour of the steel on the dynamic ductile fracture phenomenon. The resistance of a steel to ductile tearing is primarily governed by its plasticity, i.e. the work energy required to deform the material until failure, which is related to the area under the stress-strain curve, as is illustrated in Figure 5.12.

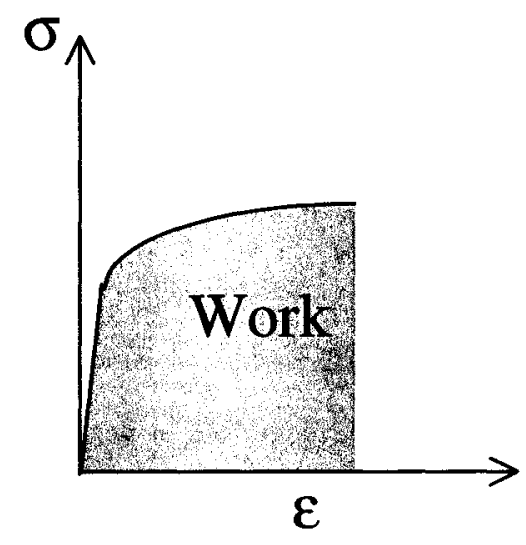

Figure 5.12: Graph illustrating the concept of deformation work to fracture (energy/vol)

By plotting a graph of deformation work to fracture versus fracture velocity for some of the literature data available on X70-type linepipe steel [8], as is shown in Figure 5.13 , it is readily apparent that the resistance to tearing is not simply correlated with the energy absorbed to failure. Therefore, it is appropriate to perform a sensitivity analysis to 
the plasticity variables used in Equation 4.1: n, B, and $\bar{\varepsilon}_{\mathrm{f}}^{\mathrm{pl}}$. The base values used for the plasticity variables are $0.15,990$ and 1.30 , respectively. Upon examination of the sensitivity analysis shown in the graph in Figure 5.14, it is apparent that the change in crack-tip velocity is most sensitive to ' $\mathrm{n}$ ' and $\bar{\varepsilon}_{\mathrm{f}}^{\mathrm{pl}}$, the strain-hardening rate and failure strain, respectively. Thus, these results suggest that the rate of strain-hardening and failure strain strongly influence the crack velocity. Increasing the failure strain has the effect of increasing the integration limit, thus augmenting the amount of energy absorbed per unit volume of material deformed. Increasing the strain-hardening rate, which tends to limit the localization of plastic deformation, has the effect of increasing the extent of the plastic zone ahead of the crack-tip. In contrast, the tearing phenomenon appears to be least sensitive to 'B'.

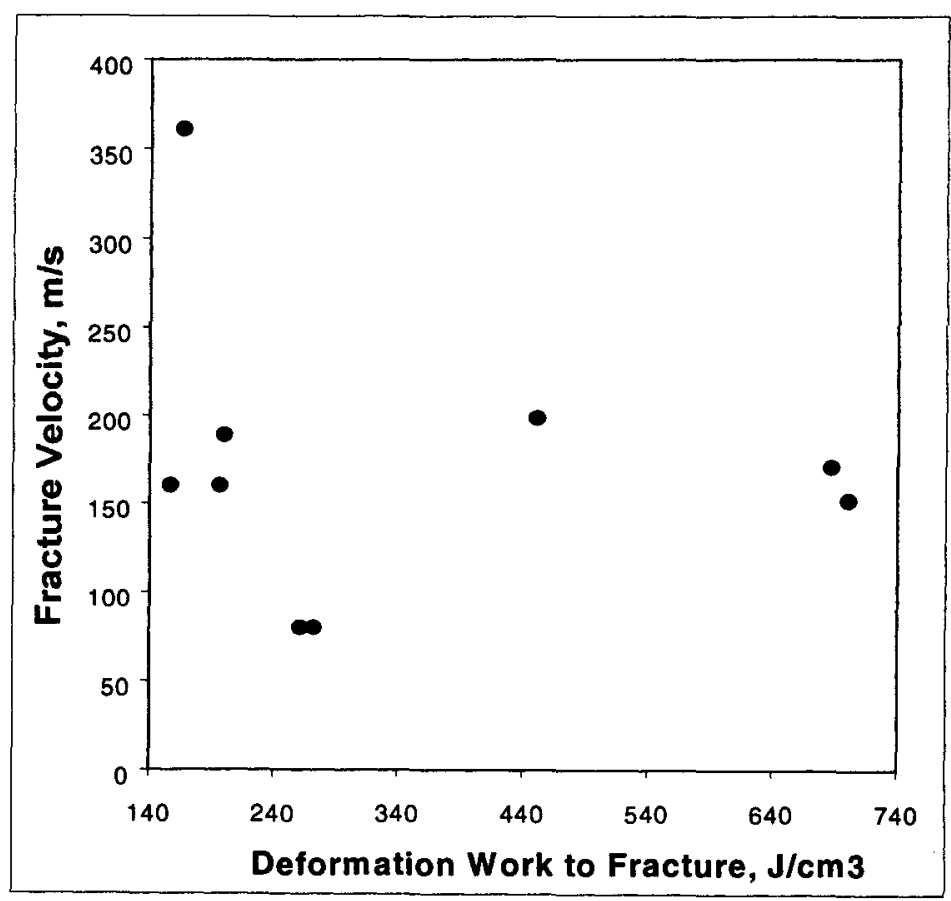

Figure 5.13: Graph of the measured fracture velocity versus the calculated deformation fracture work for literature data [8] 


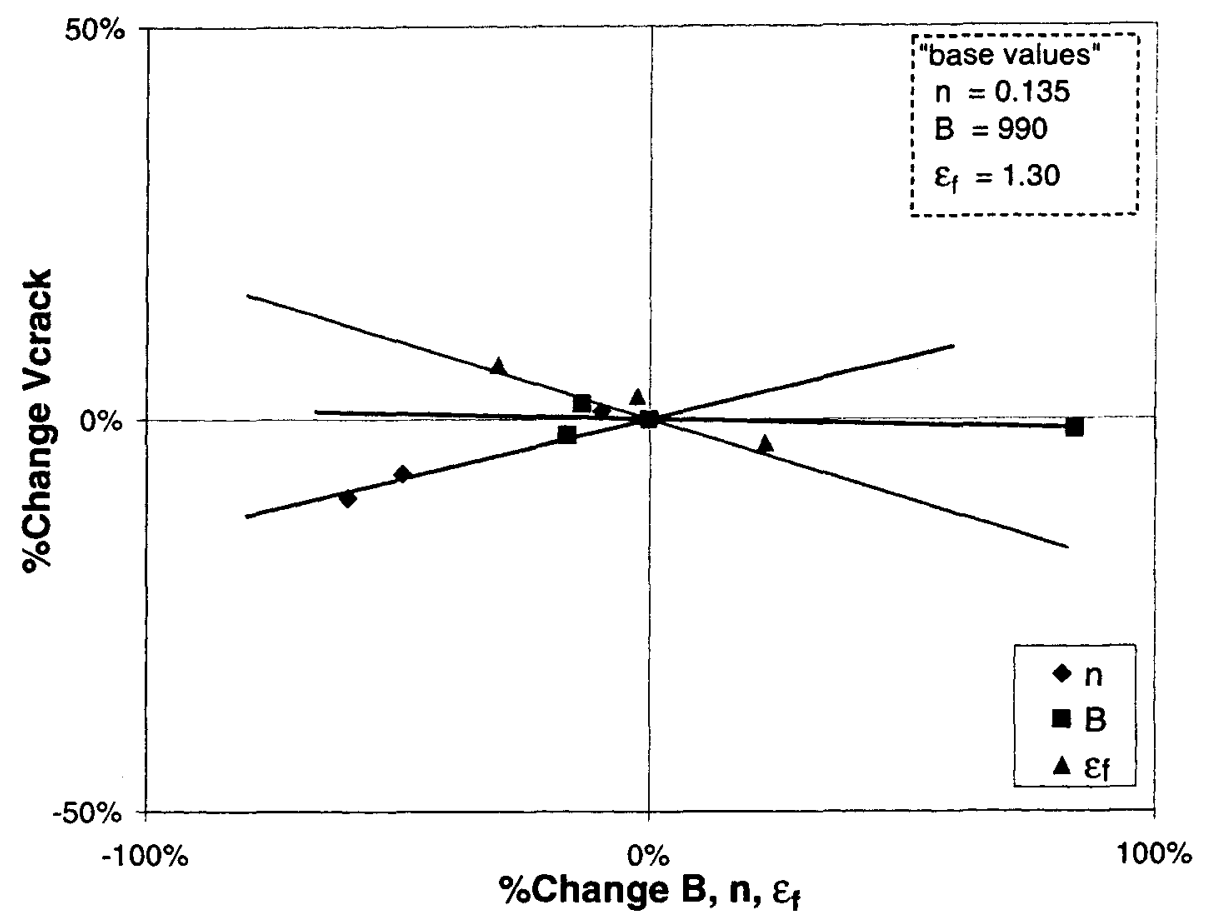

Figure 5.14: Sensitivity analysis of fracture velocity to the plasticity variables

\subsubsection{Mesh-Size}

The finite element analysis method requires the discretization of the workpiece, and one concern is the sensitivity of the results to the size of the mesh. The mesh size was varied by mainly concentrating on the size of the elements in the path of the advancing tear, as displayed in Figure 5.15. Single-pipe simulations were run with each simulation having the characteristics shown in Table 5.5:

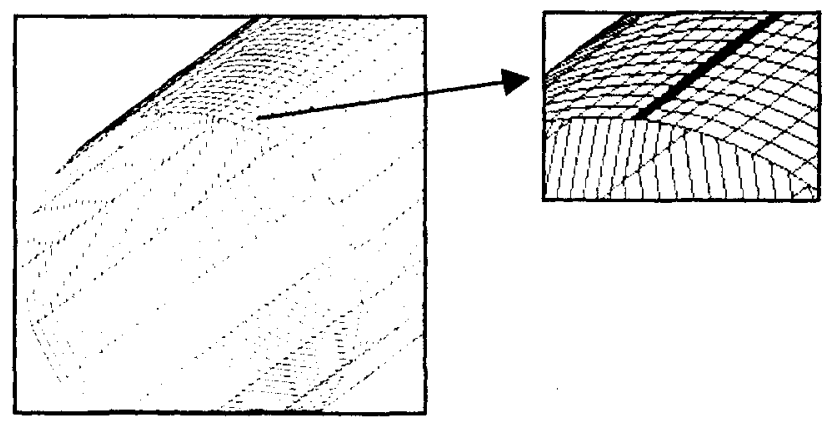

Figure 5.15: Principal elements whose size was altered for the sensitivity analysis 
Table 5.5: Material and mesh properties and results of mesh-sensitivity analysis

\begin{tabular}{|c|c|c|c|c|c|c|}
\hline Test & $\begin{array}{c}\text { Mesh Size } \\
(\mathrm{cm})\end{array}$ & A/P & $\begin{array}{l}\text { Yield } \\
(\mathrm{MPa}) \\
\end{array}$ & $\begin{array}{l}\text { UTS } \\
(\mathrm{MPa})\end{array}$ & $\varepsilon_{\text {uts }}$ & $\bar{\varepsilon}_{\mathrm{f}}^{\mathrm{pl}}$ \\
\hline 1 & 1 & $P$ & 450 & 578 & 0.092 & 0.95 \\
\hline 2 & 5 & $P$ & 450 & 578 & 0.092 & 0.95 \\
\hline 3 & 6 & $P$ & 450 & 578 & 0.092 & 0.95 \\
\hline 4 & 12 & $A$ & 450 & 578 & 0.092 & 0.95 \\
\hline 5 & 1 & $A$ & 450 & 642 & 0.060 & 1.6 \\
\hline 6 & 5 & $A$ & 450 & 642 & 0.060 & 1.6 \\
\hline 7 & 6 & A & 450 & 642 & 0.060 & 1.6 \\
\hline 8 & 12 & A & 450 & 642 & 0.060 & 1.6 \\
\hline
\end{tabular}

It is apparent from the graph of the crack-tip position versus time shown in Figure 5.16 that the finer-meshed simulation propagated at a faster velocity; approaching the actual full-scale crack arrest test measured velocity of $190 \mathrm{~m} / \mathrm{s}$. Therefore, a finer sized mesh appears to give crack velocity predictions that rapidly approach measured values. Additionally, the data reported in Table 5.5 demonstrate that although the crack-tip velocity increases with a refinement in mesh size, the critical prediction of the material's ability to resist the propagation of a ductile crack remains consistent, except for the extremely coarse mesh size of $12 \mathrm{~cm}$. In the other mesh-size cases, the material behaved similarly with either mesh size, regardless of whether the tear either propagated or arrested. 


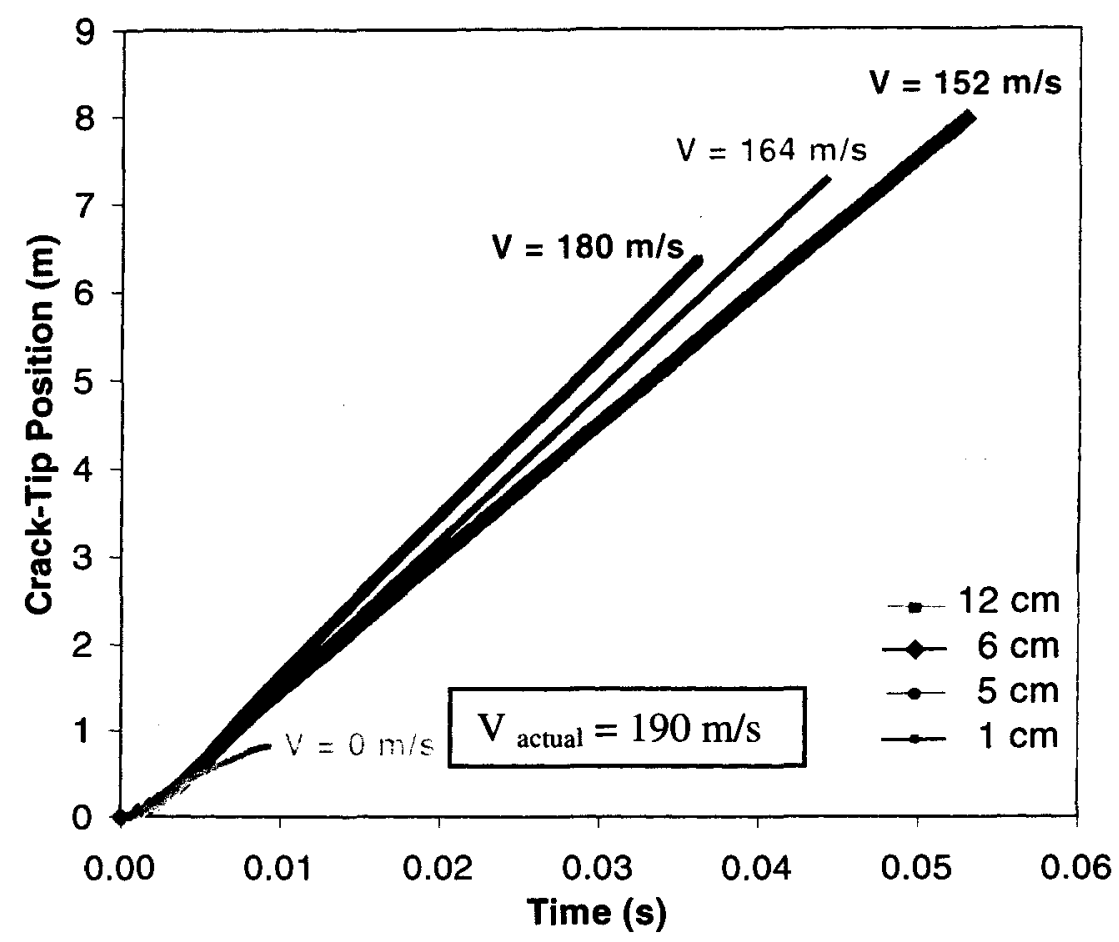

Figure 5.16: Graph of results for the finer meshes used for the tests in Table 5.5

\subsubsection{Post-Crack Gas Decompression Characteristics}

It is evident that both the action of the gas decompressing within the enclosed pipe section and the remaining gas pressure that is applying a load on the flaps behind the crack-tip play an important role in this phenomenon. An analysis was performed in order to investigate the effect of different post-crack gas decompression characteristics on the propagation behaviour of the tear. The pipe material had the following properties:

$\begin{array}{ll}\text { Elastic Mod } & =224 \mathrm{GPa} \\ \text { Yield } & =450 \mathrm{MPa} \\ \text { UTS } & =536 \mathrm{MPa} \\ \varepsilon_{\mathrm{uts}} & =0.06 \\ \bar{\varepsilon}_{\mathrm{f}}^{\mathrm{pl}} & =0.80\end{array}$

and the pipe had the following characteristics:

$\begin{aligned} \text { Diameter } & =1.2 \mathrm{~m} \\ \text { wall thickness } & =15.0 \mathrm{~mm} \\ \mathrm{P}_{0} & =9.68 \mathrm{MPa}\end{aligned}$ 
The post-crack gas decompression equation utilized for the simulations had the form of Equation 5.2, but the constant $A_{2}$ was varied from 1.0 to 3.0. Utilizing a higher value for $A_{2}$ has the effect of increasing the rate at which the pressure decreases with increasing distance from the bottom of the pipe towards the top of the pipe. It is evident from Figure 5.17, in which the crack-tip position versus time is plotted, that changing the parameter $A_{2}$, which translates to an increased sensitivity to the change in gas pressure with height, within this range had an insignificant influence on the crack-tip velocity. Future sensitivity analyses perhaps should involve varying this parameter over a much greater range.

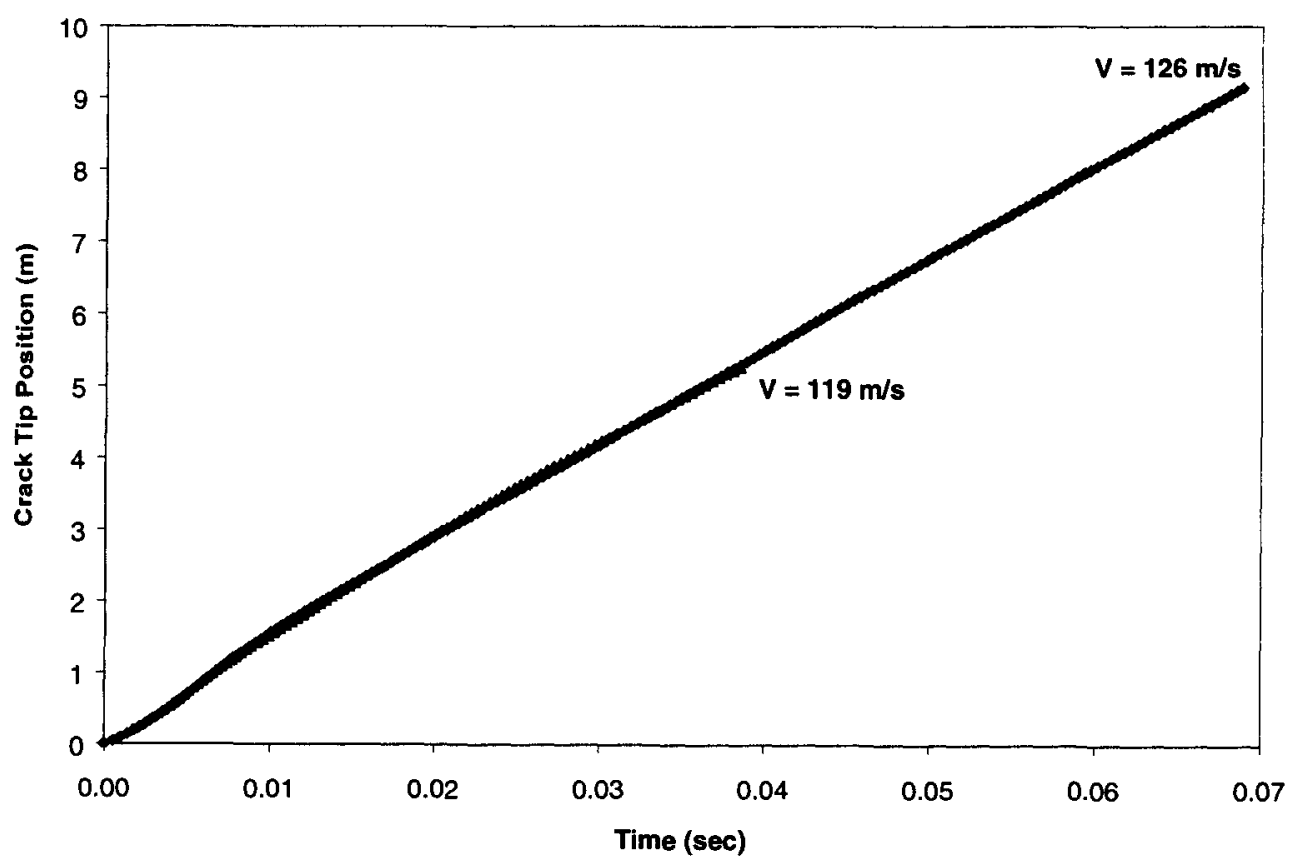

Figure 5.17: Graph of results for the comparison of gas decompression characteristics

\subsubsection{Multiple Linepipe Simulations}

Full-scale crack arrest tests consist of several segments of linepipe with different material properties attached together, as illustrated in Figure 5.18. In addition to setting 
up the model to simulate the full-scale crack arrest test, another primary objective of these simulations was to observe the effects of this set-up on the fracture propagation behaviour.

Upon running a simulation, it can be seen that the general deformed appearance of the pipe after the full-scale test is well reproduced. Qualitative agreement is reproduced in the flaps formed behind the crack-tip and in the wrinkling of the edges of the pipe wall after failure, as shown in Figure 5.19. These wrinkles are the result of tensile extension of the torn edge immediately behind the fracture tip and subsequent buckling compression, and of longitudinal tensile extension ahead of the fracture tip.

Fracture Direction

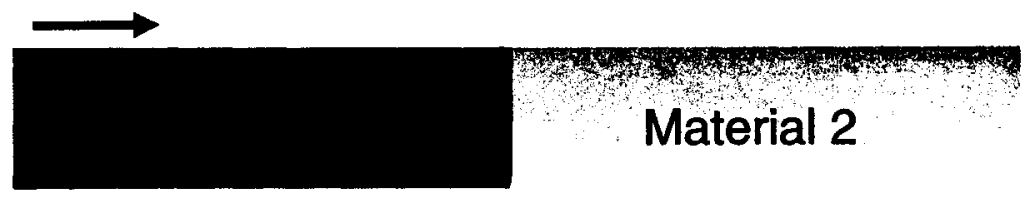

Figure 5.18: Schematic diagram of the use of several linepipe segments for the set-up of a full-scale linepipe burst test

Additional validation of the simulation is obtained by reproduction of the through-thickness strain profiles in the circumferential direction away from the fracture surface, which is shown in Figure 5.20 for steel 3 of Table 4.1. Locations 1 and 2 represent measurements while locations 3 to 7 represent calculations from the model at 0 , 1.0, 2.0, 3.0 and 4.0 meters, respectively, from the beginning of the linepipe. Note that the through-thickness strain is at a maximum at the torn edge and then decreases in a near- exponential fashion over a distance of $150 \mathrm{~mm}$. These profiles show that the plastic zone ahead of the crack-tip extends to about $1 / 8$ diameter on either side of the crack path. 


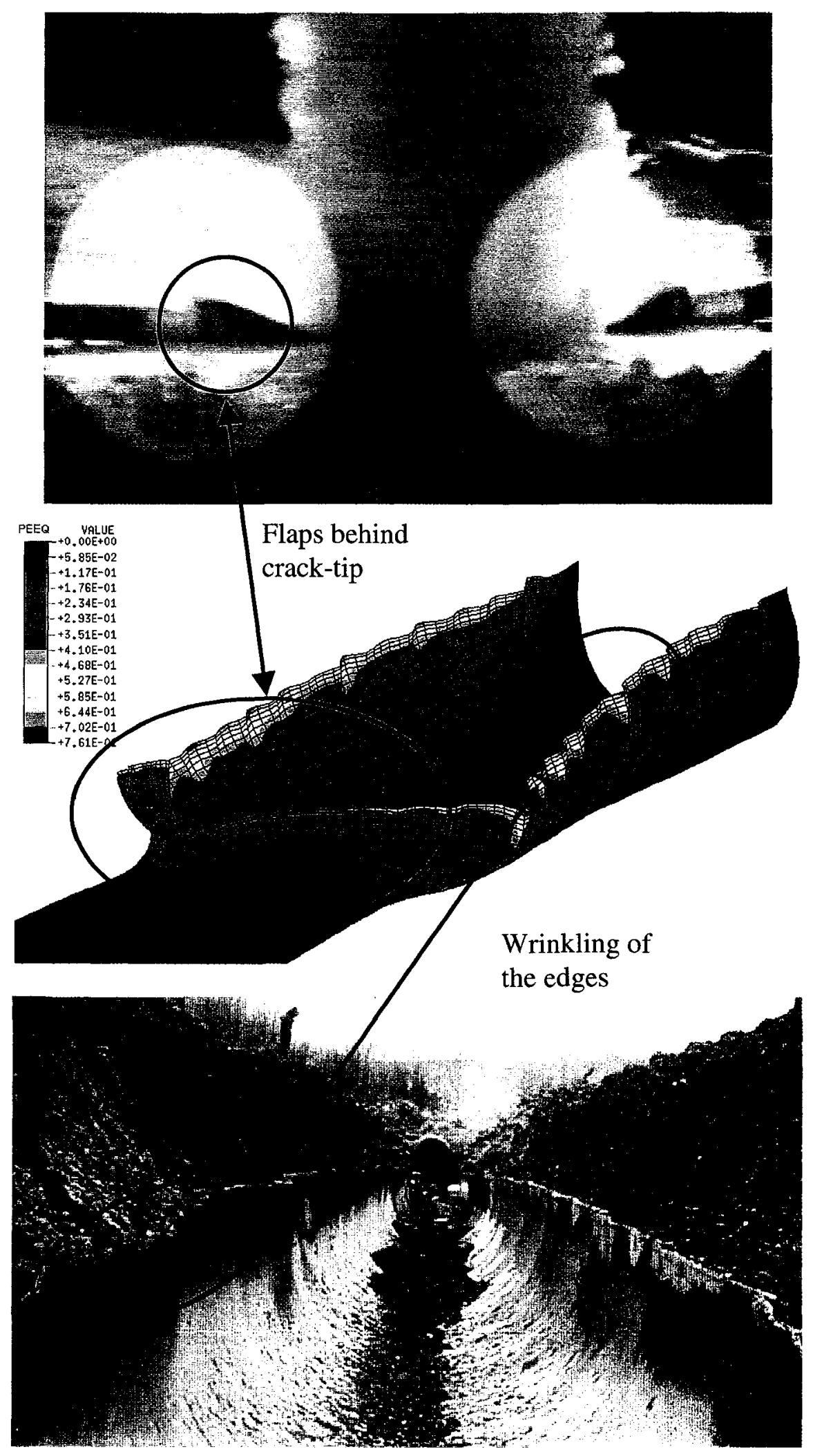

Figure 5.19: Qualitative comparison between the model's predictions and observations from full-scale crack arrest tests 


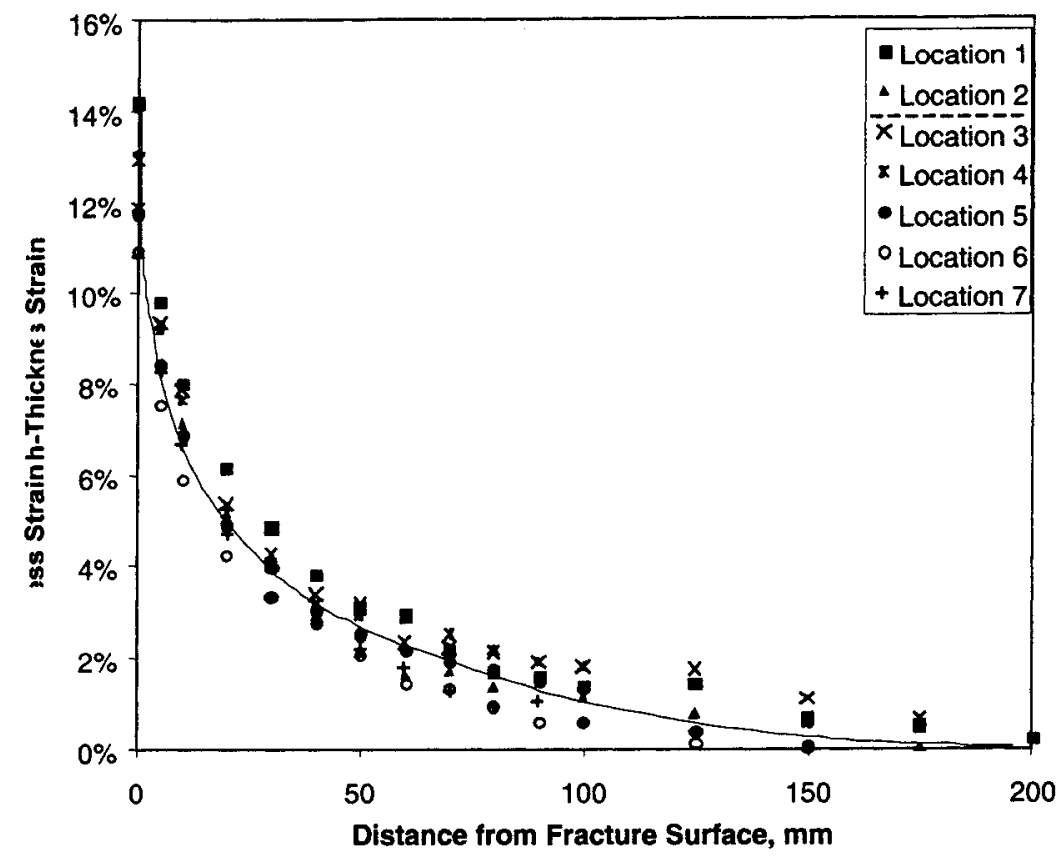

Figure 5.20: Graph of the through-thickness strain profile from the fracture surface for various arbitrary locations along the pipe axis for Steel 3 from Table 4.1

\subsubsection{Effect on Crack-Tip Propagation Characteristics}

A number of authors have noted that the propagation characteristics of a ductile crack are influenced by a mismatch in the flow properties of two joined materials [9 11]. To investigate this phenomenon, simulations were run using multiple linepipe segments. Here, two pipe segments were modeled with a diameter of $1.0 \mathrm{~m}$ and a wall thickness of $0.015 \mathrm{~m}$. In each case the first pipe segment was $3 \mathrm{~m}$ long while the second had a length of $12 \mathrm{~m}$, and the crack was initiated in the first segment.

To examine the effect of increasing the toughness when transiting from one pipe to another, two simulations were run. In the first, the first pipe -segment was given the properties of linepipe 1 in Table 5.6, while the second pipe had the flow properties of linepipe 2. In the second simulation the properties of the first segment were unchanged while the second pipe was characterized by linepipe 2 . The crack-tip velocities obtained 
in the first two simulations are plotted in Figure 5.21. Here, the data from simulation 1 are plotted as blue points and those from simulation 2 are plotted in red. In both cases, after an initial transient, the crack-tip achieves a steady-state velocity of $153 \mathrm{~m} / \mathrm{s}$. As the plastic zone ahead of the crack-tip starts to penetrate the second pipe segment, the cracktip velocity starts to decrease, even though the crack tip is still located in the first pipe. In simulation 1 , the crack velocity continues to decrease until it reaches a minimum value of $30 \mathrm{~m} / \mathrm{s}$ at a point $0.1 \mathrm{~m}$ inside the second pipe. This velocity is maintained until the crack-tip has penetrated about $0.6 \mathrm{~m}$ inside the second pipe at which point the crack-tip accelerates once more. A steady velocity of $73 \mathrm{~m} / \mathrm{s}$ is established at a point about $1.8 \mathrm{~m}$ inside the second pipe. The acceleration of the crack-tip can be associated with a change in flap geometry as they enter the second pipe.

Table 5.6: Material properties and results of multi-linepipe sensitivity analysis

\begin{tabular}{|c|cccc|}
\hline Linepipe & $\begin{array}{c}\text { Yield } \\
(\mathrm{MPa})\end{array}$ & $\begin{array}{c}\text { UTS } \\
(\mathrm{MPa})\end{array}$ & $\varepsilon_{\mathrm{uts}}$ & $\bar{\varepsilon}_{\mathrm{f}}^{\mathrm{pl}}$ \\
\hline $\mathbf{1}$ & 450 & 578 & 0.092 & 0.8 \\
$\mathbf{2}$ & 450 & 642 & 0.060 & 1.3 \\
$\mathbf{3}$ & 450 & 642 & 0.060 & 1.6 \\
$\mathbf{4}$ & 450 & 578 & 0.07 & 1.1 \\
\hline
\end{tabular}

In the case of simulation 2, where the second pipe is more "tough" than for simulation 1 , the transition is characterized by a continuous decrease in velocity until arrest occurs at a point about $0.1 \mathrm{~m}$ inside the second pipe.

A simulation was also performed where the first pipe has the flow properties of linepipe 4 in Table 5.6 while the second pipe has the properties of linepipe 1. As shown in Figure 5.22, after an initial transient, a steady velocity $(91 \mathrm{~m} / \mathrm{s})$ is established in the first segment. Once the plastic zone starts to penetrate the less tough segment 2 , the crack velocity begins to increase. This increase continues until the crack enters the second segment at which point a new steady velocity of $153 \mathrm{~m} / \mathrm{s}$ is established.

The simulations indicate that when there is a marked difference in the flow properties between two pipe segments, there is a region of transition in crack velocity. 
Chapter 5: Pipeline Rupture

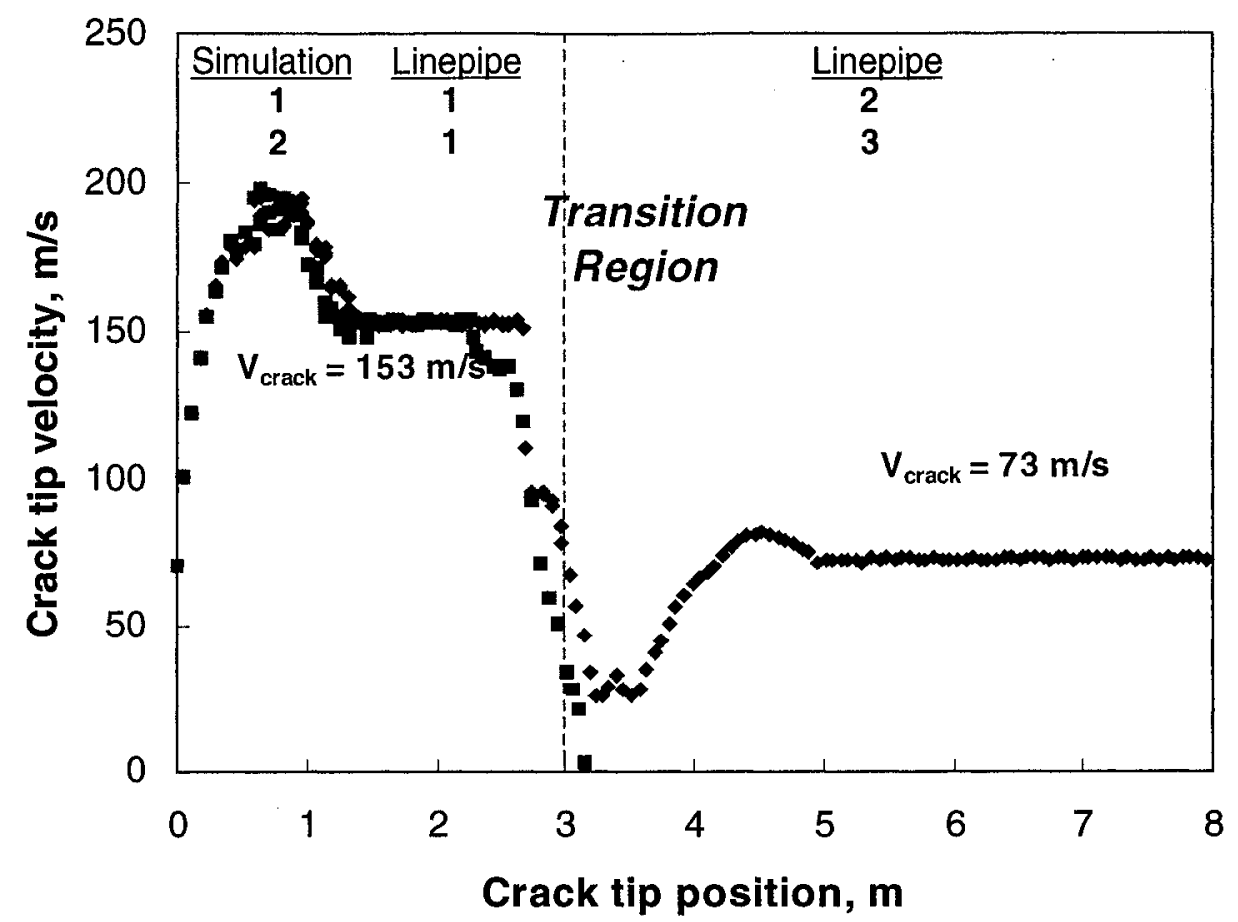

Figure 5.21: Graph of crack tip velocity versus crack tip position for 2 different cases of a tougher pipe placed after the initiator

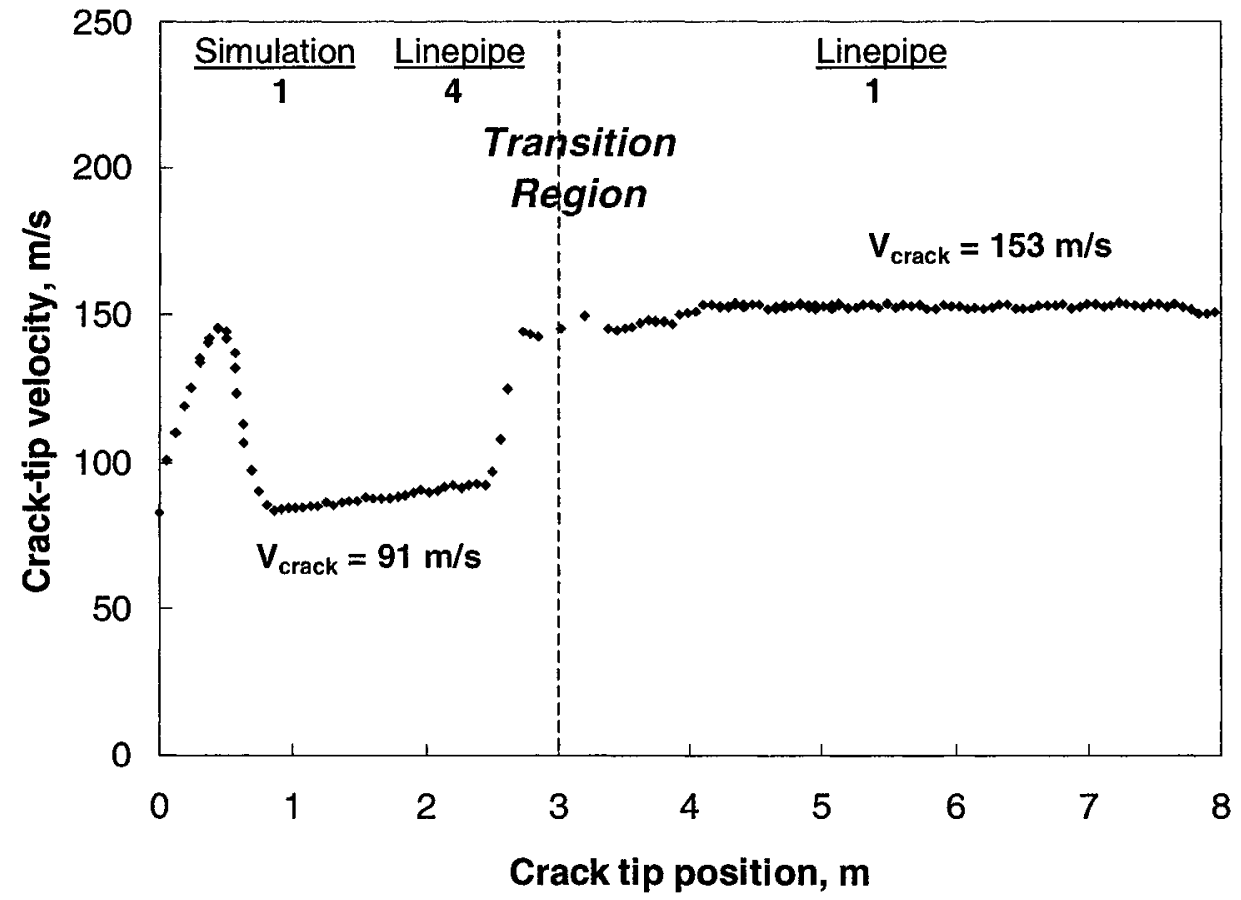

Figure 5.22: Graph of crack tip velocity versus crack tip position for a less tough pipe following a tougher pipe 
This region extends from about $0.5 \mathrm{~m}$ before the junction between the two segments to about 1.0 to $1.5 \mathrm{~m}$ after the junction. The first boundary is set by the extent of the plastic zone ahead of the crack tip while the second boundary is controlled by the distance required to establish a new steady-state flap profile that is characteristic of the flow properties of the second pipe segment.

The preceding simulations have demonstrated that the characteristics of the crack-tip propagation are heavily dependent on the flow-stress-response properties of the material within the deformation zones ahead and behind it.

Additional simulations were performed in which the initiator linepipe segment possessed the material properties shown for linepipe 1 in Table 5.6, while the second segment had properties similar to linepipe 2 in the same table. For each simulation, the failure parameter, $\bar{\varepsilon}_{\mathrm{f}}^{\mathrm{pl}}$, of the second linepipe segment was varied from 0.80 to 1.60 in steps of 0.15 . This has the effect of changing the integration limit when determining the energy required to plastically deform the material until failure occurs. Figure 5.23 illustrates the effect of changing the deformation work to fracture, which is done simply by modifying the failure strain, on the ductile fracture-tip propagation characteristics. It can be clearly seen that between strains of 0.80 to 1.45 , the crack-tip velocity has an inverse-exponential dependence on the failure strain. Further analysis would be required in order to determine whether the crack is arrested abruptly beyond a failure strain of 1.45 , which corresponds to a crack-tip velocity of less than $60 \mathrm{~m} / \mathrm{s}$, or whether it undergoes a gradual decrease until stopping when the failure strain is set to 1.6

\subsubsection{Stress and Strain State}

Simulating the full-scale crack arrest test presents the opportunity to review the evolution of certain variables, such as either stress or strain components, which can only be assessed for an actual test post-mortem because the evolution cannot be measured in an actual test. 


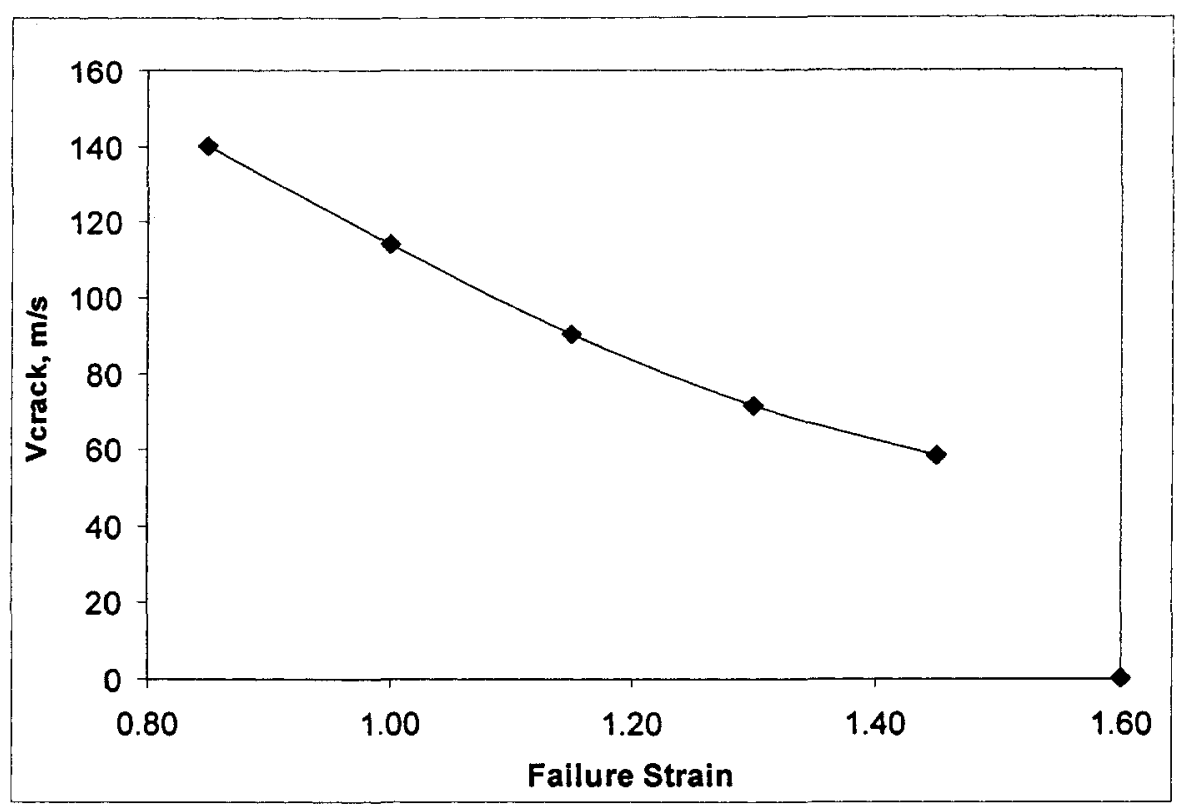

Figure 5.23: Graph of crack-tip velocity versus the material failure parameter

For the simulation, linepipes 1 and 2 from Table 5.6 were used and the evolving stress and strain data were analyzed. The extent of the plastic zone can be derived from the stress distribution ahead of the crack as shown in Figure 5.24. It can be seen that, in this case where the pipe diameter is $1.0 \mathrm{~m}$, the effective stress is greater than the initial effective yield in a zone that leads the crack by at least $2.5 \mathrm{~m}$. This observation is consistent with detailed studies of stress and strain distributions during full-scale tests [8].

Additionally, it can be seen from Figure 5.24 that the initial equivalent Von Mises yield stress, which is illustrated by the horizontal line, is at first exceeded in axial tension. At about $0.5 \mathrm{~m}$ ahead of the crack, the hoop stress increases due to the progressive separation of the flaps. In this regime, a diffuse neck is initiated on the top of the pipe. The neck intensifies at about $0.06 \mathrm{~m}$ ahead of the crack-tip with local thinning leading to the final separation of the pipe.

For a propagating ductile crack, fracture begins as a result of general plastic instability. It may be recalled that a Forming Limit Diagram (FLD) defines all combinations of surface strains over which plastic instability and necking can occur [12]. 
The diagram can also be used to track the strain path as the pipe progresses from initial yielding through a range of strain states to necking and final separation.

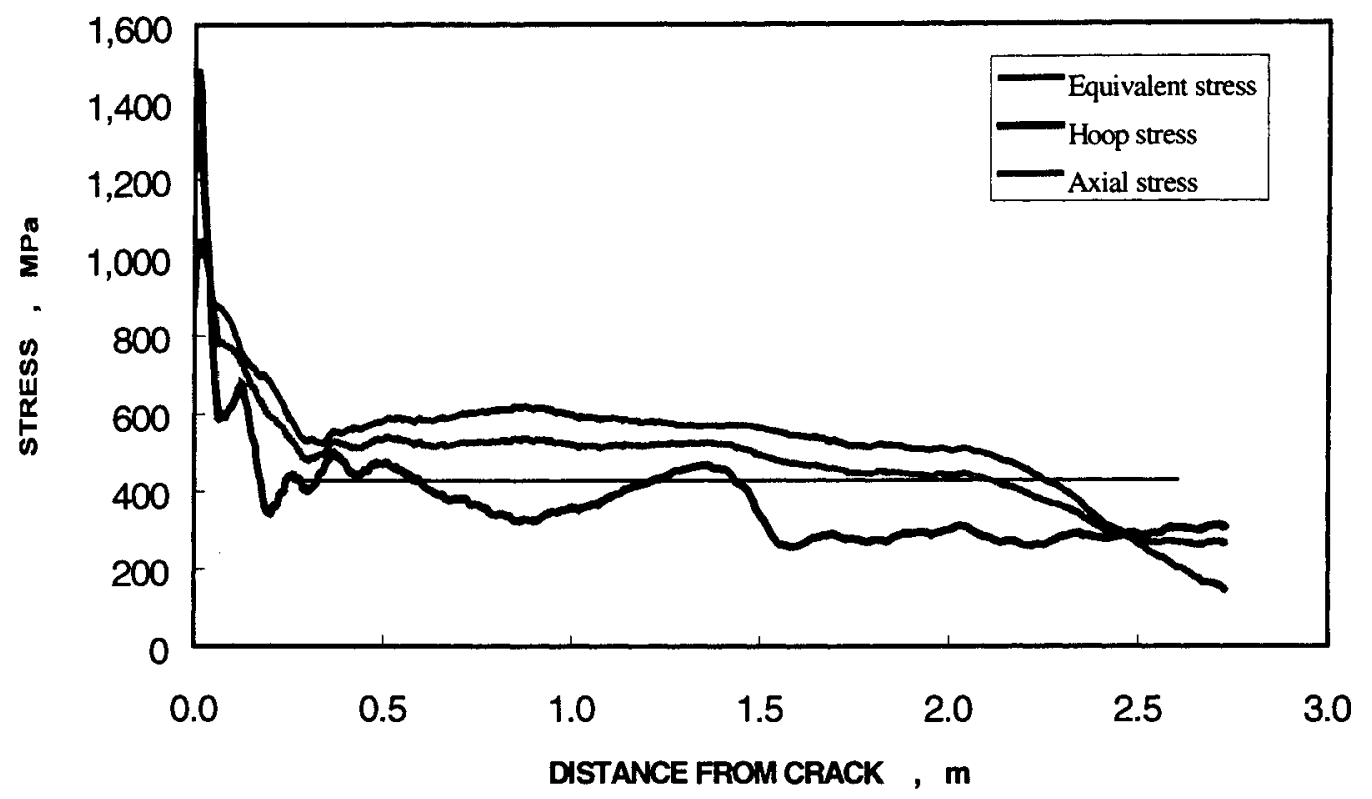

Figure 5.24: A graph of the stress versus the distance ahead of the fracture-tip. The horizontal solid line indicates the initial equivalent von Mises yield stress of the pipe material

Some data from multiple tests illustrating the extent and magnitude of the strain components obtained by post-mortem analysis of data from strain gauges and photo-resist grids close to the fracture surface are shown as red circles in Figure 5.25. It can be seen that the final strain-state for a full-scale crack arrest test is predominantly in the biaxial stretch mode.

Analysis of the final strain-state in the Charpy test reveals some important differences, also illustrated in Figure 5.25. The strain path for material in the fracturezone of a Charpy test varies with relative distance from the notch [8]. At the notch, the strain-state is initially uniaxial tension, while at the anvil strike it is initially plane strain compression in the minor direction. The entire range of strain states differs from that of the material in the fracture path during a full-scale crack-arrest test. As the crack propagates in the CVN specimen, the state of strain in the vicinity of the crack-tip is 
located between uniaxial tension and shear. Accordingly, the CVN test does not sample the states of stress and strain experienced by the material during dynamic ductile fracture of pipelines. From the sheet metal industry, it is known that the strain state affects the failure point of a material.

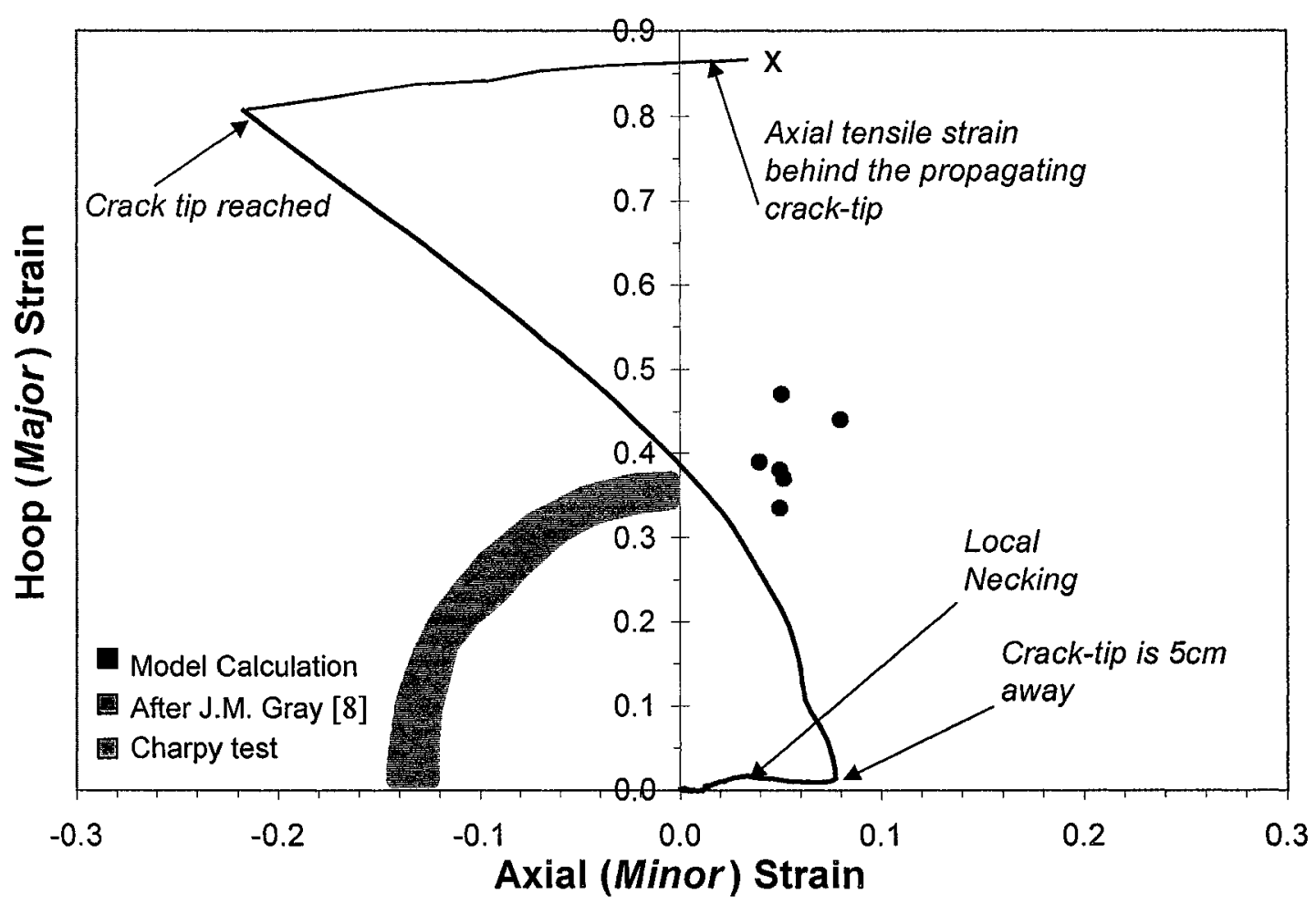

Figure 5.25: Graph comparing the final strain state experienced during the crack-arrest test and Charpy test, and the calculated in-plane strain history for the linepipe material in the crack path

The blue curve in Figure 5.25 represents the in-plane strains for material in the path of the dynamic ductile fracture obtained by simulation. Here, the major and minor strains correspond to the hoop and axial strains, respectively. A positive value of the major and minor strains reflects the location of the strain path within the "stretch" side of the FLD $[8,13,14]$. The illustrated strain path reveals that plastic strain is initially almost entirely plane strain in the axial direction, even beyond the onset of diffusenecking. All of the initial, pipe-wall plastic deformation occurs in the longitudinal direction, with most of it occurring prior to the onset of circumferential strain [8]. In addition, the total longitudinal strains incurred during ductile fracture can be as much as 
$10 \%$, as has been reported elsewhere $[8,15-19]$. Once the crack-tip is close to the material location under examination, i.e. less than $0.05 \mathrm{~m}$ away, the strain path undergoes a transformation from strain in the longitudinal direction to quasi-uniaxial tensile strain in the hoop direction. As the crack tip approaches and the material is strained, the absolute strain state changes from plane strain tension in the axial direction, to biaxial tension, to plane strain in the hoop direction and finally into the region of the chart referred to as 'draw'. Final failure in the heavily-necked region occurs with a slightly compressive axial strain. Additionally, after the crack-tip passes, the material is deformed in tension in the axial direction as the pipe opens away from the fracture path and the absolute strain state is biaxial tension. It is clear from Figure 5.25 that the end point of the deformation path agrees with data reported from post burst test measurements [8]. It is only through these simulations that the evolution of the stress and strain states can be considered. Analysis of the post-mortem test data alone can lead to the conclusion that the strain is entirely in the biaxial stretch regime, while the simulations clearly reveal that the strain path is much more complicated. This information can assist in designing a laboratoryscale test in which the mechanical properties of the material are determined under the state of strain actually experienced during a running ductile fracture.

\subsection{Full-Scale Verification}

In order to validate the entire methodology, computer simulations of a full-scale pipe experiment, conducted by the Iron and Steel Institute of Japan [8, were performed to reproduce the ductile fracture propagation characteristics. This test was selected for this purpose because sufficient material property data existed to reconstruct the uniaxial flow behaviour of the steels. The linepipe tested was low-carbon, ferrite-pearlite X70 grade steel. The set up of the full-scale test and the mechanical properties of these steels are shown in Figure 5.26. In all cases, the diameter was 1.22 meters, the wall thickness 18.3 millimeters, and the pipe was pressurized with air to $11.6 \mathrm{MPa}$. This pressure corresponds to 0.80 specified minimum yield stress. Air was used because it behaves similar to a single-phase, lean gas, but does not present the risk associated with the use of 
methane. The simulations of this test were performed using two pipe segments, selected pair-wise from the test set using the same experimental conditions.

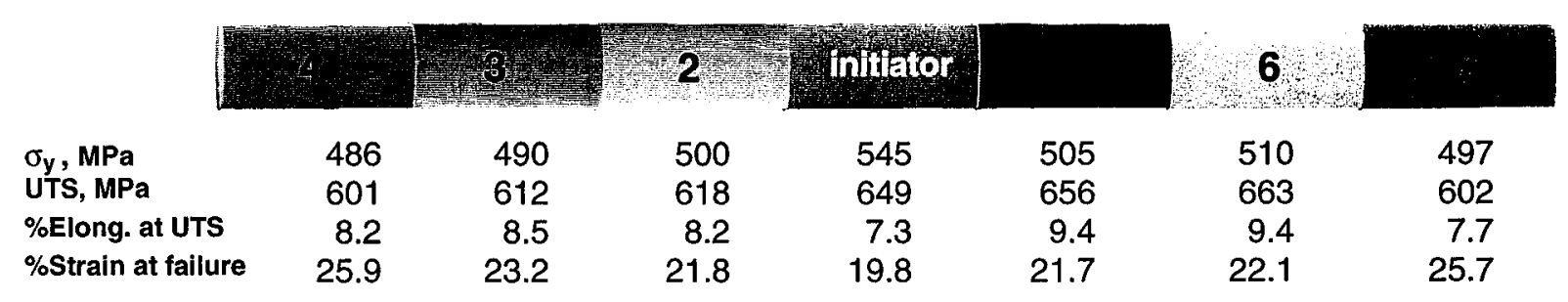

Figure 5.26: Diagram of the Kamaishi test set up along with the material properties for each linepipe segment

A critical test of the viability of the model is whether the simulations reproduce the condition for fracture propagation or arrest. In Table 5.7 and Figure 5.27, the instantaneous crack velocities generated by the model are compared with the rates measured in the full-scale tests for the various X70 grade steels in Table 4.2 [8]. In Figure 5.27, the colour of the data points corresponds to the colour used for the linepipe segments in Figure 5.26. From Figure 5.27, it can be clearly seen that the model not only distinguishes between steels that allow the fracture propagate from those that produce arrest. These latter tests are represented by the data points at the origin of the chart. Furthermore the simulations provide reasonable estimates of the expected fracture velocities in "propagate" pipes.

The greatest discrepancy occurred for steel 1 , which was the initiator pipe. A possible explanation for this is the form of the material response model, which did not include strain-rate sensitivity for either the flow stress evolution, or the failure parameter. Additionally, greater refinement of the finite element mesh might have resulted in crack tip velocities that more closely approach the measured velocities, but this would have been at the expense of the simulation time.

It can be seen from Figure 5.27 that the model's prediction error decreases as the arrest condition is approached, suggesting that the model provides effective prediction of the conditions required for arrest. 
Table 5.7: Comparison of predicted and measured crack velocities

\begin{tabular}{|cccc|}
\hline Steel & $\begin{array}{c}\text { Measured Fracture } \\
\text { Velocity } \\
m / s e c\end{array}$ & $\begin{array}{c}\text { Predicted Fracture } \\
\text { Velocity } \\
m / s e c\end{array}$ & Deviation \\
\hline 1 & 340 & 254 & 25.3 \\
2 & 115 & 100 & 13.0 \\
3 & 80 & 74 & 7.5 \\
4 & 0 & 0 & 0.0 \\
5 & 177 & 158 & 10.7 \\
6 & 140 & 121 & 13.6 \\
7 & 0 & 0 & 0.0 \\
\hline
\end{tabular}

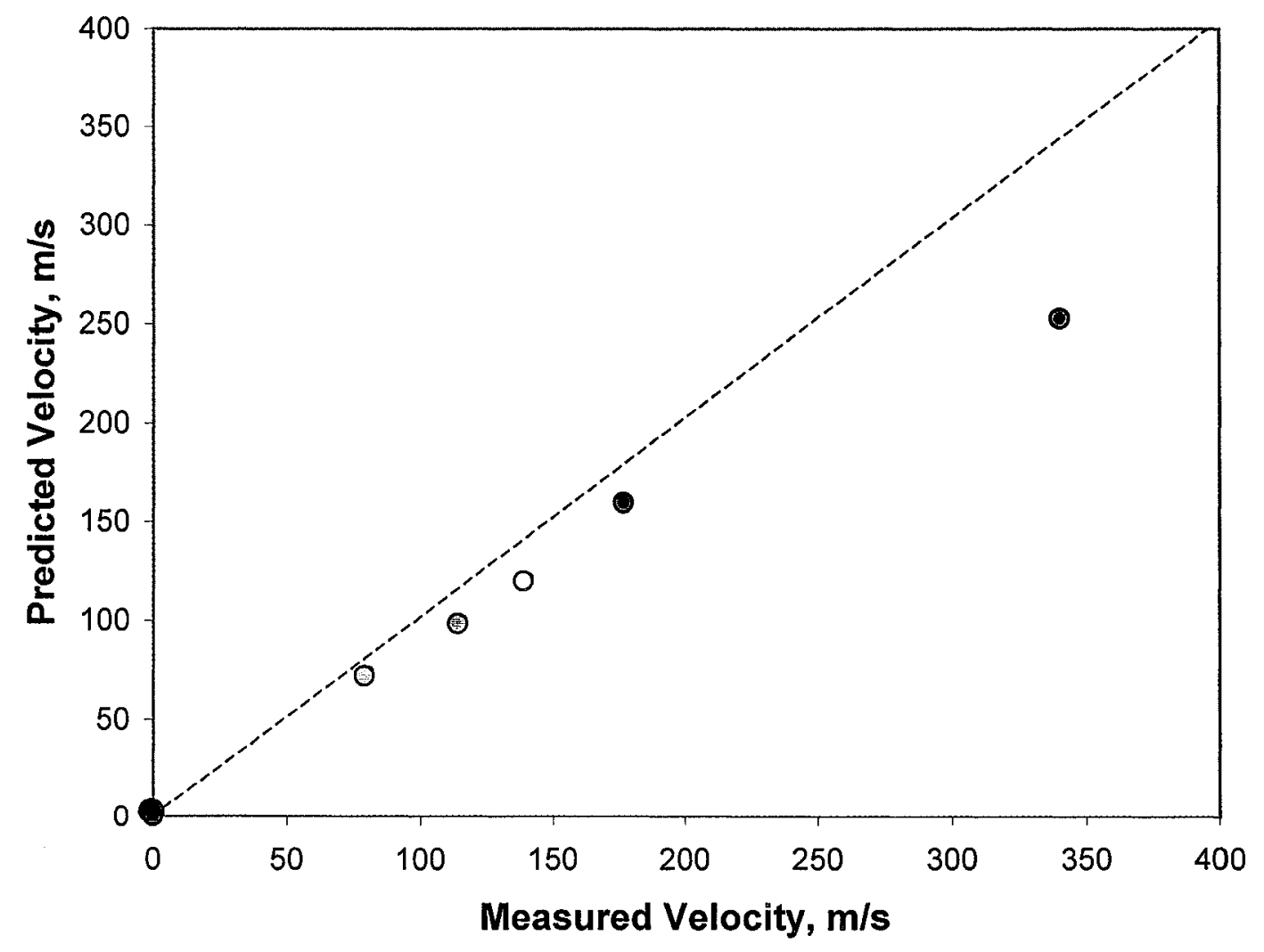

Figure 5.27: A graph of the predicted versus measured fracture velocities 


\subsection{Higher Grade Linepipe Steel}

Several virtual full-scale crack arrest tests were undertaken using materials with properties equivalent to higher-grade X100 linepipe steel, as seen in Table 5.8, which was used in a recent full-scale crack arrest test [20]. The properties used in the material response algorithm, such as the yield stress, are similar to the actual test steels are shown in Table 5.9. Although the actual test consisted of several linepipe segments welded together for a single test, the virtual crack arrest tests each consisted of 3 pipes, in which the first pipe was the initiator (Steel 1), the second pipe was made from one of the other steels in Table 5.9, and the third segment was made either from the same steel as in segment 2 or from another steel in the table. The virtual experimental set-up is shown in Table 5.10. The tests had the properties and initial conditions shown in Table 5.11 and the set-up illustrated in the schematic diagram in Figure 5.28. Due to symmetry conditions, only half of the initiator pipe (Steel 1) was used. The full length of the second pipe was connected to the first, where only 4 meters of the third pipe was connected on the end. The third segment was utilized in order to evaluate whether or not the crack-tip would arrest within the full eight meter length of the second pipe, and also to examine any effects of the properties of the third segment on the crack tip propagation characteristics in the second segment.

Table 5.8: Material properties of higher-grade linepipe steels [20]

\begin{tabular}{|c|c|c|c|c|}
\hline Steel & $\begin{array}{c}\text { Yield } \\
(M P a)\end{array}$ & $\begin{array}{c}\text { UTS } \\
(M P a)\end{array}$ & YS/UTS & $\begin{array}{c}\text { Charpy } \\
(J)\end{array}$ \\
\hline 1 & 773 & 858 & 0.90 & 151 \\
\hline 2 & 755 & 829 & 0.91 & 170 \\
\hline 3 & 663 & 762 & 0.87 & 263 \\
\hline 4 & 722 & 778 & 0.93 & 284 \\
\hline
\end{tabular}


Table 5.9: Material properties used for the virtual higher-grade linepipe steels

\begin{tabular}{|c|c|c|c|c|}
\hline Steel & $\begin{array}{c}\text { Yield } \\
(M P a)\end{array}$ & 'n' & $\begin{array}{c}\text { B } \\
(M P a)\end{array}$ & $\bar{\varepsilon}_{\mathbf{f}}^{\mathbf{p l}}$ \\
\hline 1 & 773 & 0.061 & 1073.5 & 0.91 \\
\hline 2 & 755 & 0.072 & 1091.5 & 1.22 \\
\hline 3 & 663 & 0.070 & 971.1 & 1.40 \\
\hline 4 & 722 & 0.077 & 1056.4 & 1.57 \\
\hline
\end{tabular}

Table 5.10: Table outlining which steels used for which segment for each simulation

\begin{tabular}{|cccc|}
\hline Test & $\begin{array}{c}\text { Segment 1 } \\
\text { Steel }\end{array}$ & $\begin{array}{c}\text { Segment 2 } \\
\text { Steel }\end{array}$ & $\begin{array}{c}\text { Segment 3 } \\
\text { Steel }\end{array}$ \\
\hline 1 & 1 & 2 & 3 \\
2 & 1 & 3 & 4 \\
3 & 1 & 4 & 4 \\
4 & 1 & 2 & 2 \\
5 & 1 & 3 & 3 \\
\hline
\end{tabular}

Table 5.11: Conditions for the full-scale crack arrest test simulations

\begin{tabular}{|l|l|}
\hline Test length $(m)$ & 16.0 \\
\hline Linepipe segment length $(m)$ & 8.0 \\
\hline Nominal diameter $(m)$ & 1.42 \\
\hline Nominal thickness $(m)$ & 0.0191 \\
\hline Nominal grade & $\mathrm{X} 100$ \\
\hline Pressurizing medium & pure air \\
\hline Test pressure $(\mathrm{MPa})$ & 12.6 \\
\hline Test hoop stress $(\mathrm{MPa})$ & 469 (corresponding to 68\% of SMYS) \\
\hline Test temperature $\left({ }^{\circ} \mathrm{C}\right)$ & 20 \\
\hline
\end{tabular}




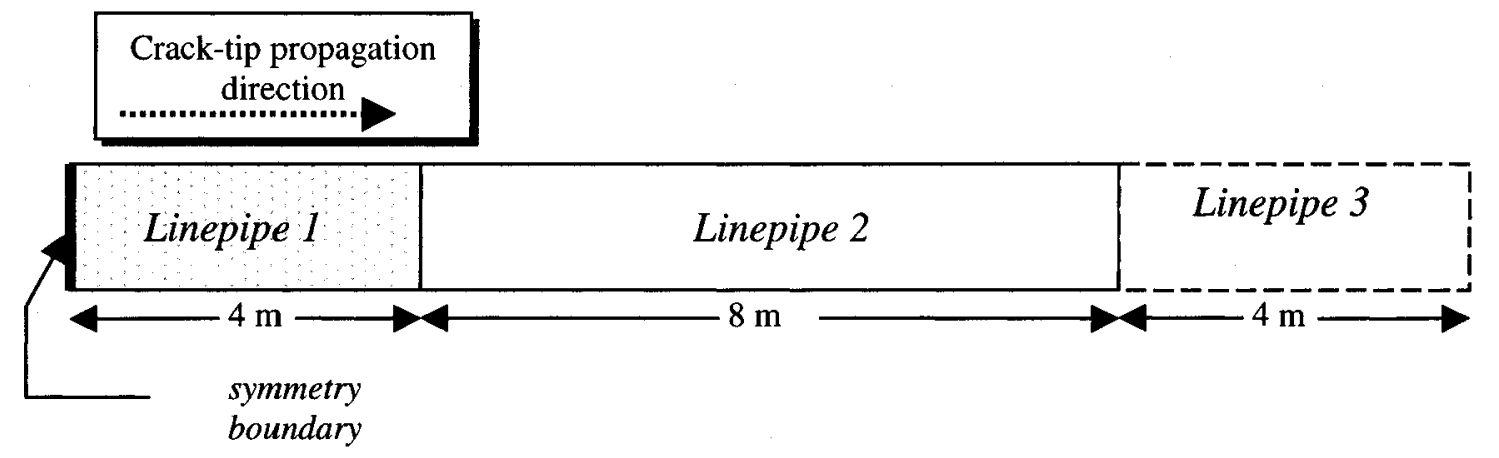

Figure 5.28: Schematic diagram of the set-up for the virtual crack-arrest test for the higher grade steel linepipe

The empirical ductile fracture equations used to predict the full-size Charpy energy values are shown in Table 5.11. It can be seen in Table 5.12 that the predicted Charpy values for arrest range from $126 \mathrm{~J}$ to $275 \mathrm{~J}$. When comparing the calculated Charpy values in Table 5.12 with the measured values, it can be seen that all of the equations predict that the fourth steel would arrest a propagating ductile fracture. It is notable that some of the equations also predicted that the crack would arrest in the initiator pipe.

Obviously the crack propagated in the linepipe made from Steel 1 because this was the initiator pipe. The results from the actual crack arrest test and from the virtual tests are shown in Table 5.13. In the actual test, the crack arrested at the end of linepipe 3. The results from the virtual crack-arrest tests demonstrated that the crack propagated in the linepipe made from steel 2, while it arrested close to the end of the linepipe made from Steel 3, as is shown in Figure 5.29 for test simulations 2 and 5. Almost all the empirically based equations failed to predict that the dynamic ductile fracture would arrest in Steel 3. Additionally, in extra simulations performed with linepipe 2 and 3 made from the steel 3, the crack propagated. This behaviour seems to illustrate that the properties of the steel ahead of the crack tip, i.e. in the process zone, have a very significant influence on the propagation characteristics of the fracture, as demonstrated earlier in Figures 5.21 and 5.22. 
Table 5.11: Empirical equations for ductile fracture arrest [21]

\begin{tabular}{|ll|}
\hline $\begin{array}{l}\text { Equation } \\
\text { Battelle Simplified (BSE) }\end{array}$ & $\begin{array}{l}\text { CVN Necessary to Arrest a Ductile Fracture } \\
\text { AISI }\end{array}$ \\
$\mathrm{C}_{\mathrm{v}}=3.5766 \cdot 10^{-5} \sigma_{\mathrm{h}}^{2}\left(\mathrm{R}_{\mathrm{p}} \mathrm{h}\right)^{1 / 3}$ \\
British Gas Corp. & $\mathrm{C}_{\mathrm{v}}=3.569 \cdot 10^{-4} \sigma_{\mathrm{h}}^{1.5}\left(2 \mathrm{R}_{\mathrm{p}}\right)^{0.5}$ \\
& $\mathrm{C}_{\mathrm{v}}=1.5015 \times 10^{-3} \cdot \sigma_{\mathrm{h}}\left(2.08 \cdot \frac{\mathrm{R}_{\mathrm{p}}}{\mathrm{h}^{0.5}}-\frac{\mathrm{V}_{\mathrm{a}} \cdot \mathrm{R}_{\mathrm{p}}{ }^{1.25}}{\mathrm{~h}^{0.75}}\right)$ \\
Mannesmann & $\left.\mathrm{C}_{\mathrm{v}}=19.99 \cdot \exp \left(0.287 \times 10^{-8}\right) \cdot \sigma_{\mathrm{h}}^{1.76}\left(2 \mathrm{R}_{\mathrm{p}}\right)^{1.09} \mathrm{~h}^{0.585}\right]$ \\
\hline
\end{tabular}

Table 5.12: Calculated and predicted CVN values for the higher-grade steel

\begin{tabular}{|c|c|c|c|c|c|}
\hline & & Steel 1 & Steel 2 & Steel 3 & Steel 4 \\
\hline \multicolumn{2}{|c|}{ Actual CVN (J) } & 151 & 170 & 263 & 284 \\
\hline \multicolumn{2}{|c|}{ Predicted CVN (J) } & \multicolumn{4}{|c|}{ Arrest / Propagate } \\
\hline Battelle & 188 & $P$ & $P$ & A & A \\
\hline AISI Equation & 137 & $\bar{A}$ & $\bar{A}$ & $\bar{A}$ & $\bar{A}$ \\
\hline British Gas Corp. & 126 & A & $A$ & A & $\bar{A}$ \\
\hline Mannesmann Equation & 275 & $P$ & $P$ & $P$ & A \\
\hline
\end{tabular}

Table 5.13: Results obtained from the actual and the virtual crack-arrest test for the higher-grade steel

\begin{tabular}{|l|l|c|c|c|c|}
\hline \multicolumn{1}{|c|}{ Propagate / Arrest } & & Steel 1 & Steel 2 & Steel 3 & Steel 4 \\
\hline Actual results & & P & P & A & A \\
\hline EMRE crack-arrest model & & P & P & A & A \\
\hline
\end{tabular}




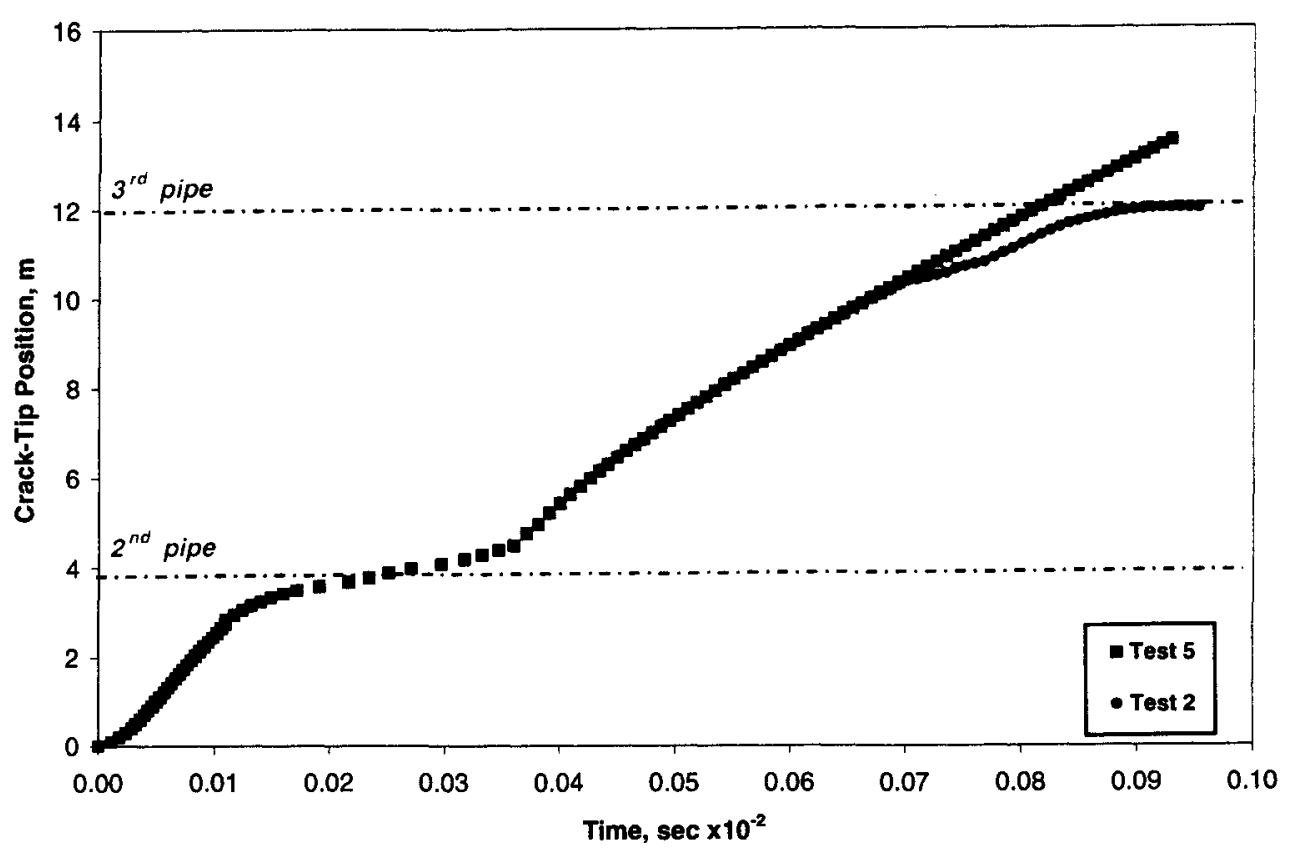

Figure 5.29: A graph of the measured crack-tip position versus time for the simulations

These results shown in Table 5.12 are further evidence that the Charpy test cannot be used with great confidence to identify the resistance of a pipe to a propagating ductile fracture [22], especially when the empirically-based correlations are applied beyond the database used in their calibration [23, 24]. The majority of these Charpy-based equations were developed from pipe test data typically less than 1 meter in diameter and with material that had Charpy toughness values less than 100 Joules [25]. The empirical correlations represented a fracture process for which other potentially significant dissipative processes, such as notch blunting, plastic deformation, and other processes that develop for higher toughness steels did not contribute to the calibration [23].

The Charpy toughness value is merely a proxy for a more complex property or a combination of properties. The shelf energy in a Charpy test cannot be more than a general indication of the overall ductility of a material in the presence of a rather blunt notch [22]. It has also been observed that the toughness values observed from the Charpy test can be specific to the machine generating the results, and differences in machine capacity can significantly alter the fracture behaviour and affect the measured toughness 
[24]. The use of Charpy energy as a proxy for fracture propagation resistance cannot be extended indefinitely, and it is not possible to extract from Charpy test results, on whatever theoretical or empirical basis, information that is not present in the first place $[22]$.

The characteristics that are dominant in determining fracture resistance of linepipe are those that reflect the ability of the material to distribute strain and to resist thinning under biaxial tension $[8,22]$, and in very tough materials, it can no longer be considered only, or even mainly, a "fracture" event. As observed in sheet metal forming, the strain to fracture represents an ultimate limit state, which is influenced by the strain state and strain path $[8,12,13$ and 22]. The strain states associated with dynamic ductile fracture in linepipe and the Charpy test are quite different, the secondary strain (that parallel to the fracture path) in the latter case being compressive rather than tensile, as was seen in Figure 5.25. The overall extent of the plastic regions is much greater in these tough materials, than can be generally developed in any practical notch bend test. It is governed by the ability of the pipe material, close to the fracture front, to distribute strain under conditions of biaxial tension and high strain rates. Thus, a method based on the mechanical response of the material during plastic deformation will have a greater ability to predict the resistance of stronger and tougher grades of steel to dynamic ductile fracture.

\subsection{Summary}

In this chapter, full-scale linepipe burst tests were simulated to ultimately determine the resistance of the material to a propagating ductile fracture. A self-evolving finite element model of dynamic ductile fracture in pipeline has been shown to effectively simulate the behaviour of a series of X70 grade linepipe that was tested by the Iron and Steel Institute of Japan. The mechanical behaviour of the different steels used in the study was characterized by yield stress, work-hardening rate and strain to failure measured in uniaxial tension, which was then used to develop the flow stress behaviour 
of the material under various states of true stress and strain. The gas decompression was modeled assuming ideal gas behaviour and isentropic decompression with the unfailed pipe, and an empirical model for gas flow in the pipe opening.

It was demonstrated that a sufficiently long time is required to initially load the pipe to full line pressure in order to avoid stress oscillations. Although the resistance to tearing was shown to not simply correlate with the energy absorbed to failure, the rate of work hardening and the failure criterion were demonstrated to have the greatest influence on the propagation characteristics of the crack-tip. The properties of the material in the process zone ahead of the crack-tip, as well in the flap-region behind the crack-tip, were shown to influence the propagation characteristics of the crack-tip. The stress and strainstate of the material in the process zone ahead of the propagating crack-tip were shown to undergo a complex evolution during the failure process. The model was shown to effectively reproduce the burst pipe geometry as witnessed in full-scale crack arrest tests. Additionally, the model was shown to be capable of predicting the resistance to running ductile fracture for pipelines made from lower grade steels.

For crack arrest tests of higher strength grades of linepipe steel that had increasing Charpy energy values, most of the Charpy test based empirical equations were shown to falsely predict the ability of the various linepipe to arrest a dynamic ductile failure. The results from the simulations of one of these tests demonstrated that, as in the actual test, the crack would arrest in the third segment, but this appeared to be heavily influenced by the material properties of the following segment.

The conclusions and suggestions for future work are presented within the next chapter. 


\section{REFERENCES}

1. Kanninen, M.F., Leung, C.P., O’Donaghue, P.E., Morrow, T.B., Popelar, C.F., Buzzichelli, G., Demofonti, G., Hadley, I., Rizzi, L., and Venzi, S., "The Development of a Ductile Fracture Model", Joint Final Report, AGA Contract No. PR-15-527, and PR-182-526, AGA-Pipeline Research Committee, July 1992

2. Kanninen, M.F., Morrow, T.B., Grant, T.S., and Demofonti, G., "The Development and Validation of a Ductile Fracture Analysis Model', Final Report, AGA Contract No. PR-15-9121, PR-15-9209, and PR-182-9210, AGA-Pipeline Research Committee, May 1994

3. Eiber, R.J., Bubenik, T.A., and Maxey, W.A., "Fracture Control Technology for Natural Gas Pipelines", Project PR-3-9113, NG-18 Report No. 208, American Gas Association, December 1993

4. Picard, D.J. and Bishnoi, P.R., "The Importance of Real-Fluid Behaviour and Nonisentropic Effects in Modeling Decompression Characteristics of Pipeline Fluids for Applications in Ductile Fracture Propagation Analysis", Canadian Journal of Chemical Engineering, Vol. 66, February 1988, pp. 3-12

5. Bell, R.P., Isopleth Calculations for Ruptures in Sour Gas Pipelines, Energy Processing/Canada, July-Aug., 1978, p. 36-39

6. Wilson, D.J., The Release and Dispersion of Gas from Pipeline Ruptures, Research Report for Pollution Control Division, Alberta Environment, Edmonton, Alberta, 1979

7. Abaqus Explicit User's Manual, Version 5.8-14, Hibbitt, Karlsson, and Sorenson, USA, 1999

8. Gray, J Malcolm, Final Report for AGA Project No. NG-18(4), American Gas Association, February 1984

9. Suresh, S., Sugimura, Y. and Tschegg, E.K., "The Growth of a Fatigue Crack Approaching a Perpendicularly-Oriented Bimaterial Interface", Scripta Metallurgica et Materialia, v 27, n 9, Pergamon Press, November 1992, pp. 1189-1194

10. Dawson, P.R., Needleman, A. and Suresh, S., "Issues in the Finite Element Modeling of Polyphase Plasticity", Materials Science and Engineering A, Elsevier Science, February 1994, pp.43-48

11. Brechet, Y.J.M, Dawson, P., Embury, J.D., G'sell, C., Suresh, S. and Wenk, H.R., "Recommendations on Modeling Polyphase Plasticity: Conclusions of Panel Discussions", Materials Science and Engineering A, Elsevier Science, February 1994, pp. 1-5

12. Hecker, S.S., "Simple Techniques for Determining Forming Limit Curves", Sheet Metal Industries, Nov. 1974, 671 
13. Savoie, J., Jain, M., Carr, A.R., Wu, P.D., Neale, K.W., Zhou, Y. and Jonas, J.J., "Predictions of Forming Limit Diagrams Using Crystal Plasticity Models", Materials Science and Engineering A, Elsevier Science, 1998, 128-133

14. Jain, M., Allin, J. and Lloyd, D.J., "Fracture Limit Prediction Using Ductile Fracture Criteria for Forming of An Automotive Aluminum Sheet", International Journal of Mechanical Sciences, Vol. 41, no.10, Pergamon Press, 1999, 1273-1288

15. Buzzichelli, G., Venzi, S. and Aloe, G., "Designing Against Ductile Fracture Propagation in Pipelines on the Basis of Instrumented Full-Scale Burst Tests and Advanced Laboratory Tests", Proceedings of Fracture in Gas Pipelines, Moscow, March 21-22, 1984, 179-217

16. Aloe, A., Bramante, M. and DiCandia, A., "Progress on the Study of Ductile Fracture Propagation in Gas Pipelines - Main Aspects Concerning Pipe Deformation", presented at DEPEC, Denver, Colorado, Sept. 28-30, 1982

17. Sugie, E., Kaji, H., Taira, T., Mimura, H. and Nara Y., "Interim Report on Full-Scale Burst Tests in Japan by ISIJ HLP Research Committee", API Standardization Conference, Houston, June 16-20, 1980

18. Hertzberg, Richard W., Deformation and Fracture Mechanics of Engineering Materials, Fourth Edition, John Wiley \& Sons, 1996, pp. 19-24

19. Kawaguchi, Y., "Study on the Propagating Shear Fracture in Linepipes by the Partial-Gas Burst Test", Trans. ISIJ v 22, 1982, p. 617

20. Demofonti, G., Mannucci, G., Spinelli, C.M., Barsanti, L. and Hillenbrand, H.G., Large Diameter X100 Gas Linepipes: Fracture Propagation Evaluation by Full-Scale Burst Test, Pipeline Technology, Volume 1, R. Denys (Editor), Elsevier Science, 2000, pp. 509-520

21. Luton, M.J., ExxonMobil Research and Engineering, Private memo, October 2000

22. Rothwell, A.B., Fracture Propagation Control for Gas Pipelines - Past, Present and Future, Pipeline Technology, Volume 1, R. Denys (Editor), Elsevier Science, 2000, pp. 387-405

23. Leis, Brian N., Predicting Fracture Arrest Based on a Relationship Between Charpy Vee-Notch Toughness and Dynamic Crack-Propagation Resistance, Pipeline Technology, Volume 1, R. Denys (Editor), Elsevier Science, 2000, pp. 407-420

24. Leis, Brian N., Contrasting Fracture Behavior Characterized Using Charpy VeeNotch and Dynamic-Tear Test Methods, Pipeline Technology, Volume 1, R. Denys (Editor), Elsevier Science, 2000, pp. 343-358

25. Wilkowski, G.M. and Mihell, J.N., Ductile Fracture Arrest Methodology for Current and Future Grades of Linepipe Steels, Proceedings of the International Symposium on Materials for Resource Recovery and Transportation, CIM, 1998, pp. 267-295 


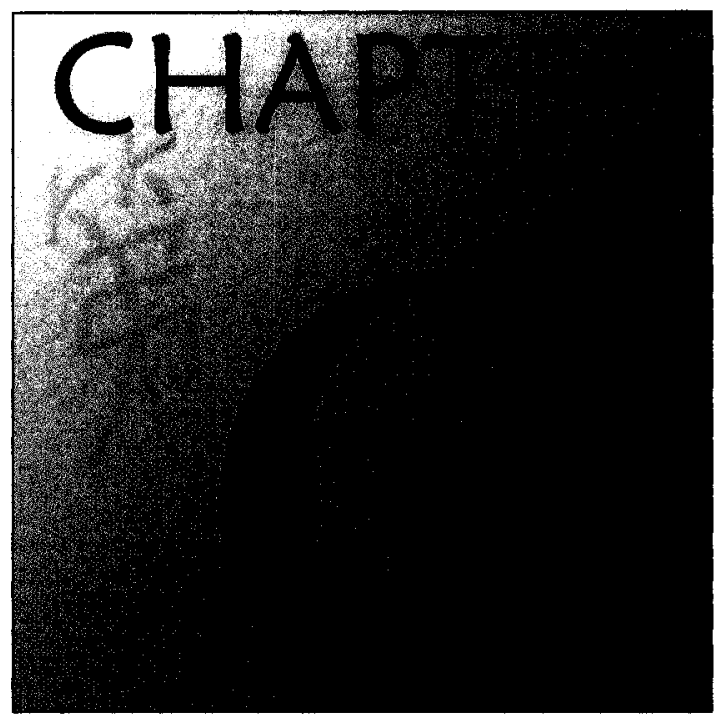

\section{Conclusions and Recommendations}

\subsection{Conclusions}

In the present investigation, simulations of full-scale crack arrest tests in linepipe were performed using virtual materials with a wide variation in flow stress behaviour that is characteristic of steel used in modern pipelines. The gas decompression behaviour was determined analytically, while the material flow behaviour was obtained from prior experimental work reported in the literature and from finite element simulations of these laboratory tests. The main conclusions drawn from this work are the following:

\section{Virtual Laboratory Tests:}

1. The failure parameter, which is essentially a value of equivalent plastic strain, for the material response algorithm was determined by correlating the percent 
elongation values from real and virtual tensile tests. This parameter was found to range from 1.12 to 2.56 for some X70 grade steels that were examined, while it was found to vary from 0.91 to 1.57 for some of the higher strength steels used in a recent full-scale crack arrest test performed to evaluate their resistance to dynamic ductile fracture.

2. Although the virtual Charpy test was unable to accurately predict the absolute values as measured from the real laboratory tests for some X70 grade steels, it did reproduce the trends. The difference between the calculated and measured values is probably due to the lack of sensitivity of the material response algorithm's failure parameter to the state of stress of the material, particularly the hydrostatic stress.

\section{Full-Scale Crack Arrest tests:}

1. This work produced the first simulation in which the crack tip was not advanced 'artificially', but propagated or arrested in response to the entire system, i.e. the state of the linepipe and the decompressing gas. The characteristics of the propagating crack evolve in response to the virtual experimental setup.

2. A finite amount of time ( $>10^{-3}$ seconds) is required for loading the pipe in order to avoid the presence of stress oscillations at the beginning of the simulation.

3. For simulations in which the variables defining the flow stress behaviour were altered, the crack tip velocity was observed to be most sensitive to variations in the rate of work hardening and the material failure parameter.

4. As the mesh size for the simulation was decreased, the calculated crack tip velocity was seen to increase asymptotically towards the values measured from full-scale crack arrest tests. 
5. For the range of pressure profiles examined, the crack tip velocity is not sensitive to slight variations in the pressure profile from the bottom to the top of the pipe behind the crack tip.

\section{Multi-Linepipe Simulations:}

1. For virtual crack arrest tests in which multiple segments were utilized, the model was able to effectively reproduce the burst pipe geometry, i.e. the flap formation immediately behind the crack tip and the oscillations in the pipe wall further behind the crack tip.

2. The characteristics of the crack-tip propagation are observed to be heavily dependent on the flow-stress-response properties of the material within the deformation zones ahead and behind the crack tip.

3. For simulations in which only the failure parameter for the material response algorithm was varied, the crack-tip velocity was seen to have an inverseexponential dependence on the failure strain.

4. The states of stress and strain ahead of the propagating crack tip were shown to undergo a complex evolution during the failure process.

5. Initial plastic deformation in the material ahead of the propagating crack tip was observed to occur predominantly in the axial direction of the linepipe.

6. Examination of the hoop and axial strain demonstrated that the strain occurs mainly in the region of biaxial tension throughout the process of dynamic ductile failure in pipeline.

7. The state of strain the material undergoes in a full-scale crack-arrest test is vastly different than what occurs in a drop weight tear test or in a Charpy test. 
Full-Scale Verification:

1. On the basis of literature data for full-scale crack-arrest tests performed using X70 grade linepipe steel, the model was shown to be in good agreement with the arrest/propagate measurements.

2. The model was also shown to be in good agreement with the crack velocity measurements for full-scale crack-arrest tests performed using X70 grade linepipe steel.

\section{Higher Strength Steel}

1. For higher strength grade linepipe steels used in a recent full-scale crack arrest test, most of the existing Charpy-based models were unable to match the results measured from the test.

2. Simulations using the higher strength steel for the crack arrest test demonstrated that the crack-tip would arrest in the linepipe made from the third steel, as measured from the actual test.

3. The model also seemed to indicate that the crack tip arrested not only because of the intrinsic toughness of the steel, but also in large part because of the properties of the steel in the linepipe immediately following it. 


\subsection{Recommendations for Future Work}

1. The failure parameter utilized in the material response algorithm should be modified from a single parameter to a function of the state of stress of the steel, as expressed in Equation 4.3. This may further improve the predictions of the Charpy simulations.

2. In order to account for materials that exhibit different yield behaviour in different directions, the effect of yield anisotropy should be accounted for in the material response algorithm by modifying it to utilize data from laboratory tests performed in different orientations.

3. For gases exhibiting two-phase decompression, i.e. natural gas containing less than ninety percent methane, the gas decompression algorithm should be modified to account for the decompression behaviour of rich gases. The modifications could be accomplished by either the addition of an inline algorithm for the decompression of rich natural gases that takes variations in composition into consideration, or for a particular gas composition, a simplified algorithm could be implemented inline of the results obtained from the previously mentioned composition-sensitive algorithm.

4. Due to the fact that pipelines are usually subterranean, i.e. they are buried under one meter or more of backfill, the effect of various types of backfill should be added to the overall model. The presence of backfill would alter the amount of intrinsic resistance required to arrest a propagating ductile fracture. This could eventually be expanded to take into account pipelines that are underwater.

5. Variations (non-homogeneity) in mechanical properties and through-thickness throughout a segment of linepipe should be taken into consideration by the material response algorithm by providing the means to utilize such data.

6. The effect of the welded regions (the girth and seam welds and the associated heat affected zones) on the propagation characteristics of the ductile failure should be examined. This could be done by modification of the element mesh and the addition of modeling parameters for the material response algorithm for these regions. 


\section{Statement of Originality and Contribution to Knowledge}

The present work includes the following original contributions:

1. The first simulation of a full-scale crack-arrest test in which the state of the specimen evolves as a result of the initial and current conditions, and a crack is not forced to advance at any predetermined rate. The model utilizes the explicit finite element method and consists of additional algorithms for the material response and the gas decompression. The virtual test effectively reproduces the burst pipe geometry as witnessed in full-scale crack arrest tests. Additionally, the model was shown to be capable of predicting the resistance to running ductile fracture for pipelines made from lower grade steels.

2. For the first time, the effect of the plastic flow parameters on the crack-tip propagation characteristics was examined. The propagation characteristics of the crack-tip during dynamic ductile failure were shown to be most sensitive to the strainhardening rate, but to depend to a slightly lesser degree on the true strain at failure obtained from a tensile test. These results are of considerable importance for an understanding of the material properties required for a steel to possess the intrinsic ability to arrest a propagating ductile fracture.

3. The effect of adjacent linepipe segments with varying flow stress behaviour was examined. The characteristics of the crack-tip propagation were shown to be heavily dependent on the flow-stress-response properties of the material within the deformation zones ahead and behind it. This has important implications regarding previous full-scale crack-arrest test data in that steels that were designated to arrest a propagating ductile fracture may have done so only because of the material properties of the adjacent linepipe segment. 
4. Although the final state of strain of the material directly in front and adjacent to the propagating ductile fracture has been shown in the literature to be biaxial, it was shown for the first time that this final state occurs after a complex strain path. For the material directly in the path of the propagating ductile fracture, the strain was shown to be initially in the axial direction, and then changed to be primarily tensile in the hoop direction. After failure, the material immediately adjacent to the fracture surface undergoes further strain in the axial direction. This complex strain path denotes that future design of pipeline steels could exploit anisotropy due to thermomechanical processing and pipe forming in order to enhance the intrinsic ability to arrest a propagating ductile fracture.

5. The crack tip propagation characteristics were shown to be more sensitive to the material flow stress behaviour than the gas decompression profile behind the crack tip.

6. It was demonstrated for the first time that when the true strain at failure in a tensile test increased, the velocity of a propagating ductile fracture decreases in an inverse exponential manner until it reaches a critical velocity where it arrests. 